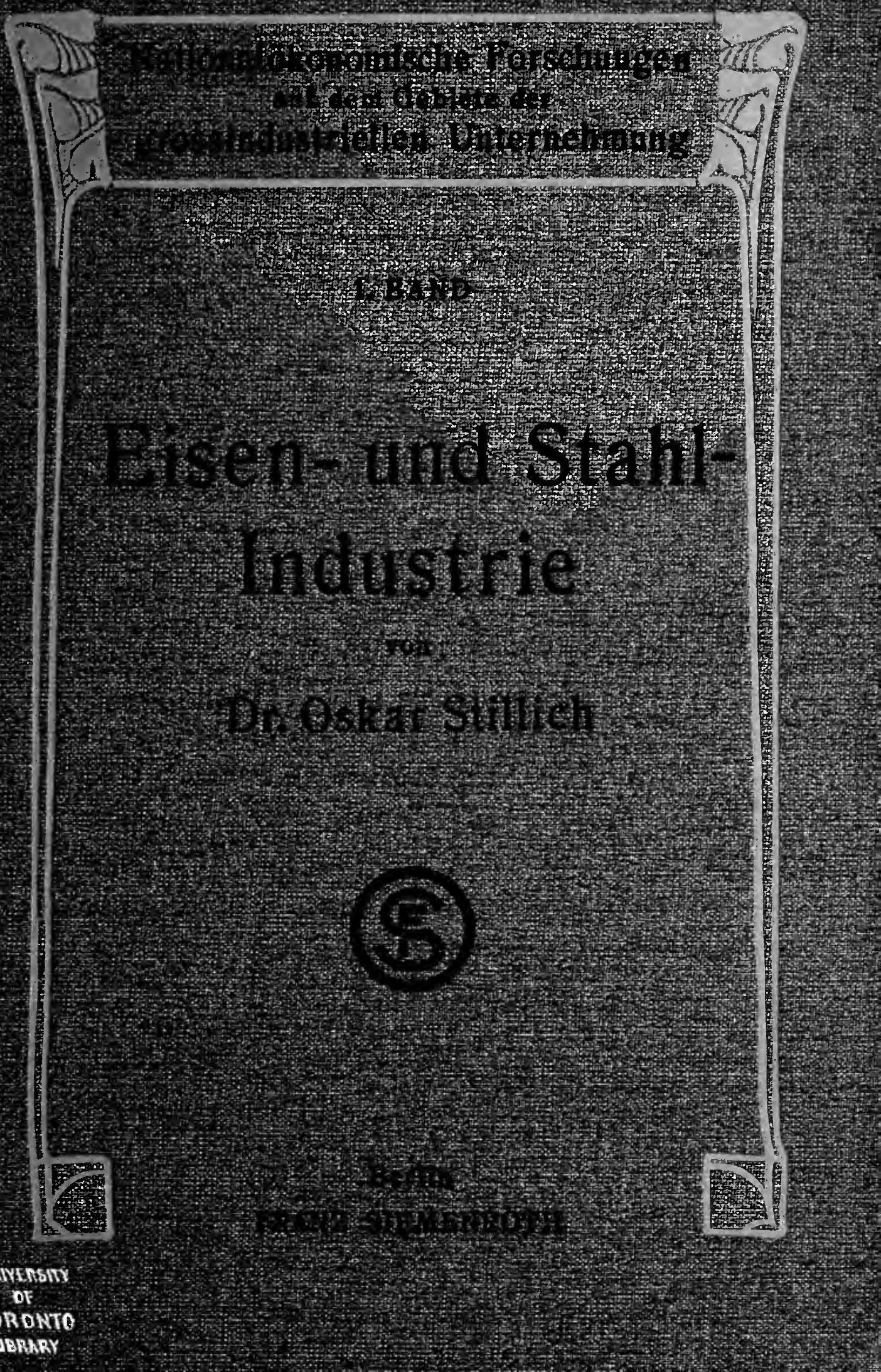




O. Stillich

Nationalökonomische Forschungen

\author{
Band I
}



Nationalökonomische Forschungen auf dem Gebiete der grossindustriellen Unternehmung. BAND I.

\section{Eisen- und Stahl-} Industrie

von

\section{Dr. Oskar Stillich,}

Dozent an der Humboldt-Akademie in Berlin.
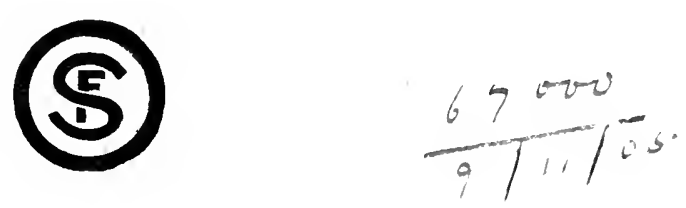

Berlin 1904.

FRANZ SIEMENROTH

W., Dennewitzstr. 2. 



\section{Inhalt.}

Seite

Vorwort

VII - XII

1. Der Hoerder Bergwerks- und Hüttenverein ... . . . . . . 1-52

2. Die Ilseder Hütte und das Peiner Walzwerk. . . . . . . . . . 53-90

3. Die Dortmunder Union . . . . . . . . . . . 91-137

4. „Phönix“, Aktiengesellschaft für Bergbau und Hüttenbetrieb. . 138-180

5. Die vereinigte Königs- und Laurahütte . . . . . . . . . . 181-238 



\section{Vorwort.}

Mit der vorliegenden Arbeit übergebe ich den ersten Band meiner „Nationalökonomischen Forschungen auf dem Gebiete der großindustriellen Unternehmung" der Öffentlichkeit. In den folgenden Bänden werde ich dann die größten, bedeutendsten und volkswirtschaftlich interessantesten Aktiengesellschaften des Kohlenbergbaus, der Maschinenfabrikation, der Elektrotechnik, der Industrie der Nahrungs- und Genußmittel, der chemischen Industrie, der Textilindustrie sowic der Transportgewerbe behandeln. Die Verwirklichung dieses Programms soll, so hoffe ich, eine Lücke in der volkswirtschaftlichen Literatur der Gegenwart ausfüllen. Denn die monographische Darstellung großkapitalistischer Betriebe, wie sie ihren prägnantesten und reinsten Ausdruck in der Form der Aktiengesellschaft erhalten haben, ist bis heute ein fast unbeschriebenes Blatt der deskriptiven Nationalökonomie. Es fehlen daher für die vorliegenden Studien alle speziellen Vorarbeiten. Aber vielleicht gerade deshalb hat es etwas Verlockendes, diese unbetretenen Pfade zu wandeln, und dieses jungfräuliche Gebiet zuerst zu durchspähen. Zwar gibt es über die genannten Standard-Industrien Deutschlands in technischer Beziehung eine unendlich große Literatur, aber sie ist fast durchgehends bar aller ökonomischen Gesichtspunkte. Das ist nicht ohne weiteres verständlich. Für den Ingenieur ist die Technik die Herrin, die Königin; für den Nationalökonomen aber die dienende Magd. Es versteht sich von selbst, daß diese Platzanweisung durch die Verschiedenheit der beiden $W$ issenschaften bedingt ist. Im einzelnen kommt die technische Literatur für das vorliegende Programm nur insoweit in Betracht, als das technische Moment zur Verdeutlichung und Erklärung ökonomischer Vorgänge und Zusammenhänge dient. Aber die in technischer Hinsicht um Rat gefragten Bücher sind - das ist nicht anders zu erwarten - von dem Tau der nationalökonomischen Wissenschaft wenig oder gar nicht benetzt. 
Dieser eine Grund würde bereits stark genug sein, um es verständlich zu machen, daß die vorliegenden Untersuchungen natürlich noch sehr weit davon entfernt sind, etwas Lückenloses zu bieten und allen Ansprüchen zu genügen. Allerdings liegt die Schuld an der relativen Unvollkommenheit im Detail, vor allem an der Sprödigkeit der Spitzen der Verwaltungen, die mit ihrem Materiale geizten, anstatt freigebig zu sein, hier, wo es am Platze ist. Die Möglichkeit der Beschaffung des Rohmaterials lielt sich daher in engen Grenzen. Zwar schlummert in den Archiven der großen Aktiengesellschaften ein ungeheures Material den Dornröschenschlaf. Aber es fehlt in den Kreisen der Großindustrie (ich denke hier vorläufig nur an die Eisenindustrie), die doch der Wissenschaft so unendlich viel verdankt, das subjektive und objektive Verständnis dafür, diesen Dank zu erwidern. Ich möchte freilich aus dieser Tatsache keinen Vorwurf konstruieren. Tout comprendre, c'est tout pardonner. Das geringe Entgegenkommen bei den verantwortlichen Leitern großer Unternehmungen in bezug auf die Förderung wissenschaftlicher Interessen, soweit sie nicht das Geschäft berühren, hängt ohne Zweifel mit dem rein kapitalistischen Charakter großgewerblicher Betriebe aufs engste zusammen. Man hat es mir allerdings seinerzeit in den beteiligten Kreisen sehr übel genommen, als ich an anderer Stelle*) über den Charakter der Spielwarengroßindustriellen Sonnebergs sclirieb, ,daß sich bei einigen der Gesichtswinkel des Geschäfts so sehr in den Vordergrund des Urteils schiebt, daß sie alles darunter betrachten und danach bewerten" und zur Illustration des Gesagten darauf hinwies, daß mir bei meinen Untersuchungen einige Chefs rund heraus erklärten, „sie hätten kein Interesse daran, mir etwas zu zeigen oder Auskunft zu erteilen, - weil das für ihr Geschäft nichts einbrächte." Man hat dies als Ausnahmefall bezeichnet. Ich habe jetzt Gelegenheit gehabt, in der Großeisenindustrie ganz analoge Erfahrungen zu machen. Der Generaldirektor eines in diesen Studien näher beschriebenen Unternehmens erklärte, nachdem ich ihm meinen Plan auseinandergesetzt und er mir die Geschäftsbücher einmal von außen gezeigt hatte: „Wir haben nur einen einzigen Zweck, und der heißt Geld verdienen!“ Der Betriebschef einer' Kohlenzeche äıBerte sich, bei einem Rundgang durch die Zechenanlagen, ganz ähnlich: „Unsere Auf-

*) Siehe mein Buch: Die Spielwarenhausindustrie des Meininger Oberlandes. Jena 1899 , p. 39. 
gabe ist fördern! fördern! fördern!" Das ganze Denken und Trachten dieser, wenn auch nicht aller Unternehmer steht, nackt ausgedrückt, im Dienste der „Mathematik des Geldverdienens“. Dem Unternehmen Gewinne abzulisten ist ihr ewiges Sinnen und der Stolz ihres Lebens. In diesen Aktiengesellschaften erreicht der kapitalistische Geist unserer Zeit seine höchste Vollendung. Wissenschaftliche Zwecke werden nur soweit gefördert, als es für das Geschäft von Vorteil ist. „To make money“, das ist die Parole. Darüber hinaus ist man indifferent. Man fürchtet durch Überlassung von Material für wissenschaftliche Zwecke womöglich gar, die Dividende könnte $1 / 2 \%$ heruntergehen, und dieser Verlust würde keine Erkenntnis aufwiegen! Daher schweigt man licber. In diesem Sinne sprach sich auch der Kommerzienrat Fr. Baare in der 42. ordentlichen Generalversammlung der Aktionäre des Bochumer Vereins für Bergbau und GuBstahlfabrikation aus. Er sagte: „Wie ich bereits im vorigen Jahre hervorgehoben habe, ist es nicht zweckmäßig, zuviel Einzelheiten in Ziffern zur öffentlichen Kenntnis zu bringen, daher wollen wir bemüht sein, für die Zukunft die detaillierten Angaben tunlichst zu vermeiden." (Geschäftsbericht über das Jahr 1895/96.)

Ich war aus diesem Grunde auf ein verhältnismäßig unvollständiges, spärliches und noch dazu einseitiges Material angewiesen. Vor allen Dingen auf die Geschäftsberichte. Aber auch diese wurden mir nicht einmal von allen Gesellschaften, an die ich mich wandte, zur Verfügung gestellt, so daß ich sie mir z. B. beim Hoerder Bergwerks- und Hüttenverein auf indirektem Wege durch das mit diesem Unternehmen in Verbindung stehende Bankhaus beschaffen mußte. Viel Material enthalten diese Quellen nicht. Sie sind wortkarg. Sie protokollieren aus der Fülle der Ereignisse nur das notdürftigste. Als weiteres Material wurden Fest- und Ausstellungsschriften, Kataloge etc. herangezogen. Alle diese Quellen enthalten meistens eine Summe positiver Tatsachen, aber in einseitiger, subjektiver Beleuchtung. Die Schattenseiten, die dunklen Flecken in dem Bilde, werden retouchiert, damit den Interessenten kein Gefühl der Beunruhigung beschleiche. Außerdem beruhen sie durchgehends nicht auf wissenschaftlichen Arbeitsmethoden und beanspruchen es vielleicht auch nicht einmal. Die von der Wissenschaft längst gebrandmarkten Verfahren leben hier noch ein ungestörtes Stilleben. Was soll man dazu sagen, wenn in den erwähnten Quellen statt der quantifizierten immer noch die arithmetische Durchschnittsdividende berechnet wird, um den Aktionären 
ein Ergebnis vorzuspiegeln, das in Wirklichkeit gar nicht besteht, oder wenn man in der in den Geschäftsberichten mitgeteilten Lohnstatistik einen Durchschnittslohn pro Kopf berechnet ohne Rücksicht darauf, ob es jugendliche oder erwachsene, gelernte oder ungelernte Arbeiter sind und schließlich sogar noch die Gehälter der Direktoren etc. den Arbeitslöhnen zuzählt! Dieses Material genügte also in seiner Unvollkommenheit und Einseitigkeit allein nicht, es mußte ergänzt werden durch persönliche Bcobachtungen und Befragung. Einem Besuche der Betriebsanlagen hat keines der behandelten Werke irgendwelche Schwierigkeiten in den Weg gesetzt. Das muß besonders anerkannt werden. Dadurch wurde ich in die Lage versetzt, der Schilderung jenen Hauch von Frische und Lebendigkeit zu geben, welcher über dem persönlich wahrgenommenen, im Gegensatz zu dem bloß aus trockenen Geschäftsberichten geschöpften Stoff liegt. Vor allem aber wurde es möglich, das einseitige Material der Verwaltungen bis zu einem gewissen Grade zu rektifizieren, das heißt die Geschichte der großen Werke wenigstens teilweise von einem kritischen Standpunkte aus zu behandeln. Es ist ja natürlich auch durch persönliche Beachtung, selbst wenn sie durch ein längeres Studium der Technik*) und der einschlägigen Verhältnisse vorbereitet wurde, sehr schwer, einem großen Betriebe bis ins Herz zu sehen, seine Lebensbedingungen zu zerfasern, und ich bin mir vollständig bewußt, daß das Ganze nur einen fragmentarischen Charakter trägt und caß auch Irrtümer mit untergelaufen sind. Allein das Bestreben, der Wahrheit wenigstens nahe zu kommen, wird man aus den späteren Ausführungen doch überall hervorleuchten sehen.

Auf diesen Quadern bauen sich die folgenden Studien auf.

Alles in allem: ich biete viel im Verhältnis zu dem, was man bis jetzt in unserer Wissenschaft über die wirtschaftlichen Lebensbedingungen der einzelnen großen Eisen- und Stahlwerke weiß, und wenig im Vergleich zu dem vorhandenen, mir aber nicht zugänglichen Material. In bezug auf das letztere wäre es verfehlt, die Größe des Zicles durch die Kleinheit der Verhältnisse ersticken zu lassen.

Der vorliegende erste Band behandelt nun einige größere Repräsentanten der Eisen- und Stahlindustrie. Es sind Etablissements

*) Hier verdanke ich besonders viel den ausgczeichneten Vorlesungen des Geh. Bergrats Professor Dr. H. Wedding an der Technischen Hochschule in Charlottenburg über Praktische Eisenhüittenkunde und seinen zahlreichen Schriften. 
von Weltruf. Und doch ist die Geschichte dieser bedeutenden Firmen - wie ich mich oft selbst überzeugte - nicht einmal den eigenen Beamten der Werke bekannt, geschweige denn erst den Aktionären oder ferner stehenden Interessenten.

Die folgenden Monographien sind ihrem Charakter nach - das möchte ich besonders betonen - verschiedenartig. Jeder liegt eine besondere Disposition zu Grunde. Es kam mir vor allen Dingendarauf an, das herauszufinden, was fürjedes einzelne Werk besonders charakteristisch ist und um die gefundene Generalideedas vorhandene Material zu gruppieren. Diese Arbeitsmethode enthält gleichzeitig die Erklärung für die von oberflächlichen Kritikern vielleicht beanstandete Tatsache, daß bei dem einen Werk ausführlich die Organisation der Verwaltung, die Arbeiterwohlfahrtseinrichtungen, die Absatzkrisen etc. behandelt sind, bei dem anderen aber gar nicht berührt oder nur flüchtig begrüßt werden.

Dic erste der folgenden Einzeldarstellungen beschäftigt sich mit dem Hoerder Bergwerks- und Hüttenverein. Ich betrachte ihn als Typ für die auf der Massenfabrikation aufgebaute hochkapitalistisch entwickelte Eisenindustrie des Westens. Dann folgt die Geschichte der Ilseder Hütte und des Peiner Walzwerks. Hier sammeln sich die Ideen zur Erklärung der Erscheinung, warum dieses Werk eine überdurchschnittliche Rentabilität aufweist, d. h. Dividenden zahlt, an deren Höhe die Rente keines anderen Unternehmens derselben Fabrikation heranreicht. An die Darstellung der Ilseder Hütte schließt sich die der Dortmunder Union. Hier bildet die Beantwortung der Frage nach den Ursachen der dauernden Unrentabilität den Angelpunkt der Untersuchung. Weiter folgt die Entwicklungsgeschichte der Phönixhütte. Hier versuche ich die Schicksale einer auf dem Prinzip der Dezentralisation beruhenden Parallelgesellschaft zur Dortmunder Union sowohl nach der Seite der Analogien als auch nach der Seite der Abweichungen hin zu schildern. Den Schluß bildet die über 100jährige Geschichte des führenden, Werkes der Oberschlesischen Eisenindustrie, der vereinigten Königs- und Laurahütte. Das besonders hervortretende Moment war hier die bei weitem geringere Ausbildung des kapitalistischen Systems im Gegensatz zu dem an erster Stelle behandelten westfälischen Werk. Das sind die Grundgedanken. Sie sind nur angedeutet. Aber sie zeigen, daB die folgenden Einzeldarstellungen ein zusammenhängendes Ganze bilden und als solches beurteilt zu werden den Anspruch erheben können. Es wäre 
vielleicht sehr viel cinfacher gewesen, die Monographien alle nach einer Schablone zu behandelı, doch dies überlasse ich denjenigen, die nach Schema F zu arbeiten gewohnt sind.

Zunı Sçıluß möchte ich nicht unterlassen, darauf hinzuweisen, da $B$ meines Wissens der erste, der auf die Notwendigkeit und Nützlichkeit der nationalökonomischen Analyse groBindustrieller Betriebe aufmerksam machte, kein geringerer ist, als Otto Warschauer, der in der Verbindung und Durchdringung von Technik und Wirtschaftslehre der Behandlung der Nationalökonomie an den technischen Hochschulen neue Wege wies.

Vive, vale. Si quid novisti rectius istis

Candidus imperti; si non: his utere mecum.

Horaz Ep. I. 6. 67.

Charlottenburg, Frühjahr 1904. 


\section{Der Hoerder Bergwerks- und Hüttenverein.}

Der Hoerder Bergwerks- und Hüttenverein ist die erste größere Hochofenanlage im rheinisch-westfälischen Kohlenbecken. $\mathrm{Er}$ ist eine Gründung des A. Schaaffhausenschen Bankvereins in Cöln, einer Bank, die bis heute in enger Beziehung zur westdeutschen Montanindustrie steht und deren wechselreiche Geschichte als Crédit mobilier immer noch eines Bearbeiters harrt.

Bei der Gründung von Aktiengesellschaften der Eisenindustrie, vielleicht auch anderer Industrien, lassen sich zwei Typen unterscheiden. Entweder wird eine Anzahl einzelner, verschiedenen Eigentümern gehörender Betriebe, die häufig räumlich weit auseinanderliegen, zu einem einzigen großen kapitalistischen Unternehmen zusammengeschmolzen, oder aber ein einziger Privatbetrieb wird in eine Aktiengesellschaft umgewandelt, um an einem Zentralpunkte die Produktion durch Erweiterung der Produktionsmittel in größere Dimensionen überzuführen. Der erste Fall liegt vor bei der Dortmunder Union und der Aktiengesellschaft „Phönix" und wir werden sehen, daß diese ihre Geresis auf ihr technisches und ökonomisches Schicksal nicht ohne Einfluß gewesen ist. Der letztere Fall trifft für die meisten anderen Gesellschaften zu, unter ihnen auch für den Hoerder Bergwerks- und Hüttenverein.

Im Jahre 1841 errichtete ein Industrieller namens Hermann Dietrich Piepenstock aus Iserlohn in Hoerde ein Puddel- und Walzwerk, welches er zu Ehren seines Sohnes „Hermannshütte“ nannte. Wo früher die alten Grafen von der ,Mark" gehaust hatten, da hielt nun die schwere Industrie ihren Einzug. Die schon vor dem Jahre 1300 erbaute Burg wurde das Kontor eines Kaufmanns und heute hat in dem renovierten Aufbau des alten Schlosses eine Aktiengeselischaft ihre Geschäftsräume!

Dieses Puddel- und Walzwerk wäre vielleicht von der Cölnischen GroBfinanz nicht weiter beachtet worden, hätte man nicht im Jahre 
1849 in der Nähe von Dortmund, Hoerde, Witten und Sprockhövel ausgedehnte Kohleneisensteinlager*) aufgefunden. Diese Entdeckung hatte für das Großkapital eine alarmierende Wirkung. Während die Hermannshütte früher ihr Roheisen aus der Ferne kaufen mußte, und zwar größtenteils aus Belgien, zum Teil aus England und dem Siegerlande, tauchte jetzt die Möglichkeit auf, aus dem metallurgischen Reichtum am Produktionsstandorte selbst die nötigen Rohmaterialien zu einem Preise $\mathrm{zu}$ beziehen, der beim Import fremder Erze ausgeschlossen schien. Kostete doch anfangs des Jahres 1852 das Roheisen in Belgien 56,40 Mark pro Tonne und mit Fracht und Zoll 83,50 Mark in Hoerde, während sich das deutsche Roheisen, wie es in den Holzkohlenöfen des Siegerlandes hergestellt wurde, auf 90 Mark stellte.**) Für Westfalen war daher an eine lohnende Eisen-

*) Lun Verständnis der rohstofflichen Grundlagen dieses und auch der im folgenden behandelten Werke seien hier einige allgemeine Bemerkungen über die Klassifikation und das Vorkommen der Eisenerze nach den Ausführungen Weddings an der Technischen Hochschule in Charlottenburg eingeschaltet. Man teilt die Eisenerze ein nach ihrem Reichtum an eisenhaltigen Bestandteilen. An der Spitze stehen die bis 72\% reines Eisen enthaltenden Magneteisenerze, die, soweit sie phosphorreich sind, die Grundlage der schwedischen Eisenexportindustrie bilden. (Gellivara, Grängesberg.) Bis zu 700\% Eisen enthalten dann die Roteisenerze. Diese vielfach nahezu phosphorfreien Erze haben nicht nur eine Bedeutung für England, sondern vor allen auch für die amerikanische Eisenindustrie. Den ersten Platz nehmen ein die großen Lagerstätten am Lake superior. In dritter Linie folgen dann die besonders für Deutschland wichtigen Brauneisenerze mit einem Maximalgehalt von $60 \%$ Eisen. Auf sie gründet sich die oberschlesische Eisenindustrie, die Eisenindustrie in Ilsede, an der Lahn und vor allen die in Lothringen und Luxemburg. Dort wird ein im Bruche feinkörniges Eisenerz (Minette $=$ kleines Erz) gefördert, das bereits $76 \%$ alles in Deutschland überhaupt gexonnenen Eisenerzes ausmacht. Dann folgt an vierter Stelle das Spateisenerz, das bis $48 \%$ reines Eisen enthält. Es kommt bei uns vor allem im Siegerlande vor, wo es in unabsehbare Teufen niedergeht. Wegen seines hohen Mangangehaltes ( 8 und mehr Prozent) eignet es sich vorzüglich zur Spiegeleisenfabrikation. Eine Spielart des Spateisensteins ist der Toneisenstein, der die Grundlage der englischen Eisenindustrie (Cleveland) bildet und der Kohleneisenstein, im englischen Blackband (= Schwarzstreifen) genannt. Die schottische Roheisenindustrie gründet sich noch heute auf die Verhüttung dieses Eisensteins. Außerdem kommt es vor in Steiermark, im ungarischen Erzgebirge und in England. Am niedrigsten im Eisengehalt stehen schließlich die Schwefelkiese.

**) Zum Vergleich sei bemerkt, daß ein halbes Jahrhundert später, im Jahre 1902, der Durchschnittslieferungspreis des Roheisensyndikats in Düsseldorf für Puddel- und Stahleisen ab Siegen 59,53 M. pro Tonne betrug. 
erzeugung im großen Stile noch nicht zu denken. Die Erzlager waren nicht bekannt, und die Eisenbahnen nach den großen Erzbezirken, den stillen Waldtälern des Siegerlandes, noch nicht genügend ausgebaut. Es eröffnete sich daher für das anlagelüsterne Kapital eine ungeheurc Perspektive, als die öffentlichen Blätter immer verlockendere Nachrichten über das Auffinden von Kohleneisenstein oder Blackband in Westfalen brachten. Infolgedessen trat eine Anzahl Herren zusammen, und im Jahre 1852 wurde die Firma Piepenstock \& Co. gegen Hingabe von 3,3 Millionen Mark an die Vorbesitzer in die Aktiengesellschaft „Hoerder Bergwerks- und Hüttenverein" umgewandelt. Die kleine Firma sollte, vom Kapital befruchtet, in einen Großbetrieb ausgereckt werden. Nachdem die landesherrliche Bestätigung erfolgt war, begann die Gesellschaft am 1. März 1852 ihre Wirksamkeit. Heute blickt sie auf eine über fünfzigjährige Geschichte zurück, aus der uns ein reiches Leben entgegenflutet. Die gegenwärtige Verwaltung, der man, wie schon im Vorwort erwähnt, eine allzu große Liberalität in bezug auf Förderung wissenschaftlicher Arbeiten nicht nachsagen kann, hat die Hauptpunkte dieser fünfzigjährigen Geschichte von ih rem Standpunkte aus in einer kleinen Festschrift niedergelegt, die mir neben den Geschäftsberichten für die folgende Darstellung von Wert gewesen ist und die ich daher eingehend benutzt habe. Es gibt wohl kein anderes Unternehmen, das sich so als Paradigma eignete, um dentypischen EntwicklungsgangderGroBeisenindustrie Westfalens auf dem Hintergrunde groBer Zeitperioden zu schildern, wie der Hoerder Verein. Deshalb behandeln wir ihn an erster Stelle.

Die Triebfeder, die zur Umwandlung des Privatunternehmens in eine Aktiengesellschaft führte, lag, wie wir sahen, in der Entdeckung von Eisensteinlagern in Westfalen und der dadurch gegebenen Möglichkeit, durch den Bau von Hochöfen die Roheisenerzeugung an den Ort der Weiterverarbeitung zu binden. Mit großen und stolzen Erwartungen begrüßte man die neuen Erzfunde. Ein enormes Steigen der Grundrente muBte die Folge sein. In dem Prospekt, welcher zur Errichtung der Gesellschaft erlassen wurde, wird bereits berechnet, daß die Erzlager für Jahrhunderte ausreichen. Die psychologische Disposition des Gründers ist eben der Optimismus. „Heute“, heißt es in dem Prospekt, ,steht unzweifelhaft fest, daB in den bis jetzt aufgestellten Flötzen ein Reichtum an Eisenstein vorhanden ist, welcher mehr als hinreicht, eine große Anzahl von 
Hochöfen auf Jahrhunderte zu alimentieren". Und in dem ersten Geschäftsberichte von 1852/53 urteilt die Verwaltung folgendermaßen: „Wenn für irgend eine Gesellschaft, so ist gewiß für die unsrige der Anspruch begründet, daß sie die erste gewesen ist, welche sich die Eisenproduktion im großartigen Maßstabe zum Vorwurf genommen und durch ihre unvergleichliche Lage, durch den unerschöpflichen Reichtum ihrer Eisensteingerechtsame, sowie durch die groBe Produktionsfähigkeit der Hermannshütte an der Spitze der deutschen Eisenindustrie bleibe." In der erwähnten Festschrift wird noch mitgeteilt, daß ein Probeschmelzen mit $175000 \mathrm{~kg}$ Eisenstein aus der Zeche „Argus" auf der königlichen Sayner Hütte ergab, daß das auf der Hoerder Hütte erzeugte Stabeisen alle Proben im Kaltbiegen, Warmbiegen, Spitzen, Lochen und Breiten aushielt und große Zähe und Härtigkeit aufwies. Auf dieser Tatsache baute sich der Plan auf, mit den bestehenden Puddel- und Walzwerken eine große Hochofenanlage zu kombinieren. Als die Gesellschaft gegründet wurde, hatte sic noch keine eigenen Hochöfen. Das hängt zusammen mit ihrer Abhängigkeit vom Auslande in Hinsicht auf den Rohstoffbezug. Nunmehr wurden nicht ganz $2 \mathrm{~km}$ von Hoerde in nächster Nähe von Dortmund nach und nach 6 Hochöfen gebaut. Für diesen Bau waren in dem gesamten Aktienkapital 1,8 Millionen Mark vorsesehen. Die Selbstkosten des Roheisens veranschlagte man auf 48 Mark für den Zentner. Die Produktion sollte also wesentlich gegen früher durch die eigene Erzgewinnung verbilligt werden. Verhältnismäßig klein erscheint die Summe, die für den Erwerb von Kohlen- und Eisensteinfeldern in Aktien ausgegeben wurde. Sie betrug nur 0,9 Millionen Mark. Das hängt damit zusammen, da $B$ die Gründer ohne Entgelt eine Anzahl Eisensteinfelder, Mutungen und Schurfscheine erworben und sie in die Gesellschaft eingebracht hatten. Dafür sollten sie $1 / 3$ des über $5 \%$ des Aktienkapitals hinauswachsenden Reingewinns erhalten. Diese Beteiligung wurde 1855 gegen Zahlung von 1,8 Millionen Mark in Obligationen der Gesellschaft abgelöst. Die Obligationen wurden selbst in Raten bis zum Jahre 1871 getilgt.

Wir haben gesehen, da $B$ das Privatunternehmen, aus dem der Hoerder Verein hervorging, gar keine Hochöfen besaß und infolgedessen auf den Ankauf des Roheisens angewiesen war, daß dann aber infolge der Entdeckung von Blackband in der Nähe von Hoerde, bei Dortmund, 6 Hochöfen errichtet wurden. Aber die großen Erwartungen, die man auf diese Eisenlager setzte, sollten sich nicht 
erfüllen. Die Flötze erwiesen sich weder als, ,reichhaltig noch als nachhaltig". Sowohl nach der Tiefe als nach der Länge hin nahmen sie rapide ab. Allerdings haben sie in den ersten Jahren den Hoerder Verein mit seinem wichtigsten Rohstoff versorgt. Die von ihm erworbenen Zechen ,Argus", „Friedrich", „Adele“, „Union" etc. bildeten bis in die Mitte der 60er Jahre die Grundlage der Roheisenfabrikation des Unternehmens, dann trat eine schnelle Abnahme ein. Auswärtige Erze mußten wieder in größeren Mengen eingeführt werden. In dem Geschäftsbericht über das Jahr 1867/8 heißt es bereits: „Unsere Eisenproduktion ist in bczug auf den Produktionspreis wesentlich durch die Höhe der Fracht des Eisensteins bedingt, und wird dies in um so höherem Grade, je mehr wir uns veranlaßt finden, außer dem uns in nächster Nähe unseres Eisenwerkes zu Gebote stehenden Blackband größere Quantitäten Eisenstein aus größerer oder geringerer Ferne aus eigenen Gruben zu fördern, oder aus fremden Konzessionen zu beziehen." Es handelt sich hier um einige Gruben bei Ibbenbüren, ferner im Siegerlande, bei Wetzlar, sowie im Harz. „Das im Bergbau wechselnde Glück", heißt es in der Festschrift, ,ist hier unserem Unternehmen leider nicht hold gewesen. Eine große Bedeutung haben die Gruben nie erlangt. Jetzt ist auf allen der Betrieb längst eingestellt." Nachdem die Blackbandgewinnung von 1864-1877 immer mehr abgenommen hatte, wurde im letzteren Jahre der Betrieb aufgegeben. Nach der Einführung des Thomasprozesses allerdings erlebten die alten Blackbandgruben eine Periode der Renaissance. Im Jahre 1884 wurde der Betrieb auf den Schächten Schleswig und Holstein wieder aufgenommen und bis zum Jahre 1897 noch eine Million Tonnen gefördert, ,dann aber ist die Kohleneisensteingewinnung, da sich die Beschaffenheit des Eisensteins sowohl im Fallen wie im Steigen des Flötzes mehr und mehr verschlechterte, wahrscheinlich für immer eingestellt." Damit wurde nach kurzer Auferstehung endgültig ein Gedanke zu Grabe getragen, der bei seinem ersten Auftauchen so ungeheure Erwartungen ausgelöst hatte, um sie nachher zu täuschen. Wie dereinst die alte Privatfirma ihren Erzbedarf aus Belgien und anderen Ländern einkaufen mußte, so ist die Aktiengesellschaft heute ebenfalls darauf angewiesen, den größten Teil ihrer Erze aus dem Auslande, resp. aus fremden Gruben des Inlandes zu beziehen. Damit gerät sie in Abhängigkeit von den Schwankungen der Konjunktur und des Marktes. Aber Hoerde bietet in dieser Beziehung keine Ausnahme unter den großen Werken des Dortmunder Be- 
zirks. Ich werde später einige Zahlen, die mir beim Hoerder Verein nicht zur Verfügung stehen, für die Dortmunder Union geben. Westfalen ist, vom Siegerland abgesehen, ein eisenerzarmes Land, seine Eisenindustrie beruht auf dem Kohlenreichtum. Der Schwerpunkt des deutschen Eisenbergbaus und seine Zukunft liegt heute in ElsaßLothringen und Luxemburg. Bereits jetzt werden dort mehr als drei Viertel aller in Deutschland geförderten Eisenerze gewonnen. Gefördert wurden im Jahre 1901

in Elsaß-Lothringen . . 7,6 Millionen $\mathrm{t}$ i. W. v. 20,30 Millionen $M$.

in Luxemburg . . . . . " " " " " " " $9,4,4$ "

im Oberbergamtsbez. Bonn 2,40 " " " " " " " " " " " " " " ", "

Die Produktion der anderen Oberbergamtsbezirke beträgt $1 / 2$ Mill. Tonnen und weniger, fällt also nicht sehr ins Gewicht.

Infolge dieser bedeutenden Verschiebung in den Verhältnissen der Erzproduktion sehen sich heute die rheinisch-westfälischen Werke mehr oder weniger stark genötigt, sich in Luxemburg, Lothringen oder inı Siegerlande selbst Eisensteingruben zu erwerben. So beteiligte sich auch der Hoerder Verein 1895/96 mit ein Drittel an der in der Entwicklung begriffenen Grube „Reichsland“ bei Bollingen. Allein diese Grube hat bis jetzt wenig die Hoffnungen erfüllt, und in dem Geschäftsbericht 1902/3 heißt es: „Die Erzqualität entspricht noch nicht ganz unseren Erwartungen. Für die nächste Zeit werden noch weitere Zuschüsse notwendig sein." Die Abschreibungen in dem genannten Geschäftsjahre betragen $25 \%$.

Mit dem Augenblick aber, mit dem diese entfernt liegende Grube in Lothringen in den Besitz des westfälischen Werkes übergeht, gewinnt für dieses die Frachtfrage eine überragende Bedeutung. Fast in allen Geschäftsberichten großer Werke, die sich in der erwähnten Lage befinden, kehren immer wieder die Klagen über die hohen Frachten, bis dieselben am 1. Juni 1901 ermäßigt wurden. Immerhin erscheint auch jetzt noch das Hoerder Werk im Vergleich mit den lothringischen Werken benachteiligt. Die Entfernung bis zu den Minettelagern beträgt $325-350 \mathrm{~km}$. Diesen Weg hat das Erz von Lothringen bis Westfalen zu durchlaufen, umgekehrt aber auch die nun zu einer Tonne Roheisen rund 3 Tonnen Erz, dagegen nur eine Kohle, die aus Westfalen in den Minettebezirk versandt wird. Da Tonne Koks nötig sind, so ist es ökonomisch richtiger, die eine Tonne Brennmaterial den 3 Tonnen Erz entgegenzuführen als umgekehrt. Deshalb hat sich in Lothringen die Eisenindustrie so kräftig 
entwickelt, weil man dort die Erze zur Stelle hat und ihnen nur die Kohle zuzuführen braucht. Gerade umgekehrt aber liegen die Dinge beim Hoerder Verein. Er ist demnach hinsichtlich des Hauptrohstoffs seiner Hochöfen recht ungünstig gestellt.

Der zweite wichtige Rohstoff für die Eisenhütten ist die Kohle, resp. der Koks. In bezug auf das Gewicht brauchen sie mehr Kohlen wie Eisen. Das Ziel des Eisenhüttenbetriebs besteht freilich darin, eine Tonne fertiges Fabrikat mit einer Tonne Koks zu erzeugen unter der Voraussetzung der Selbstverarbeitung des Roheisens. Heute kann man im allgemeinen annehmen, daß zur Erzeugung einer Tonne Roheisen etwa eine Tonne Kohlenstoff in der Form von Koks gebraucht wird, zur Erzeugung einer Tonne Fabrikat beim Schweißeisenprozeß etwa 8 Tonnen, beim Flußeisenproze $B 4$ bis $4 \frac{1}{2}$ Tonnen. Der große Wechsel der Betriebssysteme, die ich später schildere, hat also in ökonomischer Beziehung zu einer kolossalen Ersparung an Kohlenstoff resp. Kohlen geführt, was allerdings in den Ziffern für die Kohlenförderung der einzelnen Werke wegen ihrer kapitalistischen Tendenzen nicht zum unmittelbaren Ausdruck kommt.

Der Hoerder Verein hat von vornherein wie die meisten Werke das Prinzip der Selbstbedarfsdeckung in bezug auf den Kohlenkonsum durchzuführen versucht. In einer so kohlenreichen Gegend wie dem Ruhrbezirk wäre auch eine andere Politik gar nicht verständlich gewesen. Daher werden in den Jahren 1854-1856 Kohlenfelder bei den Dörfern Brackel und Asseln erworben, und zwar zum Gesamtpreise von 105000 Mark. Im Jahre 1859 wurden die Vorrichtungsarbeiten aufgenommen und die gewonnenen Kohlen in der „Hermannshütte" verbraucht. Die Kohlen wurden anfangs alle per Achse transportiert. Der Kohlenbergbau war in den 50er Jahren durchaus von den tierischen Arbeitskräften abhängig. Haben doch die Kohlengruben noch heute ausgedehnte Pferdeställe unter der Erde, während der oberirdische Transport durch Lokomotiven geschieht. Nun zeigte sich aber sehr bald, daß die gewonnenen Kohlen sich nicht verkoken ließen. Da nun aber die Hochöfen nicht Kohlen, sondern Koks brauchen, so konnte man dieses Material für die Roheisenerzeugung nicht verwerten. Daher heißt es im Geschäftsbericht über das Jahr $1861 / 2$, d. h. über eine Zeit, zu der die Blackbandgruben noch auf dem Höhepunkt ihrer Ergiebigkeit standen: „Nur einer der Faktoren unserer Produktion, die Kohlengewinnung, hat bis jetzt nicht in so vollem MaBe und in solcher Qualität sich entwickelt, 
wie wir bei Gründung unseres Kohlenbergwerkes auf Grund des Gutachtens bewährter Fachmänner hoffen zu dürfen glaubten. Die Chancen, welche allem Bergbau anhaften, sind im Hoerder Kohlenwerke im Laufe des letzten Betriebsjahres infolge wiederholter Betriebsstörungen, namentlich aber in dem Umstande hervorgetreten, daß die produzierte Kohle zwar für die „Hermannshütte“, nicht aber in gleichem Maße zu Koks für die Hochöfen sich eignete."

Es werden dann noch weitere Kohlenfelder gekauft. Jedes der 6 Felder kostete 60000 Mark. In den Jahren 1863-1870 reichte die Kohlenproduktion für den Bedarf der „Hermannshütte“ aus, der sich auf 360--370 Tonnen stellte, aber die Koks für die Hochöfen mußten weiter zugekauft werden.

Die Festschrift verzeichnet noch folgende, für die Weiterentwicklung wichtige Daten: „Es wurde im Jahre 1864 die erste Kohlenwäsche erbaut und Querschläge nach Norden zur Untersuchung der neuen Felder getrieben. Am 20. Oktober entstand eine längere Betriebsstörung dadurch, daB ein Brand die Gebäude, in welchen die Wasserhaltungs- und Fördermaschine untergebracht waren, zerstörte, und die Maschinen selbst beschädigte. Im Jahre 1866 wurden zum ersten Male Kokskohlen an die Hochofenanlage geliefert. Die Menge derselben war nur gering und belief sich auf 30-40 Tonnen täglich. Sie stieg in dem nächsten Jahre auf 50-65 Tonnen täglich. Im Jahre 1865 war die Produktion des Kohlenwerkes auf 700 Tonnen täglich angewachsen und es hatte sich gezeigt, daB auf der Hochofenanlage in dem an Stelle der alten Kokshochöfen erbauten Coppeeöfen, ein weit größerer Zusatz von eigenen Kohlen mit Erfolg möglich war. Es wurde deshalb beschlossen, die Kohlenwäsche so weit zu vergrößern, daß sie die ganze Kohlenförderung bewältigen und täglich 300-350 Tonnen Kokskohlen liefern konnte . . . Die Untersuchung des Feldes nach Norden hatte unterdessen ergeben, daB auch dort keine höher liegenden Flötze, die eine besser backende Kohle führen konnten, zu erwarten waren. Trotzdem wurden im Jahre 1872 auf der Grube 72 Koksöfen erbaut auf Grund der besseren Ergebnisse, welche in den neuen Öfen der Hochofenanlage mit den eigenen Kohlen erzielt wurden. Die Öfen kamen im Jahre 1873 in Betrieb, sie ergaben jedoch keine guten Resultate und wurden 1874 wieder außer Betrieb gesetzt, bis es, nachdem eine Normalspurverbindung vorhanden war, ermöglicht wurde, fremde Kohlen zur Mischung heranzuziehen. Im Jahre 1880 wurden die Öfen wieder angesteckt und blieben dann bis zum Jahre 1886 in Betrieb. Im 
Jahre 1871 wurde der Plan gefaßt, in dem östlichen Teile des Grubenfeldes einen dritten Förderschacht abzuteufen. Der Schacht erhiclt den Namen „Holstein“ ... Er wurde mit Fördermaschinen, Wasserhaltungsmaschinen und Kohlenwäsche vollständig ausgebaut und erhielt im Jahre 1885 einen AnschluB an die von Schacht „Schleswig“ zur „Hermannshütte“ führende Eisenbahn."

Diese Ausführungen zeigen, da $B$ eine volle Selbstbedarfsdeckung nicht stattfand, daß namentlich Koks zugekauft werden mußten, und daß die Geschichte des Werkes auch von verunglückten Koksanlagen zu erzählen weiß. Viel wichtiger ist nun aber der gegenwärtige Status. In bezug auf diesen heißt es weiter: „Gegenwärtig ist die Förderung der Gruben „Schleswig“ und „Holstein“ auf ca. 400000 Tonnen Kohlen jährlich gestiegen, hiervon wird etwa die Hälfte auf der Hochofenanlage zur Koksproduktion verwandt, der Rest zum Teil auf der „Hermannshütte“ verbraucht, zum Teil in Form von Stückkohlen und gewaschenen Nüssen an Dritte verkauft. Auch jetzt ist es noch nicht möglich, die Kohle, welche dem Eßkohlenflötz entstammt, allein zur Koksfabrikation zu verwenden. Es muß immer noch ein Teil guter Fettkohle zugemischt werden. Durch die Verbesserung der Konstruktion der Koksöfen und der Kohlenmischervorrichtung ist aber der Prozentsatz der Kohlen, die in der Mischung zu verwenden möglich sind, größer geworden, und die Kohlengruben bilden immer noch eine wertvolle Grundlage für den Betrieb der Hüttenwerke." In diesen Sätzen liegt der Schwerpunkt für die Beurteilung des Hoerder Vereins in bezug auf seine Kohlenproduktion. Seine Kohlenförderung genügt vollauf, so daß er noch einen Teil verkauft, aber diese Kohlen eignen sich nur teilweise zur Koksproduktion. Sie müssen mit anderen zugekauften Kohlen gemischt werden. In dieser Mischung ist allerdings der Prozentsatz der eigenen Kohlen größer geworden, infolge verbesserter Koksofenkonstruktionen und guter Kohlenmischervorrichtungen, allein ausreichend ist er nicht! Es werden daher jährlich ca. 250000 Tonnen Kohlen zugekauft. Wir sehen also, daß eine reine Selbstbedarfsdeckung in bezug auf die Kohlen angestrebt wurde, aber an den Eigenschaften der letzteren scheiterte.

Außer Eisenerz und Kohlen, resp. Koks braucht jede Eisenhütte nicht unbeträchtliche Mengen Kalkstein, einmal für den Thomasprozeß, dann aber vor allem als Zuschlag für den HochofenprozeB, bei dem es darauf ankommt, daB die Bergarten gleichzeitig mit dem gekohlten Eisen schmelzen. Es ist Sache der Eisenprobierkunst, die Höhe 
des Zuschlags festzustellen. Diesen Punkt hat die Festschrift vergessen. Bei der Besichtigung des Werkes erfuhr ich, daB es eigene Kalksteinbrüche in Luxemburg besitzt. Der letzte Geschäftsbericht erwähnt 2 Kalksteinbrüche in Letmathe und Hemer.

Fassen wir nunmehr die Resultate dieses Abschnittes kurz zusammen. Die Umwandlung der alten Firma Piepenstock in eine Aktiengesellschaft mit einem Kapital von 6 Millionen Mark hing mit den Perspektivenzusammen, die das Endeder 40 er JahreentdeckteVorkommen von Blackband im Dortmunder Bezirk eröffnete Dieses Eisenerz bildete bis zum Jahre 1864 die Grundlage der Roheisenproduktion in Hórde. Danntrat eine allmähliche Abnahme ein, und 1877 wird der Betrieb still gelegt, um dann nach Einführung des Thomasprozesses von 1884-1897 nocheinmal a ufgenommenzu werden. Auch die übrigen Gruben hielten nicht, was sieversprachen. Infolgedessen beruht heute die Roheisenerzeugung des Hoerder Vereins nicht auf selbstgeförderten, sondern auf gekauften Erzen. An dieser Tatsache ändert sich nicht vieldurch den 1895/96 erfolgten Erwerb einer Minette Konzession in Lothringen, da die hohen Erzfrachten den Transportzustark verteuerten, als daB er hätte gröBere Dimensionen annehmen können.

Dieselbe Rohstoffpolitik, allerdings mit glücklicherem Erfolge lag den MaBnahmen des Hoerder Vereins zugrunde in bezug auf die Versorgung des Werkes mit Kohlen. Auch hier treibt es Selbstbedarfsdeckungswirtschaft. Diese wird aber nicht vollständigerreicht, und $z$ war aus folgenden Gründen: Die eigenen Kohlenwarennichtgenügend backfähig, infolgedessen konnten sie nicht zur Koksproduktion verwandt werden. Sie kamen in Betracht nurfürdie Versorgung derHermannshütte, nicht aber für die Hochöfen. Nach Erwerb der beiden Zechen "Schleswig" und „Holstein"wird es all mählich möglich, einen gröBeren Teil der Kohlen zur Verkokung zu verwenden. Sie fördern jährlich etwa 400000 Tonnen. Mit Ausnahme eines kleinen, zum 
Verkaufgelangenden Quantums deckt diese Förderung einen Teil des eigenen Kohlenbedarfes. Der Mehrverbrauchvonjährlichetwa 250000 Tonnen muB angekauft werden. Es sind das die zur Mischung nötigen Feinkohlen für die Kokserzeugung.

Was folgt nun in wirtschaftlicher Bezielıung aus diesen Darlegungen? Infolge seiner Abhängigkeit in bezug auf den Erz-, weniger in bezug auf den Kohlenbedarf ist der Hoerder Verein heuteden Schwankungender Konjunkturin hohem Maße unterworfen. Die Preisverhältnisse des Rohstoffmarktes bilden einen in die Lagedes Betriebes einschneidenden Faktor. Das gilt vor allem für das Eisenerz. Die groBen Rohstoffkartelle haben allerdings die Preisschwankungen gemildert, eine Stabilisierung der Konjunktur ist ihnen aber bekanntlich nicht gelungen.

Nach diesen Erörterungen über die natürlichen Grundlagen des Unternehmens gehen wir zur Schilderung der Betriebssysteme über.

Der Hoerder Bergwerks- und Hüttenverein beruhte bei seiner Gründung auf einem Betriebssystem, das wir zunächst etwas eingehender kennen lernen müssen. Dabei wird es nötig sein, auch wieder die technische Seite nur in so weit zu berücksichtigen, als sie zum Verständnis ökonomischer Erscheinungen dient.

Die Erzeugung handelsfertiger Ware, soweit sie nicht durch bloßes Gießen des Roheisens in Formen entstand, war in der ersten Hälfte des 19. Jahrhunderts abhängig von dem PuddelprozeB. Auf ihm basierte ursprünglich der Hütterbetrieb. Die „Hermannshütte“ hatte im Jahre 185246 Puddelöfen. Der Puddelprozeß beruhte auf der Zuführung von Sauerstoff zum geschmolzenen Eisen. Der Sauerstoff oxydierte den Kohlenstoff und die Nebenbestandteile ( $\mathrm{Si}, \mathrm{Mg}$, $P$ und S). Die Umwandlung des Roheisens in Schmiedeeisen beruhte auf der Entfernung dieser Nebenbestandteile durch Oxydation. Der Herd des Ofens wurde mit Kohlen beschickt, und die glühenden Gase bestrichen dann das Eisen; dasselbe wurde glühend und überzog sich mit einer Schlackenschicht. Dadurch wurde es von der sauerstoffreichen Flamme abgesperrt. Nun öffnete der Puddler die Tür und führte eine Eisenstange hinein, die vorn ausgebogen war. Mit diesem Rührhaken durchfurchte er das ganze Bad. Dadurch 
konnten Schlacken und Eisen auseinandergezwungen werden. Es war eine schwierige und sehr anstrengende Arbeit. Der Erfolg des Puddelns hing von der persönlichen Kraft und Geschicklichkeit, sowie von der Aufmerksamkeit des Puddlers ab. Seine erste Aufgabe bestand darin, durch Rühren mit dem Haken das Eisen immer von neuem mit dem Sauerstoff in Berührung zu bringen. Auf einem bestimmten Punkte des Prozesses kochte dann die glühende Schlacke über und floß durch die Arbeitstür in ein davor gestelltes Blech ab. Außer dem Umrühren hatte der Puddler noch eine zweite schwere Arbeit auszuführen. War die Schlacke abgegossen, dann kristallisierte das Eisen. Die Kristalle schweißten aneinander, und um nun die erforderliche GleichmäBigkeit des Kohlenstoffgehalts zu erzielen, muBte der Puddler mit einer Brechstange an dem einen Ende des Herdes beginnend, die teigige Masse in einzelne Klumpen losbrechen, umwenden und aufeinanderhäufen. Man nennt dies umsetzen. Der ganze Ofeninhalt wurde auf diese Weise auf einen Haufen gebracht. Nun brach der Puddler Stücke von dieser Masse los und türmte sie aufeinander. Daraus wurden dann Ballen von annähernd Kugelgestalt gemacht, und diese mit einer Zange aus dem Ofen herausgenommen. Man nennt diese Kugeln Luppen. Sie kommen unter den Dampfhammer, werden unter demselben zu Brammen breit geschlagen und von dort unter die Luppenwalze gebracht, um zu Rohschienen ausgewalzt zu werden. Man nennt dieses Eisen $\mathrm{Sch}$ we i $B$ eisen, weil bei seiner Darstellung, bei welcher die Temperaturdes Eisens seinen Schmelzpunkt (1500 Grad) nicht übersteigt, das Eisen den teigartigen, nicht den flüssigen Zustand annimmt, d. h. Kristalle bildet, die sich zu Klumpen zusammenschweiBen lassen. Wird dieses Eisen, sofern es einen Kohlenstoffgehalt von $2,3-0,05 \%$ besitzt, plötzlich von seiner hohen auf gewöhnliche Temperatur abgekühlt, z. B. durch Eintauchen in kaltes Wasser, so wird seine Härte außerordentlich gesteigert, es wird glashart. Solches härtbares Eisen nennt man zum Unterschied vom bloßen Schmiedeeisen Stahl.*)

Der ganze PuddelprozeB ist, wie wir sehen, abhängig von der Geschicklichkeit des Arbeiters. Er beruht auf Handarbeit. Die Tech-

*) Die Praxis allerdings bezeichnet als Stahl vielfach lediglich FluBeisen; d. h. im flüssigen Zustande durch den Bessemer-Thomas- oder MartinProzeß gewonnenes Eisen. Die Gewinnungsstätte hierfür nennen wir auch in der folgenden Darstellung "Stahlwerk". 
niker haben sich viel Mühe gegeben, diese, die Körperkräfte schr stark absorbierende Tätigkeit, die bei einer sehr hohen Temperatur den Puddler auch physisch mitnimmt, durch Maschinen verrichten zu lassen. Tunner und andere begrüßten diese Versuche von Standpunkte der Menschlichkeit, indem sie die anstrengende Puddelarbeit geradezu für menschenunwürdig erklärten. Dieser technisch soziale Fortschritt ist aber im Stadium des Experiments stecken geblieben. Man ersann viele Konstruktionen, aber keine bewährte sich. Der Maschine fehlt eben der Verstand des Menschen, wenn sie auf ein Hindernis stöBt. Der Puddler achtet z. B. genau darauf, $\mathrm{daB}$ der Boden glatt bleibt. Kommt ein Hindernis, dann nimmt er eine Stange und beseitigt es. Daher mußte bei den Puddelmaschinen immer noch ein Arbeiter mix einer Stange dabeistehen. In England benutzte man übrigens anfangs diese Maschinen als Abschreckungsmittel gegen Streiks. Einige Unternehmer stellten sie auf, um sie bei Streiks in Tätigkeit zu setzen, aber auf die Arbeiter wirkte das blol in erster Zeit. Sie merkten bald, daß hier eine Übertragung der Arbeit an die Maschine nicht möglich sei. Auf dem Kontinent waren. wie Beck*) berichtet, trotz der allgemeinen Aufmerksamkeit, welche das maschinelle Verfahren, besonders bei der Wiener Weltausstellung auf sich gelenkt hatte, die Erfolge gering, weil es bei dem billigen Arbeitslohn und dem teuren Bezug der Futtererze im Betriebe kostspieliger als das alte Verfahren war.

So lange der Puddelprozeß das herrschende System war, blieb die Eisenerzeugung in verhältnismäßig engen Grenzen. An eine Massenproduktion war noch nicht zu denken, denn ein solcher I'uddclofen verarbeitete in 24 Stunden etwa 3 Tonnen Roheisen. Es konnten also in den 46 Puddelöfen des Hoerder Vereins nur ca. 138 Tonnen täglich gefrischt werden. Allerdings versuchte man dic Puddelöfen zu vergrößern, um sie zu befähigen, täglich 10 Tonnen zu verarbeiten. Nahm der Ofen aber um das Doppelte zu, dann mußten zwei Puddler arbeiten. Immer blieb die Abhängigkeit des Prozesses von der Tätigkeit des Puddlers bestehen.

In diesen beiden Punkten haben wir das volkswirtschaftlich Charakteristische dieses Betriebssystems zu suchen. Es beruhte auf der Handarbeit äußerst geschickter, befähigter und kräftiger Arbeiter. Es gelang mit diesem System nur die Verarbeitung kleiner Eisenmengen, deren Qualität je nach der Arbeit verschieden war.

*) Beck, „Geschichte des Eisens", 5. Band pag. 593. 
In dem ersten Stadium der kapitalistischen Entwicklung in der Eisenindustric konnte man sich nicht allzu lange mit diesen Verhältnissen zufrieden geben. Es kam darauf an, den ProzeB der Herstellung unabhängig von der Intelligenz und Kraft des Arbeiters zu machen, ihn vollständig zu mechanisieren, und zwar auf der Grundlage der Massenproduktion. Das aber war technisch erst möglich in dem Augenblick, wo es gelang, das zu entkohlende Eisen nicht in dem schwer zu bearbeitenden teigigen, sondern im flüssigen Aggregatzustande zu gewinnen.

Diese Aufgabe praktisch gelöst zu haben, ist das unsterbliche Verdienst Bessemers.

Da nun das nach diesem genannte Verfahren ein ganz neues Betriebssystem darstellt, das, von Krupp abgesehen, in Deutschland zuerst auf der Hermannshütte des Hoerder Vereins angewandt wurde, so werden wir uns nach kurzer Schilderung der Persönlichkeit Bessemers*) und seiner Erfindung vor allem mit ihrer Einführung in Hoerde zu beschäftigen haben.

Bessemer war Engländer. Alle großen, bahnbrechenden Fortschritte der Eisenindustrie sind nicht von Deutschen, sondern von Engländern ausgegangen. Er war Nichtfachmann. Gerade weil ihm eisenhüttenmännische Kenntnisse fehlten, folgte er um so vertrauensvoller seinen originellen Ideen. Hierüber hat er sich später einmal folgendermaßen geäußert: „Meine Erfahrungen bezüglich Erfindungen zeigen, daB die Fabrikanten viele kleine Verbesserungen in den verschiedenen Abteilungen ihrer Fabrikation auffinden, aber dieselben stellen im allgemeinen verhältnismäßig nur geringe Fortschritte vor, welche ihrer Natur nach eng mit dem Verfahren verbunden sind, das sie täglich anwenden, während im Gegensatz die großen Erfindungen von Leuten gemacht werden, welche keine Fachkenntnisse der betreffenden Fabrikation besitzen."

Bessemers Erfindung beruhte auf einem sehr einfachen Prinzip. $1855 \mathrm{kam}$ ihm der Gedanke, Roheisen in Schmiedeeisen dadurch zu verwandeln, daB er Wind durch die glühende Masse hindurchblies. Niemand hatte es vor ihm für möglich gehalten, daß man ohne Brennmaterial, durch bloßes Einblasen der Luft, das Eisen entkohlen könne, und daß dabei infolge Verbrennens von Nebenbestandteilen

") Ich entnehme die diesbezüglichen Angaben Becks „Geschichte des Eisens" IV. Band, p. $901 \mathrm{ff}$. 
so viel Wärme erzeugt werde, daß das Eisen vollständig flüssig bleibt.

Bessemer verwandte zu diesem Prozesse ein Gefäß in Gestalt einer Birne, die mit kieselsaurem Material (Quarz mit Ton als Bindemittel) ausgekleidet war. Daher nennt man dieses Verfahren auch das saure. Dic Engländer nannten das Gefäß Convertor. Das Produkt war flüssiges Eisen, das aus der Birne direkt in Eisenprismen (Coquilien) gegossen wurde. Während wir beim Puddeln als Ergebnis Schweißeisen kennen lernten, sehen wir hier Flußeisen entstehen. Dieser Unterschied ist für die später darzustellenden Verhältnisse von Wichtigkeit. Denn seit der Einführung des Bessemerprozesses beginnt ein fürchterlicher Zurückdrängungskampf des Flußeisens gegen das Schweißeisen. Wie das Alte und Unvollkommene zähe an der Vergangenheit festhält, so die damaligen industriellen Werke, die ihre Puddelbetriebe durch das neue Verfahren bedroht sahen. Mit Recht sagt Beck: „Indem sie dasselbe bemängelten, handelten sie zum Teil aus Notwehr."

Daher war es von besonderer Bedeutung, daß Krupp und der Hoerder Verein die ersten waren, die das Bessemerverfahren in ihren Betrieben einführten, und bald folgte ein Werk dem andern. Eine Revolution großen Stils in der Eisenindustrie begann.

Die große ökonomische Tragweite des Bessemerverfahrens lag in der Überwindung derjenigen Punkte, die wir beim Puddelverfahren als den Bedürfnissen der kapitalistischen Produktionsweise nicht genügend erkannt hatten. Mit der Einführung des neuen Betriebssystems nahm die Produktion einen riesigen Umfang an. Um 3 Tonnen Roheisen im Puddelofen in Schweißeisen zu verwandeln, brauchte man 24 Stunden, um aber im Convertor dieselbe Menge in Flußeisen überzuführen, 20 Minuten. Als Bessemer im Jahre 1880 zum Ehrenbürger der Stadt London gemacht wurde, sagte er folgendes: „Früher hat man 2-3 Wochen gebraucht, um Stahl zu machen, heute braucht man 15-20 Minuten. Früher kostete die Herstellung der Tonne Stahl 50 Pfund, heute 6-7 Pfund.“ Diese Kürze der Zeit verbilligte, wie schon aus den Worten Bessemers hervorgeht, natürlich das Flußeisen gegenüber dem Schweißeisen beträchtlich. Dazu kam, daß der Prozeß in der Bessemerbirne durchaus mechanisch durchgeführt werden konnte. Der Wind wird durch große Gebläsemaschinen durchgetrieben. Um die Birne zu kippen, hat man hydraulische Vorrichtungen. Die Gießpfannen werden durch einen Kran herbeigefahren, der ebenfalls hydraulisch montiert ist. 
Kurz, die menschliche Arbeitskraft tritt vollständig in den Hintergrund, es verbleibt ihr nur die Bedienung der Maschineneinrichtung, Der Arbeiter hat nur Aufsichtsfunktionen und nur hie und da greift er leise ein. Ich brauche nicht erst zu betonen, daß die zu diesem System gehörigen mechanlischen Einrichtungen außerdem die Investierung großer Summen stehenden Kapitals erforderlich machen.

Das Bessemerverfahren revolutionierte die Eisenindustrie, aber es hatte für Deutschland doch nicht die Bedeutung, wie für England, und zwar aus dem Grunde, weil dieses Verfahren gekettet war an eine bestimmte Beschaffenheit des Rohstoffes. Das zu verwendende Eisenerz durfte nämlich nicht phosphorreich sein. Der Phosphor verbrannte bei dem Verfahren nicht mit, er blieb im Eisen und machte es kaltbrüchig. Daher konnte man nur phosphorfreies oder -armes Eisenerz verwenden, d. h. ein Eisen unter 0,1\% Phosphor. An diesem aber hatte Deutschland Mangel. Es war daher auf große Eisenimporte aus dem Auslande, namentlich aus England und Spanien angewiesen. Nur wenige deutsche Hüttenwerke konnten Flußeisen aus einheimischen Erzen erblasen. Es waren dies die Georgs-Marienhütte in Osnabrück, die Königin-Marienhütte in Zwickau und die Bayerische Maxhütte. Die meisten übrigen Werke, die Bessemer-Roheisen schmolzen, mußten die Erze hierfür aus dem Auslande beziehen. So der Hoerc̉er Verein, die Dortmunder Union, die Gutehoffnungshütte, die Phönixhütte und andere. Bei der englischen Eisenindustrie aber lagen die Verhältnisse ganz anders. Sie nahm unter der Herrschaft dieses Betriebssystems einen gewaltigen Aufschwung.

Im Jahre 1863 entschloß sich der Hoerder Verein, als erstes Werk in Deutschland die Patente Bessemers zu enwerben. 1864 wurce der erste Flußstahl gegossen und 1867/68 die Anlage eines neuen Stahlwerkes mit 3 Convertern à 6 Tonnen Ladung beschlossen. Damals waren die Converter noch so klein, da $B$ sie nur 6 Tonnen faßten. Aber welchen riesigen Fortschritt gegenüber der Produktion im Puddelofen bedeutete dies! Heute beträgt auf dem Hoerder Werk die Beschickung für jede Birne 18 Tonnen! In 12 Stunden werden 30-33 Chargen geblasen.

Ich möchte in diesem Zusammenhang noch auf die zollpolitisch interessante Tatsache aufmerksam machen, daß in den 60er Jahren, wo sich der Produktionsprozeß von der Beschränktheit der menschlichen Arbeitskraft losmachte, eine freihändlerische Ausgestaltung des 
Zolltarifs stattfand, um dem zu erwartenden Massenabsatz seinen Weg zu erleichtern.

Dieses System sollte aber erst am Ende der 70er resp. Anfang der S0er Jahre eine große Bedeutung für den Hoerder Verein und die ganze rheinisch - westfälische Eiscnindustric gewinnen, indem es für die Verarbeitung phosphorreichen Roheisens geeignet gemacht wurde. Diese gewaltige Änderung knüpft ebenfalls an den Namen eines Engländers an, nämlich Gilchrist Thomas'.

Thomas gehörte jener Kategorie von Menschen an, die man „Theoretiker" nennt. Er war kein sogenannter Praktiker, und doch verdankt ihm die Eisenindustrie mehr als allen eisenindustriellen Technikern zusammengenommen. Thomas hatte auf der Royal School of Mines Hüttenkunde studiert und sich eingehend mit dem Problem der Entphosphorung des Eisens beschäftigt. Dieser lästige Bestandteil machte die große Menge phosphorreicher Erze für den Bessemerprozeß ungeeignet. Die technisch gebildete Welt rang förmlich mit einer Lösung der Frage, wie dem abzuhelfen sei. Die Möglichkeit der Entphosphorung stand im Mittelpunkte des Intercsses. Zahllose Versuche verliefen ohne Resultat. Die Hoffnung, zum Ziele zu gelangen, war daher stark gesunken. „Deshalb war es", schreibt Beck, ${ }^{*}$, ,nicht sehr zu verwundern, als im Herbst 1878 bei dem Meeting, welches das Iron Steel Institute gelegentlich der Weltausstellung in Paris abhielt, ein junger Mann von 28 Jahren, zartem Körperbau, unscheinbarem Aussehen, der eine praktische Tätigkeit in der Eisenindustrie nicht aufzuweisen hatte und mit der Behauptung auftrat, die Frage der Entphosphorung durch die Herstellung eines basischen Futters im Convertor zu lösen, dieser nur geringe Beachtung fand, und man den von ihm angemeldeten Vortrag wegen vorgerückter Zeit von der Tagesordnung absetzte. Dieser junge Mann war Sydney Gilchrist Thomas, und worüber er berichten wollte und was anzuhören hervorragende Eisenindustrielle verschmähten, war die große Erfindung, die bald darauf unter dem Namen des Thomasverfahrens die größte Sensation erregte und einen Triumphzug durch alle industriellen Länder der Erde hielt, so rasch und erfolgreich wie wohl kaum jemals eine anderer technische Erfindung."

Diese Erfindung, die bald die Welt erobern sollte, beruhte auf 3 Grundgedanken. 1. Der Convertor enthält nicht wie beim Bessemerproze $B$ ein kieselsaures, sondern ein basisches Futter. Schon

*) a. a. O. 5. Band pag. 635 .

Stillich, Nationalökonomische Forschungen, Band I. 
vor Thomas hatte man Kalk benutzt, aber alle Versuche, die Birne mit Kalk auszukleiden, schlugen fehl, weil der Kalk in der Hitze zerfiel. Thomas fand nun ein Bindemittel im Ton. Er mischte Dolomit mit Ton, und mit dieser Mischung versah er das Innere des Convertors. Darin liegt seine erste große Erfindung. 2. Während des Prozesses wird die Phosphorsäure gebunden, und zwar durch einen Kalkzuschlag. 3. Um eine Entphosphorung eintreten zu lassen, muß nach der Verbrennung des Kohlenstoffes nachgeblasen werden, denn die Phosphorsäure verbindet sich mit dem Kalk erst, wenn sämtlicher Kohlenstoff aus dem Eisen entfernt ist.

In Deutschland wurde der erste durchschlagende Erfolg auf zwei Hüttenwerken erzielt, nämlich in Hoerde und auf den Rheinischen Stahlwerken. Beide Werke erwarben gemeinschaftlich die Patente für Deutschland. Sie wurden für dieses gewissermaßen die Generalagenten des Erfinders. Wollte ein deutsches Werk den ThomasprozeB einführen, so hatte es sich an den Hoerder Verein zu wenden, der dann die Benutzung des Thomaspatentes gegen eine bestimmte Abgabe gestattete. Diese bestand in einmaliger Zahlung von 90000 Mark, wovon Thomas 60000 Mark, die Vertreter 30000 Mark erhielten. Außerdem in einer Abgabe von $2 \frac{1}{2}$ Mark pro Tonne fertigen Stahls, wovon aber $1 \frac{1}{2}$ Mark solange nicht gezahlt wurden, bis der angesammelte Betrag die Anzahlungssumme erreicht hatte. Von dieser laufenden Abgabe erhielt Thomas 11/2 Mark, die Agenten 1 Mark pro Tonne. In einem Jahre nach Erwerbung der Licenz mußte das unternehmende Werk gebaut und betriebsfähig sein.*)

Am 22. September 1879 wurde die erste Thomascharge auf der Hermannshütte des Hoerder Vereins erblasen, an demselben Tage auch auf den Rheinstahlwerken. Bereits im nächsten Jahre führten die große Mehrzahl der deutschen und auch der österreichischen Werke, für die der Hoerder Verein allein die Generalvertretung hatte, den Thomasproze $B$ bei sich ein. Aus dem Gesamtverkaufe der Licenzen fiel ihm bis zum 19. April 1894, an welchem Tage das Patent ablief, ein Reinertrag von 3414105 Mark zu.

Die Einführung einer für die deutsche Eisenindustrie so wichtigen Erfindung hatte nun zur Folge eine Verschiebung der in ternationalen Konkurrenzverhältnisse. Das Bessemerverfahren hatte für England den größten Vorteil gebracht, denn dieser Prozeß knüpfte, wie wir sahen, an ein phosphorarmes Eisenerz an, das

*) Siehe Beck a. a. O. Band 5, pag. 997. 
England in großen Massen besitzt. Das Thomasverfahren aber ist gebunden an ein phosphorreiches Eisenerz. Je stärker der Phosphorgehalt, desto besser verläuft der Prozeß, denn die für denselben nötige Wärme wird durch die Verbrennung des Phosphors geliefert. Derselbe dient gleichsam als Heizmaterial. Daher ist z. B. das llseder Roheisen, das 3\% Phosphor enthält, das Ideal aller Eisenhüttenleute, die mit dem basischen ProzeB arbeiten. Da nun in deutscher Erde großc Reichtümer stark phosphorhaltiger Eisenerze schlummern, die bis 1879 nur einen minimalen Wert besaßen, so mußte, da nunmehr Schmiedeeisen durch den Thomasprozeß billiger hergesteilt werden konnte als durch den BessemerprozeB, diese Erfindung und ihre Nutzbarmachung in der Praxis der deutschen Eisenindustrie auf dem Eisenmarkte einen ungeheuren Vorsprung garantieren. Seit Beginn der 80er Jahre ist daher sowohl die Förderung von Eisenerzen, die nunmehr gerade infolge ihres Phosphorgehaltes einen großen Wert bekamen, als auch die Erzeugung von Roheisen in cin stark beschleunigtes Tempo übergetreten: Jähes, gebirgsartiges Ansteigen der bis dahin sich nur sachte hebenden, der Horizontalen nahebleibenden Kurve. Nur ein Land kennt eine noch stürmischere, jähere, und infolgedessen noch stärker durchbrochene Kurvenbewegung der Eisenproduktion: Nordamerika.

Durch seine Erfindung hat Thomas seinem Vaterlande einen schlechten Dienst erwiesen. Er hat die Konkurrenzfähigkeit Englands auf dem Eisenmarkte der Welt zugunsten Deutschlands herabgedrückt. Er war, landläufig gesprochen, ein schlechter Patriot. Er hat die Stimmung derer gefördert, die an den gehässigen Beziehungen großer Kulturnationen ein Interesse haben. Die Disharmonien zwischen Deutschland und England auf dem Weltmarkte haben auf dem Gebiete der Stahlfabrikation durch Thomas eine Verschärfung gefunden.

Wir haben im vorhergehenden zwei prinzipiell voneinanderverschiedene Betriebssystemekennen gelernt, von denen das erste in die Morgenperiode, das zweite aber in die Mittagszeit der kapitalistischen Entwicklungderwestfälischen Eisenindustrie hineinfällt. Geradezu typisch zeigt sich dies in der Geschichte des Hoerder Bergwerks- und Hüttenvereins. Derganze Betriebdesselben war ursprünglich aufgebaut auf der Puddelarbeit. Dieselbe lieferte kleine Massen Schmiedeeisen und war ab. 
hängig von der Geschicklichkeit der Arbeiter. Infolgedessen wardie Güte des Fabrikates ständigem Wechsel unterworfen. Sie ist heute auf dem Hoerder Vereinverschwunden. Auf anderen Hüttensteht sie, wie wir sehen werden, auf dem Aussterbeetat. Sie wird teilweise am Leben erhalten durch die Rückständigkeit des Schmiedehandwerks. Der Dorf$s c h m i e d k a n n$, infolgeseiner überlebten Technik, das FluBeisen nicht so gut bearbeiten wie das SchweiBeisenundbleibtdaherdem letzterentreu. Daszweite Betriebssystem ist das Birnenverfahren, das von dem HoerderVerein als derersten Aktiengesellschaft 1863 e rworben und eingeführtwurde. Das FluBeisen beginnt nunmehr das Schweißeisen allmählich zu verdrängen. Die Einführung dieses Verfahrens bedeutete nicht nur für den Hoerder Verein, sondern für die meisten deutschen Eisenwerke eine vermehrte Abhängigkeit vom Auslande. Der Importvon spanischen und skandinavischen Erzen nimmt gewaltigzu. Aberauchdieses Systemerlangterstdurch eine Spielart für Deutschland allgemeine Anwendung: durch das Thomasverfahren. Es bedeuteteden gröBten Fortschritt, den die deutsche Eisenindustrie gemacht hat. Auch hier ging bei der Einführung Hoerde bahnbrechend voran und sicherte sich durch Übernahme der Patente Deutschlands und Österreichs einen Gewinn von $3 \frac{1}{2}$ Millionen Mark.

Durch das Bessemer-sowohl, als a uch durch das Thomasverfahren wurde die Herstellung schmiedbaren Eisenserstim großen $M$ a Bstabemöglich. Jetzt erst stand einer Massenfabrikation und einem ungeheuren Aufschwung der Eisenindustrienichtmehr die Abhängigkeit von den menschlichen Arbeits kräftenim Wege. Ein System lebloser Mechanismen schiebtsich an Stelleder alten, auf Handfertigkeit beruhenden Arbeit. Damit wird eine Entwicklung eingeleitet, die sämtliche übrigen Abteilungen des Eisenhüttenbetriebes ergreifen sollte, ich meine, die immer größere Vervollkommnung des mechanischen Betriebes, die Ersetzung des ungelernten Ar- 
beitersdurchdie Maschine, und amitim Zusammenhange das immer stärkere Hervortreten des gelernten und qualifizierten Arbeiters innerhalb der mechanischen Produktion.

Wir werden nun die kapitalistischen Expansions- und Mechanisierungstendenz näher zu verfolgen haben

1. beim Hochofenbetrieb,

2. im Stahlwerk,

3. im Walzwerk.

Als der Schweißeisenbetrieb noch die Grundlage der gesamten Produktion bildete, und die eine Massenfabrikation ermöglichende Betriebsform noch unbekannt war, verspürte doch der Hoerder Verein das Sehnen, seine Produktion zu vergrößern. Denn die Vermehrung der Erzeugung ist jedem kapitalistischen Betriebe Lebensbedürfnis. Diese Vermehrung konnte auf zweierlei Weise vor sich gehen. Einmal durch Angliederung anderer Werke, und dann durch Verbesserung, vor allen Dingen Vergrößerung der Produktionsmittel. Den ersten Weg beschritt der Hoerder Verein ohne, den letzteren mit Erfolg. Im Jahre $1854 / 55$ trat er in Unterhandlung mit dem Besitzer der Beckeroder Eisenhütte im damaligen Königreich Hannover. Die Hütte sollte zu einem Preise von 945000 Mark erworben werden, dazu ein in der Nähe gelegenes Kohlenfeld. In dem Geschäftsbericht des genannten Jahres heißt es: „Dieselben Gründe, die einer Konzentration in Hoerde widerraten, sprechen der Erweiterung des Unternehmens auf ein neues, bisher unbebautes Feld das Wort und lassen auf das für eine solche Erweiterung zu verwendende Kapital eine Rentabilität in Aussicht nehmen, welche hinter der Rente des heutigen Unternehmens schwerlich zurückstehen dürfte." Aber die geplante Erweiterung konnte nicht realisiert werden, weil die Hannoversche Regierung im letzten Stadium der Verhandlungen dem Verein das Korporationsrecht in Hannover nicht erteilte, sondern die Bildung einer selbständigen Gesellschaft für das genannte Werk verlangte. Dieser Weg war den Unternehmern also abgeschnitten. Erst gegen Ende der 90er Jahre wurde er, wie wir noch sehen werden, wieder betreten.

So war denn der Hoerder Verein zur Vermehrung seiner Produktion, sowie zur Erhöhung des Profits auf die Vervollkommnung seiner Produktionsmittel angewiesen. Dies ist aber in den meisten Fällen gleichbedeutend mit Automatisierung des Betriebes. Auch hier 
reflektiert das Bild im kleinen die Züge, die an der gesamten Großeisenindustrie charakteristisch sind.

Beginnen wir mit den Hochöfen. Die Aufgabe derselben besteht in möglichst massenhafter Produktion von Roheisen. Als der erste Hochofen des Hoerder Vereins am 26. Februar 1854 angeblasen wurde, war an eine Massenerzeugung noch nicht zu denken. Das war ein kleiner Ofen von 16,2 m Höhe und 4,5 m Kohlensackweite. Die Tagesproduktion belief sich bis auf 20 Tonnen. Diese geringe Masse war das Maximum. Ebenso gering war die Leistungsfähigkeit der in den folgenden Jahren in denselben Dimensionen erbauten Öfen. In der Gründerperiode, als die Produktion der Hochöfen wegen der schlechten Beschaffenheit des Koks und der vermehrten Produktion von Bessemereisen zurückging, schritt man dann zum Bau zweier neuer Öfen mit eigenen Gebläsemaschinen und Kesseln. Diese Hochöfen waren bereits $18,5 \mathrm{~m}$ hoch und hatten eine Kohlensackweite von $5,5 \mathrm{~m}$. Die Tagesproduktion stieg auf 45 Tonnen. Sie betrug also das Doppelte der Produktion der alten Öfen. Im Anfang der 80er Jahre, als sich bei dem Hoerder Verein die große technische Neuorganisation vollzog, als ein nach großen Roheisenmassen verlangendes Thomasstahlwerk fertig war, errichtete der Hoerder Verein an Stelle der alten 8 kleinen 4 neue, große Hochöfen. „In der gründlichen Ausgestaltung unseres Hochofenbetriebes erblicken wir die wesentlichste Grundlage einer gedeihlichen Entwicklung unseres Unternehmens ..." heißt es in dem Geschäftsbericht über das Jahr 1883/84. Diese Hochöfen hatten eine Höhe von $19,5 \mathrm{~m}$ und eine Kohlensackweite von $6 \mathrm{~m}$. Die Tagesleistung stieg um mehr als das Doppelte. Sie betrug 100-120 Tonnen. Diese Verbesserung bedeutete gleichzeitig eine größere Mechanisierung des Hochofenbetriebes, und damit Hand in Hand gehend, eine Verminderung der Produktionskosten. Diese äußerte sich einmal in der Abnahme des Koksverbrauches bei der Roheisenherstellung, und außerdem in der Ersparung von Löhnen. In dem Geschäftsbericht über das Jahr 1884/85 wird darüber folgendes mitgeteilt: „Die Konzentration des Hochofenbetriebes auf wenige, aber größere und besser ausgerichtete Öfen hat, abgesehen von anderen Vorteilen, zur Folge gehabt, daß trotz der um mehr als 5 Mill. kg gesteigerten Produktion, die beim Hochofenbetriebe verausgabten Arbeitslöhne insgesamt um 30000 Mark niedriger sich beziffert haben als im Jahre 1883/84, obschon der Durchschnittslohn des einzelnen Arbeiters infolge der vermehrten Leistung gestiegen ist." Aber damit war die 
Möglichkeit einer höheren Leistung noch nicht erschöpft. Anfang der 90er Jahre kamen neue Hochöfen in Betricb, die $22 \mathrm{~m}$ hoch waren und eine Tagesproduktion von 180-190 Tonnen aufwiesen, das heißt das mehr als Neunfache der ursprünglichen Erzeugung.

Un die Produktion an Roheisen noch mehr zu vergrößern, kaufte der Hoerder Verein 1898 für 1,2 Millionen Mark die von Bornsche Hochofenanlage zu Dortmund. Dieselbe besteht aus zwei Hochöfen mit einer Jahresproduktion von etwa 100000 Tonnen. Heute hat das Hoerder Werk 6 große Hochöfen. Es ist für den dauernden Betrieb von 5 Hochöfen eingerichtet. Die Jahresproduktion betrug 1902/03 324791 Tonnen Roheisen. Davon waren nicht weniger als 310055 Tonnen Thomaseisen. Dazu kommt noch die Produktion der oben erwähnten Dortmunder Anlage, von der aber im genannten Geschäftsjahre, vom 1. April bis 30. Juni nur ein Ofen in Betrieb war, der 10605 Tonnen Roheisen produzierte.

Das sind auBerordentlich lehrreiche Details, die das Expansionsstreben eines großen kapitalistischen Betriebes besser beleuchten, als allgemeine Schilderungen es zu tun vermögen.

Hand in Hand damit geht eine möglichste Mechanisierung des Betriebes. Der Arbeiter wird durch die Maschine ersetzt. Wo das nicht möglich ist, wird vielfach seine Arbeit durch besondere Apparate kontrolliert.

Als in den 60er Jahren die Lürmannschen Formen, die einen kontinuierlichen Abfluß der Schlacke ermöglichen, eingeführt wurden, wies man zu ihrer Empfehlung nicht bloB auf die Möglichkeit einer Steigerung der Produktion hin, sondern auch darauf, daß die Einführung eine Verminderung der bisherigen Arbeiterzahl um ein Drittel erlaube und $\mathrm{da} B$ bei den Übrigbleibenden ein geringerer Grad von Geschicklichkeit notwendig sei.*) Überhaupt erfordert die Bedienung des Hochofens heute fast durchgehend ungelernte Arbeiter, die den Transport der Stoffe besorgen usw.

Diese Tendenz der Ausschaltung des Lebendigen mit dem Wachstum der Produktion beim HochofenprozeB ist noch nicht am Ende angelangt. In letzter Zeit kann man amerikanische Beschickungsvorrichtungen bereits bei einzelnen Hochöfen sehen. Eine solche Einrichtung besteht zwar nicht auf dem Hoerder Werk, aber auf einem in der Nähe gelegenen Hochofen des Stahlwerks Hösch in Dortmund.

*) Siehe: Ludwig Sinzheimer: Der volkswirtschaftliche Charakter der technischen Entwicklung des deutschen Eisenhüttengewerbes, München 1892, p. 34 
Der Förderwagen wird durch elektrische Kraft unter einem Winkel von ca. $50^{\circ}$ bis an den oberen Teil des Hochofens gezogen. Dort angekommen, kippt er selbsttätig um, verweilt einen Augenblick, wird dann selbsttätig umgesteuert, so $\mathrm{da} B$ er wieder zurückläuft. Dadurch werden nach den Angaben meines Gewährsmannes 6-8 Arbeiter erspart, die sonst an dem Förderwagen beschäftigt sind. Nur ein Arbeiter ist nötig, und zwar zum Aufziehen der Glocke. Von dieser Glocke fällt die Beschickung in den Kegel. Das Wesentliche dieser Einrichtung besteht darin, daß das Hineinschütten von Kohlen und Eisenerz unter Luftabschluß stattfindet. Den Gichtgasen wird die Flucht in die Luft versperrt.

Über diese Einrichtung sagt ein Fachmann, Wedding, folgendes:*)

„Mit Recht wird allgemein angestrebt, dem Hochofen mechanische Beschickungsvorrichtungen anzupassen. Eine solche Vorrichtung macht den Betriebsleiter unabhängig von der Trägheit und Unaufmerksamkeit ungeschulter Arbeiter. Je mehr Mangel an geschulten Arbeitern eintritt, je mehr man darauf angewiesen ist, so rohe Arbeiten, wie sie das Einfüllen der Grundstoffe in die Gicht des Hochofens bedingt, ungeübten Arbeitern zu überlassen, um so mehr werden sich auch deren schlechte Eigenschaften geltend machen. Denn je weniger ein Arbeiter Zweck und Einfluß seiner Arbeiten kennt, um so weniger Aufmerksamkeit wird er darauf verwenden. Nun ist die Arbeit des Beschickens eines Hochofens auf der Gicht äußerst einfach. Es gehört nur dazu, daß die den Arbeitern zugewogenen und zugeförderten Mengen von Stoffen rechtzeitig und an der richtigen Stelle in den Trichter des Ofens geschüttet werden, um beim Senken des Kegels oder beim Heben der Glocke an die geeignete Stelle des Hochofens zu gelangen. Bekanntlich sind zwei wichtige Regeln nötig, nämlich: Die Brennstoffe mehr in die Mitte als die Erze, die kleinen Erze an die Seite, die großen Stücke in die Mitte zu bringen und ferner alles gleichmäßig, d. h. ringförmig in dem Ofen zu verteilen. Das ist auch von ungeübten Arbeitern leicht zu erfüllen, wenn die Vorrichtungen richtig getroffen sind; denn es handelt sich dann nur darum, daß die Arbeiter die Stoffe gleichmäBig um den Schütttrichter verteilen und daß sie rechtzeitig das Auffüllen besorgen ... Aber die Arbeit auf der Gicht des Hochofens ist sehr lästig. Wind und Wetter, der Kälte und der Hitze sind die

*) Verhandlungen des Vereins zur Beförderung des Gewerbefleißes 1900 pag. 325 . 
Arbeiter dort besonders ausgesetzt und daher kommen leicht Fehler vor. Es ist daher nichts gerechtfertigter, als diese Handarbeit durch Maschinen entbehrlich zu machen." Wir sehen, wie auch hier das soziale Moment bei der Einführung technischer Neuerungen eine Rolle spielt. Wie lange der Hocrder Verein sich der praktischen Verwertung dieser Erwägungen wird entziehen können, steht dahin.

Die Anlage der Hochöfen ist für die Hermanıshütte keine günstige, weil sie zu weit voneinander entfernt liegen. Ein pünktliches Handinhandarbeiten zwischen den Hochöfen und den Convertern war größtenteils nicht möglich. Diese Abhängigkeit des Stahlwerkbetricbes vom Hochofenbetriebe wurde nun auBerordentlich herabgemindert durch die 1890 zuerst auf dem Kontinent in Hoerde erfolgte Erbauung eines Roheisenmischers. „Es war", heißt es in der Festschrift, „längst das Bestreben der Hüttentechniker gewesen, das Umschmelzen des Roheisens dadurch zu vermeiden, daß man dasselbe in flüssigem Zustande vom Hochofen den Convertern zuführte. Auch in Hoerde war dieses Verfahren schon in den 70er Jahren beim Bessemerproze $B$ eingeführt worden. Die Sache war aber auf die Dauer daran gescheitert, daß bei der großen Entfernung ein pünktliches Handinhandarbeiten nicht immer möglich war. Nach der Einführung des Thomasverfahrens wurde der Betrieb in dieser Weise wiederum aufgenommen. Derselbe gelangte aber erst zur Vollkommenheit, als ein Roheisenmischer eingeschaltet wurde . . . Der Hörder Verein kaufte die Patente für Europa und verbesserte das Verfahren, indem er für die Erfindung, durch Mischen von schwefelhaltigen mit manganreichem Roheisen den Schwefelgehalt auf ein Minimum zu reduzieren, Patente erwarb." Das Verfahren, durch den Roheisenmischer den für den Thomasprozeß unerwünschten Schwefel aus dem Roheisen vollständig auszuschalten, verdankt die Eisenhüttenindustrie dem Hoerder Verein.

Eine stärkere Ausdehnung des mechanischen Betriebes läßt sich nun aber noch verschiedentlich weiter verfolgen. Sie zeigt sich vor allem auch bei den Sicmens-Martinöfen. Das Charakteristische dieser Öfen besteht darin, daß sie nicht wie die Puddelöfen mit festem, sondern mit gasförmigem Brennstoff geheizt werden. Es sind Flammöfen. Die sogenannten Siemensschen Generatoren verbinden eine weit über das natürliche $M a ß$ gesteigerte Verbrennungstemperatur mit einer wesentlichen Ersparnis an Brennstoff. Martin konstruierte nun Öfen, in denen das Eisen durch diese Gase geschmolzen wird. Zu Beginn der Hitze schmilzt man eine zwischen 5-50\% 
des ganzen Einsatzes wechselnde Menge Roheisen nieder und beschickt dann den Ofen mit Abfällen aus den mechanischen Werkstätten etc. Die Abfälle werden gleichsam in dem Roheisenbad aufgelöst. Auf diese Weise bekommt man ein fast chemisch reines Flußeisen, dem dann wieder Kohlenstoff zugesetzt wird. Infolgedessen kann man ein Eisen von vorgeschriebener Zusammensetzung mit größter Treffsicherheit erzielen. Ökonomisch ist dieser Prozeß von so hoher Bedeutung, weil durch ihn die außerordentlich großen Mengen alten Eisens und die zahlreichen Eisenabfälle eines großen Werkes vorteilhaft verwandt werden können. Man nennt dieses Material Schrot. Solchen Schrot liefert einmal der eigene Betrieb selbst, außerdem aber wird altes Eisen von Händlern an die Werke verkauft. Es besteht übrigens auch ein Schrotverband, der nötigenfalls den Bedarf der Werke deckt. Der Hoerder Verein hat heute 6 solcher Martinöfen in Betrieb, im ganzen hat er 9 . Sie beruhen auf dem basischen Prozeß. Das Ausbringen beträgt 18 Tonnen. In 12 Stunden können 3-4 Chargen gemacht werden. Diese Öfen stellen im Monat 10000 Tonnen Siemens-Martinstahlblöcke her. Das ist für deutsche Verhältnisse eine gute Leistung. Trotzdem bleibt sie bedeutend hinter der der amerikanischen Öfen zurück. Nach den Mitteilungen Weddings über das Eisenhüttenwesen auf der Pariser Weltausstellung*) haben die Martinöfen in Amerika bereits einen Einsatz von über 100 Tonnen. Sie sind allerdings als Kippöfen eingerichtet.

Was die Technik des Martinofenprozesses anbelangt, so liegt das Ideal der Zukunft in seiner kontinuierlichen Ausgestaltung, d. h. in seiner ununterbrochenen Fortführung. Das ist bis jetzt in Deutschland $z u$ verwirklichen nicht gelungen. Hingegen hat man in Hoerde einen anderen Fortschritt, der die mechanische Aus gestaltung der Beschickung betrifft, realisiert. Die Martinöfen werden teilweise bedient durch einen elektrisch angetriebenen Chargierkran. Der Schrot und das Roheisen werden auf einer Chargiermulde durch einen Motor in den glühenden Ofen hineingeschoben und entleert. Auf der Maschine steht ein einziger Mann, der nur die Hebel zu dirigieren hat, während alles übrige die Lademaschine rein automatisch besorgt. Wedding beschreibt die Tätigkeit dieser elektrisch betriebenen Lade-

*) Verhandlungen des Vereins zur Beförderung des Gewerbefleißes Berlin 1900. 
maschine für Martinöfen, zu der nur ein einziger Arbeiter gebraucht wird, der in keiner Weise unter der Hitze zu leiden hat, folgendermaßen:*) Die Maschine besteht aus 4 Motoren. Der eine Motor dient zur Bewegung des Wagens vor dem Ofen entlang, um die mit Eisen gefüllten Behälter (Mulden oder Löffel, welche je 1 Tonne Material fassen) zu greifen und zum Ofen zu bringen, darauf leer wieder zurückzuführen. Der zweite Motor hebt den Löffel bei der Einführung in den Ofen, um die Sohle nicht zu beschädigen und um locker über das noch nicht eingeschmolzene Material im Ofen fortzukommen. Der dritte Motor schiebt den Löffel vor und zieht ihn nach der Entleerung aus dem Ofen zurück. Der vierte kleinste Motor dreht ihn im Ofen um $180^{\circ}$ und entleert ihn so.

Diese Einrichtung steckt auf der Hermannshütte noch in den ersten Anfängen. Natürlich ist eine einzige Lademaschine zur Beschickung von 6 Öfen nicht ausreichend, und der menschlichen Arbeit bleibt hier noch das meiste zu tun übrig. Die Arbeit am Martinofen aber gehört zu den schwersten, die es gibt. Die Arbeiter leiden ungeheuer unter der Glut, welche aus der geöffneten Arbeitstür des auf mehr als $1500^{\circ}$ erhitzten Ofens ausströmt. Daher halten sie es nicht viele Jahre aus: sie gehen $z u$ anderen Tätigkeiten über oder sterben eher. Mit 10 Jahren sind sie verbraucht. Die ungeheure Hitze, die bei der Beschickung des Ofens ausstrahlt, bedingt, daß die Arbeiter nur ganz leicht bekleidet sind. An den blauen Schweißkitteln erkennt man den Feuermann. Der wie Wasser über den Körper rieselnde Schweiß beizt die Farbe teilweise heraus. Auf den Kleidern erscheinen Schweißblumen. Haut und Haare auf dem Gesicht verbrennen, ebenso auf den Armen. Infolgedessen bedeutet es einen ungeheuren technisch-sozialen Fortschritt, die Beschickung des Ofens einer maschinellen Vorrichtung anzuvertrauen. Natürlich liegt die Einrichtung auch im Interesse der Produktion, denn bei der mechanischen Beschickung leidet der Ofen und die Arbeit desselben nicht so unter dem Eintritt der kalten Luft von außen durch die geöffnete Arbeitstür, andererseits spart man mindestens zwei Stunden Ladezeit, eine Anzahl von Arbeitern und zudem ist die Charge eine größere. Für uns überwiegt natürlich die Schwere des sozialen Moments. Die bedeutende Abkürzung der Zeit, die der Arbeiter unmittelbar vor dem Ofen stehen muß, dürfte für diesen

*) Sitzungsberichte des Vereins zur Beförderung des Gewerbefleißes 1895 pag. 251. 
gleichbedeutend mit einer Lebensverlängerung sein. Auf dem Hoerder Verein hat man allerdings erst e in e automatische Beschickungsvorrichtung, aber 2 neue bereits bestellt. Die Folge dieser Mechanisierung des Produktionsprozesses ist wieder das Freiwerden von Arbeitern. Vor dem Aufkommen der Chargierkräne waren 6-8 Arbeiter für die Bedienung der Martinöfen nötig. Heute sind z. B. auf der Dortmunder Union, einem in technischer Beziehung vorzüglich ausgestatteten Unternehmen, nur noch 2 Mann übrig geblieben. Damit Hand in Hand dürfte dann eine Erniedrigung der Löhne gehen. Die Martinofenarbeiter waren ehemals die bestbezahltesten Arbeiter. Sie verdienten 6-12 Mark pro Schicht. Durch die mechanische Beschickungsvorrichtung wurde ihnen die schwerste Arbeit abgenommen und damit ein Grund gegeben, ihren Lohn zu reduzieren.

Nicht überall freilich läßt sich die Arbeit des Menschen in heißer Temperatur durch mechanische Einrichtungen ersetzen. In jedem Walzwerke bleiben immer noch eine Anzahl Arbeiter, trotz aller automatischen Vorrichtungen übrig. In Hoerde hat man im Schienenwalzwerk infolgedessen eine intermittierende Arbeitszeit eingeführt. Eine Gruppe von Arbeitern walzt 20 Stück Schienen. Dann tritt für sie eine Pause ein. In derselben können sie sich erfrischen. $\mathrm{Zu}$ diesem Zwecke steht ihnen Eiswasser mit Rum zur freien Verfügung. Währenddessen tritt die zweite Gruppe in Tätigkeit, um dann wieder von der ersten Gruppe abgelöst zu werden. Das Walzen von 20 Stück dauert ca. $1 / 2$ Stunde. Diese Einrichtung ist keineswegs auf allen Walzwerken eingeführt.

Ein gutes Beispiel, wie die Automatisierung ökonomisch und sozial wirkt, bietet das Blockwalzwerk des Hoerder Vereins. Dieses Werk hat eine Monatsleistung von 28000 Tonnen. Es werden in demselben die schwersten Stahlblöcke in einer Hitze zu Halbzeug und Fertigmaterial (Platinen, d. h. Halbfabrikate der Blechfabrikation, Knüppel, d. h. Halbfabrikate der Drahtfabrikation, schwere Träger, d. h. Eisen in Gestalt eines T, U Eisen und Schienen) ausgewalzt. Dieses Blockwalzwerk wurde für $31 / 2$ Millionen Mark gebaut und im Februar 1892 dem Betriebe übergeben. An dem Unterschiede zwischen dem alten und dem neuen Blockwalzwerke kann man den ungeheuren Fortschritt messen, der auf diesem Gebiete den Arbeitsprozeß beherrscht. Das neue Walzwerk empfängt die warmen Blöcke aus dem Bessemerwerk nach Ausgleich der Wärme in Gruben oder Rollöfen auf Rollgängen. In dem alten Werke wurde der Transport durch Arbeiter besorgt. Die Hebeleute sind ersetzt durch die Roll- 
gänge, die den Block bis vor den Einstich fahren. Gewöhnlich steht heute ein Mann an jeder Seite der Blockstraße. Das alte System aber brauchte ihrer drei. Diese hatten den glühenden Block mit Hebeln und Zangen emporzuheben. Heute verrichten diese Arbeit Hebezeuge. Das Herumwerfen der Blocks geschieht durch den mechanischen Klappstuhl. Auch die Streckenleute, dic das Eisen zu richten hatten, sind verschwunden. Ihre Tätigkeit ist ersetzt durch mechanische Richtbänke. Die Abschlepper, die einst das Eisen mit Haken faßten, um es zur Adjustage zu schleppen, sind in dem neuen Walzwerk ersetzt durch mechanische Vorrichtungen, die auf Rollgängen das Walzprodukt weiter transportieren. Dic Fabrikate werden schließlich mechanisch verladen, ein Paternosterwerk hebt sie direkt auf den Wagen.

Die moderne Eisenindustrie hat aber nicht nur die Ersetzung der rein mechanischen Arbeit durch die Maschine vollzogen, sondern auch die künstlerische Tätigkeit durch den Automaten ganz oder teilweise $z u$ ersetzen versucht. Solche Künstler sind die in jedem, mit einer Eisengießerei versehenen Betriebe vorkommenden Modellschreincr. Sie haben die Aufgabe, nach den Zeichnungen der technischen Bureaus Holzmodelle zu entwerfen, z. B. für Lokomotivräder, Walzen, Coquillen etc. Die Herstellung der Modelle erfordert Präzision und Geschicklichkeit. Heute kann man in der Stahlfaçongießerei jedes Werkes, wo der Flußstahl in Formen gegossen wird, Formmaschinen beobachten, die noch feiner und tadelloser arbeiten als die Menschenhand. So werden z. B. in Hoerde bei der Herstellung von Zahnradmodcllen Formmaschinen benutzt, die viel schneller und besser arbeiten, als der geschickteste Modellformer es vermöchte. Auch hier ist der Automat eingeführt worden, um an Arbeitslohn zu sparen. Darüber sagt Beckert in seiner „Gemeinfaßlichen Darstellung des Eisenhüttenwesens“") folgendes: „Gute Former müssen ihrer Geschicklichkeit entsprechend hoch bezahlt werden. Trotz der höchsten Löhne konnten die EisengieBereien in den Jahren der stürmischen Entwicklung nach 1871 nicht genügend Former erhalten und sahen sich gezwungen, die Herstellung der Formen mittels mechanischer Vorrichtungen, der Formmaschinen, zu versuchen. Was damals als Notbehelf erschien, ist heute ein wichtiges Hilfsmittel zur Erzeugung von Massenartikeln geworden, die nur durch Verwendung bloßer Handarbeiter, also ohne gelernte Former, in einer

*) 5. Auflage 1903, pag. 51/52. 
Zahl, Genauigkeit und Sauberkeit geliefert werden können, wie es durch die sorgfältigste Handformerei nicht möglich ist. Hebt man nämlich die Modelle mit mechanischen Vorrichtungen genau senkrecht aus der Form, so wird jede Verletzung dieser, wie sie durch das geringste Schwanken der Hand eintritt, vermieden; der schwierigste (das Ausheben) und der langwierigste (das Ausbessern der Verletzungen) Teil der Formerarbeit ist erspart. - Hebt die Maschine nur die Modellteile aus, so bleibt das Feststampfen des Formsandes noch von Hand auszuführen; das kann aber ein gewöhnlicher Arbeiter verrichten. Manche Formmaschinen übernehmen auch noch diesen Teil der Arbeit, freilich nicht, indem sie den Sand stampfen, sondern zusammendrücken, was wohl bei ziemlich niedrigen Modellen, doch nicht in allen Fällen angängig ist. Die zuerst erwähnten Maschinen sind deshalb verbreiteter.

Neben den geschilderten Formmaschinen, mit denen besonders Formerlöhne gespart werden sollen, gibt es noch eine andere Gruppe, die Räderformmaschinen, deren Vorzüge in äußerst genauer Arbeit und in Ersparnis der teuren Modelle bestehen. Die Modellkosten sind schon im allgemeinen sehr hoch, besonders groß aber für Zahnräder. Da zudem die Holzmodelle trotz größter Sorgfalt nicht in der gewünschten Genauigkeit erzeugt werden können und bei vielfachem Gebrauch ihre Form merklich verändern, so sind Zahnräder mit genau gleichmäßiger Teilung und durchaus übereinstimmenden Zähnen nach Modellen gar nicht herzustellen. Die Formmaschinen aber, welche nur mit einem kleinen Teile des Modells, nämlich mit nur zwei Zähnen, arbeiten, geben, allerdings bei höherem Aufwand für Formerlohn, Erzeugnisse von der höchsten Genauigkeit.“

Es ist selbstverständlich, daß durch all diese Einrichtungen die Produktionskosten ermäBigt werden, denn die Maschine arbeitet billiger und besser wie der Mensch. Die größte Verbilligung des B e triebes, die ebenfalls wieder auf dem Hoerder Werke zuerst eingeführt wurde, aber war die Nutzbarmachung der Hochofengase für Betriebszwecke.

Auf jedem Hochofenwerk findet man Gebläsemaschinen, die atmosphärische Luft ansaugen und zusammenpressen. Diese Luft wird in sog. Winderhitzern heute auf etwa $900^{\circ}$ erhitzt und dann durch den Hochofen getrieben. Der in diesem aufsteigende Gasstrom blieb nun, nachdem er seine physikalische und chemische Arbeit erfüllt, in den Jugendjahren der kapitalistischen Entwicklung des Hochofenbetriebes ungenutzt. Auf der Zinne des Hochofens, der 
sog. Gicht, verbrannten die abströmenden Gase mit prachtvoller Flamme. Aber die Posie dieses Anblicks ging bald verloren. 1858 wurde auf dem Hörder Werk ein neuer Reserveofen erbaut, bei dem zum ersten Male Einrichtungen angebracht waren, die den Zweck hatten, die abströmenden Gase abzufangen und sie zur Heizung der Kessel zu verwenden. Diese Fangvorrichtungen fanden später bei allen Hochöfen Eingang. Aber bei dieser Verwendung blieb man nicht stehen. Auf dem Hochofenwerke existierte längst ein nicht unbeträchtlicher Gasüberschuß. Aber die weite Entfernung von der Hermannshütte verhinderte es, entweder das Hochofengas oder den mittels desselben erzeugten Dampf dorthin zu leiten. Als nun aber die elektrische Kraftübertragung in die Praxis eingeführt war, ergab sich die Möglichkeit, das Plus an Gas für den Betrieb der Hocrder Hütte nutzbar zu machen. Nunmehr wurden an Stelle der Dampfmaschinen Gasmotore aufgestellt, die, mit Hochofengas gespeist, direkt zum Antrieb der Dynamomaschinen verwandt werden konnten. Die Festschrift enthält hierüber folgende Mitteilungen: „Nachdem eine kleine Versuchsmaschine im Monat Dezember 1895 bewiesen hatte, daß der eingeschlagene Weg gangbar war, wurden nach längeren Verhandlungen mit den verschiedenen Maschinenfabriken am 21. September 1896 bei der Berlin-Anhaltischen Maschinenbau-Aktiengesellschaft in Dessau drei 600pferdige Gasmotoren bestellt. Nach Überwindung vieler Schwierigkeiten kam die erste Maschine im August 1898 in Betrieb und arbeitet seitdem die elektrische Zentrale mit großem Erfolg. Sie ist jetzt außer mit den oben erwähnten Maschinen mit zwei Deutzer Motoren von je 1000 Pferdekräften ausgerüstet, und wird mittels von der ElektrizitätsAktiengesellschaft vormals Schuckert \& Co. gelieferter Dynamos Drehstrom von 3000 Volt Spannung erzeugt, der sowohl auf der Hermannshütte wie auf den Kohlengruben zu den verschiedensten Zwecken verwendet wird." Was hier mit wenigen Worten gesagt ist, bedeutet einen der größten Fortschritte auf dem Gebiete des Eisenhüttenwesens, und zwar hauptsächlich in ökonomischer Beziehung. Die Verbilligung des Betriebes, oder mit anderen Worten die Senkung der Produktionskosten ist ein mit der mechanischen Ausgestaltung Hand in Hand gehender Faktor.

Welche Konsequenzen haben nun die im vorhergehenden geschilderten, mit dem Wachstum der Produktion und der Automatisierung verbundenen Tatsachen in sozialer Beziehung?

Soweit ich sehe, zeitigt diese Entwicklung zweierlei. Sie wirkt 
einmal reduzierend auf die Arbeiterzahl. Die Zahl der Arbeiter nimmt zwar absolut beträchtlich zu, relativ aber ab. Im Vergleich mit dem Wachstum der Produktion sinkt die Zahl der beschäftigten Arbeiter. Die Arbeiterzahl des Hoerder Bergwerks- und Hüttenvereins betrug im Jahre 1854 etwas über 2000, im Jahre 1900 nicht ganz 7500, das heißt sie war um mehr als das $31 / 2$ fache gestiegen. In dem ersten genannten Jahre betrug die Menge der Fertigfabrikate etwa 20000 Tonnen, im Jahre 1900 über 290000 Tonnen, das heißt sie hatte sich mehr als vervierzehnfacht. Der Anteil des Produktionsfaktors menschlicher Arbeit ist also beträchtlich geringer geworden, anders ausgedrückt, die relative Zahl der Arbeiter ist gesunken.

Diese Tatsache ist aber noch mit einer zweiten, nicht minder wichtigen, verknüpft. Ohne Zweifel wurden in der ersten Periode der großindustriellen Entwicklung in den Eisenhütten zahlreiche ungelernte Arbeitskräfte verwandt. Der Typus des ungelernten Arbeiters ist die Frau und das Kind. Daher hat Karl Marx recht, wenn er von der Großindustrie im allgemeinen sagt: Weiber- und Kinderarbeit war das erste Wort der kapitalistischen Anwendung der Maschinerie. Noch heute finden wir, wie bei der Beschreibung der Königs- und Laurahütte gezeigt werden soll, Weiberarbeit in der Eisenindustrie Oberschlesiens. Beim Hoerder Verein und in den übrigen rheinisch-westfälischen Werken fehlt dagegen der Typus des weiblichen Arbeiters. Hier kommen nur männliche Arbeitskräfte in Betracht. Diese ungelernten und daher schlecht bezahlten Arbeiter hatten ganz bestimmte, teilweise die Körperkräfte stark absorbierende Funktionen auszuüben. Noch heute überwiegt, wie wir sahen, der ungelernte Arbeiter beim Hochofenbetrieb. In eine zweite Periode tritt nun die Entwicklung mit der nahezu gänzlichen Durchführung der Automatisierung des Betriebes, mit der Vervollkommnung der Arbeits- und Werkzeugmaschinen, mit der Einführung von Kränen zum Transport von Lasten. Nunmehr werden die Arbeiten, für die früher ein Heer unqualifizierter Arbeiter nötig war, von mechanischen Vorrichtungen übernommen. Wenn man die Technik bei der Beschickung der Hochöfen, im Stahlwerk oder im Walzwerk auch nur ganz oberflächlich verfolgt, immer erkennt man, daß der ungelernte Arbeiter mehr und mehr durch spezielle Vorrichtungen ersetzt wird. Die Masse der ungelernten Arbeiter lichtet sich also, aber an die alten Plätze treten teilweise neue gelernte Arbeiter. Es würde heute gar nicht mehr möglich sein, einen ungelernten Arbeiter bei der Bedienung einer Walzenstraße zu ver- 
wenden; er würde sich selbst unglücklich machen. Daß für die Bedienung der Maschinen wie der Sägen, der hydraulischen Einrichtungen, der Kräne gelernte Maschinisten verwandt werden, ist ein Gebot der Notwendigkeit. Auf der zweiten Stufe der Entwicklung eines kapitalistischen Großbetriebs wird also der ungelernte Arbeiter immer mehr durch die Maschine verdrängt. Die zur Bedienung derselben herangezogenen Arbeiter aber bestehen aus hochqualifizierten, technisch bis zu einem gewissen Grade vorgebildeten Männern. Natürlich ist damit das Thema nicht erschöpft.*) Es soll nur die ersten Anregungen geben, und wir werden später bei den Großbetrieben anderer Industrien darauf zurückkommen.

Fassen wir zusammen: Der Hoerder Verein ist ein großkapitalistisches, auf Erzielung eines möglichst hohen Profits berechnetes Unternehmen. Es repräsentiert eine typische Erwerbsgesellschaft der westfälischen EisengroBindustrie. Für diese aber ist die Vergrößerung und Mechanisierung der Produktion Lebensprinzip. Der Ingenieur nennt dies Vervollkommnung des Betriebes. Die Produktion soll steigen, der Produktionspreis aber sinken. In diesem Sinnewurdedie Erweiterungder Hoerder Anlagen durch den nicht zustande gekommenen Ankauf der Beckeroder Eisenhütte versucht. Die Expansion der Erzeugung vollzog sich hauptsächlich durch die Vergrößerung und Verbesserung der Produktionsmittel. Die Leistung der Hochöfen wächst von 20 auf $180-190$ Tonnen. Die Aufstellung eines Roheisenmischers verhindert die Abhängigkeit des Stahlwerkes vonder entfernt liegenden Hochofenanlage, die durch den Ankaufdes Dortmunder Werkes noch vergrößert wird. Durch Einführung automatischer Beschickungsvorrichtungen für die Martinöfen wird der Menschenhand eine beschwerliche und gefährliche Arbeit abgenommen. Auch in den Walzwerken tritt der automatische Betrieb immer mehr an Stelle der alten, auf Handarbeit basierten Einrichtungen. Wie dies ökonomisch und sozial wirkt,

*) Vergl. die geistvollen Ausführungen J. Germans über „Die Qualifikation der Fabrikarbeit" in der „Newen Zeit“, 21. Jahrg., II. Bd, No. 30. 
sahen wir a us dem Vergleich des alten und neuen Blockwalzwerkes in Hoerde. Ja, die Mechanisierung des Produktionsprozesses machtselbstvorder künstlerischen Tätigkeit nicht Halt. Auf der Hermannshütte sind Formmaschinen in Tätigkeit, die hydraulisch betrieben werden, und die Form eines Zahnrades a uf die dazubestimmte Masse abdrücken. Sie arbeiten präziser und schneller wie Menschenhand. Mit der, immer weitere Kreise des Herstellungsprozesses ergreifenden Einführung mechanischerVorrichtungensinkenceteris paribus die Produktionskosten. Den groBartigsten Fortschritt in dieser Beziehung bildet die in Hoerde eingeführte Verwertung der Hochofengase. Schon Endeder 50 er Jahre tritt an Stelle der mit der Hand ausgeführten Heizung der Maschinen mit Kohlen die Heizung mit Gichtgasen. In den 90 er Jahren wird dann an Stelleder DampfmaschinederGasmotor zum mechanischen Antrieb der Maschinen herangezogen. Die Folgendergeschilderten Umgestaltung des Betriebes bestanden nun einmal in dem relativen Sinken der Arbeiterzahl und dann in der partiellen Ersetzung des ungelernten durch den qualifizierten Arbeiter.

Wir haben nun weiter die Frage zu behandeln, wie die großen wirtschaftlichen Erschütterungen den Hoerder Verein beeinflußten. Die $\mathrm{E}$ in wirkung von $\mathrm{Kr}$ is e $\mathrm{n}$ auf große Unternehmungen ist von Fall zu Fall verschieden. Wir werden z. B. in der Ilseder Hütte ein Unternehmen kennen lernen, das durch die Krisis von 1857 bis 1860/61 außerordentlich stark mitgenommen wurde. An dem Hörder Bergwerks- und Hüttenverein hingegen ging diese Krisis ohne wesentliche Störung vorüber. Ganz unbeeinflußt blieb er allerdings nicht. „Insbesondere mußte", heißt es in dem Geschäftsbericht über das Jahr 1858/59 „die Einstellung der Eisenbahnbauten in den unserem Debit angehörenden Staaten auf die Industrie, welche in ihren Hauptfaktoren fast ausschließlich auf Unternehmungen gedachter Art angewiesen ist, den deprimierendsten Einfluß haben." Aber im großen und ganzen ist die erste Periode seines Bestehens von 1852-1873 die erfolgreichste gewesen, die er in den Annalen seiner 
Geschichte zu verzeichnen hat: Kleines Aktienkapital, verhältnismäBig hohe Reingewinne, gute Dividenden. Die alte, gute Geschäftspraxis, die Vergrößerung des Betriebes aus den Betriebsüberschüssen zu bestreiten, war für das Unternehmen der leitende Gesichtspunkt. In den Geschäftsbericht über das Krisenjahr 1857/58, in dem noch 9\% gezahlt werden konnten, heißt es: „Der Verwaltungsrat glaubt an dem System bedeutender Abschreibungen für Verbesserungen um so mehr strikt festhalten zu sollen, als gerade in der Branche, die wir betreiben, stets neue Verbesserungen im Betriebe sich Bahn brechen und neue Anlagen erfordern, welche aus den Überschüssen des Betriebes gedeckt werden müssen, wenn nicht eine der gesteigerten Produktionskraft entsprechende Vermehrung des Aktienkapitals stattfinden soll."

Die Verhältnisse in dieser ersten Periode werden am besten beleuchtet durch die finanziellen Ergebnisse derselben.

\begin{tabular}{|c|c|c|c|c|c|c|}
\hline Jahr & Aktie & nkapit & & Reingewi & & Dividende \\
\hline $1852 / 3$ & 6 & Mill. & M. & 572,943 & M. & $5 \%$ \\
\hline $1853 / 4$ & 6 & " & $"$ & 604,686 & $"$ & $8 \%$ \\
\hline $1854 / 5$ & 6 & ", & " & 838,101 & , & $10^{3} / 4 \%$ \\
\hline $1855 / 6$ & 7,5 & $"$ & ", & $1,020,780$ & ", & $13 \%$ \\
\hline $1856 / 7$ & 7,5 & " & $"$ & $1,257,249$ & " & $13 \%$ \\
\hline $1857 / 8$ & 7,5 & $"$ & " & 998,224 & $"$ & $9 \%$ \\
\hline $1858 / 9$ & 7,5 & ", & $"$ & 621,294 & " & $5 \%$ \\
\hline $1859 / 60$ & 7,5 & $"$ & $"$ & 254,313 & $"$ & $3 \%$ \\
\hline $1860 / 1$ & 7,5 & " & " & 338,142 & $"$ & $4 \%$ \\
\hline $1861 / 2$ & 7,5 & " & ", & 536.850 & ," & $61 / 2 \%$ \\
\hline $1862 / 3$ & 7,5 & " & " & 675,900 & $"$ & $8 \underset{p}{\alpha}$ \\
\hline $1863 / 4$ & 7,5 & ," & ", & 846,867 & $"$ & $8 \%$ \\
\hline $1864 / 5$ & 8,7 & $"$ & $"$ & $1,059,600$ & $"$ & $9 \stackrel{\%}{\%}$ \\
\hline $1865 / 6$ & 8,7 & ," & ", & $1,175,400$ & $"$ & $10 \%$ \\
\hline $1866 / 7$ & 9,093 & , & $"$ & 818,427 & $"$ & $9 \not \partial$ \\
\hline $1867 / 8$ & 9,093 & ", & ", & 464,088 & " & $5 \%$ \\
\hline $1868 / 9$ & 9,507 & $"$ & " & 665,538 & $"$ & $7 \%$ \\
\hline $1869 / 70$ & 9,9 & ", & , & 792,021 & ", & $8 \underset{p}{\alpha}$ \\
\hline $1870 / 1$ & 105 & $"$ & " & 829,236 & $"$ & $6 \%$ \\
\hline $1871 / 2$ & 11,7 & $"$ & ", & $1,231,950$ & $"$ & $8 \%$ \\
\hline $1872 / 3$ & 12,0 & " & ", & $1,267,650$ & ," & $8 \%$ \\
\hline $1873 / 4$ & 14,745 & , & ," & 624,000 & ", & $4 \%$ \\
\hline
\end{tabular}

Die erste Periode wird nun von einer zweiten abgelöst, die wir von 1873-1895 rechnen können. Es ist eine für den Hörder Verein unglückliche Zeit. Sie setzt ein mit der großen Krisis des Jahres 1873. Diese 5 Jahre lang das Geschäftsleben lähmende De- 
pression hat auch für den Hoerder Verein tiefgreifende Folgen gehabt. Es ist hier nicht der Ort, die allgemeinen Ursachen des Niedergangs der Konjunktur zu untersuchen. Ich möchte nur auf die speziellen, in den Verhältnissen der Eisenindustrie selbst begründeten Ursachen hinweisen, soweit sie in den Geschäftsberichten angedeutet werden. Es kommt in Betracht:

1. Die Einführung des Bessemerverfahrens, durch das eine Massenproduktion überhaupt erst möglich wurde. Infolgedessen Stärkung der englischen Konkurrenz aus früher erwähnten Gründen. Die Festschrift sagt hierüber folgendes: „Sehr viel trug aber auch an den schlechten Verhältnissen der Umstand Schuld, daß die Hochofenindustrie in ihrer technischen Entwicklung zurückgeblieben war und von der englischen überflügelt wurde. Die in den fünfziger Jahren erbauten Hochöfen von 16-17 Meter Höhe mit ihren veralteten Windheizapparaten hatten für den Betrieb auf weißes Puddeleisen verhältnismäßig sehr gute Resultate ergeben; der Koksverbrauch belief sich nicht höher als auf $1250-1350 \mathrm{~kg}$ bei einem Möllerausbringen von 32 bis $33 \%$. Die Erze, zum großen Teile in der Umgegend gewonnen, waren billig, das Hörderwerk und andere Werke mit ihm hatten infolgedessen eine solide Grundlage. Nachdem das Bessemerverfahren die Herstellung von Eisenbahnmaterial mehr und mehr eroberte und auch die Schienen aus Flußstahl hergestellt wurden, änderten sich diese Verhältnisse; es mußten mit hohen Frachtkosten phosphorarme Nassauer, Siegener und Harzer Erze beschafft werden, die im Vergleich zu den in England verschmolzenen Erzen verhältnismäßig arm waren, während später nach Einführung der spanischen Erze die an der Küste gelegenen englischen Hochöfen erst recht im Vorteil waren. Aus diesen Erzen mußte ein tiefgraues siliciumreiches Roheisen erblasen werden. Hierzu eigneten sich die Hochöfen und Apparate nicht. Der Koksbedarf stieg in Hörde von 1250 auf 1700 bis $1800 \mathrm{~kg}$, ja in den Jahren 1873 und 1874 auf $2200 \mathrm{~kg}$ pro Tonne Roheisen. Die tägliche Produktion ging bei den alten Öfen wieder von 30 Tonnen auf 20 Tonnen zurück. Der 1874 angeblasene neue Hochofen arbeitete zwar etwas besser, seine Produktion fiel aber gegenüber derjenigen der alten Öfen nicht ins Gewicht. Die englischen Werke mit ihren reicheren Erzen rüsteten ihre Anlagen mit größeren Hochöfen und besseren Windheizapparaten aus, die einen geringen Koksverbrauch und eine hohe Produktion ergaben. Auch verbesserten sie ihre Transportvorrichtungen sehr erheblich: in Deutschland fehlte aber 
nach der Überspekulation sowohl das Kapital, wie die Unternehmungslust. Man hatte nicht den Mut, neues Geld für die jahrein, jahraus mit Unterbilanz arbeitenden Eisenwerke aufzuwenden, um so weniger, als der Wechsel in der Zollpolitik der Regierung den letzten Rest des Vertrauens in die Zukunftspolitik der Eisenindustrie wegnahm.“

2. Eine kolossale Abnahme des Innenverbrauchs an Eisen. Der Bedarf des Inlandes sank von 2,9 Millionen Tonnen im Jahre 1873 auf 1,5 Millionen Tonnen im Jahre 1879; vor allem infolge des plötzlichen Nachlassens im Ausbau des Eisenbahnnetzes. Damit im Zusammenhange ein Sinken der Nachfrage nach Schienen, dem wichtigsten Massenartikel der großen Werke

3. Der Wettbewerb der seit der VergröBerung Deutschlands durch die Annexion Elsaß-Lothringens mitkonkurrierenden Lothringer Eisenindustrie auf dem deutschen Markt. Der Hinzutritt Elsaß-Lothringens wies die bedeutende Eisenindustrie dieses Landes, die bis dahin vorwiegend in Frankreich ihren Absatz gefunden hatte, dem deutschen Markte zu, weil Frankreich seine hohen Eingangszölle nach dem Kriege aufrechterhielt. Diese Verschiebung in den Absatzverhältnissen Lothringens wurde besonders deshalb so fühlbar, weil nach Einstellung der Fabrikation schweißeiserner Schienen diese Werke sich auf die Fabrikation von Façoneisen warfen, um darin den westfälischen Werken Konkurrenz zu machen. In dem Geschäftsbericht des Hoerder Vereins über das Jahr 1875/76 wird geklagt: „Die Konkurrenz der Bessemerwerke hat die Verkaufspreise der Gußstahlschienen so sehr herabgedrückt, daß eiserne Schienen nur noch in sehr seltenen Fällen angewandt werden. Die zunehmende Verwendung eiserner Lang- und Querschwellen ist zwar geeignet, den Ausfall an Arbeit für Eisenschienen einigermaßen zu ersetzen, doch kommt diese Arbeit hauptsächlich den Lothringer Werken zugute, welche ihr Absatzgebiet für schwere und leichte Façoneisensorten auf unsern natürlichen Markt ausgedehnt und, begünstigt durch die Möglichkeit sehr wohlfeiler Produktion und uns gegenüber ungerecht billiger Tarife, während des letzten Jahres noch mehr befestigt haben. Das bedeutende Arbeitsbedürfnis sämtlicher großer Eisenwerke hat den Langschwellenpreis weit unter die Selbstkosten herabgedrückt; dasselbe gilt von Handelseisen und Eisen zu Bauzwecken. In diesem Artikel wird die westfälische Industrie durch die Lothringer Werke aus Süddeutschland, der Schweiz und einem Teile von Mitteldeutschland verdrängt. Die Schlesier, durch billigeres Roheisen und wohlfeilere Frachten begünstigt, haben große 
Vorsprünge vor uns in Sachsen und auf dem Berliner Markte. Die Nord- und Ostseehäfen werden mit englischer Ware billiger versorgt, als wir sie aus Westfalen liefern können. Vom Westen her schränkt Belgien mit seinen, zwar in der Qualität schlechteren, aber weit billigeren Eisenfabrikaten unser natürliches Absatzgebiet ein, namentlich soweit es sich um ordinäre Bleche und gewöhnliches Material für Brückenbau handelt."

4. Aufhebung der Eingangszölle auf Roheisen im Jahre 1873. Diese Aufhebung war das Resultat der Agitation der EisengroBindustriellen, die durchaus Freihändler waren. Ihr hervorragendster Repräsentant war Freiherr von Stumm. In der Reichstagssitzung vom 10. Juni 1873 sagte er: Ich kann nur immer und immer wiederholen: die deutsche Eisenindustrie verlargt keinen Schutz. Im Gegenteil, sie wünscht nur auf das dringendste den internationalen Freihandel; sie wünscht es, da sie es in hohem MaBe in ihrem Interesse hält, und ich kann versichern, daB, wenn Sie auch nur die Hauptkontinentalstaaten zu einem für Eisen freien Zollgebiet vereinigen könnten, die Eisenindustrie nicht nur nicht damit zufrieden sein könnte, sondern sogar besser fahren würde, als sie sich im Augenblicke befindet. Nach Einführung dieses handelspolitischen Systems aber machten dieselben Kreise es für die Notlage der Eisenindustrie verantwortlich, die es vorher befürwortet hatten. Dabei darf nicht außer acht gelassen werden, daB in der Krisenperiode tatsächlich die Mehreinfuhr von Eisen aller Art von Jahr zu Jahr abnahm und zwar von 536000 Tonnen im Jahre 1873 bis auf 39000 Tonnen im Jahre 1878 (nach Sering, der alles auf Roheisen umrechnet). 1879 wurde dann im autonomen Tarif ein Roheisenzoll von 10 Mark pro Tonne eingesetzt, der auch heute noch besteht.

5. Erhöhung der Frachten für Rohmaterialien und Fertigfabrikate der Eisenindustrie. Über die Tarifierung heißt es in dem Geschäftsbericht des Hoerder Vereins von 1874/75: „Den westfälischen Hütten wird dadurch die Konkurrenz mit Schlesien nach dem Osten unmöglich gemacht, indem z. B. die Schlesischen Hütten für Stabeisen nach Berlin und nach den Ostseehäfen pro Ztr. und Meile 1,24-1,74 Pfennige zahlen, während die westfälischen Werke für ihren Transport dahin 1,80-2,50 Pfennige entrichten müssen."

6. Eine Reihe von sozialen Einrichtungen, welche störend auf die Entwicklung und Konkurrenzfähigkeit der deutschen Eisenindustric einwirken. Was damit gemeint ist, geht aus folgenden Worten des Geschäftsberichts über das Jahr 1876/77 hervor: „Wir erkennen 
die Notwendigkeit der bestehenden Organisation unseres Militärwesens zur Erhaltung der Größe und Machtstellung unseres Vaterlandes vollkommen an; wir unterstützen in gleicher Weise die humanen Bestrebungen, welche sich in der Gewerbegesetzgebung und insbesondere in den Bestimmungen über das Lehrlingswesen und die Beschäftigung jugendlicher Arbeiter dokumentieren. Doch dürfen wir darauf hinweisen, da $B$ durch diese Einrichtungen der deutschen Industrie die Heranbildung tüchtiger Arbeiter wesentlich erschwert wird."

Die Notlage des Hüttenwerkes in der Krisis der 70er Jahre blieb auch nicht ohne Folgen für das städtische Gemeinwesen. Hoerde hat heute noch die Züge und den Charakter einer Hüttenstadt. Es ist mit der Hütte groß geworden und das Wohlergehen des ganzen Gemeinwesens stand von jeher mit dem Prosperieren des Werkes in innigem Zusammenhange. In den 70er Jahren hatte die Stadt Hoerde erst 11000 Einwohner. Sie hat sich mit dem Emporwachsen des Werkes stetig vergrößert. Als die Krisis hereinbrach, begann die Bevölkerungszahl zu sinken. In dem städtischen Budget machte sich bald ein Defizit bemerkbar, das nur durch steigende Sätze der kommunalen Klassensteuer ausgeglichen werden konnte. Die Zahl der Klassensteuerpflichtigen nahm von 1873-1876 um $25 \%$ ab. Das Steuererträgnis verminderte sich um 18\%. Der Zuschlag zur Klassen- und klassifizierten Einkommensteuer betrug:

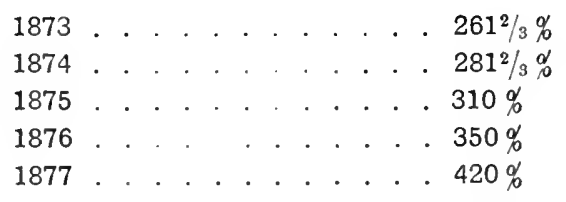

Diese enorme Steigerung der kommunalen Lasten infolge der gesunkenen Rentabilität der Werkstätten rief eine förmliche Flucht aus der Stadt hervor. Jeder, der nicht gezwungen war, in Hoerde zu leben, verlegte seinen Wohnsitz nach außerhalb, wodurch allerdings die Zunahme des Pauperismus noch gefördert wurde.

Während dieser allgemein ungünstigen Verhältnisse wurde sogar die Rohstoffpolitik des Hoerder Vereins, die, wie wir erkannten, auf die Etablierung der Selbstbedarfsdeckungswirtschaft hinauslief, eine Fessel für denselben. Sie erhöhte seine Produktionskosten gegenüber den nicht kombinierten Betrieben. Das ist auch 1878 in der Eisenenquetekommission von dem Sachverständigen des Hoerder 
Vereins, Herrn Massenez, offen ausgesprochen worden. Er sagte:*) „Fast sämtliche Werke, welche ihre Rohmaterialien selbst gewinnen, sind heute in weit ungünstigerer Lage als diejenigen, welche bloß eine Veredelung der Materialien vornehmen. Heute arbeitet unsere ganze Industrie vom Erzbergbau und Kohlenbergbau angefangen, mit Schaden. Diejenigen Werke, welche die an sich naturgemäßeste und solideste Basis besitzen, indem sie ihre Rohmaterialien selbst gewinnen, haben heute mit weit größeren Schwierigkeiten zu kämpfen, als Werke, welche beispielsweise lediglich Stahlschienenfabrikation betreiben und ihre Kohlen und ihr Roheisen kaufen müssen. Wir kaufen heute unsere Rohmaterialien billiger, als wir sie selbst darzustellen vermögen."

An die Krisis der 70er Jahre schloß sich in den 80er Jahren, nach einer kurzen Erholung, ein abermaliger großer Konjunkturwechsel. Dieser Rhythmus des industriellen Lebens hat den Hoerder Verein auch in dieser Periode sehr stark beeinflußt. Während in der Krisis der 70er Jahre die fremde Konkurrenz, namentlich die englische, der Eisenindustrie tiefe Wunden schlug, war es in der Krisis der 80er Jahre die Konkurrenz der heimischen Werke untereinander, die für den Hoerder Verein große ökonomische Nachteile im Gefolge hatte. In den 80er Jahren arbeitete das Werk daher größtenteils ohne finanziellen Erfolg. In dieser Zeit geht namentlich das Drahtgeschäft zurück, das sich anfang der 80er Jahre in Rheinland-Westfalen zu großer Bedeutung entwickelt hatte. Während der Krisis, dic von 1883-1888 dauerte, blieben die Aufträge des Auslandes größtenteils aus. Infolgedessen wurde bereits 1883 die Drahtstraße des Werkes außer Betrieb gesetzt. Das wirkte zurück auf die Herstellung des Halbfabrikates, aus dem der Draht liervorgeht, nämlich der Knüppel (Stahlbillets), deren Produktion auf dem Hoerder Werk ziemlich umfangreich war. Von dem genannten Halbfabrikat wurden produziert:

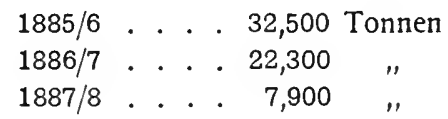

Dieses außerordentliche Zurückgehen der Stahlbilletproduktion zeigt, wie stark der Markt damals gesättigt war.

Während dieser Krisis wird ein neuer Produktionszweig aufge-

*) Reichsenquete für die Eisenindustrie 1878, p. 386. 
nommen, nämlich die Herstellung von Panzerplatten. In dem Geschäftsbericht von 1887/88 heißt es: „Gegenüber den rasch und in steigender Progression hervortretenden Anforderungen nach Lieferung von Schiffsbaumaterial für die bedeutendsten Schiffswerften Deutschlands und von Panzermaterial für das In- und Ausland, konnte man sich der Notwendigkeit nicht entziehen, die betreffende Abteilung der Hermannshütte mit den erforderlichen Ausrüstungen nach jeder Richtung hin so rasch als möglich zu versehen." Im Jahre 1887 wurde infolgedessen auf der Hermannshütte die Fabrikation von Panzerplatten und anderen Schiffsbaumaterialien in großem Umfange aufgenommen, nachdem man damit im kleinen bereits vor einigen Jahren begonnen hatte. $\mathrm{Zu}$ diesem $\mathrm{Zwecke}$ wird das Martinwerk auf 8 Öfen vergrößert und eine zweite Reversierblechstraßc aufgestellt. Allein diese Produktion wurde wieder aufgegeben, wahrscheinlich wegen der Konkurrenz von Gruson. Dies Werk erdrückte schon damals alle Konkurrenz in diesem Artikel. 1892/93 wurde es dann von Krupp erworben und damit jener ungeheure Antagonismus geschaffen, unter dem die Weltfirma bis heute leidet, nämlich auf der einen Seite immer widerstandfähigere Panzer zu fabrizieren, auf der anderen Seite aber Kanonen, die immer stärkere Panzer durchschlagen. Die Festschrift des Hoerder Vereins gibt als Grund für die Aufgabe der Fabrikation von Panzerplatten an, da $B$,sich auf die Daucr die geschaffenen Einrichtungen bei den Fortschritten der Technik auf diesem Gebiete nicht als genügend leistungsfähig erwiesen."

Der Rest der 80er Jahre, 1886/87-1889/90 ergab dann infolge Ausgabe von Prioritätsaktien wieder bessere Resultate. Daß aber die Gesellschaft unter schwicrigeren Verhältnissen arbeitete, kam in der Krisis von 1890/94 zum offenen Durchbruch. Es treten in diesen Jahren wieder starke Verluste ein, über deren Ursache nichts Näheres bekannt ist. In den Kreisen der Technik besteht die Meinung, da $B$ dic wissenschaftlichen und vielfach erfolglosen Versuche und die damit verbundenen experimentellen Anlagen große Summen verschlangen, ohne der Gesellschaft eine Rente abzuwerfen. In dieser Zeit wird weder für die Prioritäts- noch für die Stammaktien eine Dividende gezahlt.

Damals in die 80er und den Anfang der 90er Jahre fallen die großen baulichen Änderungen, die bereits erwähnt wurden. Die umfassenden Um- und Neubauten konnten in bezug auf ihre Leistungsfähigkeit nicht zur Ausnutzung gebracht werden, weil in den Krisen die Aufträge 
stark zurückgingen und in einzelnen Artikeln gänzlich zusammenschrumpften.

Einen Überblick über die Resultate des Betriebes gibt folgende Tabelle, die die Zeit von 1874/75 bis 1894/95 umspannt:

\begin{tabular}{|c|c|c|c|c|c|c|}
\hline Jahr & Aktienkapi & & Reingewin & & Dividende & \\
\hline $1874 / 5$ & $14,738,520$ & M. & - & & - & \\
\hline $1875 / 6$ & $14,789,960$ & ", & $-262,786$ & M. & - & \\
\hline $1876 / 7$ & , & " & $-881,492$ & " & - & \\
\hline $1877 / 8$ & $7,368,900$ & ," & $-108,092$ & ", & - & \\
\hline $1878 / 9$ & ," & " & - & & - & \\
\hline $1879 / 80$ & , & " & $-389,647$ & ", & - & \\
\hline $1880 / 1$ & " & ", & 381,647 & $"$ & $4 \%$ & \\
\hline $1881 / 2$ & " & " & 221,348 & $n$ & - & \\
\hline $1882 / 3$ & $"$ & " & 467,394 & $"$ & - & \\
\hline $1883 / 4$ & " & " & 202998 & ", & - & \\
\hline $1884 / 5$ & " & " & 436,944 & $"$ & - & \\
\hline $1885 / 6$ & $"$ & $"$ & 896,493 & , & Prior-Akt & Stamm-Akt. \\
\hline $1886 / 7$ & $11,868,900$ & $"$ & 475,000 & ", & $6 \%$ & $1 \%$ \\
\hline $1887 / 8$ & $14,868,900$ & ", & 700,000 & " & $6 \%$ & $1 \%$ \\
\hline $1888 / 9$ & $22,368,900$ & " & 700,000 & " & $6 \%$ & $1 \%$ \\
\hline $1889 / 90$ & " & $"$ & 904,000 & " & $5 \%$ & - \\
\hline $1890 / 1$ & ", & , & $-1,549,549$ & " & - & - \\
\hline $1891 / 2$ & $"$ & " & $-2,404,574$ & " & - & - \\
\hline $1892 / 3$ & ", & " & $-2,404,575$ & ," & - & - \\
\hline $1893 / 4$ & $17,508,000$ & ", & 263,088 & $"$ & - & - \\
\hline $1894 / 5$ & $"$ & ", & 898,191 & $"$ & - & - \\
\hline
\end{tabular}

In der sich an das letztgenannte Jahr anschließenden Aufschwungsperiode folgten die Betriebsergebnisse der rasch ansteigenden Konjunktur, um dann allerdings in den Jahren 1901/02 wieder wenig befriedigend zu sein.

Über die letzte Depressionsperiode äußert sich der Geschäftsbericht von 1902/03 folgendermaßen: „Um unsere Werke in solchem Umfange beschäftigen zu können, daß ein einigermaßen rationeller Betrieb möglich war, mußten große Mengen unserer Fabrikate für die Ausfuhr verkauft werden. Hierbei hatte der freie, ungehinderte Wettbewerb der deutschen Werke untereinander zur Folge, daß die Preise immer weiter zurückgingen und schließlich einen Stand erreichten, der eine volle Deckung der Selbstkosten gewiß in vielen Fällen ausgeschlossen hat. Von welcher Bedeutung für unsere Gesellschaft das Exportgeschäft geworden ist, erhellt daraus, da $B$ vom Gesamtversand unserer Fabrikate, der im Jahre 1902/03 sich auf 
352035 Tonnen bezifferte, 150850 Tonnen $=42,85 \%$ exportiert wurden.

Über das Betriebskapital, den Reingewinn und die Dividende der letzten Hochkonjunktur und der sich daran schließenden Baisse geben folgende Zahlen AufschluB:

Jahr Aktienkapital Reingewinn

\begin{tabular}{|c|c|c|c|}
\hline $1895 / 6$ & $22,528,090$ & M. & $1,349,055 \mathrm{M}$ \\
\hline $1896 / 7$ & $25,528,000$ & ,. & $2,410,620$ \\
\hline $1897 / 8$ & 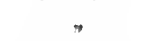 & , & $3,831,717$ \\
\hline $1898 / 9$ & $27,028,000$ & , & $4,797,198$ \\
\hline $899 / 1900$ & $n$ & ," & $4,660,301$ \\
\hline $1900 / 1$ & ", & ", & $3,169,162$ \\
\hline $1901 / 2$ & ." & , & $2,048,013$ \\
\hline $1902 / 3$ & ," & ", & $1,508,037$ \\
\hline
\end{tabular}

Dividende Prior.-Aktien Stamm-Akt.

$\begin{array}{rl}5 \% & - \\ 8 \% & - \\ 9 \% & 2 \% \\ 14 \% & 9 \% \\ 14 \% & 9 \% \\ 10 \% & 5 \% \\ -\% & - \\ 4 \% & -\end{array}$

Dieser Überblick über die finanziellen Ergebnisse ist sehr lehrreich.

Wir sehen: Während ihres $50 \mathrm{jährigen} \mathrm{Bestehens}$ hat, wenn wir von dem letzten Jahre absehen, die Gesellschaft $17 \mathrm{~J}$ ahre hindurch keine Dividende gezahlt. Wegen Mangel an Material ist es nicht möglich, die speziellen Ursachen der schlechten Geschäfte in jeder einzelnen Periode genau festzustellen. Eins aberergibt sich aus dem Vorhergehenden mit genügender Sicherheit: Die Perioden des Niederganges der Konjunktur sind geradebei dem Hoerder Verein besonders scharf und prononziert zum Ausdruckgekommen. Allerdingshat die Krisis, die in seine erste Entwicklung fällt, ihn wenig affiziert, um so tiefer aber gruben die Baissen in den folgenden drei Dezennien ihre Furchen ein. Das selbe gilt von der Krisis $1900 \mathrm{ff}$.

Aber trotzdem steht das Hoerder Werk keineswegs als Ausnahme da. Seine Gewinnergebnisse sind nur ein Spiegel der Unternehmergewinne der Eisenindustrie im allgemeinen. Denn nach den Untersuchungen Waggons*) beträgt das durchschnittliche Dividendeneinkommen des Aktionärs in der deutschen Eisenindustrie nur zwischen $5-6 \%$. Diese Industrie rangiert nach seiner Einteilung an vorletzter Stelle.

*) Eduard Waggon: Die finanzielle Entwicklung der deutschen Aktiengesellschaften von 1870-1900. Jena 1903, pag. 169. 
Eng verknüpft mit dem Wechsel der Konjunktur und den Ge. schäftsergebnissen des Hoerder Vereins steht die Geschichte des Aktienkapitals und des ganzen finanziellen Auf$\mathrm{b}$ a $\mathrm{u} \mathrm{s}$ dieser Unternehmung. Wir sahen, daß die ersten Jahre seines Bestehens eine Zeit großer Blüte der deutschen Eisenindustrie waren. Infolgedessen tritt schon relativ frühzeitir das Streben nach Expansion, nach Erweiterung der Anlagen und Vergrößerung der Betriebsmittel hervor. Aber in den 50er Jahren hatte der emporkeimende Großbetrieb noch nicht die Bewegungsfreiheit, die er heute besitzt. Das alte Aktienrecht- forderte für die Kapitalserhöhungen die Einholung der Genehmigung der Staatsregierung. Diesen Weg mußte auch der Hoerder Verein einschlagen, nachdem bereits in der ersten Generalversammlung im Jahre 1852 eine Vergrößerung des Kapitals beschlossen war. Diese Genehmigung aber wurde versagt. Die Regierung stand damals noch im Banne der Traditionen des 17. und 18. Jahrhunderts, die die Erhaltung und Förderung des Kleinbetriebes sich zum Ziele setzten. Darunter hat das Großkapital anfangs viel zu leiden gehabt. Ehe diese Fesseln gesprengt wurden, war das Unternehmertum darauf angewiesen, womöglich den Monarchen selbst für seine Pläne zu gewinnen. Diese Gelegenheit trat für den Hörder Verein ein, als der damalige König Friedrich Wilhelm IV. am 6. Oktober 1855 die Werksanlagen besichtigte. Die Folge davon war, daß die Zustimmung der Regierung nicht allzulange darauf, am 21. Mai 1856, erteilt wurde. Das Aktienkapital wurde um $1 \frac{1}{2}$ Millionen erhöht und die jungen Aktien den Aktionären al Pari angeboten. Diese Erhöhung trat zuerst auf in der Bilanz des Jahres 1855/56. Dann bleibt das Aktienkapital von $71 / 2$ Millionen Mark stabil bis zum Jahr 1863/64.

An die Aufnahme der Bessemerstahlerzeugung auf der Hermannshütte schließt sich nun eine Kette von Kapitalserhöhungen. Bis zum Ausbruch der großen Krisis des Jahres 1873 steigt es allmählich von 7,5 auf 14,7 Millionen Mark. Mit einem, wenn auch langsam verdoppelten Betriebskapitale tritt das Unternehmen in die Krisis. Nun haben wir früher bereits gesehen, daß 4 Jahre mit einer Unterbilanz von 1,6 Millionen Mark abschlossen, und 2 Jahre weder Gewinn noch Verlust hatten (siehe Seite 42). Nachdem bereits für Abschreibung und Verluste in den Jahren 1873/74 und 1874/75 der Reservefond aufgezehrt worden war, wurde am 1 . Juli 1878 die Unterbilanz der vorangehenden Jahre durch ein Verfahren aus der Welt geschafft, das bei Aktiengesellschaften in Finanzkalamitäten sehr oft vorkommt. Der 
Nominalwert der Aktien wurde von 600 auf 300 Mark heruntergesetzt, das heißt, das gesamte Aktienkapital um die Hälfte vermindert. Das Aktienkapital von 14,7 Millionen Mark betrug, auf die Hälfte reduziert, noclı 7,37 Millionen Mark. Daraus ergibt sich ein ebenso hoher Buchgewinn. Mit dieser ungeheuren Summe von 7,37 Millionen Mark hat die Gesellschaft einmal ihre Verluste gedeckt, die in den Bilanzen der Jahre 1875/76-1877/78 nur mit 1,2 Millionen Mark angegeben sind, was vielleicht zu niedrig ist, andererseits den bis auf die Neige erschöpften Reservefond gespeist, so daß dieser mit dem Betrage von 1 Million Mark nahezu wieder die Höhe der 60er Jahre erreichte. Das Jahr 1879/80, in dem die Eisenindustrie wieder einen Aufschwung nahm, schloB trotzdem für den Hoerder Verein mit einem Verlust im Betrage von 389647 Mark ab, der jedoch aus dem Reservefond gedeckt werden konnte.

In den Anfang der 80er Jahre fällt dann die vollständige Rekonstruktion der Hermannshütte. Es wurde ein Thomaswerk mit drei Zehntonnen-Konvertern errichtet, weil das alte, im Jahre 1863 erbaute Bessemerwerk nicht mehr konkurrenzfähig war. Ferner trat an Stelle des alten ein neues Bandagenwalzwerk. Zu ihm gesellte sich ein Hammerwerk mit Hämmern von 250 und $35 \mathrm{Ztr}$. Schwere. Zur besseren Verwertung der Stahlabfälle und zum Zwecke der Herstellung besonderer Stahl- und Flußeisenqualitäten wird ein Siemensmartinwerk von drei Öfen und Nebenanlagen gebaut. Im Stahlschienenwalzwerk wird eine neue schwere Walzenstraße für die Fabrikation von Schienen, Schwellen, Drahtknüppeln und schweren Façoneisen aufgestellt, und die Adjustage für Schienen und Schwellen auf mehr als das Doppelte vergrößert. Das Stabeisenwalzwerk wird transloziert, ebenso die Achsen- und Universalstraße; die Drahtstraße wird im Raume des ehemaligen Schienenwalzwerkes aufgestellt. Mit diesen Um- und Neubauten mußte sich notwendigerweise eine vollständige Umgestaltung des Gleisnetzes der Verbindungsbahn, und zur Gewinnung der Bauplätze und Lagerräume eine ganz enorme Bewegung von Erd-, Schlacken- und Schuttmassen verbinden. Diese Massen umfaßten einen Inhalt von mehr als $150000 \mathrm{cbm}$.

Die hier bloB in ihren wesentlichen Punkten angedeutete betriebstechnische Rekonstruktion im Anfang der 80er Jahre erforderte natürlich große Geldmittel. Bis zum 1. Juli 1884 betrug der Kostenaufwand für die Um- und Neubauten ca. 7,3 Millionen Mark. Ein Teil dieser Neubauten wurde aus dem Buchgewinn bezahlt, der 
durch die Reduktion des Aktienkapitals entstanden war. Außerdem hatte die Gesellschaft 1880 eine Anleihe von 4 Millionen Mark aufgenommen.

Außer dem Aktienkapital und dieser Anleihe aber hatte der Hoerder Verein noch bedeutende Bankschulden. In den 70er und 80er Jahren mußte er den Bankkredit in hohem Maße in Anspruch nehmen. Die beiden Bankhäuser, mit denen er hauptsächlich in Verbindung stand, waren der A. Schaaffhausensche Bankverein und Deichmann \& Co. Diese Firmen versagten auch in den schlechten Zeiten ihre finanzielle Unterstützung nicht, ja, sie konnten auch gar nicht anders. Der A. Schaaffhausensche Bankverein hat es selbst einmal in einem seiner Geschäftsberichte, dem über das Jahr 1875, ausgesprochen, daß die Banken sich der Industrie gegenüber in einer $Z$ wangslage befinden. Sie sind in schlechten Zeiten genötigt, weitere Mittel zur Verfügung zu stellen, um die Sicherheit der eigenen, bereits geleisteten Vorschüsse zu gewähren und den Weiterbetrieb der betreffenden Werke zu ermöglichen. Es bleibt den Banken häufig nichts anderes übrig, als von zwei Übeln das kleinere zu wählen. Aus diesem Grunde ist auch die Verbindung zwischen den Effektenbanken und der Industrie in den Zeiten der Krisen eine verhältnismäßig innige.

Als nun der Buchgewinn verbraucht und der Bankkredit bis an seine Grenze gespannt war, wurde ein neuer Weg eingeschlagen, um dem Unternehmen Geld zuzuführen. Im Jahre 1887 wurde beschlossen, das Grundkapital von 7368900 Mark durch Ausgabe von Prioritätsaktien auf 14868900 Mark zu erhöhen. Es wurde also eine neue Kategorie von Aktien geschaffen, die den bisherigen, den nunmehrigen Stammaktien, im Dividendenbezuge vorausgehen sollten. Die 7,5 Millionen Prioritätsaktien sollten den 7,3 Millionen Stammaktien gegenüber vorweg eine Dividende von $5 \%$ erhalten. Im Jahre 1889 erfolgte eine weitere Erhöhung um 7,5 Millionen Mark, so $\mathrm{da} \beta$ das im Dividendengenuß privilegierte Kapital jetzt doppelt so groß war als das Stammkapital.

Aber das allein genügte noch nicht. Anfang der $90 \mathrm{er}$ Jahre war die Situation so kritisch geworden, daß der Hoerder Verein tatsächlich vor dem Bankrott stand. Über diese Zeit sagt die Festschrift folgendes: „Am 1. Juli 1891 war wiederum eine erhebliche schwebende Schuld aufgelaufen, während zugleich nach einem kurzen Aufschwung der Konjunktur in den Jahren 1889 und 1890, von der Mitte des Jahres 1890 an, ein heftiger geschäftlicher Rückschlag ein- 
getreten war, welcher eine erhebliche Entwertung der Bestände des Werkes und einen Arbeitsmangel auf demselben zur Folge hatte. Durch diese Umstände war der Hoerder Verein in eine sehr kritische Lage geraten, und nur eine weitere kräftige Unterstützung seitens der Banken konnte denselben vor dem Untergang bewahren." Die tieferliegenden Ursachen dieser ungünstigen Lage sind, wie schon gesagt, heute schwer festzustellen. Teilweise dürften sie mit den Ende der 80er und Anfang der 90er Jahre vorgenommenen Umbauten in Zusammenhang stehen. In dem Geschäftsbericht über das Jahr 1889/90 heißt es: „Die Lage der wichtigsten Walzwerkabteilungen zur Produktionsstätte und des von ihnen zu verarbeitenden Materials der Gußstahlfabrik (gemeint ist das Thomaswerk) war von jeher eine ungünstige und bedingte weite Transporte auf ungünstig situierten Wegen." Infolgedessen wird ein neues Block- und Fertigwalzwerk für Schienen, Schwellen, Knüppel, Platinen und schwere Façoneisen in der Nähe des Thomaswerkes angelegt. Mit der Inbetriebsetzung dieser Anlage erhoffte man eine fundamentale Veränderung des ganzen Walzwerkbetriebes für schwere Profileisen und eine Vereinfachung im Betriebe des Thomaswerkes beim Gießen der Blöcke, sowie eine namhafte Verminderung der Abfälle beim Gießen und Walzen. Mit diesen Andeutungen allein aber sind die Ursachen der finanziellen Krisis des Hoerder Vereins natürlich nicht erschöpft.

Diese technische und die noch nötigere finanzielle Reorganisation der Gesellschaft übernahm der bis zum Jahre 1903 an der Spitze des Unternehmens stehende Geheime Kommerzienrat Tull. Gegen eine starke Opposition aus Aktionärkreisen wurde nun ein Plan in die Praxis umgesetzt, der folgende Grundzüge aufweist. Zunächst wird eine neue hypothekarisch eingetragene Anleihe von 10 Mill. Mark aufgenommen. Durch Beschluß der Generalversammlung vom 11. Dezember 1893 wird den Aktionären die Wahl gelassen, „die Prioritätsaktien entweder durch Zuzahlung von 25\% oder durch Zusammenlegung von $3: 1$ in Prioritätsaktien A, die Stammaktien durch Zuzahlung von $50 \%$ ebenfalls zu Prioritätsaktien A, oder durch Zusammenlegung von 8:1 zu neuen Stammaktien umzuwandeln." Der Erfolg dieses Beschlusses war, daß die Gesellschaft neue Mittel erhielt. Die Konversion ergab eine verfügbare Summe von 9622565 Mark, davon wurden verwandt: 2,4 Millionen zur Deckung der Unterbilanz, 6,2 Millionen Mark zu außerordentlichen Abschreibungen und der Rest zur Dotierung verschiedener Fonds. 
Das der Gesellschaft außerdem zugeführte neue Aktienkapital belief sich auf 4885500 Mark. Das gesamte Aktienkapital der Gesellschaft betrug nach Ausführung des Beschlusses der Generalversammlung 16980000 Mark Prioritätsaktien lit. A und 528000 Mark Stammaktien. Mit diesen Maßregeln war die finanzielle Reorganisation vollendet. Nicht weniger als eine Summe von mehr als $91 / 2$ Millionen Mark war nötig gewesen, um das Unternehmen vor dem Konkurse zu retten!

Mit dem Beginn der Hochkonjunktur im Jahre 1895 tritt der Hoerder Verein in eine Periode der Kapitalserhöhungen. Durch Generalversammlungsbeschlu $\beta$ vom 28. Oktober 1895 wird das Aktienkapital durch Ausgabe von weiteren 5020000 Mark Prioritätsaktien lit. A auf 22 Millionen Mark, durch Beschluß vom 15. Februar 1897 auf 25 Millionen Mark und durch BeschluB vom 22. Oktober 1898 auf 26,5 Millionen Mark erhöht. Heute beträgt es, wenn man die 528000 Mark Stammaktien hinzurechnet, 27028000 Mark. Dazu kommt eine Obligationsschuld von 9588000 Mark und eine unbedeutende Hypothekenschuld von 1693 Mark nach der Bilanz vom 30. Juni 1903.

Das wäre in kurzen Zügen die Geschichte der finanziellen Schicksale des Hoerder Vereins. Fassen wir noch einmal die Hauptpunkte zusammen: Die Gesells chaft begann mit einem Kapital von 6 Millionen, heute beträgt dasselbe etwas über 27 Millionen Mark. Z $Z$ ischen diesen beiden

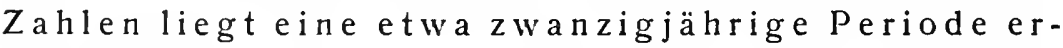
füllter Erwartungen und eine etwa ebensolange PeriodederEnttäuschung. Dieletztere, die wirbereits in dem Abschnitt über den EinfluB der Krisen auf das Werkkennenlernten, weist $z$ weimalgroBe Kapitalreduktionen auf. Die erste, am Ende der 70 er Jahre, ergibt einen Buchgewinn von 7,5 Millionen $M$ ark (1876/77), die $z w e i t e$, am Anfangder 90 er Jahre, einensolchenvon 9,6 Millionen $M$ ark, das hei $B$ t über $17 \mathrm{Millionen} \mathrm{Markgingenden} \mathrm{Aktionärenverloren,}$ ganz abgesehen davon, daB sie 17 Jahre lang überhauptkeine Dividende bezogen. Die finanzielle Rekonstruktion beruhte, wie wirsahen, hauptsächlich in der Schaffung privilegierter Aktien lit. A. Diese Aktien bestehen noch heute. Alles in allem ergibt sich, daB das Unternehmen $z$ war seine finanziellen 
Krisen unter der Patronage seiner alten Bankverbindungen überwunden hat, da $B$ aberdiese Überwindungerkauft war mitgroßen und dauernden Opfern von seiten der Aktionäre.

Unsere Schilderung würde unvollständig sein, wollten wir nicht auch den Einf $1 \mathrm{u} B$ behandeln, den das Hoerder Werk a uf seine $\mathrm{Umgebung}$ ausgeübt hat. Es hat zunächst den Charakter der Gegend verändert. Aus einem agrarischen ist ein industrielles Milieu geworden. An anderer Stelle wurde bereits bemerkt, daß die Tendenz zur Vermehrung der Produktivkräfte jedem kapitalistischen Unternelumen weseneigentümlich ist. Auch der Hoerder Verein dehnte sich aus, er erweiterte seine Produktionsmittel und occupierte früher landwirtschaftlich benutztes Terrain. Die anliegenden Wiesen und Felder wurden aufgekauft. Wo einst blühende Blumen sich im Winde wiegten, da entladen jetzt hohe Schornsteine ihre Rauchmassen. Die gesamten Anlagen bedecken heute einen Flächenraum von $2^{1} / 2$ Millionen qm. Dieses Terrain wird durchkreuzt von zahlreichen Schiencnwegen. Die Länge der eigenen Schienenwege beläuft sich heute auf $95 \mathrm{~km}$. Die Innentransporte werden von 44 Lokomotiven ausgeführt. Die Zahl der eigenen normalspurigen Eisenbahnwagen beträgt 380 .

Ein so großes Unternehmen braucht natürlich tausende von Arbeitskräften. Als in dem eh'rıals landwirtschaftlichen Milieu die schwere Industrie FuB faßte - und es geschah das bekanntlich hier viel später als in Oberschlesien - da hatte sie sich die Arbeiter in einem hartnäckigen Kampfe mit der Landwirtschaft erst zu crobern. Es war ein langandauernder AnlockungsprozeB. Er bewirkte, daß die Verdichtung der Bevölkerung zunahm. $183+$ zählte Hoerde 1471 Einwohner, 1900 aber ca. 25000 . Die Arbeiterzahl des Hoerder Vereins betrug 1852 ca. 1700,1860 ca. $2600,18704525,1880$ 3044, heute beträgt sie 7694 (nach dem Geschäftsbericht des Jahres 1902/03.)

Diese Arbeitermassen mußten vermehrt und vermindert werden können, denn für den Hoerder Verein, wie für jedes kapitalistische Unternehmen, ist es von größter Wichtigkeit, seine Arbeiterzahl der jeweiligen Größe der Produktion anzuschmiegen. Der gebundene Arbeitsvertrag, wie ihn die alte Berggesetzgebung kannte, war daher nicht geeignet, den Betrieb dem Wechsel der Konjunktur anzupassen. Das Jahr 1860 brachte dann der Montanindustrie den freien Areitsvertrag. Der Geschäftsbericht über das Krisenjahr 1859/60 
erwähnt in dieser Beziehung, ,daß ein Gesetz erlassen sei, - gemeint ist die 1860 erlassene Novelle zur Gewerbeordnung von 1851 welches von allen Bergbauunternehmern als ein bedeutender Fortschritt mit Freuden begrüßt worden sei. Die gesetzliche Bestimmung vom 21. Mai 1860, wodurch die Annahme und Entlassung von Bergleuten der freien Vereinbarung anheim gegeben wurde, sichere die allein gedeihliche freie Verwendung der sich darbietenden Arbeitskräfte, jene unnatürlich beengenden Schranken beseitigend, welche, als ein AusfluB des Rechtes der Bergbehörden, die An- und Ablegung der zum Knappschaftsverbande gehörigen Bergarbeiter zu verfügen, sowie die sogenannten Normallöhne festzustellen, sich bisher mit so nachteiligem Effekte geltend machten, daB sie eine privilegierte Arbeiterkaste statuierte. Der Wegfall des früheren Übelstandes werde die ersprießliche Folge haben, daß durch eine einheitliche, ausschlieBlich von dem Werksbeamten gehandhabte Disziplin der Arbeiter zur Folgsamkeit und zu gesteigerten Leistungen angehalten werden könne und so einer, bei Aussicht auf gewissermaßen garantierten Normallohn immer tiefer einreißenden Erschlaffung selbst der besseren Kräfte vorgebeugt werde."

Natürlich konnten die Arbeiter, die das Werk brauchte, nicht aus den heimatlichen Fluren allein herangezogen werden. Zwar setzten sich bei jeder Betriebsvergrößerung früher zahlreiche Bewohner des Sauerlandes und Hessens in Bewegung, aber die Menschenmasse der benachbarten Bezirke reichte nicht aus; immer gröBer wurde der Bedarf nach Eisen- und Hüttenarbeitern, und so wurde denn schlieBlich der deutsche Osten als Rekrutierungsbezirk für die westfälische Montanindustrie in Angriff genommen. Das ist der Zug nach dem Westen, auf dessen Geschichte und psychologische und soziale Bedeutung und Begründung ich hier nicht näher eingehen kann.

Um diese Massen zu halten, mußten Arbeiterwohlfahrtse in richtungen geschaffen werden. In erster Linie wurden Arbeiterwohnhäuser gebaut. Werke, die dies unterließen, hatten dauernd nicht genügend Arbeitskräfte, bis sie sich auch dazu entschlossen. Noch in der ersten Zeit des Bestehens hatte der Hoerder Verein viel unter Arbeitermangel zu leiden. In der Festschrift heißt es hierüber : „Die Zahl der Puddelöfen, Dampfhämmer und anderer Betriebsmaschinen wurde allmählich vergrößert (im Jahre 1857/58 wurden 53 Puddelöfen betrieben), einer allzu groBen Ausdehnung des Betriebs wurde aber dadurch gesteuert, daB es sehr viele Schwierigkeiten machte, eine 
genügende Zahl Arbeiter anzuwerben und denselben Wohnungen zu verschaffen." Über die Arbeiterwohnungspolitik macht der Geschäftsbericht voln 1868/69 einige Andeutungen. Dort heißt es: „Zwar hat das bisher von uns befolgte System, den soliden Arbeiter durch Gewährung von Vorschüssen aus der Krankenkasse zur Erwerbung einer eigenen Wohnstätte aufzumuntern, gute Früchte getragen, es entspricht jedoch dieser Modus nicht mehr den gesteigerten Bedürfnissen. Die Verwaltung beschloß daher, auf einem bereits acquirierten und sehr passend gelegenen Terrain in der Nähe des Klarenbergs nach und nach eine größere Anzahl Arbeiterwohnungen zu errichten und damit bereits im neuen Geschäftsjahre zu beginnen."

Der Hoerder Verein gab also, wie hieraus hervorgeht, den Arbeitern ursprünglich Darlehn zum Bau der eigenen Wohnstätten, dann aber nimmt die Gesellschaft den Bau selbst in die Hand, und es entstehen die bekannten Arbeiterkolonien. Heute hat der Verein in der Nähe seiner verschiedenen Werks- und Grubenanlagen 210 Wohnhäuser mit 86 Beamten- und 666 Arbeiterwohnungen; auBcrdem eine Arbeiterkaserne, in welcher 180 Arbeiter ohne Familien wohnen.

Nun kam es aber nicht blo $B$ darauf an, dem Arbeiter während der Dauer des Arbeitsvertrages cine Wohnung zu garantieren, sondern auch ihn bis zu einem gewissen Grade gegen die Wechselfälle des Lebens sicher zu stellen. Zu diesem Zwecke wird eine von dem Vorgänger des Hoerder Vereins begründete Krankenkasse gleich im ersten Geschäftsjahre zu ciner Unterstützungs- und Pensionskasse erweitert. Sie gewährte dem Arbeiter in Krankheitsfällen freie ärztliche Behandlung, freie Medikamente und einen entsprechenden Beitrag für den sonstigen Lebensunterhalt. In Todesfällen wurden aus ihr die Beerdigungskosten bestritten, sowie eine Unterstützung der Witwen. Der arbeitsunfähig Gewordene erhiclt aus ihr eine Pension. Die Alimentierung der Kasse erfolgte durch eine Beisteuer der Arbeiter und durch einen Zuschuß der Gesellschaft. Über das Verhältnis des Anteiles beider Zuschüsse ist nichts Näheres angegeben. Wir sehen hier bereits die Vorläufer der modernen Arbeiterversicherung. Längst ehe die staatliche Arbeiterfürsorge einsetzte, hatte der gesunde Egoismus der Unternehmer im Bergwerks- und Hüttenbetrieb erkannt, welche Aufgaben auf diesem Gebiete vorliegen. 1857 wurde dann ein Krankenhaus für kranke und verletzte Arbeiter erbaut und im Jahre 1897 durch Anbau eines Flügels vergrößert. 
Neben dieser Unterstützungskasse schuf man eine Sparkasse; durch dieselbe sollte der Arbeiter wirtschaftlich erzogen werden.

Um auch, ,auf seine sittliche und geistige Fortbildung einen wohltätigen Einfluß auszuüben" wurde auf Veranlassung der Königlichen Regierung zu Arnsberg eine Sonntagsschule ins Leben gerufen.

Fassen wir zusammen: $M$ it der Entwicklung des Hoerder Vereins verblaBt allmählichderlandwirtschaftliche Charakter der Gegend, die umwohnenden Arbeiter treten in den Dienst der Fabrik. Mit der Aus dehnung der Betriebsanlagen aber reicht die heimische Bevölkerung zur Deckung der Arbeiternachfragevonseiten des Werkes nicht mehraus. Es werden Arbeiter aus dem Sauerlande und aus Hessen angeworben. SchlieBlich stellt der deutsche Osten ein ansehnliches Kontingent. Heutenimmt der polnische Arbeiter einen dauernden Platzin den westfälischen Hüttenwerken ein. Diese nähern sich dadurch denoberschlesischen Betrieben, wo durch die billige Arbeitdes polnischen Arbeiterseine ErmäBigung der Produktionskosten erzielt wird. Infolge der Vergrößerung des Hoerder Werkes steigt die Arbeiterzahlvonder Mittedesvorigen bis zum Anfange desneuen Jahrhundertsvon 1700 a uf über 7000 . Diese Arbeitermassenkonntendauernd dem HörderVerein nur erhalten bleiben durch Schaffung von Wohlfahrtseinrichtungen. Als solchelernten wirkennen vor allem Arbeiterkolonien, eine Arbeiterkaserne, eine Krankenkasse, die seit Bestehen der Reichsversicherungsgesetzgebung von der Pensionskasse getrenntist, danneine Sparkasse undeine Sonntagsschule. Jedenfalls können wirsagen: der HoerderVerein hat diese Einrichtungengeschaffen, weilesihmsonst nicht möglich gewesen wäre, einen festen Arbeiterstand zu erhalten. Sozialpolitisch betrachtet erfüllendiese Wohlfahrtseinrichtungen kaum das Minimum an Forderungen, das man indieser Beziehung an sie zu stellen berechtigt ist. 


\section{Die Ilseder Hütte.}

Das erste Projekt der Gründung des im folgenden dargestellten Unternehmens knüpft an die Entdeckung reicher Braunciscnerzlager an, die um die Mitte des verflossenen Jahrhunderts in der Nähe des Dorfes Groß-Ilsede bei Peine in Hannover gefunden wurden. Auch hier entsprang der Plan, diese Naturschätze auszubeuten, ganz wie wir dies beim Hoerder Bergwerks- und Hüttenverein kennen gelernt hatten, der Interessensphäre des mobilen Kapitals. Der erste, der die neue Entdeckung finanzierte, war ein Celler Privatbankier namens Hostmann. Er gründete 1856 die Bergbau- und Hüttengesellschaft zu Peine und begann im folgenden Jahre mit dem Bau der Hütte. Bald darauf wurden die nach dem Statut notwendigen Organe bestellt, und die Organisation der kaufmännischen und technischen Beamten begonnen. Aber die historische Temperatur dieses Jahres war nicht günstig. Die aufsteigende Konjunktur war ins Stocken geraten, nachdem bereits vorher das Wetterleuchten am politischen Firmament den allzu stürmischen Unternehmungsgeist des Großkapitals etwas gedämpft hatte. Die große Handels- und Kreditkrisis des Jahres 1857, deren Schatten noch die folgenden Jahre verdunkeln, durchkreuzten die Pläne des genannten Finanziers. Wohl aus diesem Grunde war die von ihm ins Leben gerufene Aktiengesellschaft eine Totgeburt. Die Hütte kam gar nicht in Betrieb. Sie figuriert in der Liste der verkrachten Unternehmungen. Zwar hatte der Prospekt die glänzendsten Erwartungen ausgesprochen: Mit einem projektierten Betriebskapital von 15 Millionen Mark sollten nicht weniger als 8 Hochöfen nebst Zubehör gebaut werden. Ein Walzwerk, eine Gießerei, eine Maschinenfabrik sollten das Eisen zu Halb- und Ganzfabrikaten veredeln. Allein von dem Kapital wurde nur ein minimaler Teil gezeichnet und das großartig gedachte Unternehmen kam nicht zur Ausführung. Die Presse griff es an, die Regierung des damaligen Königreichs Hannover legte ihm alle möglichen Schwierigkeiten in den Weg, und 
so war das Resultat ein vollständiger Mißerfolg. 1858 geriet der Gründer der Gesellschaft in Konkurs; er verlor sein ganzes Vermögen. Unter der Wucht dieser Tatsache nahm sich der unglückliche Mann das Leben. Auf den Trümmern der alten wurde von seinem Schwiegersohn, dem Rechtsanwalt Haarmann, 1858 eine neue Gesellschaft gebildet, die das Bergwerk aus der Debetmasse des Toten erstand. „Außerdem wurde durch einen Kontrakt mit dem Hostmannschen Kurator der Hüttenplatz, die angefangenen Hochöfen und sonstigen Bauten, die angelieferten Kessel und Maschinen und die aufgehäuften Vorräte, sowie alle mit der Bergbau- und Hüttengesellschaft zu Peine zusammenhängenden Rechte gegen eine Zahlung von 195000 Mark in bar und 30000 Mark in Aktien und gegen die Verpflichtung, Aktionäre, Beamte und Baugläubiger dieser Gesellschaft, wenn und so weit sie im Konkurse zur prioritätsmäßigen Befriedigung gelangen würden, abzufinden, eigentümlich erworben. ${ }^{(*)}$ ) Die verjüngte Gesellschaft konstituierte sich unter der Firma Ilseder Hütte. Sie repräsentierte ein reines Roheisenwerk. Dasselbe eröffnete seinen Betrieb am 12. September 1860. An diesem Tage wurde der erste der beiden Hochöfen angeblasen. $\mathrm{Zu}$ den Hochöfen gehörten zwei Gebläsemaschinen mit zusammen $540 \mathrm{cbm}$ ansaugbarem Luftquantum pro Minute und eine Kesselanlage mit 16 Dampfkesseln. Zum Zwecke der Bewegung der Erzmassen wurde eine Grubenbahn gebaut. Sie war schmalspurig und für den Pferdebetrieb eingerichtet. Die Ausführung und die Kosten übernahm eine Hamburger Firma. Letztere betrugen 75000 Mark. Dafür mußte die Gesellschaft 5\% Zinsen auf 108000 Mark, d. h. auf die Abtretungssumme nach 5 Jahren und $1 \mathrm{Pfg}$. Zinsen für jeden transportierten Zentner Erz zahlen. 1870 wurde dann der Roßbahnbetrieb durch den Lokomotivbetrieb ersetzt. Das war die ursprüngliche Anlage, die bei weitem nicht an die umfassenden Pläne eines kombinierten Betriebes heranreichte, die Hostmann realisieren wollte. Aber sein Name sollte doch in den Annalen des Unternehmens weiter fortleben. Es stellte sich nämlich heraus, daß Hostmann noch Forderungen an die Bergbau- und Hüttengesellschaft zu Peine hatte. Dafür erhielten nun seine Witwe und deren Erben eine jährliche Rente von $2 \%$ des Reingewinns. Später wurde daraus eine fixe Rente von jährlich 9000 Mark. Gegenwärtig erscheint unter den Passiven der Bilanz der

*) Siehe Festschrift: Die Ilseder Hütte, ihre Entstehung und weitere Entwicklung von 1858 bis auf die heutige Zeit. Hannover 1884 . 
Ilseder Hütte 120000 Mark Ablösungskapital, aus dem die jährliche Rente gezahlt wird. Diese Einrichtung war ursprünglich gerechtfertigt, zumal da auch die Familie in ärmlichen Verhältnissen lebte. Heute, nach 40 Jahren, hat sie jeden Sinn verloren.

Die Geschichte der neuen Gesellschaft, die zunächst mit einem Aktienkapital von ca. 11/2 Millionen Mark arbeitete, ist zunächst eine Leidensgeschichte, befeuchtet von den Tränen, die die Krisis 1857 bis $1861 \mathrm{im}$ Gefolge hatte. Die Produktion des Unternehmens beruhte, wie aus der ganzen Betriebsanlage hervorgeht, ausschließlich auf der Produktion von Roheisen. Der eine im Betriebe befindliche Hochofen produzierte damals pro Hochofentag 191/2 Tonnen. Vergleicht man diese Leistung mit der heute üblichen, - 1902 produzierte ein Hochofen der llseder Hütte 209 Tonnen pro Hochofentag - so muß man die erstere Leistung als erstaunlich niedrig bezeichnen. $\mathrm{Zu}$ der geringen Leistung gesellten sich die Schwierigkeiten des Absatzes. Am 1. Januar 1863 besaß die Hütte ein unverkauftes Lager von 3020 Tonnen Roheisen. 1866 sogar von 7200 Tonnen. Die Konsumenten wollten das Eisen wegen seines hohen Phosphorgehaltes nicht verarbeiten. Man kannte damals noch kein Verfahren, um denselben zu beseitigen. Das Eisen wurde brüchig und für viele Zwecke der Fabrikation untauglich. Die Sprödigkeit der Abnehmer, die der des Eisens mindestens gleichkam, ließ sich nur durch niedrige Verkaufspreise überwinden. Der erste Geschäftsbericht*) erzählt uns, wie der Hochofen abwechselnd an- und ausgeblasen werden mußte. Dann kam ein neues Unglück: Der Kernschacht brannte durch und der Ofen mußte außer Betrieb gesetzt werden. 1864 war der eine Hochofen nur 183, der andere 224 Tage in Betrieb, das heißt die beiden Hochöfen feierten zusammen 325 Tage, oder jeder beinahe ein halbes Jahr (genau 5 Monate). 1863 schloB die Hütte mit einem Defizit von 41982 Mark ab.

Die Aktien lagen in den Händen einmal der früheren Aktionäre, die bereits Einzahlung auf die alte Gesellschaft geleistet hatten, und zweitens in den Händen der Handwerker und Gläubiger, die mit Aktien bezahlt wurden, da es an Geld fehlte. Jahrelang erhielten diese Leute keine Dividende. 1861 wurden zwar 3\% verteilt, in den folgenden 3 Jahren aber gar nichts. Auch in die Geschäftsberichte zog der Pessimismus ein: Ein Ton der Klage geht durch alle Zeilen. Vor

*) Siehe Bericht der Ilseder Hütte über den Betrieb der Hütte seit ihrer Gründung. Celle 1865. 
allem war es der große Geldmangel, der der Gesellschaft die freie Atmung nahm. Es klingt fast wie Ironie, wenn in dem Geschäftsbericht von 1865 die Frage erwogen wird, ob das notwendige Kapital aus den Betriebsüberschüssen auf Kosten der Dividenden beschafft werden sollte, oder aber durch eine Anleihe. Man hatte bereits drei Anleihen aufgenommen. Die vierte, die man nunmehr projektierte, belief sich auf über 405000 Mark. Addiert man aber sämtliche Betriebsüberschüsse von 1861-1865 zusammen, ohne Berücksichtigung des Verlustes von 41982 Mark im Jahre 1863, so kommt man noch nicht einmal auf die Hälfte der notwendigen Summe (200693 Mark). Das erforderliche Geld wurde also durch eine Anleihe aufzubringen versucht. Es dürfte wohl selten der Fall sein, daß die Obligationen eines industriellen Unternehmens zu so günstigen Bedingungen offeriert wurden, wie die der Ilseder Hütte. Der Betrag von 405000 Mark sollte unter folgenden Bedingungen zur Emission gelangen: Die auf das Vermögen der Ilseder Hütte zu ingrossierende Anleihe, welche in 1080 Abschnitte à 375 Mark zerlegt wird, ist von seiten der Darleiher unkündbar, wird mit $7 \%$ verzinst und gewährt dem Inhaber das Recht, im Falle die Aktionäre der Hütte eine Dividende von mehr als $7 \%$ erhalten, die gleiche Mehrsumme als Überdividende zu erheben, zu welchem Zwecke den Obligationen Zins- und Dividendencoupons beigefügt sind. Die Ilseder Hütte ist berechtigt, nach 5 Jahren die Anleihe auf einmal oder in beliebigen Abteilungen, in letzterem Falle durch Auslösung, in der Art zu kündigen, daß sie dem Inhaber den fünfzehnfachen jährlichen Durchschnittsbetrag der von demselben seit der Emission genossenen Zinsen und Dividenden auszahlt. Außerdem wurde den Obligationären versprochen, daß das Grundkapital nicht vermehrt werden sollte, und da $B$ die noch unbegebenen Aktien außer Kurs zu setzen seien. Man sollte meinen, das Kapital würde in Massen auf solche verlockenden Bedingungen eingegangen sein. Aber das Gegenteil war der Fall. In dem Geschäftsbericht von 1866 heißt es: „Inzwischen sind die Zeitverhältnisse für die Begebung dieser Anleihe so ungünstig gewesen, daß von dieser Anleihe noch 233250 Mark zu plazieren sind." Das war ein vollständiger Mißerfolg, der in das System von Widerwärtigkeiten hineinpaßt, mit denen das Schicksal die erste Jugend der Ilseder Hütte trübte. Es mag genügen, an diesem einen Beispiele aus der finanziellen Entwicklung die Schwierigkeiten anzudeuten, mit denen das Unternehmen zu kämpfen hatte. 
Wer hätte damals in den 60er Jahren ahnen können, daß die Aktien der Ilseder Hütte dereinst wie ein Meteor am Horizont der Börse aufsteigen und das rentabelste Anlagepapier auf dem Eisenmarkte werden würden!

Welches waren nun die Ursachen, die aus diesem unfruchtbaren Boden ein blühendes Gewächs hervorwachsen ließen, unbildlich gesprochen, die das alte mit Verlust arbeitende oder nur ganz kärglichen Gewinn abwerfende Werk in ein Überfluß über Tausende von Menschen ausschüttendes Unternehmen verwandelten? Das wollen wir nunmehr untersuchen. Die Beantwortung dieser Frage soll als Leitmotiv für die folgenden Ausführungen gelten, den $n$ in $\mathrm{der}$ überdurchschnittlichen Höhe des Ertrages liegtdas Charakteristische der ökonomischen Entwicklung des Unternehmens.

Auf drei großen Quadern sollte sich das spätere Gebäude eines hochrentierten Unternehmens erheben. Diese waren

1. Der natürliche metallurgische Reichtum und die Beschaffenheit der zur Ilseder Hütte gehörenden Erzfelder, oder nationalökonomisch gesprochen, das Vorhandensein einer Differentialrente.

2. Die Finanzpolitik des Unternehmens.

3. Die Gründung und spätere Erwerbung des Peiner Walzwerkes und die mit dieser Kombination verbundene vollständige Änderung in den Absatzverhältnissen.

Kapital und Arbeit der Aktiengesellschaft Ilseder Hütte basieren auf ausgedehnten, größtenteils in der Nähe der Hütte vorhandenen Erzlagern, die sich in einer Mächtigkeit von $6-20 \mathrm{~m}, 4,5-5 \mathrm{~km}$ in die Breite und ca. $10 \mathrm{~km}$ in die Länge erstrecken. Aus diesem Reichtum der Erde schöpft die Gesellschaft ihren wichtigsten Rohstoff für den Hüttenbetrieb. Aus ihm stellt sie ihr Roheisen her und zwar ursprünglich in zwei, heute in drei Hochöfen (hinzu kommt einer außer Betrieb).

Aber das Erz ist nicht nur in so großer Masse vorhanden, $\mathrm{da} B$ es für unübersehbare Zeit zur Alimentierung der Öfen ausreicht, sondern es liegt auch so nahe an der Erdoberfläche, daß die Kosten der Gewinnung sehr geringe sind. In der Eisenenquetekommission des Jahres 1878 äußerte sich ein Sachverständiger, Herr Wintzer, über diese Verhältnisse folgendermaßen:") „Bekanntlich

*) Reichsenquete für die Eisenindustrie, 1878, p. 252. 
produziert das llseder Werk das verhältnismäßig meiste und billigste Eisen, aber ich darf wohl sagen, wohl auch mit das schlechteste, das in Norddeutschland produziert wird. Es produziert aber, und auch solches Eisen wird verkauft. Es rangiert stets mit dem Luxemburger Eisen, hat aber mehr Mangan wie letzteres und gewisse gute Eigenschaften: Es wird sehr schweißbares Stabeisen daraus hergestellt. Die Produktionskosten in Ilsede sind so erstaunlich billig, $\mathrm{da} B$ es Ihnen wohl von Interesse sein wird, auch darüber die Zahlen zu hören. Es liegt das aber in den $n$ a tür lich en Verhältnissen des Erzvorkommens: Die Leute haben keine Erzgruben, sondern Erzfelsen, wovon sie herunterhauen, Kalkstein und Eisenstein, alles ist durcheinandergewachsen. Sie können die Erze nehmen, wie sie sie für die billigste Fabrikation gebrauchen." Die Selbstkosten gibt der genannte Experte für Ilseder Erze nebst Zuschlägen auf 2,60 Mark pro Tonne an.

Die Gesellschaft betreibt heute 10 Gruben, davon 8 im Tagebau. Der Abbau erfolgt terrassenförmig. Erst in neuester Zeit hat man in zwei Abteilungen mit dem Tiefbau begonnen. Vorläufig ist man damit beschäftigt, den unterirdischen Abbau durch Strecken und Bremsberge vorzurichten, da der Tagebau in einigen Jahren wegen der Mächtigkeit des Deckgebirges nicht mehr rationell sein dürfte. Gegen Ende der 60er Jahre aber war daran noch nicht zu denken. Die Eisenerze lagen noch an der Peripherie der Erdoberfläche, mit Kreidemergel überdeckt, der von den Abräumern damals wie heute losgesprengt und abgefahren wurde. Dieser Tagebau ist bedeutend billiger wie der Tiefbau. Es sind keine kostspieligen Schächte und maschinellen Einrichtungen nötig, um das Erz ans Tageslicht zu fördern. Bohrmaschinen z. B. werden beim Tagebau nicht verwandt. Eine solche elektrische Bohrmaschine, System Siemens \& Halske, deren das Werk heute im Tiefbau 7 besitzt, kostet immerhin 4000 Mark, und eine mit Preßluft getriebene, von denen gegenwärtig 6 vorhanden sind, ca. 800 Mark. Vor allem aber fallen ins Gewicht die Förderkosten. Je tiefer in die Nacht der Erde der Bergmann steigen muß, desto höher werden unter sonst gleichen Verhältnissen die Produktionskosten. Wir haben in ganz Deutschland ähnlich günstige Verhältnisse wie in Ilsede nur in Elsaß-Lothringen und Luxemburg. Dort wird die Minette, ein Brauneisenerz, das etwas feinkörniger ist, unter ebenso günstigen Bedingungen gewonnen, aber die Erträge erreichen doch nicht die der Ilseder Hütte. Wir haben also die Erfolge der llseder Hütte zunächst in einer von der Natur gegebenen, 
von der menschlichen Intelligenz ganz unabhängigen Tatsache zu suchen: In der Ausdehnung der Erzlager und der Lagerung des Eisens an der Oberfläche der Erde. Der sich hieraus ergebende Mehrertrag istalso ökonomisch die Folgedes Bestehens einer Differentialrente. Infolgedessen sind die Herstellungskosten des Roheisens in Ilsede sehr geringe, jedenfalls geringer als auf den konkurrierenden Werken Rheinland-Westfalens und auch Oberschlesiens, obgleich die Ilseder Hütte diesen Werken gegenüber insofern im Nachteil ist, weil sie die für den Produktionsproze $B$ nötigen Kohlen und Koks in Ermangelung eigener Kohlenzechen kaufen muß. Wie niedrig vergleichsweise die Selbstkosten des Roheisens in Ilsede sind, geht auch aus den Angaben Symphers hervor, die dieser auf Grund einer Erhebung im Jahre 1895 in einer Denkschrift*) macht. Danach betrugen die Selbstkosten für Thomas- und Puddelroheisen pro Tonne:

\begin{tabular}{|c|c|c|c|}
\hline & im Ruhrgebiet & $\begin{array}{c}\text { auf der } \\
\text { Ilsederhütte }\end{array}$ & in Oberschlesien \\
\hline \multirow{4}{*}{$\begin{array}{l}\text { Erzeinsatz und Zuschläge. } \\
\text { Kohlen und Koks . . . } \\
\text { Löhne für Arbeiter inkl. } \\
\text { Ingenieure, Materialien } \\
\text { und Reparaturen . . . }\end{array}$} & $27,50 \mathrm{M}$. & $8,00 \mathrm{M}$ & $30,50 \mathrm{M}$ \\
\hline & 12,00 & $16,50 \quad "$ & $14,00 \quad "$ \\
\hline & & & \\
\hline & & 6,50, & 7,50, \\
\hline & $46,00 \mathrm{M}$. & $31,00 \mathrm{M}$ & $52,00 \mathrm{M}$. \\
\hline
\end{tabular}

Auf dieser Basis niedriger Produktionskosten konnte nun die Unternehmertätigkeit mit Erfolg einsetzen, wenn es gelang, mit einem Minimum an Kapital ein Maximum an Leistung zu erzielen. Die ersten Ansätze dazu wurden gemacht in der Aufschwungsperiode von 1868-1873. Am Schluß der 60er Jahre verspürte das Unternehmen den ersten Hauch einer besseren Zeit, und diese Periode ist es auch, in der die Grundlagen der späteren Prosperität teils gelegt, teils gefestigt werden. Eine bedeutende Rolle spielt nun die finanzielle Rekonstruktion des Unternehmens und seine spätere Finanzpolitik, die von großem Erfolge begleitet war.

Bis zum Jahre 1868 hatte die llseder Hütte wie eingangs erwähnt, mit großen Schwierigkeiten zu kämpfen. Die Aufnahme von

*) Sympher: Die wirtschaftliche Bedeutung des Rhein-Elbe-Kanals, Berlin 1899, p. $144 / 5$. 
Hypotheken und anderen Anleihen begegneten Mißtrauen und Bedenken. Die Zinssätze waren hoch, und die Plazierung verursachte vie!fach Schwierigkeiten. So wurde, um noch ein Beispiel anzuführen, 1864 um den Bau einer normalspurigen Eisenbahn von Ilsede nach Peine zu ermöglichen, eine 5prozentige Anleihe von 456600 Mark zum Emissionskurse von $72 \%$ ausgegeben, d. h. das Kapital mußte mit ca. $7 \%$ verzinst werden.

Die Ilseder Hütte brauchte als kapitalistisches, schon in ihrer ersten Entwicklungsperiode rasch wachsendes Unternehmen natürlich fortwährend große finanzielle Mittel. Um diese zu erhalten, gab es drei verschiedene Wege. Die Verwaltung konnte den kurzfristigen Lombardkredit in Anspruch nehmen, und das hat sie auch in großem Maßstabe getan. Aber es ist eine alte Erfahrung, daß dieser Kredit sehr teuer ist. Der Lombardzins, der 1\% über Bankdiskont notiert, eignet sich daher nicht für längere Inanspruchnahme. In den Zeiten der Not, wo dieser Weg allein offen stand, hat die Hütte ihr Zinsenausgabekonto hierfür stark belasten müssen.

Der zweite Weg ist die Erhöhung des Aktienkapitals durch Ausgabe junger Aktien. Von dieser Möglichkeit ist von der Verwaltung wenig Gebrauch gemacht worden. Das eingezahlte Kapital betrug 18611543500 Mark; erst 1869 wird es auf 1950000 Mark erhöht, und auf dieser Höhe bleibt es bis zum Jahre 1880, wo das Peiner Walzwerk, wie wir später sehen werden, hinzuerworben wurde.

Ein dritter Weg ist die Ausgabe von Obligationen. Dieser Weg ist von der Hütte in umfangreichem Maße beschritten worden. In den Jahren 1866-1868 überstieg die Höhe der Anleihen die Höhe des Aktienkapitals. Für die folgenden Jahre stellte sich das Verhältnis folgendermaßen: Das Aktienkapital betrug, wie erwähnt, 1950000 Mark, die Obligationsschuld:

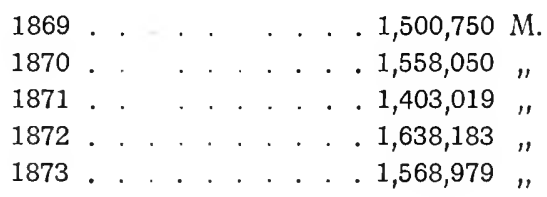

Der Schwerpunkt der finanziellen Leistungsfähigkeit aber lag darin, daß die Verwaltung begann, große Reservefonds zu schaffen und die Mittel für die notwendigen neuen Anlagen aus den Betriebsüberschüssen zu bestreiten.

Durch dieses Verfahren ist es in der Tat möglich geworden, 
das Aktienkapital nicht stark und schnell anwachsen zu lassen. Darin liegt in bezug auf die finanzielle Entwicklung der Schlüssel, warum die Ilseder Hütte später so hohe Dividenden abwarf, wie sie keine andere Aktiengesellschaft der Eisenindustrie zahlte, denn die Reinerträge ergeben eine um so höhere Dividende, je kleiner das Aktienkapital ist, auf das die Rente berechnet wird. Dic erwähnte Finanzpolitik wird nun schon frühzeitig durchgeführt.

Der Rohgewinn steigt von 1868-1873 von 394134 Mark bis auf 1503352 Mark. Aus diesen Steigerungen werden die Reservefonds gespeist. Diese betrugen, wenn man die Ziffern für Amortisations- und Abschreibungskonto, den eigentlichen Reservefond und die Betriebsreserve addiert,

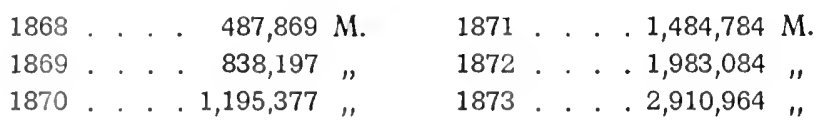

Unter Zuhilfenahme dieser Summen konnte man nicht nur anfangs die aus den Anlagekonten ersichtlichen Neuanschaffungen bezahlen, sondern später sogar noch einen Teil der Hypotheken tilgen und das Betriebskapital vermehren. Das ist die gute, alte Geschäftspraxis, die eine hohe Verzinsung des Kapitals überhaupt erst ermöglicht. Aber sie ist kausal betrachtet immerhin abhängig von den Überschüssen, die der Betrieb liefert. Diesem Prinzip ist man in der ganzen weiteren Geschichte der Ilseder Hütte treu geblieben. So heißt es z. B. in der von der Verwaltung anläBlich des 25jährigen Bestehens der Hütte herausgegebenen Festschrift: „Die Verwaltung betrachtete es bei ihrer festen Überzeugung von der Entwicklungsfähigkeit der Gesellschaft von vornherein als eine Hauptaufgabe, durch vorsichtige Verwendung der erzielten Überschüsse diese Entwicklung möglichst ohne Heranziehung neuen Kapitals zu fördern." So enthielten die drei Reservekonti 18836609306 Mark mehr als am 31. Dezember 1867. Es sind also in den genannten 16 Jahren nicht nur sämtliche Neuanlagen und Erwerbungen aus den Überschüssen bestritten, sondern noch ca. 855000 Mark zur Tilgung von Hypotheken und Vermehrung des Betriebskapitals verwandt worden.

Die ökonomisch günstige Entwicklung der Ilseder Hütte beruht in dritter Linie auf der Existenz des Peiner Walzwerkes. Es ist dies eine Aktiengesellschaft, die 1872 mit einem Kapital von 1050000 Mark gegründet wurde; eingezahlt wurden nur 945000 Mark. Aber damals ahnte man noch nicht, daß man am Vorabend 
eines großen Konjunkturniederganges stand, der einem halben Dezennium seinen Stempel aufdrücken sollte. Daher kam es, daB gerade mit dem Beginn der Krisis der Betrieb eröffnet wurde. Gegenstand des Unternehmens war, wie es im Prospekt hieB, die Verhüttung und Verarbeitung von Eisen, die Einrichtung und der Betrieb aller dazu notwendigen oder damit zusammenhängenden Hüttenwerke und Fabriketablissements, sowie der Absatz der Erzeugnisse. Dieses Programm ist, solange das Werk autonom war, nicht vollständig verwirklicht worden. Die Anlage umfaßte nur 8 Puddelund 3 Schweißöfen, eine Walzenstraße zum Auswalzen der Luppen und zur Erzeugung von schwerem Stabeisen und eine zweite WalzenstraBe für Stabeisen in leichteren Dimensionen. Das Peiner Werk beruhte also auf der Herstellung von Handelseisen. Die zum Puddeln erforderliche Roheisenmenge sicherte es sich durch einen Lieferungsvertrag mit der Ilseder Hütte. Die große Bedeutung dieses Unternehmens für die llseder Hütte, die die Gründung intellektuell und materiell begünstigt und gefördert hatte, lag nun darin, daß das Ilseder Roheisen nicht mehr weit entfernt nach den westfälischen Puddel- und Walzwerken abgesetzt werden brauchte, sondern daB der Hauptabnehmer in nächster Nähe der Hütte war. Auch das Walzwerk betont in seinen Kundgebungen wiederholt, da $B$ das wichtigste Moment seines ganzen Betriebes die tunlichst ausschließliche Verarbeitung des Ilseder Roheisens sei. Bereits im ersten Geschäftsbericht der neuen Aktiengesellschaft (1. Juli 1873-30. Juni 1874) heißt es: „Mit Genugtuung dürfen wir aber auch gleichzeitig darauf hinweisen, daß die Voraussetzungen, auf welche die Gründung unseres Etablissements basiert wurde, sich während der ersten Betriebszeit bereits als richtig herausgestellt haben, nämlich der Vorsprung, den unser Werk durch die Nähe der Ilseder Hütte vor anderen Konkurrenzwerken hat, die gleich uns llseder Roheisen verarbeiten." Dieses gegenseitige Aufeinanderangewiesensein erzeugte zwischen beiden Werken eine Interessensolidarität. Die Folge davon war, wie wir später sehen werden, eine endgültige Vereinigung in dem Sinne, daB das ganze Walzwerk von der Ilseder Hütte aufgekauft und die Aktien in ihrem Tresor deponiert wurden.

So lange es dem Peiner Walzwerke allerdings schlecht ging, hatte man daran nicht gedacht, und es ging ihm anfangs sehr schlecht. Es eröffnete, wie schon erwähnt, seinen Betrieb, als die Sterne der wirtschaftlichen Hochkonjunktur erblaßten und im Nieder- 
gange begriffen waren. Mit einem verhältnismäßig wenig geschulten Personal warf sich das Werk, wie oben bemerkt, hauptsächlich auf dic Produktion von Stabeisen. Im ersten Jahre 1873/74 wurden davon 2633 Tonnen hergestellt und eine geringe Menge Grubenschienen. Der Preis des Stabcisens fiel jedoch in den ersten 12 Monaten des Betriebes von 360 auf 180 Mark pro Tonne. Das Roheisen sank von 102 auf 60 Mark. Das Fabrikat entwertete sich also weit rascher als das Rohmaterial. Walzeisen war seit dem Sommer 1873 fast unverkäuflich. Der Verlust des ersten Jahres betrug 11202 Mark, das Defizit des zweiten belief sich auf 58627 Mark. Diese ungünstigen Resultate verführten dann dazu, lediglich auf Bestellung zu arbeiten. Dies aber hatte eine nicht unwesentliche Verteuerung der Produktion zur Folge. In dem Bericht des Walzwerkes aus dem Jahre 1874/75 heißt es: „Die eingegangenen Aufträge blieben hinter der Leistungsfähigkeit unseres Werkes zurück, und die meisten der Aufträge bestanden regelmäßig aus vielen verschiedenen Dimensionen.*) Während das erste Moment die volle Ausnutzung der Werkseinrichtungen nicht gestattete, verursachte der andere Umstand durch das notwendige Auswechseln der Walzen häufige Betriebsstillstände, welche auf den Eisenabbrand, (d. h. den Verlust) und den Kohlenverbrauch ungünstigen EinfluB ausübten. Inzwischen ist bei so ungünstigen Konjunkturen eine teurere Produktion bei vollem Absatz ein geringeres Übel als eine billigere Produktion verbunden mit einem Aufstapeln der Produkte.“ Schließlich sagt der Bericht resigniert: „Wenn die Verhältnisse sich noch weiter verschlimmern, so werden wir den Betrieb bis zum Eintritt besserer Konjunkturen einstellen müssen."

In dieser Unglückszeit war es, als man hegann, die Wirkung der zollfreien Eiseneinfuhr auf die deutsche Eisenindustrie für deren ungünstige Situation verantwortlich zu machen. „Rings umgeben von Ländern, welche durch Schutzzölle den Eintritt des deutschen Eisens erschwerten, seewärts von der englischen Konkurrenz blockiert, im Innern mit der durch vorteilhaftere elementare Grundlagen überlegenen und dabei durch die billigeren Differentialtarife protegierten englischen und belgischen Konkurrenz kämpfend, erschien die deutsche Eisenindustrie in schwerer Gefahr."

In unvergleichlich besserer Lage als das Peiner Walzwerk be-

*) Gemeint sind Aufträge für Stabeisen in verschiedenen Dimensionen. 
fand sich in den 70er Jahren die Ilseder Hütte. Dies geht aus folgenden Zahlen hervor:

\begin{tabular}{|c|c|c|c|c|}
\hline & 1873 & 1874 & 1875 & 1876 \\
\hline $\begin{array}{l}\text { Roheisenproduktion in Tonnen } \\
\text { Produktionskosten ausschließlich }\end{array}$ & 54,018 & 38,679 & 57,983 & 55,715 \\
\hline Generalkosten pro Tonne in $M$. & 64,65 & 47,90 & 39,04 & 33,40 \\
\hline $\begin{array}{l}\text { Betriebsüberschuß minus Gene- } \\
\text { ralkosten . . . . . . . }\end{array}$ & $1,503,352$ & 529,797 & 620,481 & 505,783 \\
\hline Dividende in Prozent . . . & 20 & $\begin{array}{l}20 \\
1877\end{array}$ & $\begin{array}{l}62 / 3 \\
1878\end{array}$ & $\begin{array}{c}6 \\
1879\end{array}$ \\
\hline \multirow{3}{*}{\multicolumn{2}{|c|}{$\begin{array}{l}\text { Roheisenproduktion in Tonnen . . . . . . . . } \\
\text { Produktionskosten ausschließlich Generalkosten } \\
\text { Betriebsüberschuß minus Generalkosten }\end{array}$}} & 61,783 & 69,383 & 76,854 \\
\hline & & 29,67 & 27,88 & 25,20 \\
\hline & & 492,860 & 649,963 & 614,573 \\
\hline \multicolumn{2}{|c|}{ Dividende in Prozent $\ldots \ldots \ldots$} & $62 / 3$ & 10 & 10 \\
\hline
\end{tabular}

Diese Zahlen zeigen

1. Eine zwar stark oszillierende, sich aber - vom Jahre 1874 abgesehen - auf der Höhe der Hochkonjunkturperiode haltende, allerdings von Jahr zu Jahr im Werte abnehmende Roheisenproduktion.

2. Im Gegensatz zum Peiner Walzwerk eine enorme Abnahme der Produktionskosten. Hier kam der Hütte zu gute vor allem das Sinken der Kohlenpreise. Sie besaB, damals wie heute, keine eigenen Kohlengruben. Auch die Verbesserung der technischen Anlagen hat sicherlich mitgewirkt. Die Anlagekonten weisen stets hohe Summen auf. Wie wesentlich technische Verbesserungen durch Ersparung von Rohmaterial den Betrieb verbilligen, geht unter anderem aus einer Vergleichung des Verbrauches an Koks und Kohle hervor. Pro Tonne Roheisen wurden verbraucht:

$\begin{array}{lrrrrrr} & 1873 & 1874 & 1875 & 1876 & 1877 & 1878 \\ \text { an Koks in kg } & 1233 & 1127 & 1118 & 1086 & 1067 & 997 \\ \text { an Kohle in kg } & 333 & 193 & 68 & 12 & 0 & 1,6\end{array}$

Die Abnahme des Koksverbrauchs ist ganz evident, mehr noch die der Kohle. Die letztere Tatsache hängt damit zusammen, daß man in dieser Periode beginnt, die Hochofengase zum Heizen der Dampfkessel zu benutzen.

Leider ist es nicht möglich, volkswirtschaftlich näher ins Detail dieser Erscheinung einzudringen. Wir erkennen hier nur die Gesamtwirkung, ohne im Einzelnen zu wissen, welcher Anteil an dem Sinken der Produktionskosten dem Rohmaterialpreise, der Technik, den Arbeitslöhnen etc. beizumessen ist. 
3. Ein Herunterstürzen der Betriebsüberschüsse von $1 \frac{1}{2}$ auf ca. $1 / 2$ Million, aber dann eine ziemlich gleichbleibende Bewegung um diese letztere Ziffer.

Allerdings blieb die Hütte auch vor Verlusten nicht verschont, aber sic beschränkten sich auf kleinere Summen. 1874 hatte sie von dem Braunschweiger Walzwerke für Roheisenlieferungen noch 48546 Mark zu fordern. Im Geschäftsbericht dieses Jahres heißt es: „Leider übersteigen die Forderungen der vorgehenden Hypothekengläubiger so sehr den Wert der Aktiva, daB wir beim Konkursverfahren auf unsere Forderungen irgend welche Zahlung nicht hatten erwarten können, weshalb wir es vorzogen, unsere Forderungen im Akkordverfahren für den Betrag von 7500 Mark zu verkaufen." AuBer dieser Firma stellten noch 6 andere Unternehmungen, mit denen die Hütte geschäftlich liiert war, ihre Zahlungen ein. Bei 4 dieser liquidierenden Firmen beliefen sich am 31. Dezember 1875 die Restforderungen auf insgesamt 169228 Mark; diese Summe ist nicht ganz verloren gegangen, denn in den folgenden Jahren wurde ein Teil derselben bezahlt. Alles in allem: Von der A us scheidung der ungeeigneten Elemente in dem groBen StoffwechselprozeB der 70 er Jahre konnte die Ilseder Hütte nicht ganz unberührt bleiben. Die erlittenen Schädigungen aber reichen lange nicht an die anderer Werke heran. Das wirksamste Mittel, um die Krisis abzuschwächen war, wie wir sahen, die sucessive Heruntersetzung der Produktionskosten der Tonne Roheisen von 64,65 Mark auf 25,20 Mark. Dadurch wurde eine Verbilligungerzielt, die diegesunkenen Roheisenpreise teilweise überkompensierte.

In der kritischen Periode der 70er Jahre war nach alledem der Augenblick zu einer Vereinigung der Ilseder Hütte mit dem Peiner Walzwerk noch nicht gekommen. Mit dem Jahre 1880 aber beginnt, nachdem schon das vorhergehende Jahr eine Besserung gebracht hatte, das deutsche Wirtschaftsleben wieder schneller und kräftiger zu pulsieren. Nunmehr tritt das bereits früher angedeutete Ereignis ein, das für die künftige Geschichte der Ilseder Hütte von allergrößter Bedeutung sein sollte: Die Kombination mit dem Peiner Walzwerk. Durch eine Erhöhung des Betriebskapitals der Ilseder Hütte um 262500 Mark werden die Mittel beschafft, um das Peiner Walzwerk zu erwerben. Beide Aktiengesellschaften werden durch eine 
Art Personalunion miteinander verbunden. Über diese Transaktion enthält die Festschrift folgendes: „Es wurde deshalb beschlossen, das Peiner Walzwerk zu erwerben, und zwar indirekt durch den Ankauf sämtlicher Aktien. Es geschah dieses in der Weise, daß für je eingezahite 360 Mark Peiner Walzwerkaktien 100 Mark llseder Hüttenaktien angeboten wurden, welches Angebot in kurzer Zeit von sämtlichen Aktionären des Peiner Walzwerkes akzeptiert wurde. Da das eingezahlte Aktienkapital des Peiner Walzwerkes 945000 Mark betrug, so wurden für deren Erwerb im ganzen 262500 Mark neue Ilseder Hüttenaktien emittiert. Die Ilseder Hütte wurde dadurch alleiniger Aktionär des Peiner Walzwerkes; der bequemeren Organisation wegen blieb jedoch das Peiner Walzwerk als besondere Gesellschaft bestehen. Für die emittierten 262500 Mark Aktien erwarb die Ilseder Hütte das im flotten lohnenden Betriebe befindliche Walzwerk mit einem sehr günstig gelegenen und beschaffenen Areal von ca. 70 Morgen, und auBer den Werksanlagen eine Reihe von Arbeiterhäusern, Beamtenwohnungen usw., und endlich mit einem flüssigen Betriebskapital von ca. 135000 Mark."

Aus diesen Ausführungen geht hervor, daß die Aktionäre der Hütte gleichzeitig indirekt Aktionäre des Walzwerkes wurden. In der Bilanz des Peiner Walzwerks steht heute, nachdem 1892 eine Erhöhung des ursprünglichen Kapitals von 1050000 Mark um 4950000 Mark eingetreten war, das für das Walzwerk ausgeworfene Erwerbskapital, nämlich nom. 5317500 Mark, selbstverständlich mit dem vollen Nennwert, d. h. mit 6 Millionen zu Buch. Da die Bilanz des Peiner Walzwerks in der Bilanz der Ilseder Hütte aufgeht, so ist dadurch eine stille Reserve von 682500 Mark geschaffen.

Der ök on om is che Effekt der Aufsaugung des Peiner Walzwerks durch die Ilseder Hütte war nun der, daß das von der letzteren produzierte Roheisen seinen Weltmarktpreis verlor. Ihre Einnahmen werden unabhängig von den Schwankungen der Roheisenpreise. Sie werden bestimmt durch die Verwertungsmöglichkeit des Fabrikates. Allerdings geschieht diese Änderung nicht mit einem Schlage. Erst im Laufe der Zeit wird die Konsumkraft des Walzwerkes so stark, daß nahezu sämtliches in Groß-Ilsede erzeugte Eisen von ihm verbraucht werden kann. Heute ist der Absatz an fremde Abnehmer minimal. Von dem erzeugten und vom Vorjahre übernommenen Roheisen erhielt 1892 das Peiner Walzwerk 232445000 Kilogramm. An andere Abnehmer wurde abgesetzt nur $51900 \mathrm{~kg}$.

Mit dieser Kombination wird die Möglichkeit gegeben, $\mathrm{nicht}$ 
wie bisher nur mit billigem Roheisen die Konkurrenz aus dem Felde zu schlagen, sondern nunmehr fast ausschlieblich mit billigen Halb-und Ganzfabrikaten.

Was die fin anzielle Seite der Transaktion anbelangt, so möchte ich nur auf einen Punkt aufmerksam machen. Das Walzwerk schlieBt entweder mit gar keinem oder aber mit verhältnismäBig kleinem Gewinn $a b$, der regelmäBig auf neue Rechnung vorgetragen wird. Es zahlt keine Dividende. Das überrascht. Diese eigenartige $\mathrm{Er}$ scheinung steht meines Erachtens damit im Zusammenhange, daB durch diese Methode der Bilanzierung eine nicht unwesentliche Steuerersparnis erzielt wird. $\mathrm{Zu}$ ihrer Illustration möchte ich einige Zahlen für die letzten drei Jahre heranziehen. Die Kommunaleinkommensteuer betrug in Peine 1899/1900 130\% und in den beiden folgenden Jahren $170 \%$. Die Erhöhung von 130 auf 170 hat ihren Grund darin, daß bis 1900 in der Stadt Peine noch eine besondere Kreissteuer von 40\% zur Erhebung gelangte, die jetzt von der Stadtkasse in einer Summe an den Kreis abgeführt wird. In GroBIlsede hingegen betrug die Kommunaleinkommensteuer im Durchschnitt der letzten Jahre nur $2 \%$ der Staatseinkommensteuer. Allerdings wird außerdem noch die Kreissteuer in Höhe von $40 \%$ der Staatseinkommensteuer erhoben. Es hängt also mit der eigenartigen Bilanzierung eine nicht unbedeutende Steuerersparnis des Unternehmens zusammen, die privatwirtschaftlich ja berechtigt sein mag, volkswirtschaftlich aber Bedenken unterliegt. Denn die finanziellen Erträgnisse des Unternehmens fließen nicht aus dem Verkauf des Roheisens, sondern der Walzwerkfabrikate. Infolgedessen ist auch das in Peine gelegene Walzwerk Hauptsteuersubjekt, nicht aber die Ilseder Hütte. Diese Steuerverhältnisse geben den Schlüssel, warum die Ilseder Hütte das Peiner Walzwerk unter dauernder Kontrolle hält und aus ihm eine unselbständige juristische Person macht, die im wesentlichen nur kleine oder keine Überschüsse liefert, obgleich doch im Grunde genommen von der Verwertung des Fabrikates der ganze Erfolg des Unternehmens abhängt. Wir lernen hier in der mit den Steuerverhältnissen in Zusammenhang stehenden eigenartigen Methode der Bilanzaufstellung ein weiteres Moment kennen, das auf den Reingewinn nicht ohne EinfluB ist.

Außer dieser Erwerbung ist es nun noch ein Ereignis von großer allgemeiner Bedeutung für die ganze Eisenindustrie, das im Speziellen 
für die Ilseder Hütte und das Peiner Werk eine überdurchschnittliche Prosperität zur Folge hatte. Gilchrist Thomas hatte ein Verfahren, das wir bereits kennen, gefunden: phosphorhaltiges Roheisen in ein hochwertiges Schmiedeisen zu verwandeln. Nunmehr war der Phosphorgehalt des Ilseder Roheisens von ca. $3 \%$ kein Hindernis seiner weitgehenden Verwertung mehr. Dazu kam, daB der neue Thomasprozeß bedeutend billiger war als der alte PuddelprozeB. Die Überlegenheit des basischen Prozesses über den sauren zur Erzeugung weichen Flußeisens wird bereits in dem Geschäftsbericht der Ilseder Hütte von 1879 anerkannt, dort heißt es: „Weit wichtiger als eine vorübergehende Konjunktur ist aber für unser Werk das neu eingeführte Entphosphorungsverfahren, welches die Verwendung des Ilseder Roheisens zur Erzeugung guten Stahls und Flußeisens gestattet; schon jetzt wird ein Teil unseres Produktes an Stahlwerke abgesetzt. Die weitere Verbreitung dieses Verfahrens wird die Nachfrage nach unserem Roheisen voraussichtlich vergrößern und auch den Wert desselben erhöhen ..."Die Konsequenz daraus zieht der folgende Jahresbericht, in welchem es heißt: ,,Jedenfalls liegt die Möglichkeit nahe, daß die Produktionsbedingungen für eine vorteilhafte Verarbeitung des Roheisens sich gegen früher wesentlich verschieben werden, zumal das Thomasieren eine solche Ersparung an Brennstoffen zuläßt, daß die Erzeugung der Massenartikel der Stahl- und Eisenindustrie weit weniger als früher von der Nähe der Kohlenlager abhängig ist." Die bei der Herstellung von Flußeisen und Stahl in Betracht kommende Ersparnis von Kohlen und Koks berechnete sich auf $5-600 \mathrm{~kg}$ weniger als Roheisen. Damit war der Weg vorgezeichnet, den die Verwaltung zu gehen hatte. Sie hatte zunächst das Patent zu erwerben, sich das nötige Geld $z u$ beschaffen und mit diesem a u dem Terraindes Peiner Walzwerkes eine für den ThomasprozeB eingerichtete Bessemerhütte $z u$ b a uen.

Diese drei Punkte haben wir jetzt kurz zu betrachten.

Die Patentgebühr betrug $3 \frac{1}{2}$ Mark pro Tonne produzierten Eisens. Diese Gebühr wurde nur ein halbes Jahr gezahlt. Dann kaufte das Werk gegen Zahlung einer Pauschalsumme von 650000 Mark, oder zuzüglich der für das erste Quartal gezahlten Abgabe für 671373 Mark die Konzession zur Einführung des Verfahrens. Die Summe würde noch höher gewesen sein, wenn das Werk sich nicht den deutschen Erwerbern des Patentes gegenüber verpflichtet hätte, 
bis zum 1. Januar 1887 keine schweren Eisenbahnschienen und Schwellen zu fabrizieren und für die dann folgende Zeit bis zum Ablauf der Patentdauer bei etwaiger Fabrikation dieser Artikel für diese 2 Mark pro Tonne zu zahlen.

Nachdem das Patent erworben war, handelte es sich um Beschaffung der erforderlichen Mittel zum Bau für das Thomaswerk. Diese beliefen sich auf über 4 Millionen Mark. Sie wurden teilweise bestritten aus den Betriebsüberschüssen, dic seit 1880 auf über 1 Million Mark emporsprangen, teils durch Ausgabe junger Aktien, die zu dem verhältnismäßig hohen Kurs von $250 \%$ cmittiert wurden. Im Jahrc 1884 wurden von den 737625 ausgegebenen Aktien gezeichnet 728625 und der Rest von den Emissionshäusern übernommen. Das Aktienkapital belief sich 1884 auf 2950125 Mark. Die hypothekarische Verschuldung auf 4022940 Mark. Die Gesellschaft war also nicht unbedeutend verschuldet.

Ehe diesc Summen aufgebracht waren, hatte man bereits mit dem Bau des neuen Stahlwerkes in Peine begonnen. Über die Gründe, die dafür bestimmend waren, heißt es in der Festschrift wie folgt: „Da zur Herstellung von Flußeisen und Stahlfabrikaten in solchen Dimensionen, welche sich mit e in er Hitze fertig walzen lassen, im ganzen etwa 500 bis 600 Kilogramm Kohlen und Koks pro Tonne Fabrikat w e n ig e $r$ als Roheisen erforderlich sind, so ist es klar, daß das Fabrikat bei gleichem Roheisen- und Kohlenpreise am Orte der Erzcugung dieser Artikel, in Peine, um den Betrag der Transportkosten von 500-600 Kilogramm Kohlen billiger muß hergestellt werden können als im westfälischen Kohlenrevier, und daß dieser Vorteil bei dem Verkauf der Produkte noch vermehrt wird um die Frachtdifferenz nach dem östlichen und nördlichen Absatzgebiet. Diese Voraussetzungen, welche sich nach den bisherigen Erfahrungen als durchaus richtig gezeigt haben, veranlaßten den Bau des neuen Stahlwerkes in Peine. Für die Wahl dieses Ortes entschied man sich, weil die Örtlichkeit für den Bau der neuen Anlage viel geeigneter erschien, als die zur Verfügung stehenden Anlageplätze in Groß-Ilsede, ferner, weil die Heranziehung und Unterbringung der Arbeitskräfte in Peine weniger schwierig war, als in llsede, und weil das Peiner Puddel- und Walzwerk einen tüchtigen Stamm von Beamten und Arbeitern hatte, mit welchen die Eröffnung des neuen Betriebes, die Verarbeitung des zu erzeugenden Flußeisens und die Einführung der Produkte sich leichter bewerkstelligen lieB, als mit einem ganz neu zu engagierenden Personal." 
In dem neuen Stahlwerke wurde der Thomasbetrieb am 6. September, und im neuen Walzwerk im Oktober 1882 eröffnet. Das Werk verarbeitete im folgenden Jahre bereits 27893 Tonnen Ilseder Roheisen in der nenen Thomashütte und noch 9982 Tonnen im alten Puddelwerke. Der Puddelbetrieb hat sich dann noch einige Zeit gehalten, bis er Mitte der 90er Jahre ganz verschwand, weil der Verkaufspreis des Schweißeisens in keinem Verhältnis mehr zu den Gestehungskosten stand. Anfang der 80er Jahre ging man zunächst noch zögernd in bezug auf die Herstellung von Flußstahl vor. Deshalb wurde die neue Thomashütte zunächst nur für den Betrieb in der Tagesschicht eingerichtet, und ebenso wurde dem neuen Walzwerk nur eine Walzenstraße für die Herstellung von Stahlbilletts gegeben. Daneben wurde aber auch auf den Walzenstraßen des alten Werks der gewonnene Rohstahl zu Handelseisen in verschiedenen Dimensionen ausgewalzt. Allmählich werden dann die Anlagen vergrößert und der $\mathrm{S} c h \mathrm{n}$ e $1 \mathrm{l}$ b e t $\mathrm{r}$ i e b gewinnt immer mehr an Boden. Um ihn durchzưühren, wird 1882/83 der Konvertor- und Gießraum voneinander getrennt, so daß die Gießpfannen nunmehr aus dem heißen Konvertorraum in eine besondere Gießhalle fahren müssen. Es werden weiter zwei neue Walzenstraßen gebaut, eine Blechstraße und eine Billetstraße. 1886 enstand dann Walzwerk II mit drei Walzenstraßen: Grob-, Mittel- und Schnellstraße. Die erstere dient zur Herstellung von kleinen Trägern, Grubenschienen, Winkeln usw., die Mittelstraße zur Herstellung von Stabeisen in mittleren Dimensionen, und die Schnellstraße zur Herstellung von Feineisen (Bandeisen usw.).

Welches waren nun die Folgen dieser Neueinrichtungen?

Zunächst Steigerung des Absatzes. „Die Nachfrage“, heißt es bereits in dem 1883er Bericht, ,nahm stetig zu, und das Absatzgebiet hat sich so erweitert, daß wir für das neue Fabrikat (gemeint ist Flußeisen) Abnehmer haben vom Rhein bis Oberschlesien, und vom adriatischen Meere bis zur Ostsee; auch aus England und Amerika finden sich Käufer." Diese Steigerung des Absatzes hängt nun damit zusammen, daß unter der Regie der Ilseder Hütte das Peiner Walzwerk das alte Fabrikationsprogramm änderte. Die ursprüngliche Produktion des Walzwerkes bestand, wie früher bemerkt, vorwiegend aus Stahlbillets. Die Herstellung derselben war eine verhältnismäßig einfache. An ihr konnten sich die Arbeiter zuerst in den Betrieb einarbeiten und Erfahrungen sammeln, um für die schwierigere Tätigkeit an den weiter erforderlichen Anlagen 
vorbereitet zu sein. Der Knüppel war anfangs ein Handelsartikel, der im wachsenden Maße begehrt wurde, der sich leicht in großen Posten absetzen ließ und dessen Preis ein verhältnismäßig hoher war. Er stellte sich z. B. 1883 pro Tonne auf 120 Mark. Dabei verblieb dem Werke ein guter Gewinn. Das änderte sich nun in der Mitte der 80er Jahre aus bereits bei der Beschreibung des Hoerder Bergwerks- und Hüttenvereins mitgeteilten Ursachen. Die Knüppel wurden durch die Krisis im Preise stark geworfen. Die Folge war, daB dieser Zweig der Fabrikation zu einem großen Teile verlassen wurde. Damit hängt weiterhin eine Änderung des Absatzgebietes zusammen. Heute werden Knüppel vom Peiner Walzwerk im wesentlichen nur noch für den eigenen Gebrauch und den Export, z. B. nach England, hergestellt. Der Hauptnachdruck ruht seit der Mitte der 80er Jahre nicht mehr in der Herstellung eines Halbfabrikates, sondern eines Ganzfabrikates, nämlich in der Produktion von Trägern und überhaupt von Façoneisen; ferner werden noch Flacheisen, das heißt Stäbe gewalzt und Feld- und Grubenschienen. Mit anderen Worten, ein Teil der früheren Produktion wird beibehalten. Eisenbahnschienen stellt das Werk nicht her. Dafür bekommt es jährlich von den Schienenwerken eine bestimmte Summe ausgezahlt. In diesem Verfahren liegt ein auf Übereinkommen begründetes Mittel der Konkurrenzbeschränkung. Der Vertrag wird geheim gehalten. Der Absatz der Träger tendiert hauptsächlich nicht nach Westen wie der der Stahlbillets, die als Halbfabrikat vornehmlich an die westfälische Walzdrahtindustrie abgesetzt wurden, sondern nach Mitteldeutschland. Schon der 1883er Geschäftsbericht schrieb: „In den östlich, nördlich und südlich von Peine gelegenen Teilen Deutschlands ist keine Konkurrenz zu fürchten." In dem 1884er Bericht wird von Berlin und Sachsen als dem Hauptabsatzgebiet gesprochen. Es geht also mit der eben beschriebenen Änderung der Produktion eine Änderung des Absatzgebietes Hand in Hand. Die Ware wird nicht mehr auf die von der Konkurrenz behaupteten westlichen Märkte geworfen, sondern dort abgesetzt, wo die Konkurrenz wegen der Entfernung nicht so billig liefern kann, auf unbestrittenem Gebiet. Wir lernen darin ein neues Moment der Rentabilität des Unternehmens kennen, nämlich den natürlichen Frachtvorsprung nach dem Osten gegenüberden westlichen und nach Mitteldeutschland gegenüberden oberschlesischen Werken. Das Peiner Walzwerk beherrscht diese Märkte infolgeseinergünstigen örtlichen Lage. 
Mit der Entfaltung und Entwicklung des Peiner Walzwerkes wird, wic schon früher bemerkt, die Gesellschaft immer unabhängiger vom Roheisenmarkt, auf dem sie früher ihr Eisen verkaufte. Noch 1884 wurden von dem erzeugten Roheisen der Ilseder Hütte 19300 Tonnen exportiert, 20371 Tonnen an inländische Werke abgesetzt und 63520 Tonnen an das Peiner Walzwerk geliefert. Aber bereits im folgenden Jahre spricht der Geschäftsbericht davon, da $B$ die jetzigen Werkseinrichtungen so weit gediehen seien, daB sie mit Leichtigkeit die ganze Roheisenproduktion der Ilseder Hütte verarbeiten könnten. Das ist auch in der Folgezeit der Fall gewesen. Ja, das Walzwerk hat sich sogar genötigt gesehen, in der Hochkonjunktur der 90er Jahre Roheisen aus Luxemburg hinzuzukaufen. In dem Geschäftsbericht über das Jahr 1896 heißt es nämlich: „Die Ilseder Hütte war mit 2 Hochöfen nicht imstande, den Roheisenbedarf des Walzwerkes vollständig zu decken, so daB dieses sich veranlaßt sah, größere Mengen Roheisen von auswärts zu beziehen." Die Zahlen für die gegenwärtigen Verhältnisse wurden bereits an anderer Stelle mitgeteilt. Der Schwerpunkt des Unternehmens geht daher je länger je mehr auf das Peiner Walzwerk und die Verwendung seiner Fabrikate über. Diese Verwertung wurde nun durch die Krisis der 80er Jahre allerdings geschwächt, ganz abgesehen davon, da $B$ die Produktion nicht in dem früheren Umfange aufrecht erhalten werden konnte. In der Thomashütte wurde 1886 in der Regel nur 5 Tage in der Woche gearbeitet und dadurch die Produktionskosten ungünstig beeinflußt. Die Tatsache nun, da $B$ in dieser Krisenperiode die Preise der Eisenfabrikate stark heruntergingen und die meisten Werke mit Verlust arbeiteten, führte 1887 zur Bildung des Trägerkartells, dem auch das Peiner Walzwerk beitrat. Diesem Verbande wurde der einheitliche Verkauf des von den vereinigten Walzwerken erzeugten $T$-Eisens in der Weise übertragen, da $B$ jedes Werk in einem vertragsmäßig festgesetzten Verhältnis an der Versorgung des deutschen Marktes mit gewalztem Eisen seinen Anteil erhielt. Die dem Peiner Walzwerk zugebilligte Quote, welche nach dem Absatz im ersten Halbjahre 1887 berechnet wurde, stellte sich damals auf etwa 30000 Tonnen pro Jahr. Das entsprach zwar nicht der vollen Leistungsfähigkeit des Werkes, aber es wurde dadurch in den Stand gesetzt, höhere Inlandspreise zu erhalten und infolgedessen befähigt, mehr als früher zu exportieren. Am Schlusse jedes Jahres wurde eine Ausgleichsverrechnung vorgenommen. Die versandten Tonnen der einzelnen Werke wurden zusammengezählt, die 
Summe gleich 100 gesetzt und diejenigen Werke, deren Versand über den ihnen zukommenden Anteil hinausgegangen war, hatten an die im Minus befindlichen Werke einen vorher festgesetzten Geldbetrag pro Tonne minus Versand auszuzahlen. Um dieselbe Zeit wurde der Mitteldeutsche Walzwerksverband ins Leben gerufen, in dem das Peiner Walzwerk die führende Rolle übernahm. Die Verkaufsstelle für das Stabeisen der mitteldeutschen Werke war eine Zeitlang in Peine und wurde dann nach Berlin verlegt.

Die Krisis der 80 er Jahrehatte, wie wir gesehen haben, Änderungen in der Produktion und im Absatz zur Folge. Die Herstellung der durch die schlechte Konjunktur im Preise stark geworfenen Stahlbillets wird zum großen Teile ersetzt durch die Produktion von Trägern. Das Werkgeht von der Herstellung eines Halbfabrikateszudereines Ganzfabrikates über. Damitverlegtsich der Schwerpunkt des Absatzes vom Westen nach dem Norden, Süden und Osten, hauptsächlich abernach Mitteldeutschland, und nun wird der natürliche Frachtvorsprung gegenüber den westlichen Werken zu einem Gliede in der Kette der die Prosperität des Unternehmens fördernden Kräfte. Das ihrige trugen schlieBlich noch der Träger-und Stabeisenverband bei, die durch die Krisis der 80 er Jahre als Palliativ gegen das $\mathrm{SinkenderPreise} \mathrm{inder} \mathrm{Eisenindustrie} \mathrm{ins} \mathrm{Leben}$ gerufen wurden und die fürdie Steigerung der Gewinne des Unternehmens ebenfalls nicht ohne Bedeutung waren.

Mit der Einführung des Thomasprozesses hängt nun aber noch ein Punkt zusammen, durch dessen Klarlegung erst eine rationelle Verwertung eines vorher wertlosen Nebenproduktes ermöglicht wurde. Damit kommen wir zu einem weiteren, die Rentabilität des Unternehmens günstig beeinflussenden Faktor. Es ist bekannt, daB der Thomasproze $B$ große Massen Kalk braucht, die dann als Schlacke entwerten. Infolgedessen wurde die Thomasschlacke in Peine wie auf anderen Werken zu hohen Schlackenbergen aufgetürmt, die einen Zweck und Nutzen nicht hatten, dem Werke vielmehr noch Terrain kosteten. Nun war es ein Apotheker, namens Hoyermann, aus Hoheneggelsen bei Peine, der sich seit Beginn der $80 \mathrm{er}$ Jahre experimentell mit der Frage beschäftigte, 
wie sich die Thomasschlacke verwerten ließe. Er hatte ursprünglich die Berechtigung, sich die Phosphorite der auf der Ilseder Hütte zu Roheisen verarbeiteten Eisenerze auslesen zu lassen, um sie als Düngemittel zu versenden. Aber die llseder Hütte entzog ihm später diese Berechtigung. Nunmehr kam er auf einen eigenartigen Gedanken. Er legte sich die Frage vor, wo bei der Umwandlung des Roheisens in Thomaseisen der Phosphor bleibe. Zur Beantwortung dieser Frage kam er durch die Beobachtung des Stahlschmelzprozesses in der Thomashütte des Peiner Walzwerkes. Dort blitzte in ihm die Idee auf, daß der Phosphor sich nirgends anders versteckt halten könne, als in dem Kalkzuschlag, der den Konverten zugesetzt wird, und der dann später als Thomasschlacke abfließt. Mit dieser Schlacke wurden dann Düngeversuche auf eigener Ländereien und den Gütern befreundeter Landwirte gemacht. Die Annahme, daB der Phosphor in den Kalk übergehe, bestätigte sich. Durch eine Reihe von Kulturversuchen ergab sich, daß die Thomasschlacke pulverisiert ein ausgezeichnetes Düngmittel für die Landwirtschaft sei. Hoyermann gelangte also sowohl auf dem Wege theoretischer Betrachtungsweise zu seiner Entdeckung, als auch auf dem der praktischen Beobachtung.

Die Verwertung wurde in der Weise vorgenommen, daB Hoyermann eine Thomasphosphatfabrik, in der die Thomasschlacke in Kugelmühlen zu Mehl gemahlen wurde, in der Nähe des Stahlwerkes errichtete. Das Peiner Walzwerk schloB nach diesem glücklichen Erfolge mit dem Entdecker einen Gesellschaftsvertrag. Es wurde eine Kommanditgesellschaft gegründet, in der Hoyermann persönlich haftender Gesellschafter und das Peiner Walzwerk Kommanditist war. Nach diesem Vertrage brachte Hoyermann seine Fabrik in die Gesellschaft zu Herstellungskosten ein. Das Peiner Walzwerk lieferte die Schlacken und erhielt dafür einen festen Preis. Von dem gesamten Gewinn wurden dann 10\% der Anlagekosten abgeschrieben, und der Rest gemeinschaftlich geteilt. Dieser Vertrag lief mit dem Jahre $1894 \mathrm{ab}$, und die von der Firma Phosphatfabrik Hoyermann \& Co., Kommanditgesellschaft zu Peine, betriebene Phosphatfabrik ging zu dem nach Absetzung der abgeschriebenen Beträge verbleibenden Buchwerte in das Eigentum der Hütte über und wird seitdem für Rechnung des Peiner Walzwerkes betrieben. Seit der Mitte der 80er Jahre hat dann die Thomasmehlfabrikation einen großen Aufschwung genommen. Allerdings waren es nicht in erster Linie die deutschen Landwirte, die den Wert desselben erkannten, sondern die belgischen. Die ersten größeren Massen wurden nach Belgien 
abgesetzt. Über diesen Punkt schreibt mir Herr Direktor Wipper: „Ich, der ich von Herrn Hoyermann mit der Führung seines Düngergeschäftes betraut war, hatte mir alle erdenkliche Mühe gegeben, in Deutschland in größeren Massen Verwendung für Thomasmehl zu finden, doch vergeblich. Erst die Beziehung zu dem Deutschen Verein für Moorkultur und die spätere Verbindung mit der Düngerabteilung der Deutschen Landwirtschaftsgesellschaft gaben Anregung, daB das Thomasmehl in der Landwirtschaft Eingang fand, und der Gesellschaft ist ein bestimmtes Verdienst nicht abzusprechen, der heute so hervorragend beachteten Phosphorsäurequelle mit Eingang verschafft zu haben." Damit eröffnete sich für das Peiner Walzwerk, resp. die Ilseder Hütte eine neue Einnahmequelle. Ein früher wertloses Produkt der Stahlindustrie hatte einen verhältnismäßig hohen Marktwert erhalten.

Während so auf der einen Seite eine neue marktfähige Ware geschaffen wird, geht das Streben des Werkes andererseits darauf hinaus, sich in Bezug auf die Versorgung mit Kalk vom Markte unabhängig zu machen. Bereits 1890 erwirbt die Hütte ein eigenes Kalkwerk. In dem Geschäftsbericht werden darüber folgende Mitteilungen gemacht: „Die gesicherte Beschaffung des für den Betrieb der Thomashütte notwendigen Kalkes hat uns veranlaßt, das Peiner Walzwerk bei dem in Marienhagen, im Kreise Gronau, gelegenen Kalkwerk des Herrn Friedrich Rogge als Kommanditist sich beteiligen zu lassen. Dieses Kalkwerk kann jährlich 50-60 000 Tonnen gebrannten Kalk erzeugen, dessen regelmäBiger Absatz zu lohnenden Preisen uns gesichert erscheint; außerdem hat das Werk noch einen bedeutenden Absatz an rohen Kalksteinen. Das Kapital, mit welchem das Peiner Walzwerk an diesem Kalkwerk als Kommanditist und Gläubiger beteiligt sein wird, wird Ende 1891 ca. 400000 Mark betragen." Damit ist eine Deckung des Kalkbedarfes für das Thomaswerk eingetreten.

Betrachten wir nun noch den EinfluB der Konjunktur auf die Ilseder Hütte. Obgleich zwar der Anfang der 90er Jahre für die Industrie nach der Erholung am Ende der 80er Jahre manche Enttāuschungen brachte, so ist doch das Werk innerlich so gekräftigt, daB ihm der schlechte Geschäftsgang wenig anzuhaben vermochte. Bereits 1889 hatte der Streik der Bergarbeiter im westfälischen Kohlenbecken zu vorübergehendem Kohlenmangel geführt. Um mit den zur Verfügung stehenden Kohlen möglichst lange auszukommen, wurde in llsede schwächer geblasen, ohne die Hochöfen auszulöschen oder 
dämpfen zu müssen. Es mußten ferner geringwertige Kohlen und Koks durch andere Reviere bezogen werden, welche bei ihrem Verbrauch den Betrieb ungünstig beeinflußten. Als dann 1891 wieder Arbeitseinstellungen der Bergarbeiter drohten, wurden große Kohlenreserven angeschafft. Die Preise waren hoch, obgleich die Eisenpreise bereits ins Weichen gerieten. Auch mit dem Kohlensyndikat hatte die Hütte manche Schwierigkeiten. Nachdem der Vertrieb der in Westfalen erzeugten Koks durch das westfälische Kokssyndikat geschah, konnte sich die Hütte nicht mehr dasjenige Material aussuchen, welches für ihre Zwecke am besten paßte, sondern muBte den Koks nehmen, welchen das Syndikat ihr zuteilte. Später scheinen sich jedoch die Verhältnisse gebessert zu haben. Man sieht daraus, welchen Einfluß die Lage des Kohlenmarktes speziell auf diejenigen Werke ausübt, die, wie die Ilseder Hütte, keine eigenen Kohlenzechen besitzen. Über diese Verhältnisse und Schwierigkeiten kam jedoch das Werk rasch hinweg, und von 1894-1900 setzt dann ein enormer Aufschwung ein. Das ist die glänzendste Zeit, die die Ilseder Hütte und das Peiner Walzwerk jemals erlebt haben. Sie traten in diese Periode mit erweiterten Produktionsmitteln. 1892 war das Aktienkapital bereits erhöht worden, um Walzwerk III einzurichten. 1896 war die Ilseder Hütte mit den zwei im Betriebe befindlichen Hochöfen nicht mehr imstande, den Roheisenbedarf des Walzwerkes vollständig zu decken, so daß es noch größere Mengen von auswärts beziehen mußte. Ein vierter Hochofen mußte gebaut werden. In dieser Zeit wird auch ein Teil der hypothekarischen Schulden abgestoßen. Damit im Zusammenhange steht die Erhöhung des Aktienkapitals. Darüber heißt es in dem Geschäftsbericht über das Jahr 1896: „Bei der günstigen Lage unserer Betriebs- und Finanzverhältnisse hielten wir es für ratsam, diese zu benutzen, um den gröBten Teil unserer hypothekarischen Schulden zu tilgen. Um dieses ohne Verringerung unserer Betriebsmittel bewerkstelligen zu können, wurde auf unseren Antrag von der auBerordentlichen Generalversammlung vom 7. Januar dieses Jahres einstimmig beschlossen, das Aktienkapital in der Weise um $50 \%$ zu erhöhen, daB den Aktionären auf je 2 Aktien eine neue Aktie zum Nennwert zur Verfügung gestellt werden solle." Nachdem dies beschlossen war, wurden die noch im Umlauf befindlichen Teilschuldverschreibungen der $41 / 2$ prozentigen Ilseder Eisenbahnanleihe vom Jahre 1883 im Betrage von 543000 Mark und der 4prozentigen Peiner Walzwerksanlage von 1886 im Betrage von 1785000 Mark gekündigt. Diese letzte 
Erhöhung des Betriebskapitals um 2214000 Mark erscheint nun allerdings mit der Abstoßung der hypothekarischen Schulden noch nicht zureichend begründet. Es ist nicht ausgeschlossen, daB hier noch ein anderes Motiv in Betracht kommt, das wir bei solchen Aktiengesellschaften zu finden pflegen, die sehr hohe Dividenden zahlen. Eine sehr hohe Dividende erregt den Neid der Arbeiter. Sie stellen im Stillen Vergleiche an zwischen den Löhnen, die sie in mühsamer Arbeit erwerben und den Renten der Aktionäre, die nicht arbeiten.

Es erhielten 1896

3770 Arbeiter . . . . $3,989,400 \mathrm{M}$. Lohn
Der Rohgewinn betrug $3,398,724 "$
Der Reingewinn " $2,526,159 \quad "$
Die Aktionäre erhielten $531 / 3 \%=2,360,600 \mathrm{M}$.

Solche Zahlen können leicht die Veranlassung dazu geben, daß die Arbeiter mit der Beteiligung von Kapital und Arbeit am Ertrage des Unternehmens nicht zufrieden sind. Um dies zu verhüten, verfahren dann kapitalistische Unternehmungen häufig folgendermaßen: Sie erhöhen das Betriebskapital und geben den Aktionären eine Dividende, die vielleicht höher ist wie früher, die aber in Prozenten ausgedrückt niedriger erscheint, weil sie auf der Basis eines größeren Kapitals berechnet wird. Um dies an einem praktischen Beispiele zu zeigen, wollen wir einmal annehmen, die Kapitalserhöhung von über 2 Millionen Mark bei der llseder Hütte wäre unterblieben, und die Dividende des Hochkonjunkturjahres 1899 im Betrage von 4648087 , die auf das Aktienkapital von 6640125 Mark berechnet $70 \%$ beträgt, würde auf das alte Aktienkapital im Betrage von 4426125 Mark bezogen, dann würde die Dividende nahezu 105\% betragen. Durch die Erhöhung des Aktienkapitals hat man mit dem Auftreten der Hochkonjunktur einer übermäBig hohen Prozentziffer einen Riegel vorzuschieben versucht. Heute beträgt das Aktienkapital 6640125 Mark, das Hypothekenkapital nur etwas über eine Million Mark, während wir in der Geschichte des Unternehmens Zeiten kennen gelernt haben, wo die Höhe der Hypothekenschulden die Höhe des Aktienkapitals überragte.

Unter so günstigen Finanzverhältnissen war es möglich, neue technische Verbesserungen in dem Betriebe einzuführen und die Produktionsmittel weiter zu vervollkommnen. Einer der wichtigsten Fortschritte in dieser Beziehung ist die Benützung der Hochofengase nicht mehr bloB zu Heizzwecken, sondern auch als Betriebskraft. 
Schon lange spielten die Gichtgase auf der Ilseder Hütte eine bedeutende Rolle. Bereits in den 70er Jahren wurden Einrichtungen getroffen, um sie in großen Röhren, die in die Hochofengicht hineinragten, aufzufangen und von da unter die Dampfkessel zu leiten. So ersparte man die sonst notwendig gewesene Kohle. Wir sahen bereits an den für die 70er Jahre mitgeteilten Zahlen, wie außerordentlich stark der Kohlenverbrauch der Ilseder Hütte sank, bis er im Jahre 1877 Null betrug. Daran aber hatte die Gesellschaft, die alle ihre Kohlen kaufen muß, ein ganz besonderes Interesse. Ferner benutzte man die Hochofengase zur Erhitzung des Gebläsewindes in den Winderhitzern. Heute heizen die überschüssigen Gase nicht weniger als 14 Dampfkessel, deren erzeugte Energie zum Betriebe einer elektrischen Zentrale mit insgesamt 1830 Pferdekräften dient. Diese Darrpfmaschinen erzeugen Elektrizität in 5 Dynamos, welche Drehstrom von 550 Volt Spannung liefern, der zum kleinen Teil zur Beleuchtung der Hütte und zu anderen Zwecken des Werkes verbraucht wird. Ein weiterer Teil der elektrischen Kraft wird zu den 3,5 Kilometer entfernten Bültener Erzgruben geleitet und dort zur Beleuchtung sowie zum Betriebe einer unterirdischen Pumpe, von 6 Gesteinbohrmaschinen, einer Grubenlokomotive, einer Erdsturzvorrichtung usw. verwandt. Der Rest der elektrischen Energie wird auf 10000 Volt transformiert, per Hochleitung dem ca. $7 \mathrm{~km}$ entfernten Peiner Walzwerke zugeführt, um auch dort zur Beleuchtung der Anlagen und zum Antrieb eines Walzwerkes, des Martinwerkes, der Phosphatmühle, der Verladekräne etc. zu dienen. ${ }^{(*)}$ ) Noch vor TorschluB des 19. Jahrhunderts begann man damit einen weiteren Fortschritt der Verwertung der Hochofengase in die Praxis einzuführen, nachdem, wie früher gezeigt, das Hoerder Werk bereits als erstes vorangegangen war. Es handelt sich um die Benutzung der Gichtgase zum Antrieb von Gasmotoren. 1899 begann man in Groß-Ilsede mit dem Bau einer elektrischen Zentrale für Hochofengasbetrieb, in der große Gasmotore von je 1000 Pferdekräften aufgestellt werden, die in sinnreicher Weise mit Dynamomaschinen für je 10000 Volt verbunden sind. Die so erzeugte elektrische Energie soll dann zum Antriebe der Maschinen in Ilsede, Peine und den Bergwerken ausgenutzt werden. So wird allmählich die Dampfmaschine beim Hochofen- und Walzwerksbetrieb durch die Gasexplosionsmaschine verdrängt. Diese ganze

*) Siehe Peiner Zeitung vom 6. Dezember 1902. 
neue Einrichtung ist ein Mittel, um den Betricb kolossal zu verbilligen, denn die Gichtgase stehen jedem Hochofenwerke frei zur Verfügung, während die Kohlen, die man früher benutzte, natürlich bezahlt werden mußten. Da nun mit den Hochöfen in Ilsede ein Stahl- und Walzwerk kombiniert ist, so nehmen auch diese mit ihrer Erzeugung an der Verbilligung Anteil, was nicht der Fall wärc, wenn wir es mit reinen Betrieben zu tun hätten.

Am Ende der Aufschwungsperiode im Jahre 1899 wurde in Peine auch ein Siemens-Martinwerk errichtet. In demselben werden Roheisen und Abfälle von Stahl oder Schmiedeeisen im bestimmten Verhältnis zusammengeschmolzen. Auch hier bestehen automatische Vorrichtungen, welche die mechanische Beschickung der Öfen ermöglichen. Ein elektrisch angetriebener Chargierwagen fährt bis dicht, vor dic Tür des Ofens, erfaßt mit einer Zange die bereitstehende, mit Rohmaterial oder altem Eisen beladene Mulde und schiebt dieselbe in den Ofen hincin, um sie dort zu entleeren. Die Füllung eines Martinofens, der in Peine ca. 25 Tonnen faßt, geht auf diese Weise viel schneller vor sich, als wenn die Martinarbeiter an Stelle des Kranes die Beschickung auszuführen hätten. Ist der Ofen gefüllt, dann dreht der Schmelzer an einem Schraubenrade, die Ventile der Generatorkammern werden geöffnet, und die Gase strömen in den Ofen, um dort ihre Arbeit zu beginnen. Der Prozeß dauert 6-7 Stunden und ist schon infolgedessen kostspieliger als der bloß ca. 20 Minuten in Anspruch nehmende Thomasprozeb. Aber das Martineisen ist infolge seiner weichen und feinkörnigen Beschaffenheit zur Herstellung höherwertiger Fabrikate zu benutzen und infolgedessen besonders gefragt. Die Einrichtung der ganzen Anlage auf dem Peiner Walzwerke hatte in der Hauptsache den Zweck, den A bsat z f ür Wa lzwerkserzeugnis se zu er höhen, da eine Steigerung der Roheisenerzeugung in Groß-Ilsede nicht angängig erschien. Diese Steigerung hat nun allerdings nicht stattgefunden, denn 1900 trat ein Wechsel der Konjunktur ein und die Produktion ging zurück. Sie sank von 202143 Tonnen im Jahre 1899 auf 171892 Tonnen im Jahre 1900 und blieb im folgenden Jahre, 1901, annähernd auf derselben Höhe (171378 Tonnen), um dann 1902 wieder zu steigen, nämlich auf 219350 Tonnen Walzwerkserzeugnisse. Diese Entwicklung ist aber nur dadurch möglich geworden, daß man die im Inlande nicht absetzbaren Waren auf die ausländischen Märkte warf. In welch hohem Maße auch die Ilseder Hütte und das Peiner Walzwerk in der letzten Krisenperiode vom Export lebte, 
der während der Zeit der Hochflut auf dem inländischen Markt ganz vernachlässigt worden war, zeigen folgende Zahlen:

\begin{tabular}{|c|c|c|c|c|}
\hline Jahr & $\begin{array}{l}\text { Gesamtabsatz an } \\
\text { Walzwerksprodukten }\end{array}$ & auf das & $\begin{array}{l}\text { Davon } \\
\text { Inland }\end{array}$ & auf das Ausland \\
\hline 1899 & 200,401 Tonnen & 161,258 & Tonnen & 39,143 Tonnen \\
\hline 1900 & $155,539 \quad$ " & 126,522 & , & 29,017 \\
\hline 1901 & 186,242 & 91,623 & $"$ & 94,619 \\
\hline 1902 & 210,628 & 130,574 & $"$ & 80,054 \\
\hline
\end{tabular}

Hieraus ergibt sich, daB im Jahr 1901 über die Hälfte des gesamten Absatzes nach dem Auslande ging. Welche günstige Entwicklung aber in der Zeit von 1895-1899 die Gesellschaft genommen hatte, geht am besten daraus hervor, da $B$ die Betriebsüberschüsse jährlich um ca. 1 Million Mark stiegen und demgemäß auch die Dividende11 stark anwuchsen. Es betrugen:

$\begin{array}{lccccc} & 1895 & 1896 & 1897 & 1898 & 1899 \\ \text { die Betriebsüberschüsse } & 2,057,676 & 3,398,724 & 4,816,125 & 5,258,395 & 5,998,604 \\ \text { die Dividenden } & 28 \% & 531 / 3 \% & 542 / 3 \% & 62 \% 3 \% & 70 \%\end{array}$

Diese reichen Ergebnisse konnten selbst durch die steigenden Produktionskosten nicht wesentlich beeinflußt werden. Die Herstellungskosten der Tonne Roheisen betrugen 1895 28,65, 1896 30,09, 1897 31,66, 1898 34,76, 1899 36,30, 1900 40,45 Mark. Es war namentlich der Kohlenmangel und damit Hand in Hand gehend der hohe Kohlenpreis, der einen Wermutstropfen in den Becher der Freude senkte. Auf eine Tonne Roheisen wird in Ilsede nicht ganz eine Tonne Koks verbraucht. Die dadurch herbeigeführte Erhöhung der Produktionskosten wurde allerdings überkompensiert durch die enorme Steigerung der Preise für Walzwerkserzeugnisse.

In den folgenden Baissejahren gingen natürlich die Betriebsüberschüsse wie die Dividenden erheblich zurück, hielten sich aber trotzdem auf einer Höhe, an die bei anderen Werken gar nicht zu denken war. Es betrugen die:

$\begin{array}{lccc} & 1900 & 1901 & 1902 \\ \text { Betriebsüberschüsse } & 4,938,369 & 3,649,93 & 3,876,209 \mathrm{M} . \\ \text { Dividenden } & 50 \% & 40 \% & 40 \%\end{array}$

Wir haben nun schlieBlich noch eines Momentes zu gedenken, das für die Prosperität der Ilseder Hütte und des Peiner Walzwerkes 
nicht ohne Bedeutung gewesen ist, dessen Anteil sich allerdings nur schwer feststellen läßt: der Arbeiterverhältnisse. Von den drei Produktionsfaktoren, Natur, Kapital und Arbeit ist die letztere für den Ertrag des Unternehmens natürlich auch von größter Wichtigkeit. Die Zahl der Arbeiter auf der Ilseder Hütte betrug nach Ausweis des Knappschaftsvereins Ende 19014591 oder mit Weib und Kind ca. 16000. Sie kommt also der Einwolnerzahl einer Stadt wie Küstrin oder Goslar etwa gleich. An Beamtengehältern und Löhnen wurden im genannten Jahre gezahlt 5406566 Mark. Für das letzte Jahr 1902 haben sich diese Zahlen nicht wesentlich geändert. Von den Arbeitern erhält also jeder durchschnittlich einen Arbeitslohn von 1177 Mark in Jahre. Wenn man den Durchschnitt für die Familie berechnet, so entfällt auf jedes Familienmitglied jährlich ein Durchschnittsbetrag von 337 Mark. Die Löhne sind also, wenn man scin Urteil auf die Durchschnittszahlen stützt, die obendrein durch die sicherlich nicht zu niedrigen Gehälter der hohen Beamten beschwert werden, sehr gering, jedenfalls geringer als auf den westfälischen Konkurrenzwerken, allerdings höher wie in Oberschlesien. Aber die ganze Lohnstatistik der llseder Hütte wie der anderen Werke - eine Ausnahme macht von den hier besprochenen lediglich die Ver. Königs- und Laurahütte - ist volkswirtschaftlich so gut wie unbrauchbar. Sie gibt nur die Gesamtsumme der ausgezahlten Löhne und die Zahl der Arbeiter einschließlich der Beamten sowie die daraus sich ergebenden Durchschnittsbeträge pro Kopf an. Es werden also unterschiedslos die Löhne jugendlicher und erwachsener, gelernter und ungelernter Arbeiter zusammengezählt. Dazu kommen dann noch die Gehälter der Beamten, d. h. einer Minderheit, die aber imstande ist, den Durchschnittslohn nach oben hin vollständig zu verschieben und das Lohnbild in optimistischem Sinne zu korrigieren. Wissenschaftlich ist die aus der Verschmelzung verschiedener Arbeiter und Lohnkategorien berechnete Durchschnittszahl völlig wertlos. Was die einzelnen Arbeiterkategorien verdienen, also z. B. im Walzwerk die Walzmeister, die Vor- und Hinterwalzer, die Fertigwalzer, die Hebler, ferner die Schweißer, die Roller, die Kohlenfahrer, die Strecker, sowie die ungelernten Arbeiter, habe ich nicht feststellen können, da die von verschiedenen Seiten darüber gemachten Angaben nicht übereinstimmten und auch in übrigen den Eindruck der Unzuverlässigkeit machten. Damit ist wissenschaftlich zwar nicht viel verloren; denn der Nominallohn gibt nicht dasselbe korrekte Bild der Verhältnisse wie der bedeutend schwie- 
riger zu ermittelnde Reallohn. Immerhin aber ist es bedauerlich, $\mathrm{da} B$ die Lohnlisten auch dieser Aktiengesellschaft geheim gehalten werden. Nur für die Bergwerksarbeiter habe ich einige, wie mir scheint, zutreffende Angaben erlangt. Ein Heuer, der das Erz bohrt, sprengt, sortiert, verladet und transportiert, erhält im Akkord pro Tag 3,50-4,50 Mark, im Durchschnitt 3,80 Mark bei achtstündiger Schicht. Der Verdienst der Schlepper, die das Erz im Tagebau verladen und zu den Schächten bringen, ist derselbe wie der der Heuer im Tage- und Tiefbau. Die Bahnarbeiter, die die Geleise verlegen, erhalten bei achtstündiger Schicht einen Tagelohn von 2,50 Mark. Der Lohn der Bergleute ist mäßig, denn ihre Arbeit ist mühsam und beschwerlich. Der Heuer im Tagebau ist jeder Witterung ausgesetzt, im Tiefbau hat er unter der schlechten Luft zu leiden. Der Arbeiter im Walzwerk ist beständig von Gefahren umlauert. Von den 2500 Arbeitern des Walzwerkes erlitten Unfälle 1899 509, 1900 463, 1901 479, das heißt, der fünfte Teil der beschäftigten Arbeiter erleidet im Jahre irgendwelche Verletzungen. Was die Arbeitszeit anbelangt, so wird im Walzwerk, auf der Hütte, sowie gegenwärtig auch im Tiefbau Tag und Nacht gearbeitet, und zwar hauptsächlich im Akkord. Im Walzwerk besteht die zwölfstündige Schicht. Die Arbeit ist also sehr lang, nur von der Sonntagsruhe unterbrochen. Auf der Ilseder Hütte und im Bergbau besteht die achtstündige Schicht. In bezug auf die Arbeitszeit ist also der Ilseder Hüttenarbeiter günstiger gestellt als der Peiner Walzwerksarbeiter.

Wie hat es nun das Werk angefangen, solche großen Arbeitermassen bei verhältnismäßig geringem Lohne in Groß-Ilsede und bei langer Arbeitszeit in Peine zu erlangen und festzuhalten? Es ist ihm gelungen durch Schaffung von Arbeiterwohlfahrtseinrichtungen. Man würde fehl gehen, wenn man die Bedeutung derselben für den Arbeiter unterschätzte. In erster Linie allerdings liegen sie im Interesse des Kapitals und auch bei den besten unter ihnen ist der soziale Feingehalt kein allzu hoher.

Die hervorragendsten Einrichtungen, die auf diesem Gebiete im Laufe der Zeit geschaffen wurden, sind

1. die Knappschaftskasse,

2. die Sparkasse,

3. die Arbeiterkolonien.

Über den Zweck und den Umfang des Knappschaftsvereins gibt $\operatorname{der} \S 1$ des Statuts folgende Auskunft: „Der Ilseder Knappschaftsverein hat den Zweck, seinen Mitgliedern und deren Angehörigen 
nach näherer Bestimmung dieses Statuts Unterstützungen zu gewähren, auch derartige Einrichtungen zu begründen und zu unterhalten, welche das physische und moralische Wohl der Arbeiter befördern (z. B. Schulen, Bibliotheken, Wasch- und Badeanstalten, Kranken- und Invalidenhäuser). Der Verein umfaßt alle Arbeiter, welche beschäftigt sind auf der Ilseder Hütte in Groß-Ilsede, der Aktiengesellschaft Peiner Walzwerke in Peine und den der Aktiengesellschaft Ilseder Hütte sowohl zur Zeit gehörigen, als auch von ihr künftig zu erwerbenden Etablissements und Gruben, soweit diese im Kreise Peine, südlich der Eisenbahn Hannover-Braunschweig, oder in den Gemarkungen der braunschweigischen Ortschaften Bodenstedt, Vallstedt, Beddingen, Sauingen usw. liegen."

Jedes Mitglied ist verpflichtet, bei seiner Aufnahme ein Eintrittsgeld von einer Arbeitsschicht zu zahlen und außerdem einen laufenden Betrag, welcher 3 Pfennig von jeder Mark des verdienten Lohnes beträgt. Ebensohoch ist die Beisteuer, welche die Gesellschaft zahlt. In die Kasse fließen auch die Strafgelder bei Verstößen gegen die Arbeitsordnung. Die Gesamtbeträge beliefen sich im Jahre 1901 auf 150603 Mark. Die Kasse gewährt ihren Mitgliedern im Falle der Krankheit eine kleine Unterstützung, bestehend in freier Kur und Arznei und einer Geldentschädigung für den während der Zeit der Krankheit ausfallenden Lohn, ferner eine Invalidenund Witwenpension, eine Waisenunterstützung und Begräbnisbeihilfe.

Dic Verwaltung des Vereins erfolgt durch einen Vorstand. Er besteht zunächst aus 12 Knappschaftsältesten, die von den Bergleuten und sonstigen Arbeitern des Peiner Walzwerkes gewählt werden. Außerdem aus 2 Mitgliedern, welche die Direktion der llseder Hütte, einem Mitgliede, welches die Direktion des Peiner Walzwerkes, und 3 Mitgliedern, welche die Knappschaftsältesten aus ihrer Mitte oder aus der Zahl der Bergbeamten wählen. Hier liegen demnach die Verhältnisse günstiger, als sie Pieper für das Ruhrrevier schildert. In seinem Buche über die Lage der Bergarbeiter*) schreibt er, „daB die Werksbesitzer durch verschiedene Mittel, besonders ducrh das Institut der Knappschaftsältesten ... die Knappschaftskassenverwaltung fast voliständig in ihre Gewalt und unter ihren Einfluß gebracht haben."

Ein Mangel des Knappschaftsstatuts besteht allerdings in der

*) Pieper, „Die Lage der Bergarbeiter im Ruhrrevier", Stuttgart und Berlin 1903, p. 193. 
Hemmung der Freizügigkeit. Verläßt der Arbeiter die Hütte, so gehen ihm alle trotz langjähriger Beitragszahlung erworbenen Rechte verloren. Im Statut heißt es $\S 28$ : „Mitglieder des Knappschaftsvereins, welche aus der Werkarbeit freiwillig austreten, oder Mitglieder eines anderen Knappschaftsvereins werden, scheiden aus dem Knappschaftsverein aus“ und $\S 29$ : „Mit dem Verluste der Mitgliedschaft hören alle Ansprüche des bisherigen Mitgliedes, auch der Invaliden, an den Verein sowohl für seine Person als für seine Angehörigen von selbst auf, ohne Rücksicht auf die geleisteten Beiträge. Beim Wiedereintritt eines früheren Mitgliedes in die Dienste eines Vereinswerkes leben die Rechte desselben an den Knappschaftsverein in der Regel nicht wieder auf. Dem Knappschaftsvorstande bleibt es jedoch vorbehalten, „Ausnahmen zu gestatten.“

Die zweite Wohlfahrtseinrichtung der Ilseder Hütte, die ein volkswirtschaftliches Interesse bietet, ist die Sparkasse. Bereits im Jahre 1869 gründete die Ilseder Hütte eine Sparkasse für ihre Arbeiter, und ihr folgte 1887 das Peiner Werk mit derselben Einrichtung. Diese Sparkasse wurde, wie es in der Jubiläumsschrift heißt, aus 2 Gründen ins Leben gerufen: 1. um die Arbeiter wirtschaftlich zu erziehen und 2. um sie gegen die Lehren der Sozialdemokratie zu immunisieren. Bis zum Jahre 1869 fehlte es, wie der Bericht sagt, an einer bequemen Gelegenheit für den Arbeiter, seine Ersparnisse fruchtbringend anzulegen; vielfach wurden die ersparten Gelder in harten Talern in Kästen und Schränken mit mangelhaftem Verschluß deponiert, und konnten an diesen wenig sicheren Orten leicht gestohlen werden. Um dieselbe Zeit machten in Braunschweig sozialistische Agitatoren den Versuch, die Arbeiter für die neue Lehre zu gewinnen. „Um nun diesem Übelstande zu begegnen, die Arbeiter wirtschaftlich zu erziehen und sie zugleich für das Wohl der Gesellschaft zu interessieren, wurde im Jahre 1869 die Sparkasse begründet." Jeder Arbeiter hat bis zum heutigen Tage das Recht, Einlagen bis zum Betrage von 1500 Mark zu machen. Diese Sparkasse unterscheidet sich also von anderen Sparkassen durch eine Limitierung der Einlage. Das hängt damit zusammen, weil der Zins ein besonders hoher ist. $\S 8$ des Sparkassenstatuts lautet: „In dem Jahre, in welchem die Ilseder Hütte an ihre Aktionäre mehr als 5\% Dividende verteilt (und das ist bisher regelmäBig der Fall gewesen), erhalten diejenigen Einlagen, welche während des ganzen Kalenderjahres bei der Ilseder Hütte belegt waren, einen Überzins, welcher zuzüglich der $5 \%$ Zinsen mit der an die Aktionäre 
zur Verteilung kommenden Dividende übereinstimmt, jedoch wird unter keinen Umständen mehr als 20\% (5\% und 15\% Überzins), beim Peiner Walzwerk nur 10\% vergütet, auch wenn an die Aktionäre ein höherer Betrag zur Verteilung gelangt.“ Mit anderen Worten, derjenige Arbeiter der Ilseder Hütte, der der Sparkasse nach und nacl 1500 Mark übergeben hat, und im Laufe des Jahres sein Guthaben nicht verändert, erhält jährlich von ihr 300 Mark zurück. Nun muß man aber nicht etwa glauben, daß die Hütte dieses jährliche Opfer von 300 Mark umsonst auszahlt. Sie verfolgt damit bestimmte Zwecke. Sie benutzt diese 300 Mark dazu, um dic Löhne nach Möglichkeit zu stabilisicren, d. h. sie übt auf den sparenden Arbeiter einen Druck aus, in der Richtung, daß er zu dem bisherigen Lohn im Dienste der Gesellschaft bleibt, anderenfalls hört die Verzinsung mit cinem Schlage auf, sein Guthaben wird gekündigt. In $\S 14$ heißt es nämlich: „Dic Ilseder Hütte behält sich das Recht vor, sämtliche oder einzelne Guthaben der Sparer zu kündigen und jederzeit sofort auszuzahlen ...", in $\S 15$ : „Entlassene oder sonst außer Dienst kommende Inhaber der Sparbücher haben ihre Guthaben beim Austritt des Dienstverhältnisses*) in Empfang zu nehmen, da vom Tage des Dienstaustritts an die Verzinsung ihres Guthabens aufhört." Die Verzinsung wird also nur unter der Bedingung gewährt, daß der Arbeiter nie seine Arbeit einstellt. Streiks sind dadurch hintangehalten, und in der Tat haben Arbeitseinstellungen auf dem Werke bisher niemals stattgefunden. Eine offene Frage, zu deren Beantwortung mir jedoch das Material fehlt, ist die, ob die Verwaltung diese Summe nicht am Lohne spart und sic gleichsam als Prämie auf niedrigen Lohn betrachtet. So ruht auch diese nach außen hin glänzende Einrichtung für die Wohlfahrt der Arbeiter doch im Schatten egoistischer Interessen des Großkapitals.

Wieviele Arbeiter sind nun imstande gewesen, der Sparkasse Einlagen zu übergeben und den verlockenden Überzins abzuheben, der ja im Gegensatz zur Dividende der Aktionäre nach oben hin begrenzt ist? Auf diese Frage gibt Antwort folgende Statistik: Im Jahre 1901 übergaben der llseder Hütte Einlagen 1919 Grubenund Hüttenarbeiter (und 56 höhere und niedere Beamte). Von dem

*) Es muß natürlich heißen: „,bei ihrem Austritt aus dem Dienstverhältniß.“ - Die Veröffentlichungen der Ilsederhütte sind, wie die Geschäftsberichte der meisten Aktiengesellschaften, im Kaufmannsdeutsch abgefaßt, das sogar vor direkten Sinnwidrigkeiten nicht zurückschreckt. So wird z. B. in $§ 16$ des Sparkassenstatuts von der "tadellosen Aufführung eines Verstorbenen" gesprochen. 
Peiner Walzwerk waren es 1136 Einleger incl. der Beamten. Die Zahl der Arbeiter betrug nach Ausweis des Knappschaftsvereins Ende 1900 4464. Von diesen Arbeitern waren also 3055 Sparer, d. h. $68 \%$. In Wirklichkeit ist die Zahl etwas zu hoch, weil ja auf dem Peiner Walzwerk die Beamten mitgezählt sind. Immerhin ergibt sich, daß ca. zwei Drittel sämtlicher Arbeiter imstande sind, etwas in die Sparkasse zu tragen. Damit ist natürlich nicht gesagt, daB ihr Lohn zureichend ist, denn Ersparnisse können auch gemacht werden durch partielle Nichtbefriedigung notwendiger Lebensbedürfnisse.

Wir haben jetzt gesehen, wie hoch die Zahl der sparenden Personen ist, wir wollen nunmehr berechnen, wie hoch die Durchschnittseinlage sich beläuft. Das Guthaben der Ilseder Arbeiter betrug 2845500 Mark, das der Peiner Einleger 1014615 Mark,*) zusammen 3860115 Mark. Die durchschnittliche Einlage beträgt also 1264 Mark, nämlich in Peine 893, in Ilsede aber 1482 Mark.

Die ausgezahlte Tantieme betrug für die llseder Arbeiter 1901 323202 Mark, für die Peiner Einleger 1900 nur 49039 Mark. Der Ilseder Arbeiter erhält also durchschnittlich 128 Mark Tantieme, d. h. ca. 10\%, der Peiner Einleger 43 Mark, d. h. ca. 5\%. Der Arbeiter im Walzwerk steht demnach ungünstiger da, als der Arbeiter der Hütte. Dies ist ja auch erklärlich, weil die $10 \%$ Verzinsung für die ersteren nicht dieselbe Lockkraft haben wie die $20 \%$ für die letzteren.

Eine dritte Wohlfahrtseinrichtung sind die Arbeiterkolonien. Als der Betrieb noch keine großen Dimensionen angenommen hatte, genügten die Arbeiter aus den umliegenden Dörfern. Mit dem Wachsen des Unternehmens aber mußten auswärtige Arbeitskräfte herangezogen werden. Um sie zu halten, entschloß sich die Verwaltung schon frühzeitig zu dem Bau von Arbeiterwohnungen. Der Boden war billig und die Ansiedlung bot keine Schwierigkeiten. Von den beiden Systemen, die für den Bau von Arbeiterwohnungen in Betracht kommen, der Kaserne und der Cottage, wählte man das letztere. Es wurden eine Anzahl Zwei-Familienhäuser gebaut, jedoch in der Weise, daß jedes Haus aus zwei vollständig voneinander getrennten Hälften bestand. Jede Familie erhält also ihre besondere Wohnung. Dafür hat sie jährlich 120-144 Mark Miete zu zahlen. Dic meisten dieser Wohnungen bestehen aus drei Stuben und einer Kammer. Dazu kommt noch ein halber Morgen Land, der mit

*) Die erste Zahl gilt für Ultimo Dezember 1901, die zweite für 1900. 
Kartoffeln, Gemüse usw. bestellt wird, und eine Stallanlage, in der eine Ziege oder ein Schwein gehalten werden kann. Von der Peiner Landstraße aus gesehen, machen die kleinen Häuschen, wie sie aus den blühenden Kartoffelfeldern hervorragen, einen recht freundlichen und gewinnenden Eindruck; dieser Eindruck verblaBt allerdings sehr, wenn man sie näher betrachtet.

Die Cottage, die der Arbeiter bewohnt, hat er nicht als Eigentum, sondern er hat sie gemietet. Das ist für das Werk aus folgenden Gründen wichtig.

1. Das Mietshaus bildet für die Aktiengesellschaft eine Einnahmequelle, wenn auch die Verzinsung des Anlagekapitals keine hohe ist.

2. Die Fabrikleitung behält EinfluB und Macht auf den Arbeiter auch außerhalb der Arbeitszeit, selbst wenn keine Wohnungskontrolle existiert. Infolge des Kündigungsrechts der Fabrik kann jede UnbotmäBigkeit, jede Lohnbewegung mit Obdachlosigkeit bestraft werden.

3. Daher ist das Miethaus ein Mittel, sich einen tüchtigen, ruhigen, wenig fluktuierenden Arbeiterstand $\mathrm{zu}$ sichern.

Neben diesem Miethaus kommt in Betracht das eigene Haus. Die wichtigsten Bedingungen, unter denen die Arbeiter der llseder Hütte ein eigenes Haus erwerben können, sind folgende: „Bauplan und Kostenanschlag unterliegen der Genehmigung der Direktion. Die Hälfte der Baukosten einschlieBlich der Kosten des Grunderwerbs wird von der Invaliditäts- und Altersversicherungsanstalt zu Hannover zur ersten Hypothek, verzinslich mit $3 \frac{1}{2} \%$ jährlich und für die ersten 10 Jahre unkündbar hergeliehen. Den Rest des Baukapitals leiht die Ilseder Hütte unter folgenden Bedingungen. Für das hergeliehene Kapital hat der Arbeiter 3\% Zinsen jährlich zu bezahlen, außerdem sind zur Tilgung der Schuld jährlich noch weitere $2 \% \mathrm{zu}$ entrichten, so daB im ganzen jährlich $5 \%$ des hergeliehenen Kapitals zu bezahlen sind... Zur Sicherstellung der Ilseder Hütte hat der Arbeiter eine zweite Hypothek, welche unmittelbar auf die für die Invaliditäts- und Altersversicherungsanstalt eingetragene folgt, in Höhe des hergeliehenen Kapitals eintragen zu lassen. Eine weitere Sicherheit hat der Arbeiter zu leisten durch Verpfändung seines Sparkassenguthabens, wobei das Sparkassenbuch der llseder Hütte zu übergeben ist. Das Kapital ist seitens der llseder Hütte so lange unkündbar, als der Arbeiter im 
Dienste derselben steht. Hört dieses Dienstverhältnis auf, so ist das Kapital nach 6monatlicher Kündigung zurückzuzahlen.“

Wie auch hier das Abhängigkeitsverhältnis zugunsten der Fabrik ausgenutzt wird, lehrt die im vorhergehenden genannte Bestimmung, $\mathrm{da} B$ das Kapital seitens der Ilseder Hütte nur solange unkündbar ist, als der Arbeiter im Dienste derselben steht. Auch hier ist die Verquickung von Wohnungs- und Arbeitsverhältnis keine Einrichtung, die sozialpolitisch gebilligt werden kann. Bei dem Bau von Arbeiterwohnungen gehorcht die Verwaltung eben nicht sozialen Motiven, sondern dem Zwange der Notwendigkeit. Sie hätte keinen Arbeiterstamm erhalten, wenn sie dem fremd Zuziehenden nicht die Möglichkeit der Behausung geboten hätte. Damit ist allerdings erreicht, $\mathrm{da} B$ dic Privatspekulation und das Schlafstellenwesen ihre schädigende Wirkung auf die Arbeiter nicht so entfalten konnten, wie das dort der Fall ist, wo solche Arbeiterkolonien fehlen.

Außer der Knappschafts- und der Sparkasse und den Cottages gesellen sich zu den Wohlfahrtseinrichtungen der Ilseder Hütte und des Peiner Walzwerkes noch einige andere, die nicht die hohe Bedeutung der genannten drei Einrichtungen besitzen, nämlich eine Badeanstalt, ein erst seit kurzer Zeit bestehender Konsumverein in Peine mit nur 600 Mitgliedern, eine Schule zu Ölsburg, für die Beamten eine Beamtenwitwen- und Waisenkasse, und schlieBlich eine allgemeine Lebensversicherungs- und Unterstützungskasse.

Überblicken wir am Schluß noch einmal die Marksteine unserer Darstellung. Ausgangspunkt war die Frage nach den Gründen der überdurchschnittlichen Rente, die die Ilseder Hütte abwirft. Als solchelerntenwirkennen:

1. Den Reichtum und die günstige Lage der Eisenerze nahe der Erdoberfläche. Ihre Gewinnung erfolgt noch heutegröBtenteils im Tagebau; daherkeinekostspieligen $S c h a c h t e u n d M$ aschinen. $\mathrm{Nach}$ Einführung des Thomasverfahrens wirktder dreiprozentige Phosphorgehalt wie eine Werterhöhung. Aus dem Reichtum, der Lage und der Beschaffenheit der Erze ergeben sich von selbst sehrniedrige Herstellungskostendes Roheisens gegenüber anderen Werken.

2. Eine vorsichtige und kluge Finanzpolitik, die sich paart mit hoher geschäftlicher Begabung der noch heute ander Spitze stehenden Persön- 
lichkeit. Die Neuanlagen werden nach Möglichkeit aus den Betriebsgewinnen bestritten. Damit in Verbindung steht die Schaffung großer Reservefonds und die Niedrighaltung des Aktienkapitals.

3. Der billige Erwerb des Peiner Walzwerks im Jahre $18 s 0$. Infolgedessen wirdder ProduktionsprozeB dreigliedrig (Roheisen, Stahl, Walzwerksprodukte). Dadurch verliert das llseder Roheisenseinen Weltmarktpreis. Das Geschäftsergebnis wirdnicht mehr abhängig von der Verwertung des Rohstoffes, sondern von der des Fabrikates. Die niedrigen Produktionskosten des Roheisens kommen nunmehr in den Fertigerzeugnissen noch schärfer zum Ausdruck.

4. Die Methode der Bilanzierung, auf Grund deren das Peiner Walzwerk mit keinem oder kleinem Gewinn abschlie $B t$, dernichtzurVerteilung gelangt, sondern auf neue Rechnung vorgetragen wird. Dadurch wird der Kommune ein Steuerbetrag entzogen, der dem Werkzugute kommt.

5. Die Aufnahme des Thomasprozesses und damit im Zusammenhang die Einführung des Schnellbetriebes. Die Folge ist eine Steigerung des Absatzes an Stahlfabrikaten und so eine VergröBerung der Einnahme.

6. Der natürliche Frachtvorsprung nach Mitteldeutschland gegenüber den rheinisch-westfälischen Werken. Damit im Zusammenhange Änderung des Fabrikationsprogramms: Verdrängung des bisher nach den westlichen Märkten abgesetzten Halbfabrikates der Drahtindustrie (Stahlbillets) durchdie Herstellungvon T-Eisen, deren Absatzgebiet nach allen Richtungen erweitert wird.

7. Der AnschluB an das Trägerkartell und den Mitteldeutschen Walzwerksverband. Die Aufgabe auch dieser Kartelle war die Steigerung des Unternehmergewinns. 
8. Die Verwertung der früher wertlosen Thomasschlacke durch den Bau einer Thomasphosphat. fabrik. Der Mehrertrag hieraus kommt als Gewinn dem Gesamtunternehmen zugute.

9. Technische Neuerungen und Vervollkommnung der Produktionsmittel, wie Bau eines Stahlwerkes, Benutzung der Hochofengase nicht nur für Heizungszwecke, sondern auch als Betriebskraft. Infolgedessen Herunterdrückung der Produktionskosten.

10. Der gute Geschäftsgang während der Auf$\mathrm{sch}$ wungserioden von 1868-1873,1880-1883, $1887-1890,1895-1900$.

11. Die Arbeiterverhältnisse, denen durch die Arbeiterwohlfahrtspolitik eine für das Unternehmen günstige Grundlage gegeben ist.

Die Hineinzeichnung dieser speziellen und allgemeinen Gründe in den Rahmen der geschichtlichen Entwicklung des Unternehmens war der Zweck der vorliegenden Darstellung. 


\section{Die Dortmunder Union.}

Das Gegenstück zu den Verhältnissen der Ilseder Hütte bildet die Union, Aktiengesellschaft für Bergbau, Eisen- und Stahlindustrie zu Dortmund. Die industrielle Geschichte Deutschlands kennt kein großkapitalistisches Unternehmen, das in so gewaltigen Dimensionen dauernd so unfruchtbar gewesen ist wie dieses, unbildlich gesprochen, das während der ganzen Zeit seines Bestehens entweder eine tief unter dem Durchschnitt liegende, meistens aber gar keine Rente ergeben hat. Diese Tatsache rollt von selbst die Frage auf: Welches sind die Ursachen dieses finanziellen Mißerfolges? Die Beantwortung dieser Frage ist der rote Faden, der sich durch die Lebens- und Leidensgeschichte durchzieht, die wir nunmehr ausführlicher zu schildern haben.

Die Dortmunder Union ist das Verschmelzungsprodukt verschiedener Betriebe. Der Grundgedanke dieser Fusion war: Eine Anzahl großer Werke, sowohl des Kohlen- und Eisensteinbergbaus, als auch der Hochofen-, Walzwerks- und Werkstättenindustrie zu einem Riesenunternehmen zu vereinigen, welches die ganze Montan- und Eisenindustrie vom Rohprodukt bis zum Fertigfabrikat umspannt, und in dem die einzelnen Teile sich wechselseitig vertreten und ergänzen.

Dieser Grundgedanke wurde konsequent durchgeführt, indem unter intellektueller und finanzieller Assistenz der Diskonto-Kommanditgesellschaft in Berlin folgende Werke zu einem organischen Ganzen kombiniert wurden:

1. Die Dortmunder Hütte, ein Hütten- und Walzwerk mit 52 Puddelöfen, 28 Schweißöfen, 5 Walzenstraßen, einer Räderfabrik und einer Brückenbauanstalt. Zu der Dortmunder Hütte gehörte außerdem das Hochofenwerk Othfresen in der Provinz Hannover und das Kohlenbergwerk Glückauf Tiefbau bei Barop, 
in der Nähe von Dortmund. Die Dortmunder Hütte gehörte Dr. Strousberg, der sie zu dem Zwecke erworben hatte, um für seine Eisenbahnbauten das notwendige Material wenigstens teilweise selbst fabrizieren zu können.

2. Die Henrichshütte in Hattingen mit Eisen- und Kohlenzechen, 4 Hochöfen, einem Puddelwerk von 50 Öfen, einem neu errichteten Bessemerwerke, einem Walzwerk und einer Maschinenfabrik.

3. Das Horster Werk bei Steele an der Ruhr, im Volksmunde Neuschottland*) genannt, mit Eisensteingruben, 4 Hochöfen, einem Puddelwerke von 38 Öfen und einem Schienenwalzwerk. An dem Horster Werk wie an der Henrichshütte war die Diskontogesellschaft stark beteiligt.

Diese räumlich weit voneinander getrennten Unternehmungen (Horst- und Henrichshütte liegen einige $30 \mathrm{~km}$ weit von Dortmund) wurden nun, wie gesagt, zu e in e $r$ großen Erwerbsgesellschaft vereinigt. Die Fusion erfolgte in der sogenannten Gründerperiode, und zwar in der Weise, daB unter Zugrundelegung eines Aktienkapitals von 33 Millionen Mark die Vorbesitzer der Dortmunder Hütte 18 Millionen, die Vorbesitzer der Henrichshütte und des Horster Werks je $7 \frac{1}{2}$ Millionen erhielten. Den Aktionären der beiden letztgenannten Gesellschaften wurde es frei gestellt, ihre Aktien entweder gegen Aktien der Dortmunder Union umzutauschen, oder aber den Parikurs sich auszahlen zu lassen. Fast ausnahmslos acceptierten die Aktionäre beider Gesellschaften den ersteren Vorschlag. „Durch diese Vereinigung“, heißt es im Prospekt aus dem Jahre 1872, „wurde . . ein großes Ganze geschaffen, in welchem jedes einzelne Etablissement eine Spezialität verfolgen, aber auch das eine Etablissement das andere kräftigst ergänzen und unterstützen und dadurch, von der Vereinigung dauernd Vorteile ziehend, zu höheren Leistungen gelangen kann."

Man sagt wohl von einem Menschen, er ist nicht zu einer glücklichen Stunde geboren. In viel höherem Maße aber gilt das von manchen Unternehmungen, sicherlich aber trifft es für die Union zu. Die Werke wurden von der Gesellschaft zu einer Zeit erworben, als die Anlagen sehr hoch zu Buch standen und mit Aktiven und Passiven, sowie mit den beim Kauf vorliegenden Bestellungen übernommen. Dazu kamen gleich im ersten Geschäftsjahr bedeutende

*) Nach dem im Jahre 1857 gebildeten Aktienverein dieses Namens. 
Neuerwerbungen: die bis dahin in fideikommissarischem Besitz gewesenen Eisensteinfelder nebst Hütte bei Bredelar (Preis $4 \frac{1}{2}$ Million Mark), außerdem Eisen- und Hüttenwerke in Schweden (Preis $3 / 4$ Million Mark). Im ganzen wurden im Laufe des ersten drei Semester alten Geschäftsjahres für Neuerwerbungen verausgabt nahezu 6 Millionen Mark. Dazu kamen dann fast noch $91 / 2$ Million Mark für Neubauten, so daß beim Ausbruch der Krisis diese Hochkonjunkturwerte sich also auf 15-16 Millionen Mark beliefen.

Das Unternehmen stand beim Kaufe zu hoch zu Buch: es war zu teuer bezahlt. Das Jahr 1872 war in bezug auf die Preisverhältnisse ein durchaus exzeptionelles Jahr, aber darauf hatte man keine oder nicht genügende Rücksicht genommen. So sehen wir in der Überkapitalisierung der Produktionsmittel den Einschlagundersten Grund derkommenden Schwierigkeiten.

Außer dem Erwerb der Produktionsmittel spielt für jedes große Unternehmen die Organisation desselben die Hauptrolle. Soll der Betrieb nach dem Grundsatz der Erzielung des höchsten Profits arbeiten, so muß die Verwaltung, $d$. h. die anordnende Instanz und die Arbeiterschaft, d. h. die vollziehende Instanz diejenigen Garantien bieten, die für die Realisierung des genannten Zweckes notwendig sind. Untersuchen wir nun nach dieser Richtung hin die Verhältnisse bei der Union.

Organisationsfragen gehören bekanntlich zu den schwierigsten. Es war von vornherein daher nicht gerade überraschend, da $B$ bei der Union in dieser Beziehung anfangs große Fehler gemacht wurden. Nach dem ursprünglichen Plane war die Verwaltung stark zentralisiert. In dem ersten Geschäftsbericht heißt es: „Als Grundlage der Organisation unserer Verwaltung haben wir festgehalten auf der einen Seite die Einheitlichkeit der Gesamtleitung, und auf der anderen Seite die Dezentralisation in der Spezialleitung der einzelnen Betriebe und Werke, weil nur auf diese Weise die Vielseitigkeit unserer industriellen Anlagen und die dadurch ermöglichte vorteilhafte Arbeitsteilung zur vollen Geltung gelangen konnte." Trotzdem später dieses ganze Prinzip als unrichtig wieder beseitigt wird, fügt der Bericht hinzu: "Jetzt ist diese Organisation beendet und hat sich durchaus bewährt!“ An der Spitze des Gesamtunternehmens standen 3 leitende Direktoren mit 2 Stellvertretern. Für jeden einzelnen Betrieb wurde eine Betriebsdirektion eingesetzt, an deren Spitze die 
einzelnen Ressortchefs standen. Der Verwaltungsrat, dessen Pflichten durch ein besonderes Reglement festgelegt wurden, bestand aus 2 Komitees: dem westfälischen und dem Berliner Komitee. Dem ersteren wurde hauptsächlich die Bearbeitung der technischen Arigelegenheiten, dem letzteren vorzugsweise die Bearbeitung der finanziellen Fragen überwiesen, während alle wichtigen und generellen Angelegenheiten dem Plenum des Verwaltungsrates vorbehalten blieben.

Es ist für die Gegenwart nicht ganz uninteressant, die leitenden Persönlichkeiten der Union aus der ersten Periode der Zentralisation in dem Urteil eines damals noch auf der Höhe des Erfolges stehenden Mannes zu begreifen, der ohne Zweifel ein industrielles Genie war, über den aber die Nachwelt den Stab brach, denn sie beurteilt die Menschen lediglich nach ihren Erfolgen. Ich meine Strousberg. In seiner Biographie*) sagt er über die Verwaltung der Union folgendes: „Nun aber war die Direktion und Verwaltung dazu angetan, die Gesellschaft zu ruinieren. Nach dem schon erwähnten Prinzip des Herrn von Hansemann übernahmen er und die Größen, die dabei beteiligt waren, Rothschild, Oppenheim, Präsident Scheele etc. gar keine Verantwortlichkeit. Diese Herren standen an der Spitze der Gesellschaft, illustrierten dieselbe, und dieses animierte das Publikum, hohe Preise zu bezahlen ... Aber verantwortlich für die Leitung waren diese Herren nicht und wollten es nicht sein; dazu wurde ein lokaler Aufsichtsrat gewählt. Dieser war moralisch verantwortlich und diesem wurde faktisch die ganze Macht erteilt... Nun finde ich es ganz erklärlich und gerechtfertigt, daß eine Zahl kommerzieller Magnaten, die mit eigenen Geschäften überhäuft sind, die Verantwortlichkeit zurückweist, industrielle Unternehmungen zu leiten. Man kann aber einen solchen persönlichen Vertrauensposten nicht von sich auf andere übertragen und muß dann darauf verzichten, im Aufsichtsrat und gleichzeitig Gründer zu sein und einer Verwaltung oder Gesellschaft, deren Tätigkeit man nicht leiten oder verfolgen kann, den Lustre seines Namens zu geben ... Übrigens ist die Dortmunder Union kein vereinzeltes Beispiel. Namen werden überall als Lockvögel für die günstige Plazierung des Aktienkapitals gewählt, nirgends hat dieses zur Prosperität beigetragen, sondern das Publikum hat nur noch neben den gewöhnlichen Ver-

*) Dr. Strousberg und sein Wirken, von ihm selbst geschildert, 3. Auflage, Berlin 1876, p. $436 \mathrm{ff}$. 
lusten das Agio verloren. Siehe Minerva, PleBner, Kuxhavener Bahn, Donnersmarkhütte, Shamrock \& Hibernia, Laurahütte und zahllose andere Unternehmungen, wobei Robert Warschauer, Mendelssohn, Borsig, Delbrück-Leo, Berliner Handelsgesellschaft, Bleichröder, und sonst gleich hohe Namen zu finden sind. Welches war nun aber der lokale Aufsichtsrat, der als Palladium hier aufgestellt wurde? Erstens war die Zahl zu klein. Für die Exekutive ist die geringste Zahl, die möglichste Einheit das beste, der Aufsichtsrat, ein beratendes Kollegium, muB groB genug sein, um in sich Parteibildung zu ermöglichen, aus deren Reibung die Wahrheit entwickelt wird. Die Mitglieder des Berliner Aufsichtsrates wären in sich als Teil eines größeren Körpers ganz geeignet. Herr v. Born ist ein achtbarer Bankier in Dortmund, der eine gewisse Vertrautheit mit der Eisen- und Kohlenindustrie besitzt und bei darauf bezüglichen Diskussionen mitsprechen kann, der aber keineswegs dazu angelegt ist, ein so großartiges Werk zu leiten, wenigstens die Leitung zu beherrschen und ihr Richtung zu geben, und sein Kollege Grillo war, wenn man ihn auch wirklich nach seinem Glauben an sich selbst in den Kauf nehmen wollte, dazu geschaffen, v. Born vollständig kalt zu stellen, denn v. Born ist eine schüchterne, ängstlich angelegte Natur und Grillo ist das Gegenteil, und die gegenseitigen Beziehungen dieser beiden Herren waren zur Zeit derartig, daß von Born einen vollständigen Grillokultus trieb und aus Überzeugung sich ihm ganz unterordnete. Der lokale Aufsichtsrat war also nur Grillo und dieser herrschte um so allmächtiger, als für die Diskontogesellschaft ... Grillo auf diesem Gebiete ebenso maßgebend war. Unter Herrn Grillos Auspizien sind alle Fehler, die die Gesellschaft ruiniert haben, begangen worden ...

Die Direktion war ebenso unglücklich zusammengesetzt, und deshalb wurde die ganze Organisation eine falsche. Der eine Direktor spielt gar nicht mit, er ist ein ruhiger, anständiger Mann, der als Dezernent ganz gut arbeiten kann, bei Leitung eines solchen Unternehmens aber gar nicht in Betracht kommt. Die Direktion bestand daher nur aus zwei Personen, einem kaufmännischen Direktor Müller und einem Techniker Nettke. Dem ersteren ist Begabung gar nicht abzusprechen, er besitzt, Scharfblick, Energie und kaufmännische Kenntnisse, ist aber ehrgeizig bis zum ExzeB, herrschsüchtig, kleinlich eigensinnig und zänkisch, ein gutes Pferd in kräftigen Händen, ein Durchgeher, der über die Stränge schlägt, wenn er keine Meisterhand fühlt; er hielt sich plötzlich für ein großartiges Tier und arbeitete 
darauf los. Grillo und den Verwaltungsrat gewann er durch seine plausiblen Berichte und Nettke war er überlegen und räumte ihm, um vollständig freie Hand zu haben, auf einem Teil des technischen Gebietes ebenfalls freie Hand ein, um dessen Ehrgeiz, der auch brennend ist, gleichfalls zu befriedigen. Nettke hatte nicht das Zeug für seine Stellung, er konnte die Sachen nicht so groß auffassen, wie dieses hier nötig war, beim besten Willen konnte er nicht in allen Branchen bewandert sein. Es wäre daher richtig gewesen, bei einem so vielseitigen Werke, in verschiedenen Gegenden zerstreut, so viel als möglich die Branchen zu teilen, und den Chefs alle mögliche Freiheit zu lassen, und sich beobachtend, taktvoll zu halten. Anstatt dessen - und dies paßte auch in Müllers Plan wurde alles zentralisiert, und die wirklich tüchtigen Direktoren der einzelnen Werke und Branchen derart entmutigt und degoutiert, daß manche abgingen, alle unzufrieden waren und verhältnismäßig wenig leisteten. Derartiges konnte auch nicht ausbleiben, wo sich der leitende Direktor überall einmischte, überall störte, überall Unkenntnis dokumentierte und Fehler machte, und man kann sich wohl denken, welche Desorganisation hier eingetreten sein muß. Herr Müller war auf seiner Seite ebenso rücksichtslos, kaufte Materialien, ohne die Chefs zu Rate zu ziehen, und wenn es sich herausstellte, da $B$ die Ankäufe sich für die Fabrikation nicht eigneten, so mußte es doch verarbeitet werden, und wenn der betreffende Techniker, um sein Renommé nicht aufs Spiel zu setzen, remonstrierte, dann wurde Streit gesucht und von der Dortmunder Union ist mancher, der bis dahin als Fabrikationschef geachtet dastand, mit geschädigtem Ruf abgegangen." Nun führt er Beispiele an: „So erfuhr ich, daß Herr Müller ein großes Quantum Roheisen für Puddelzwecke gekauft hatte, welches zu grau war, und habe ausgerechnet, daß der Verbrauch dieses Eisens über tausend Taler täglichen Verlust verursachte. Der Walzwerksdirektor ging deshalb ab; man hätte das Eisen mit Vorteil verkaufen können: es nutzte nichts. Für den Bessemerprozeß in Henrichshütte war ebenfalls nicht genügendes Material beschafft. Aus Algier bezogene teure Erze kauft Hoerde heute von der Union, natürlich weit unter dem Preise. Mit Materialien zu hohen Preisen hatte man sich so versehen, daß man während der ganzen Zeit, wo die Preise so niedrig waren, mit Material arbeiten mußte, das teurer war als das Fabrikat. Bestellungen wurden stets zurückgewiesen. Der Bruder des Herrn Nettke hat mir selbst erzählt, daß er eine höchst annehmbare Offerte für die Staatsbahn 
auf 600000 Zentner Bessemerschienen gemacht hat; sie wurde nicht angenommen. Der Himmel hing nur für diese Herren voller Geigen, und wie konnte es anders sein, wenn alle bei Aktienspekulationen beteiligt waren und $80 \%$ Agio für billig hielten."

So weit das Urteil Strousbergs über die Mängel der Verwaltung. Ihr Fehler lag, wie wir gesehen haben, außer in dem Charakter der Persönlichkeiten vor allem in der zu starken Zentralisation. Die Zentralleitung war allzusehr mit Arbeiten, insbesondere Details, überlastet, während den unmittelbaren Leitern der einzelnen Werke zu wenig eigene Verantwortlichkeit oblag. Infolgedessen hatten sie ein zu geringes Interesse an den Resultaten der einzelnen Werke. Dieser Nachteil tritt besonders scharf in die Erscheinung bei dem neuorganisierten Dortmunder Werke.

Als nun das zweite Geschäftsjahr unter dieser Leitung einen Betriebsverlust von beinahe $41 / 2$ Million Mark ergab, wurde ein neues Reglement für die Verwaltung ausgearbeitet, das Anfang 1875 in Kraft trat. An Stelle des Prinzips der Zentralisation tritt jetzt eine weitgehende Dezentralisation, das heißt die Verantwortlichkeit der Leiter der einzelnen Werke wird verschärft. Die Direktoren waren früher ganz unselbständig. Sie hatten in den meisten Punkten keine eigene Initiative. Das wird nun ganz anders. Für die spezielle Betriebsleitung werden 5 Abteilungen errichtet, nämlich folgende: 1. Kohlenbergbau, 2. Eisensteinbergbau, 3. Dortmunder Eisen- und Stahlwerke, 4. Horster Eisen- und Stahlwerke, 5. Henrichshütte, Eisen- und Stahlwerke. Jede Abteilung wird einem Direktor unterstellt, welcher dem Verwaltungsrat selbständig verantwortlich ist. Während vorher die einzelnen Werke auch rechnerisch in dem ganzen aufgingen, wird jetzt der Grundsatz besonderer Abrechnung durchgeführt. Jedes einzelne Werk hat eine selbständige Bilanz mit Gewinn- und Verlustkonto aufzustellen. Die Generalbilanz der Union umklammert seitdem fünf den genannten Abteilungen entsprechende Spezialbilanzen. Für die Vertretung nach außen, vorzugsweise also für die gesamte kaufmännische Leitung funktioniert neben den Abteilungsdirektoren eine Zentraldirektion in Dortmund. Der Vorsitzende ist der Generaldirektor. Er führt die Aufsicht über die einzelnen Abteilungen. Er bearbeitet die kommerzielle Seite des Unternehmens, verteilt die Arbeiten an die Werke und erledigt sonstige generelle Angelegenheiten. Die Mitglieder der Zentraldirektion (heute ist es nur der Generaldirektor) und die einzelnen Abteilungsdirektoren bilden zusammen den Vorstand. Ihm liegt unter anderem die Aufgabe 
$o b$, alle Anträge der einzelnen Abteilungen an den Verwaltungsrat einer Vorberatung zu unterziehen, sowie die Beziehungen der einzelnen Abteilungen zueinander im Falle der Meinungsverschiedenheit, resp. im Hinblick auf das Gesamtinteresse der Union, sowohl generell als auch im einzelnen Falle näher festzustellen. Auch die Organisation des Verwaltungsrates wurde geändert. Wie wir gesehen haben, bestand derselbe aus 2 Komitees, von denen das eine für die Bearbeitung der vorkommenden technischen Fragen, das andere wesentlich für finanzielle Angelegenheiten und die Beaufsichtigung des Betriebes bestimmt war. Diese augenscheinlich durch die örtlichen Verhältnisse gebotene Teilung führte jedoch zu Unzuträglichkeiten. Infolgedessen werden die beiden Komitees aufgehoben und bestimmt, daB in Zukunft Komitees nur mit bestimmten einzelnen Aufgaben betraut werden sollen. Die Aufsichtsinstanz wird hier im Verwaltungsrat konzentriert. In den wesentlichen Punkten stehen diese Grundsätze noch sämtlich heute in Kraft.

Nachdem diese grundlegende Änderung in der Organisation: die Verschiebung der Macht aus einer Zentralinstanz in die Hände der Leiter der einzelnen Werke durchgeführt war, war die Konstruktion der Verwaltung nicht mehr das Entscheidende, sondern ihre Träger, das heißt die Personen. Hier sind nun allerdings auch im Laufe der Zeit zahlreiche Fehler gemacht worden. Schon der häufige Wechsel gibt zu denken. Ich habe mir aus den Geschäftsberichten folgende Änderungen zusammengestellt, ohne damit diesen Punkt zu erschöpfen: der erste Reorganisator der Union war der Bürgermeister a. D. Russell (1875). An seine Stelle trat 1881 der Königliche Eisenbahndirektor Bail, scheidet aber ,aus persönlichen Gründen“ nach einem halben Jahre wieder aus (1879/80). Auf ihn folgt als Generaldirektor Regierungsrat Seebold. Es ist zunächst, wie Strousberg richtig bemerkt, vollständig verkehrt, an die Spitze solcher vielseitigen Unternehmungen wie der Dortmunder Union Leute mit hochklingenden Namen zu stellen. Nicht der Name, sondern die Leistung entscheidet. Zweitens gehören an die Spitze Fachleute. Aber gegen dieses oberste Prinzip wird nicht nur in der Staatsverwaltung - ich erinnere an die Bestellung von Geistlichen zu Schulinspektoren im Nebenamte, oder an die Besetzung der obersten Verwaltungsstelle des größten deutschen Transport- und Handelsunternehmens mit einem General - viel gesündigt, sondern auch bei Aktiengesellschaften, z. B. bei der Union.

Nun ist zwar die Personenfrage bei einem solchen Großbetrieb 
nicht das allein ausschlaggebende Mcment in bezug auf die Rentabilität. Viel größer als der Einfluß auch des intelligentesten Direktors ist der der Konjunktur. Aber davon abgesehen, ist es ohne Zweifel nicht gleichgültig, ob eine dirigierende Persönlichkeit gelernt hat, aus den Erfahrungen der Vergangenheit Nutzen zu ziehen. Das ist bei den verantwortlichen Leitern der Union vielfach nicht der Fall gewesen. Dieselben Fehler, die früher gemacht wurden, haben sich wiederholt. Daher sagt Lindenberg*) nicht mit Unrecht von der Union: „Wohl hat es Menschen, wohl hat es Unternehmungen gegeben, welche aus den früheren Felılern gelernt haben, aber bei der Dortmunder Union ist das nicht geschehen. Dieselben Dinge, welche Strousberg an der Leitung der 70er Jahre tadelt, hat auch die Verwaltung während des Booms der 90er Jahre nicht besser gemacht. Gleichsam als $o b$ es eine ehrwürdige Tradition für sie sei, jedesmal die Konjunktur zu verpassen und in jeden neuen Boom, überladen mit minderwertigen Bestellungen, wofür man sich billiges Material nicht gesichert hat, einzutreten, nachher aber in der Krisis mit teuer gekauften Materialien ohne entsprechende Bestellungen sitzen zu bleiben, so geschah es auch diesmal ... Gleich wie die Union der 70er Jahre das Bedürfnis gefühlt hatte, zu Hochkonjunkturpreisen Gruben in Westfalen und Schweden zu kaufen, ebenso iühlte auch die Union der 90er Jahre das Bedürfnis zu ganz analogen Ankäufen von Gruben, ,welche, wenn sie wertvoll waren, was sie nicht sind, Jahre zur Vorbereitung und viel Geld erforderten, ehe sie etwas liefern konnten" und von denen man sich hätte sagen müssen, „daß man die teuer gekauften Gruben erst in Betrieb bringen werde, nachden die gute Zeit vorbei war."“،

Außer dem Beamten war natürlich auch die Qualität des Arbeitermaterials von ausschlaggebender Bedeutung. „Wir finden überall unzureichende Arbeitskräfte", heißt es im ersten Geschäftsbericht, „es fehlte insbesondere in Dortmund nicht minder an tüchtigen Beamten als an erfahrenen und hinreichenden sonstigen Arbeitskräften. Heute (das heißt 1872/73) beschäftigen wir $12102 \mathrm{Ar}$ beiter, 169 Betriebsbeamte und 165 Bureaubeamte." Diese Arbeiterzahl ist bis zur Gegenwart nicht mehr erreicht worden. Erst im Jahre 1900 beträgt der durchschnittliche Personalbestand wieder 12082 Mann, um sich in den folgenden Jahren wieder stark zu ver-

*) Otto Lindenberg: 50 Jahre Geschichte einer Spekulationsbank. Ein Beitrag zur Kritik des deutschen Bankwesens. Berlin 1903. p. 36. 
mindern. Im Anfang konnte man nicht sehr wählerisch sein. Die Gründerperiode litt unter großem Arbeitermangel. Ein großes Personal nicht bloB von Arbeitern, sondern auch von Meistern, Betriebsführern und Betriebsdirigenten mußte neu engagiert werden. MiBgriffe waren hierbei nicht $z u$ vermeiden. Die Nachfrage nach Produkten zwang dazu, den Arbeiterbedarf zu decken und über den engen Kreis bewährter und tüchtiger Kräfte hinauszugehen.

Um die Betriebsführer und Dirigenten an der Produktion zu interessieren, hatte man anfangs das System der Bruttoproduktionstantieme eingeführt. Das ging, so lange die Konjunktur noch günstig war, so lange es sich darum handelte, in erster Linie viel zu produzieren, weil auch die teurere Produktion noch großen Nutzen abwarf. Aber mit dem Eintritt der Baisse änderte sich das. Das Prinzip wird fallen gelassen. Der Geschäftsbericht 1873/74 bemerkt: „Es fehlt indes bei stattgehabter allgemeiner Anwendung dieses Prinzips an dem notwendigen Korrektiv gegen die Bemessung des Arbeitslohnes nach Akkordsätzen. Die Frage der Selbstkosten tritt in den Hintergrund; statt der Kontrolle über das nach Akkordsätzen zu bezahlende Quantum guter Arbeit besteht und bestand ein gemeinschaftliches Interesse, ein möglichst großes Quantum als gut anzuerkennen und zu buchen. Bei schlaffer und unfähiger, geschweige denn bei gewissenloser Betriebskontrolle mußten sich diese nachteiligen Einwirkungen verschärfen, und so hat sich denn auch tatsächlich bei der Union an verschiedenen Betriebsstellen eine erhebliche Differenz zwischen der gebuchten Arbeitsleistung und dem effektiven Lagerbestande herausgestellt, welche bei der letzten Inventur in dem mitgeteilten Betriebsresultat als Manko zu Tage getreten ist. Gegen diese nachteilige Wirkung hat die mit einer Fülle anderer Aufgaben belastete Zentralverwaltung kein ausreichendes Gegengewicht geboten." Ob dieser Kausalzusammenhang wirklich bestand, entzieht sich heute der Nachprüfung, jedoch sollen auch nach Beseitigung dieses Systems Werte zu Buche gestanden haben, die sich dann bei der Inventur als gar nicht vorhanden erwiesen.

$\mathrm{Zu}$ den verhängnisvollsten Momenten in der Geschichte der Dortmunder Union gehört in dritter Linie das a $11 \mathrm{mäh} l i c h$ e Verarmen ihrer Erzbergwerke in bezug auf $M$ asse und Qualität. Ökonomisch bedeutet dieser Vorgang einen riesigen Ausfall an Grundrente.

Nach der Gründung hatte die Dortmunder Union einige Eisen- 
steinzechen, Erzfelder und Gerechtsame. Dazu kamen die Eisensteinfelder bei Bredelar. Wir sehen in der Folge auch bei der Union das Bestreben, sich durch die Erwerbung eigener Erzgruben unabhängig von den Schwankungen des Marktpreises, dieses grundlegenden Rohstoffes der Hochofenindustrie zu machen. Das ist ihr nun allerdings in bezug auf das Eisenerz nicht gelungen. Die Gesamtförderung an Eisenstein belief sich 1872/73 auf ca. 230000 Tonnen, 1902/03, das heißt nach 30 Jahren, nur noch auf ca. 29000 Tonnen. Zwischen diesen beiden Zahlen liegt eine interessante Periode, in der die Union alle Hebel in Bewegung setzte, um die Produktion an Eisenerz zu vermehren. Bereits im ersten Geschäftsjahre genügte das oben erwähnte Quantum nicht. Die Verwaltung tat nun einen Schritt, der sich später als verhängnisvoller Fehler herausstellte. Im Interesse der für die Flußstahlfabrikation notwendigen Erzbezüge kaufte sie gleich im ersten Geschäftsjahre eine Holzkohlen-Hochofenanlage nebst dazu gehörigen Eisengruben in Schweden, die Svabenswerke. Der Kaufpreis dieser Anlage, einschließlich der Hütten- und Eisensteingruben, des dazu gehörigen Areals von 26000 Morgen eigener Waldungen und einer bis zum Jahre 1900 andauernden unentgeltlichen Berechtigung zur Abholzung von weiteren ca. 14000 Morgen Waldungen für den Hochofenbetrieb, betrug 3 Millionen Mark. Aber der Bezug schwedischer Erze aus eigenen Gruben war ein verfrühter Gedanke. Weder Eisenbahn noch Schiffahrt waren auf den Massentransport eingerichtet, und die Kosten dafür sehr hohe. Im Geschäftsjahre 1875/76 ergibt die schwedische Acquisition einen Verlust von 50627 Mark. Der Bezug wird nunmehr gänzlich eingestellt. Der Plan, schwedische Erze aus eigenen Werken für die Dortmunder Anlage heranzuziehen, war gescheitert. Um die VeräuBerung zu erleichtern, wurde der Buchwert der Immobilien und Anlagekonti auf $1 / 2$ Million heruntergeschrieben. 1879 endlich wird das Werk zu dem Spottpreise von $1 / 4$ Million Mark verkauft.

Vor der Einführung des Thomasprozesses hatten die eigenen Erzgruben, die größtenteils phosphorhaltige Erze enthielten, keine große Bedeutung. Es mußte der wachsende Bedarf an Bessemererzen aus dem Auslande gedeckt werden. Diese importierten edlen Eisenerze, die hauptsächlich aus England kamen, waren natürlich keineswegs billig. Erst mit der Einführung des Thomasverfahrens glaubte die Union sich vom Auslande losmachen zu können. Nun begann eine Ausbeutung der eigenen Gruben und ihrer phos- 
phorhaltigen Erze in großen Dimensionen. Für die Herstellung des nach dem alten Bessemerverfahren phosphorfreien Roheisens war Dortmund des Erzbezuges wegen ein ungünstig gelegener Platz. Umgekehrt verhielt es sich in bezug auf die Produktion des phosphorhaltigen Thomaseisens, für welches sich die benötigten Erze verhältnismäßig billig in Dortmund beschaffen ließen. Die Union war nun in der Lage, ihren eigenen Besitz an ausgedehnten Lagerstätten phosphorreicher Erze, welcher bisher brach lag, zu verwerten. Mit der Einführung des Thomasprozesses auf der Union hingen daher große Hoffnungen in bezug auf die Zukunft der cigenen Erzgruben zusammen. Diese Hoffnungen wurden getäuscht. Sehr bald ließ die Ergiebigkeit der Bergwerke nach. Im Geschäftsbericht über das Jahr 1885/86 wird bereits konstatiert, daß ,das früher sehr reichhaltige und wertvolle Vorkommen von Eisenstein auf der Grube Reinhardt in großer Teufe allmählich vollständig in Kalk übergeht, so daß die Außerbetriebsetzung derselben in Aussicht genommen ist." Ähnlich verhielten sich in der Folgezeit die anderen Gruben.

Die nächste Folge der allmählichen Verarmung der Union an dem wichtigsten Rohstoff war nun der Zukauf neuer Zechen. Im nächsten Jahre wird die Zeche Brockhauser Tiefbau zum Preise von 300000 Mark erworben. 1887 kauft die Union die bei Bückeburg gelegene Eisensteingrube Wohlverwahrt, von der sie schon früher die speziell für ihren Betrieb geeigneten Erze ankaufsweise bezogen hatte. 1888 geht die mit der zuletzt genannten marktscheidende Grube Viktoria in den Besitz der Union über. Der Kaufpreis für beide betrug 424000 Mark. Als Motiv für die Erwerbung wird folgendes angeführt (1887/88): „Bei der in absehbarer Zeit zu erwartenden Erschöpfung der Rasenerzfelder im nördlichen Deutschland und in Holland, und angesichts der von Jahr zu Jahr sich steigernden Schwierigkeiten, welche sich der ausreichenden Beschaffung von Puddelschlacke und anderen für die Herstellung von Thomaseisen brauchbaren Materialien entgegenstellen, war es notwendig, die Roheisenfabrikation, die während der letzten Jahre durch die Ausrüstung der Hochofenwerke mit den besten technischen Einrichtungen auf die Höhe der Zeit gebracht worden war, bezüglich der erforderlichen Erze möglichst unabhängig von den Schwankungen der Konjunktur zu machen." Später wird dann eine Minette Konzession in Lothringen erworben. Ein Teil derselben wird jedoch 1896 wieder verkauft, und zwar mit einem Gewinn von $3 / 4$ Millionen Mark. Dieser Gewinn wurde allerdings durch die Zubußen ab- 
sorbiert, welche, wie wir später sehen werden, für die Gewerkschaft Mengeder Steinkohlenbergwerk aufzubringen waren. Heute hat die Union die Mehrheit der Kuxe des Minette Grubenfeldes ver. Empel, aber es ist bisher nicht in Betrieb genommen worden, da, wie es im Geschäftsbericht 1902/03 heißt, ,es möglich war, den Erzbedarf anderweitig zu günstigen Preisen zu decken", mit anderen Worten, weil der Bezug aus Lothringen zur Zeit noch zu teuer ist.

Der Schwerpunkt der Erwerbungen liegt, wie aus der bisherigen Darstellung hervorgeht, in der zweiten Hälfte der 80er Jahre. Aber auch diese Neuerwerbungen hielten nicht, was sie versprachen. In der Blüteperiode von 1895 bis 1900, wo die gesamte Eisenproduktion ein beschleunigteres Tempo annahm, konnte der Eisensteinbergbau der Union mit einer wesentlichen Zunahme nicht rechnen. Eine Steigerung der Förderung wurde nur auf den Wesergruben erzielt: „Auf den Bredelarer Gruben“, heißt es in dem Bericht über das Jahr 1899/1900, ,haben sich die Verhältnisse während der letzten Jahre so ungünstig gestaltet, daß der Betrieb Zubuße forderte, und die Außerbetriebsetzung in Erwägung gezogen werden muß." In der Krisenperiode verschlechtern sich die Verhältnisse noch mehr. Der Geschäftsbericht für das Jahr 1902/03 läßt an Pessimismus nichts zu wünschen übrig. Er konstatiert, daß die Eisensteingruben einen Verlust von 151251 Mark ergaben. Über die einzelnen Gruben wird folgendes mitgeteilt: Auf der Grube Charlottenburg bei Bredelar, welche allein von den dort gelegenen Gruben noch betrieben wurde, mußte der Betrieb wegen Erschöpfung der Erzlager eingestellt werden. Dasselbe Schicksal wird die Grube Martha bei Philippstein ereilen, und zwar nach Räumung des etwa 9000 Tonnen betragenden Lagers an Eisenstein, das in der Hauptsache schon verkauft ist. Auf Grube Friedrich bei Wissen, die nur noch allein im stärkeren Maße im Betriebe war, wurden gefördert 13502 Tonnen mit einem Verlust von 29601 Mark. Dieser Verlust hängt damit zusammen, daß der Verkaufswert der Produkte dieser Grube von 18,83 Mark auf 13,21 Mark pro Tonne zurückging. Über die schon erwähnte Grube Viktoria heißt es: „Die genauen Untersuchungen unserer Wesergruben haben ergeben, daß die unterirdischen Verhältnisse der Grube Viktoria andauernd so ungünstige sind, daB sich der Abbau vorläufig nicht mehr lohnt. Der Betrieb auf dieser Grube ist deshalb vollständig eingestellt worden". Auf der Grube Wohlverwahrt hatten die Untersuchungen zwar ein besseres Ergebnis, aber die Förderung betrug 1902/03 nur 9226 Tonnen gegen 25570 
Tonnen im Vorjahre. Als Resultat ergibt sich ein permanentes Zurückgehen der Eisenerzförderung und damit im Zusammenhange eine große Wertverminderung der Erzbergwerke. Es sei hier nur auf die riesigen Abschreibungen verwiesen, die nach der finanziellen Rekonstruktion im Jahre 1896/97 vorgenommen wurden. Für diese Abschreibungen war ein Buchgewinn von 191/2 Millionen Mark disponibel. Davon wurden auf den Eisensteinbergbau nicht weniger als 8 Millionen Mark abgeschrieben, so daB er in der Bilanz vom 30. Juni 1897 nur noch mit 2,7 Millionen Mark figuriert, während er sich auf der vorjährigen Bilanz auf 10,7 Millionen Mark bezifferte. In der Generalbilanz vom 30. Juni 1903 erscheint der Eisensteinbergbau nur noch mit 1,4 Millionen Mark bewertet.

Aber die Förderung aus den eigenen Gruben hat nicht nur stark nachgelassen, sondern das Erz, das sie liefern, ist auch ein wenig reichhaltiges. Es enthält nur etwa $38 \%$ Eisen. Das ist verhältnismäBig wenig. Ein Erz von unter 30\% Eisengehalt hat unter Umständen kaum Aussicht, überhaupt noch verarbeitet $\mathrm{zu}$ werden. Infolge dieses geringen Eisengehaltes sind die Produktionskosten des daraus erblasenen Roheisens sehr hohe. Die geringe Ergiebigkeit der eigenen Erzgruben sowie der ungenügende Eisengehalt bedingen nun kategorisch die Notwendigkeit, die Herstellung von Roheisen auf fremde, das heißt zugekaufte Erze zu basieren. Die Union verarbeitete in den letzten Jahren bereits über $90 \%$ fremder Erze, von denen der größere Teil aus dem Auslande stammt. Es werden Erze mit $62-68 \%$ aus Schweden bezogen, ferner aus Spanien und Afrika, auch griechische Manganerze werden je nach den Marktverhältnissen angekauft. Die Aufträge werden einer westfälischen Transportgesellschaft erteilt, die in Emden die fremden Erze von den Dampfern in Empfang nimmt. Nach den mir von der Verwaltung gemachten Angaben werden im ganzen jährlich verhüttet 720000 Tonnen Erz. Davon sollen 360000 Tonnen aus dem Auslande, 240000 Tonnen aus fremden inländischen und 120000 Tonnen aus eigenen Gruben stammen. Die letztere Zahl ist aber ohne Zweifel zu hoch gegriffen, denn die Gesamtförderung der Union betrug im Jahre 1901/02 56593 Tonnen, und im folgenden Geschäftsjahre sogar nur noch 29111 Tonnen. Der Anteil der aus den eigenen Gruben geförderten Erze an dem Gesamtverbrauch betrug danach, wenn der letztere richtig angegeben ist, im Jahre 1902/03 nur ca. 4\%. Für die Beurteilung der Lage eines Unternehmens ist es natürlich von groBer Wichtigkeit, das Verhältnis der selbstgewonnenen und der zugekauften 
Erze genau zu kennen. Über diesen wichtigen Punkt aber schweigen sich die Geschäftsberichte beharrlich aus, und auch die Verwaltung behandelt die Sache wenigstens öffentlich als Geheimnis. Die erwähnten Zahlen sind natürlich nur approximativer Natur. Aber es geht aus ihnen deutlich hervor, da $B$ der Union heute die eigene Grundlage für ihre Produktion fehlt, nämlich das Eisenerz. Die himbeerroten Manganerze aus Südspanien, die mitunter von blauen Kristallen überzogenen Gellivaraerze aus Schweden, sowie die anderen in großen Massen auf dem Lagerplatze der Union aufgestapelten Eisenerze sind ein Beweis dafür, daß die Verarbeitung fremder Erze die Oberhand gewonnen hat. Was die Rohstoffpolitik der Union zu erreichen suchte: Unabhängigkeit von den Schwankungen der Konjunktur, hat sie nicht erreicht. Dabei darf man aber zweierlei nicht übersehen. Einmal ist wegen der hohen Produktionskosten der Erzförderung in den eigenen Gruben, bezogen auf die Tonne Roheisen, der Bezug vom Auslande immer noch billig zu nennen. Allerdings ist hier von Fall zu Fall der Weltmarktpreis ausschlaggebend. Das Werk hat daher versucht, sich namentlich schwedische Erze für eine längere Reihe von Jahren durch Vertrag zu sichern. Die Erzpreise werden dabei nach Maßgabe der Roheisenpreise bemessen. Zugrunde liegt das Prinzip der gleitenden Skala. Andererseits befinden sich die meisten Hüttenwerke des westfälischen Bezirks in ganz ähnlicher Lage. Sie alle haben mehr oder weniger nicht genügend eigenes Erz, um ihre Hochöfen damit vollständig zu befriedigen. Freilich ist auch in dieser Beziehung die Union besonders ungünstig daran, weil, wie wir sahen, der Anteil an der Versorgung der Hochöfen mit eigenem Eisenerz nur noch $4 \%$ beträgt, andererseits, weil der selbstgewonnene Rohstoff wenig Eisen enthält.

Der zweite wichtige Hilfsstoff für den Hochofen- und Hüttenbetrieb ist die Kohle. Heute hat die Union im Gegensatz zu dem Defizit an Eisen ein Plus an Kohlen. Sie setzt einen Teil derselben an Fremde ab. Die Förderung belief sich 1902/03 auf 602812 Tonnen, nach Abzug des Selbstverbrauchs der Zechen auf 575922 Tonnen mit einem Gesamterlös von 5,7 Millionen Mark. Die Hauptmasse bildet die sogenannte Förderkohle. Es ist das eine minderwertige Kohle, die einen niedrigen Preis hat. Aus diesen Förderkohlen werden durch Waschen und Sortieren die hochwertigen 
Kohlen gewonnen. Von diesen hochwertigen Kohlen wird ein Teil an das Rheinisch-Westfälische Kohlensyndikat verkauft, da sie sich in den großen Sortimenten nicht zur Verkokung eignet; infolgedessen müssen andererseits noch Koks zugekauft werden, 1902 allein für das Dortmunder Werk 80000 Tonnen. Das Werk bleibt also auch auf diesen Gebiet von der Marktlage beeinfluBt. Seine Lage wird demnach mitbestimmt durch den Kohlenüberschuß im allgemeinen und durch den Mangel an Kokskohle im speziellen.

Dic Geschichte der Kohlenversorgung der Union läßt sich nur mit großen Schwierigkeiten in den wichtigsten Punkten zusammenstellen. Wenn wir in die Vergangenheit des Unternehmers zurückblicken, so sehen wir von vornherein in scharfen und klaren Umrissen das Streben nach Selbstversorgung auftauchen. Es wird zu erreichen gesucht zunächst nicht durch Erwerbung neuer Kohlengruben, sondern durch Steigerung der Produktion der vorhandenen. Allerdings machten hier die Tatsachen einen Strich durch die Rechnung. In dem ersten Geschäftsjahre betrug die gesamte Kohlenförderung der Union annähernd ebensoviel wie heute, nämlich 577465 Tonnen mit einem fakturierten Geldbetrage von etwas über $6 \mathrm{Mill}$. Mark. In dem Geschäftsbericht über das Jahr 1873/74 wird erwähut, $\mathrm{da} B$ die Union nur zwei Drittel ihres Kohlenbedarfs aus eigenen Zechen decken könne. In der Folgezeit ging dann die Förderung beträchtlich zurück. Sie betrug 1879/80 228651 Tonnen, stieg dann mit vielen Schwankungen bis auf 374178 Tonnen im Jahre 1887/88, um dann bis zum Schluß des Jahrhunderts sich wenig über 300000 Tonnen zu erheben. Erst 1902/03 erreichte die Förderung die Höhe von 602812 Tonnen.

Die beiden Zechen, die die Únion bereits bei ihrer Gründung mit übernahm, sind noch heute in ihrem Besitz. Zunächst die Zeche Glückauf Tiefbau bei Barop. Ihre Entwicklung zu verfolgen ist leider nicht möglich. Heute steht sie mit ca. 4,9 Millionen Mark zu Buch. Im Geschäftsbericht 1902/03 heißt es: „Das im Bericht des Vorjahres erwähnte ungünstige Flötzverhalten hat auch im verflossenen Jahre den Betrieb nachteilig beeinfluBt. Dazu kam, daß die vorhandenen Tagesanlagen den Anforderungen eines modernen Betriebes immer weniger genügten. Infolgedessen sind nicht nur die Selbstkosten weiter gestiegen, sondern es ist auch eine Erniedrigung der Verkaufspreise für Kohlen und Koks eingetreten." Daran knüpft der Bericht die Hoffnung, daß diesem Übelstande bald durch die Fertigstellung der neuen Wäsche und Separation, der im Bau be- 
griffenen Koksöfen und der elektrischen Bahn zwischen den beiden Förderschächten abgeholfen werden wird. Die zweite der Union gehörende Kohlengrube Karl Friedrich bei Weitmar, die mit ca. 3 Millionen Mark auf dem Anlagekonto zu Buche steht, hat heute ebenfalls unzureichende Tagesanlagen, die die wirtschaftliche Weiterentwicklung der ganzen Grube empfindlich schädigen. Das Ergebnis im Jahre 1902/03 war ein Verlust von 12546 Mark.

Diese Zechen allein aber genügen nicht. Daher beteiligte sich die Union anfangs der 90er Jahre noch bei einer benachbarten Kohlenzeche und sicherte sich eine bis 1. Juli 1904 laufende Option. Nachdem dann vielfach die Verhältnisse der Flötze sich verschlechterten, werden 1897/98 3 neue Gruben erworben: Storksbank, Wilhelmine und Venus. Auf der bei Mengede gelegenen Zeche Adolf von Hansemann beteiligte sich die Union mit 501 Kuxen, d. h. mit 1753500 Mark, da der Kux mit 3500 Mark bezahlt wurde. Dieser Erwerb erforderte aber anfangs große Zubußen. Trotzdem setzte man von seiten der Verwaltung auf diese von der Diskontogesellschaft übernommene Zeche große Hoffnungen. Projektiert war eine Förderung von 2000 Tonnen täglich! Allerdings war die Vergangenheit der Zeche keine makelfreie. Schon vor einer Reihe von Jahren ersoff bei dem Versuch des Abteufens ein Schacht, der auf der. Zeche niedergebracht werden sollte, so daß die dafür verwendeten $31 / 2$ Millionen Mark verloren waren. Das war bereits ein böses Omen. Anfangs Januar 1901 nun meldete die Rheinisch-Westfälische Zeitung, daß die Zeche Adolf von Hansemann infolge von Undichtigkeit der Picotagen durch Wasserzuflüsse derart belästigt werde, daß wiederholt Feierschichten eingelegt werden mußten. Das Wasser sei so stark aufgetreten, da $B$ die Pferde in Sicherheit gebracht werden mußten. Über das Ersaufen dieses Schachtes enthält dann der Geschäftsbericht der Union 1901/02 folgende interessante Einzelheiten: „Infolge eines Wasserdurchbruchs in Schacht II der Zeche wurde die Dampfleitung zu der an diesem Schacht liegenden unterirdischen Wasserhaltungsmaschine beschädigt. Die Maschine konnte nicht weiter betrieben werden, und das Wasser stieg in beide Schächte bis über den $440 \mathrm{~m}$ tief liegenden Hauptquerschlag. Bei den Versuchen, die Undichtigkeit in Schacht II zu beseitigen, entstand durch Unvorsichtigkeit der mit dieser Arbeit betrauten Bergleute eine Explosion schlagender Wetter, wodurch ein Teil der Schachtzimmerung beschädigt, 2 Bergleute getötet und die Wasserförderung mit Kästen in diesem Schacht zunächst unmöglich gemacht wurde. Da diese 
Katastrophe gerade in die Zeit der stärksten Wasserzuflüsse fiel, so stieg das Wasser in den Schächten rasch auf, so daB sämtliche Baue unter Wasser standen. Nur nach unsagbaren Mühen und Anstrengungen und durch monatelange unausgesetzte Inanspruchnahme aller maschinellen Kräfte, die für die Wasserförderung zur Verfügung standen, war es endlich am 5. Mai 1901 gelungen, die Fördersohle und den Maschinenraum für die unterirdische Wasserhaltung wieder trocken $\mathrm{zu}$ legen. Die nach Inbetriebsetzung der Wasserhaltungsmaschinen sofort aufgenommenen Räumungsarbeiten in den Schächten, Querschlägen und Strecken zeigten eine starke Beschädigung dieser Baue." Der Schaden, der durch das Wasser verursacht wurde, belief sich auf 700000 Mark. Diese Summe wurde von der Diskontogesellschaft übernommen. Die Union hätte sie auch gar nicht bestreiten können. Durch diesen Wassereinbruch wurde der Betrieb um mehr als ein Jahr zurückgesetzt. Die neuen Wasserhaltungsmaschinen mit elektrischem Antriebe bemächtigten allerdings das Wasser; sie hoben $11 \mathrm{cbm}$ in der Minute, während der ZufluB nur 2,5-3 cbm betrug. Allerdings blieb infolge der geschilderten Verhältnisse die Förderung weit hinter der projektierten von 2000 Tonnen zurück. Sie betrug 1900/01 600 und im folgenden Jahre 900 Tonnen pro Arbeitstag. Mit dem Hereinbruch der Krisis wird daher der Plan erwogen, die Zeche Adolf von Hansemann abzustoßen. Sie sollte zum Buchwerte von 16,8 Millionen Mark verkauft werden. In der außerordentlichen Generalversammlung vom 9. Juni 1902 entschied man sich jedoch, um die Mittel aufzubringen, für Zuzahlungen auf die Vorzugsaktien. Im Jahre 1902/03 haben sich die Verhältnisse etwas gebessert. Die Förderung stieg von 138499 Tonnen auf 265301 Tonnen, das Erträgnis von 344195 auf 607297 Mark.

Die vorhergehenden Bemerkungen zeigen zunächst, daB die Verhältnıse der Union in bezug auf den Kohlenbergbau allerdings etwas günstiger liegen wie bei dem Eisensteinbergbau, daß sie sogar imstande ist, Kohlenzuverkaufen. Man darf dieses Moment aber nicht überschätzen, denn nur ein Teil der geförderten Kohle eignet sich zur Verkokung, und die noch fehlenden Kohlen resp. Koks müssen angekauft werden. Die wirtschaftlichen Verhältnisse der drei Zechensind als günstignichtzubezeichnen trotzder entgegengesetzten Meinung der Geschäftsberichte. So 
vertritt der Bericht des Jahres $1902 / 03$ folgende optimistische Auffassung: „Eine weitere Besserung der Lagedes Gesamtunternehmenserwarten wir a us der vollen Entwicklung unseres Kohlenbergbaus. Eingehende Untersuchungen haben ergeben, daß mit einem so bedeutenden Kohlenreichtum unsererdrei Zechen zu rechnen ist, daB bei ordnungsmäBigem A b baueineerheblicheSteigerungderFörderungund somitein Sinkender Selbstkostenundeine Erhöhung des Reingewinns zuermöglichen sein wird."Schlie Blich darf nicht übersehen werden, daB die Zechenanlagen mit dem hohen Betrag von 23,2 Millionen Mark zu Buche stehen, während die Eisensteingruben bis a uf $1,4 \mathrm{Millione} M \mathrm{Mark}$ heruntergeschriebensind. In diesen Verhältnissen liegtein weiteres, das Unternehmen gefährdendes Element.

Nachdem wir im Vorhergehenden die natürlichen Grundlagen erörtert haben, gehen wir nunmehr dazu über, in das Wesen des Betriebes selbst näher einzudringen. Der Grundgedanke bei der Bildung der Union war, wie ja auch der Name andeutet, die Vereinigung. Mehrere verschiedene Betriebe wurden zu einem Ganzen kombiniert. Sie sollten 1 . sich gegenseitig ergänzen und unterstützen, 2. Spezialitäten erzeugen, um so das ganze Unternehmen elastisch über schwere Geschäftszeiten hinwegzuführen. Durch die Zusammenlegung einzelner Werkskomplexe sollte ein Riesenunternehmen geschaffen werden, das, wie es im Prospekt heißt, ,an Größe des Ziels fast ohne Beispiel" möglichst alle Zweige der Eisenindustrie umfassen und gleichzeitig in der Lage sein sollte, die notwendigen Rohmaterialien und Halbfabrikate selbst zu erzeugen.

War diese Kombination mit ihren Zielen richtig? Das haben wir jetzt zu untersuchen.

Der Gedanke der Spezialisation war ursprünglich noch nicht im größeren Maßstabe durchgeführt. Die Walzwerke der drei in Betracht kommenden Unternehmungen basierten in der Hauptsache auf der Schienenfabrikation. Dann wirden neue Walzwerksanlagen geschaffen und damit ,die Grundlage für den Spezialitätenbetrieb gelegt nach dem Vorbilde des Auslandes." Auch der Hochofenbetrieb wurde ausgestaltet. „Gestützt auf den Kohlen- und Eisensteinbergbau“, heißt es in dem ersten Geschäftsbericht, „wird die 
Roheisenproduktion der Union vermittels 15 großer Kokshochöfen und 3 Holzkohlenhochöfen erfolgen und somit der Hochofenbetrieb der bedeutendste in einer Hand vereinigte des Kontinents sein." Es kann nun an dieser Stelle nicht meine Aufgabe sein, die geschichtliche Entwicklung der Produktion zu skizzieren - das Wesentliche darüber wird im nächsten Abschnitt behandelt werden - sondern hier kommt es lediglich darauf an, die ungeheure Vielseitigkeit der Produktion zu illustrieren, und daher bitte ich den Leser mit mir im Geiste einen Gang durch die Betriebe der zur Union gehörigen Werksanlagen zu machen.

Wir sehen da zunächst auf dem Dortmunder Werke folgendes:

1. Ein Hochofenwerk mit 5 Hochöfen und 102 Koksöfen. Jährliche Leistungsfähigkeit*) 300000 Tonnen Roheisen und 80000 Tonnen Koks.

2. Ein Stahlwerk mit 4 Convertern à 16 Tonnen, 4 SiemensMartinöfen à 25 Tonnen Fassung, 1 Tiegeischmelzofen, 1 Schmelztiegelfabrik und 1 Fabrik für feuerfeste Steine. Jährliche Leistungsfähigkeit: 300000 Tonnen Thomasstahlblöcke, 82000 SiemensMartinstahlblöcke und 3600 Tonnen Tiegelgußstahl.

3. Ein Walzwerk zur Herstellung von Schienen, Schwellen, Bandagen, Trägern, Unterlagsplatten, Laschen etc. Jährliche Leistungsfähigkeit 180000 Tonnen Walzfabrikate.

4. Ein weiteres Walzwerk mit 18 Puddelöfen zur Herstellung von Handelseisen. Jährliche Leistungsfähigkeit 96000 Tonnen Walzfabrikate.

5. Ein Hammerwerk mit 6 Dampfhämmmern und 5 Gaswärmöfen zur Herstellung von Achsen, Bandagenringen, Radscheiben, Façonstücken. Jährliche Leistungsfähigkeit 15600 Tonnen.

6. Eine Stahlformgießerei. Jährliche Leistungsfähigkeit 5000 Tonnen Stahlfaçonguß.

7. Eine elektrische Zentrale für Kraft und Licht mit 7 Dampfdynamomaschinen von zusammen 1624 Pferdekräften.

8. Eine Brückenbauanstalt mit 86 Werkzeugmaschinen. Jährliche Leistungsfähigkeit 20000 Tonnen.

*) Es handelt sich hier nur um die technisch mögliche Leistung, nicht aber un die wirkliche Leistung, die hauptsächlich durch ökonomische Momente bestimmt wird. - Die diesbezüglichen Angaben über die einzelnen Abteilungen entnehme ich einer von der Verwaltung anläßlich des Besuchs Seiner Majestät des deutschen Kaisers am 11. Aug. 1899 gemachten Zusammenstellung über den Umfang und die Betriebe der zur Union gehörigen Werke. 
9. Eine Weichenfabrik mit 27 Werkzeugmaschinen. Jährliche Leistungsfähigkeit 3800 Weichen.

10. Eine Achsen- und Räderfabrik mit 28 Schmiedefeuern, 5 Dampfhämmern, 5 Dampfmaschinen und 92 Werkzeugmaschinen zur Herstellung von Lokomotiv- und Waggonradsätzen. Jährliche Leistungsfähigkeit 10000 Tonnen.

11. Eine mechanische Werkstatt mit 52 Werkzeugmaschinen zur Herstellung von Coquillen für Stalılguß, Walzen und anderen Gußstücken. Die mechanische Werkstatt dient auch als Reparaturwerkstätte.

12. Eine Eisenbahnwagenfabrik mit 45 Werkzeugmaschinen zur Herstellung von Güterwagen sowie von Personenwagen III. und IV. Klasse. Jährliche Leistungsfähigkeit 1000 Eisenbahnwagen.

13. Eine Schiffsbauanstalt, hauptsächlich zur Herstellung von Kanalschiffen, Seekähnen, Prähmen und Pontons.

Auf der Henrichshütte finden wir eine Hochofenanlage mit zwei Hochöfen, eine elektrische Licht- und Kraftanlage, ein Puddel- und Walzwerk, das letztere namentlich zur Herstellung von Winkeleisen und Blechen, eine GieBerei und mechanische Werkstätte, sowie folgende Betriebe, die wir in Dortmund nicht sahen, und die daher hier in laufender Nummer Platz finden:

14. Eine Röhrenfabrik zur Herstellung von geschweißten Röhren, z. B. Gasröhren, Brunnenröhren, Siederöhren, Heizröhren etc. Jährliche Leistungsfähigkeit 6000 Tonnen stumpfgeschweißte und 5000 Tonnen überlappt geschweißte Rohre.

15. Eine Wagenfabrik zur Herstellung von Förderwagen für Kohlen etc.

16. Eine Faßfabrik zur Herstellung von Petroleumfässern etc. Jährliche Leistungsfähigkeit 850000 Gefäßliter.

17. Eine Verzinkerei mit 2 Zinkkesseln, vollständiger Feuerungsanlage und Beizkessel. Jährliche Leistungsfähigkeit 3600 Tonnen verzinkte Waren.

Schließlich weist das Horster Eisen- und Stahlwerk außer einer Hochofenanlage mit 2 Hochöfen und 80 Koksöfen, einem Façoneisenwalzwerk und einer Achsenfabrik

18. eine Schraubenfabrik zur Herstellung von Bolzen, Schrauben und Muttern auf.

Diese Aufzählung mag eine Vorstellung von der Vielseitigkeit und Mannigfaltigkeit der Produktion geben. Ihr Schwerpunkt liegt - und das geht weiter aus dieser Darstellung hervor - in Dortmund. 
Hier konzentriert sich heute fast die ganze Produktivkraft des Gesamtunternehmens. Das ist ein auBerordentlich wichtiger Punkt. Die Entwicklung der Produktion führt - das läßt die Vergangenheit deutlich erkennen - zu einer Stärkung des Dortmunder Werks und zu einer Schwächung der mit ihm vereinigten Betriebe. Die ganze Geschichte der Dortmunder Union ist ein schlagender Beweis dafür, da $B$ sich die Angliederung des Hattinger und Horster Werks nicht bewährte. Beide Werke treten im Laufe der Zeit in bezug auf ihre Produktivität immer stärker zurück.

Die ungünstigen Resultate, welche die Aglomerationspolitik der Gesellschaft herbeiführte, treten namentlich auch in den Abstoßungen zu Tage, die die Union überall da vornahm, wo sie konnte. Der Abstoßung der Svabenswerke in Schweden haben wir an anderer Stelle bereits gedacht. 1883/84 wurde die Hochofenanlage bei Othfresen, die bereits seit Jahren kalt gelegen hatte, verkauft, weil keine Aussicht vorlag, sie in absehbarer Zeit wieder in Betrieb zu setzen und infolgedessen der Besitz für die Union unrentabel war. Der größte Teil des Hüttenareals wurde von der Zuckerfabrik in Othfresen für den Preis von 200000 Mark erworben. 1885 ging das Gut Bredelar in andere Hände über und zwar für 400000 Mark. „Wenngleich dieser Preis", heißt es im Geschäftsbericht $1884 / 85$, ,gegen den verbliebenen Buchwert des Gutes und der mit einem Holzkohlenhochofen verbundenen Gießerei einen erheblichen Ausfall ergab, so haben wir doch zu demselben uns entschließen müssen, weil unter den gegenwärtigen Verhältnissen an eine Fortsetzung oder spätere Wiederaufnahme des Fabrikbetriebes an jener Stelle nicht gedacht werden kann, und weil der landwirtschaftliche Ertrag des Gutes außer Verhältnis mit der Zinsersparnis steht, welche wir durch die Verwendung des Kaufpreises zur Schuldentilgung erzielen." Schließlich sei noch das auf der Fabrikation von Handelseisen beruhende Aplerbecker Walzwerk erwähnt, das die Union in ihrem Drange nach kapitalistischer Ausdehnung der Produktionsmittel in Pacht genommen hatte. Die Einrichtungen dieses Werkes waren in den 90er Jahren veraltet und für die Verarbeitung von Flußeisen, auf die die Union der Not gehorchend, nicht dem eigenen Triebe, immer mehr angewiesen war, unbrauchbar. 1895 wurde der Betrieb eingestellt, weil die Fortführung desselben zu große Opfer verlangt hätte, und der mit dem 30. Juni ablaufende Pachtvertrag nicht mehr erneuert. Die Abstoßung dieser 4 Komplexe sollte, auch wenn das von der Verwaltung nicht direkt ausgesprochen wird, den ganzen Organismus gewissermaßen ent- 
lasten. Heute würde es weiter eine Erleichterung für die Union bedeuten und mit Freuden begrüßt werden, wenn auch die beiden anderen Werke, die Henrichshütte und das Horster Unternehmen wenigstens zum Buchpreise losgeschlagen werden könnten. Um das richtig zu verstehen, müssen wir uns die Verhältnisse beider Werke etwas genauer ansehen. Sie sind beide vernachlässigt auf Kosten der Ausgestaltung der Dortmunder Anlage. Ihre Aschenbrödelrolle aber ist das äußere Symptom ihres Verfalls sowohl in technischer, als auch in ökonomischer und finanzieller Beziehung.

Wir beginnen mit der Henrichshütte.

Einige $30 \mathrm{~km}$ von Dortmund entfernt erheben sich aus dem romantischen Gebirgstale der Ruhr die Hochofenanlagen und Schornsteine der Henrichshïtte, eines Unternehmens, das auf eine reiche Vergangenheit zurückblickt, die mit der Geschichte des Flusses im Zusammenhange steht, der noch heute an ihr vorüberrauscht. Der Grundgedanke bei ihrer Errichtung in den 20er Jahren des verflossenen Jahrhunderts war, die nötigen Rohmaterialien und Fabrikate auf dem Wasserwege zu transportieren. Damals gab es noch keine Eisenbahnen. Die Ruhr war ein schiffbarer FluB, und auf der Schiffbarkeit der Ruhr lag die Hoffnung auf die zukünftige Größe des Werkes begründet. Als dann die Eisenbahnen in jener Gegend aufkamen, waren die kleinen Schiffer der Ruhr gegenüber dem großen Transportunternehmen nicht mehr konkurrenzfähig. Sie steliten zum großen Teile die Schiffahrt ein, und langsam begann im Laufe der Zeit der Fluß zu versanden. So war die eine große Unterlage der Hoffnungen, die man auf sie gesetzt, geschwunden. Die Hütte wurde, dann am 1. März 1857 von dem Grafen Stolberg-Wernigerode, der sie zuerst besessen, an die Diskontogesellschait für ca. $1^{3}$, Milionen Ta'er verkauft. Diese behielt das Unternehmen im Alleinbesitz bis zum Jahre 1863, dann wurde es von der Diskontogesellschaft losgelöst und in eine Kommanditgesellschaft verwandelt. Dadurch wurde die Bank von einem Unternehmen unabhängig, das, wie Hansemann selbst zugab, „eine Fessel für die Zukunft war. “*) 1869 wurde es dann in eine reine Aktiengesellschaft umgewandelt. Allerdings beruhte damals der Hochofenbetrieb der Henrichshütte noch auf eigenem Kohlenbergbau und der Förderung eines vorzüglichen Spateisensteins. Aber der letztere

-) Siehe Model: Die großen Berliner Effektenbanken, Jena 1896, p. 21. 
hielt nicht lange vor, und so schwand auch diese Grundlage der früher auf sie gesetzten Erwartungen.

Dazu kam, daß die großen technischen Neuerungen, die vor allem auf eine völlige Automatisierung des Betriebes hinausdrängten, nur wenig Eingang fanden. Heute erinnert der Habitus des Werkes an eine vergangene Zeit. Die neuen Methoden der Eisenindustrie haben hier noch nicht Wurzel geschlagen. Die menschliche Arbeitskraft spielt noch eine überwiegende Rolle, jedenfalls aber eine größere als in dem modern eingerichteten Werke in Dortmund. Das zeigt sich bereits bei den Hochöfen. Die Henrichshütte hat ihrer zwei : einen großen neuen, der errichtet wurde an Stelle des vor einigen Jahren durch eine Explosion zerstörten alten. Der erstere soll 200 Tonnen Roheisen täglich produzieren. Daneben aber erhebt sich der kleinere alte unmoderne, von einem Mauerwerk umgebene, der es täglich nur auf eine Roheisenproduktion von 120 Tonnen bringt. Die Begichtung dieser Hochöfen erfolgt durch Hängebahnwagen. Eine große Anzahl von Schleppern ist nötig, um die Wagen zu füllen. Steigt man auf den Hochofen hinauf, so sieht man eine Winde, die 4-6 Mann zu drehen haben, um die Glocke in die Höhe zu ziehen. Anderwärts besorgt eine elektrische Winde, was hier noch die Menschenhand vollführt. Durch veraltete Gebläsemaschinen wird der Wind durch die Öfen getrieben. Das Roheisen flieBt dann in eine Gießhalle, erstarrt dort und wird in mühsamer Handarbeit zerschlagen, um dann zum kleineren Teile nach Dortmund gesandt, zum größeren aber verkauft zu werden, denn die Henrichshütte besitzt kein Stahlwerk. Bessemer- und Thomasbirnen wird man darin vergeblich suchen. Hätte sie diese Anlagen, so könnte das Roheisen gleich im flüssigen Zustande in die Pfanne und von da in die Birnen gegossen werden. Weil sie aber fehlen, muß das erblasene Roheisen, das in Hattingen verarbeitet werden soll, nach dem Dortmunder Werk geschickt und dort erst in FluBeisen verwandelt werden, um dann wieder nach der Henrichshütte zur Weiterverarbeitung zurückzukehren. In folgedessen wird der Weg, den das Produkt vom Roheisen bis zum Fabrikat durchläuft, starkverlängert. Das Fehleneines Stahlwerkes ist daher das bedenklichste Moment in der Ökonomie des ganzen Betriebes. Es verteuert die Fabrikation, und nicht immer läßt sich dieser Mehraufwand durch den Ertrag des verkauften Roheisens ausgleichen. Allerdings hat die Henrichshütte, wie wir noch sehen werden, einmal ein Stahl- 
werk gehabt. Es kam aber anfangs der 80er Jahre definitiv außer Betrieb und wurde nach Dortmund verlegt. Nur der alte, ehrwürdige, wenig rentable, für die Massenfabrikation nicht brauchbare Puddelbetrieb hat sich erhalten. Hier wird Tag und Nacht in zivölfstündiger Schicht gearbeitet. 1902/03 lieferte das Puddelwerk 16314 Tonnen Luppen. Auch die Gießerei hat veraltete Einrichtungen, alte Kräne etc. Überhaupt ist die mechanische Beförderung von Lasten nicht auf der Höhe der Zeit. Bei modern eingerichteten Profileisenstraßen braucht man fast keinen Menschen. Auf dem Walzwerk der Henrichshütte aber muß Menschenkraft verrichten, was auf anderen Werken ihr längst abgenommen ist. So laufen z. B. die großen glühenden Bleche nicht über Rollgänge, sondern werden von den Arbeitern fortgeschleppt. Dazu sind für jedes Blech etwa 8 Personen nötig. Natürlich hängt die Zahl von der Größe und Beschaffenheit des zu transportierenden Gegenstandes ab. Erst im Jahre 1902/03 erhielt die Reversierstraße einen großen Rollgang. In dem Duo-Walzwerke wird in anderen Betrieben der Stab beim Vorstich und Rückstich gewalzt, auf der Henrichshütte aber wird der Stab wieder zurückgeschoben, ohne daß Arbeit an ihm verrichtet wurde. Die Maschine leistet in dieser Zeit keinen Nutzeffekt. Die Vergeudung an Kraft tritt an Stelle ihrer Ausnutzung. So ließen sich noch viele Beispiele für die kümmerliche Entwicklung des mechanischen Betriebes anführen, der auf anderen Werken den Produktionsproze $B$ erleichtert und verbilligt.

Wir haben bisher gesehen, daß die Bedeutung des Hattinger Werkes abgeschwächt wurde 1. durch die Ungunst seines geschichtlichen Schicksals, 2. durch seine Vernachlässigung in bezug auf technische Ausgestaltung, 3. durch das Fehlen notwendiger Produktionsmittel, vor allen Dingen eines Stahlwerks. Dazu kommt noch ein vierter Punkt, nämlich der häufige Wechsel des Fabrikationsprogramıns. Diesen letzten Punkt haben wir nun noch kurz zu betrachten. Die Henrichshütte basierte ursprünglich auf der Massenfabrikation von Eisenbahnschienen. Nur nebenbei war sie auch für die Blechfabrikation eingerichtet. Während der Krisis der 70er Jahre wurde dann die Schienenfabrikation verlassen und das Werk zur ausschließlichen Herstellung großer Quantitäten von Qualitätsblechen ausgerüstet. Aus dem Schienen- wurde ein Blechwalzwerk. In dieser Zeit hatte sie auch vorübergehend eine Geschoßfabrik in Betrieb. 1875/76 stellte sie 109632 Stück diverse Geschosse her. Der Betrieb wurde jedoch wegen Mangel an Aufträgen wieder eingestellt. 
Als Ersatz für diese Einstellung erfolgte eine Ausdehnung des Gießerei- und des mechanischen Werkstättenbetriebes. 1880/81 wurde dann die Einrichtung des Stahlwerks in Henrichshütte nach dem Dortmunder Werk überführt. Die Betriebsresultate waren im allgemeinen ungünstige. Im Frühjahr 1880 waren zur Zeit der hochgehenden Konjunktur Dispositionen für Beschaffung von Rohmaterialien für die Henrichshütte getroffen worden, welche bei dem plötzlichen Umschwunge der Konjunktur sich ungünstig gestalteten und das Betriebskonto der Hütte stark belasteten, mit anderen Worten: das Rohmaterial war in der kurzen Spanne des Aufflackerns der Konjunktur zu teuer eingekauft worden. Außerdem wurde das Unternehmen durch den hohen Wasserstand der Ruhr geschädigt. Nicht weniger als fünfmal mußte der Betrieb im Walzwerk auf kürzere oder längere Zeit eingestellt werden, weil das Hochwasser in die tiefliegenden Feuerungskanäle der Schweißöfen, namentlich der Siemensschen Regenerativöfen eintrat. In den 80er Jahren sind dann Bleche und Winkel die Hauptfabrikationsartikel der Henrichshütte. Anfang der 90er Jahre wird, um dem Werke ein angemessenes Arbeitsquantum zu verschaffen, in Henrichshütte die Fabrikation geschweißter Röhren aufgenommen. Die Neuanlage kam im Hochsommer 1893 in Betrieb. Als Ergänzung der Walzwerksanlage, und um für die Herstellung der Röhren von größerem Durchmesser das Walzfabrikat selbst erzeugen zu können, wurde eine Universalwalzstraße gebaut. Heute ruht der Schwerpunkt des Hattinger Werkes in der Blech- und Röhrenfabrikation. Bleche sind bekanntlich entweder Halb- oder Ganzfabrikate. Auf der Henrichshütte werden sie in großem Maßstabe zu Röhren ausgewalzt und zur Herstellung von Fässern benutzt. Die seit 1893 bestehende Röhrenfabrik beschäftigt ca. 250 Arbeiter und gehört dem Röhrensyndikat an. Die FaBfabrik liefert vor allem Fässer für die Deutsch-Amerikanische Petroleumsgesellschaft, eine Gründung des Standard Oil Trust. Außerdem werden aus den Blechen Förderwagen für den Transport von Kohlen etc. hergestellt.

Zweitens kommt in Betracht das Horster Werk. Ursprünglich beruhte es auf der Schienenfabrikation. In der Krisis der 70er Jahre lieB die Nachfrage nach Schienen außerordentlich nach, und das Horster Etablissement mußte für die Erzeugung neuer Artikel eingerichtet werden, und zwar, der bisherigen maschinellen Ausrüstung entsprechend, für Façoneisen. Man ging also von der Schienenfabrikation über zur Herstellung von Profileisen aller Art, 
wie Bauträgern, Lang- und Querschwellen etc. Infolgedessen wurde auf dem Dortmunder Werk die Façoneisenfabrikation in der Hauptsache eingestellt. Diese Umgestaltung des Horster Eisen- und Stahlwerkes war 1877 vollendet. Im folgenden Jahre wird eine Drahtstraße neu eingerichtet. Bald jedoch zeigte sich, daß die zum Ersatz von Eisenschienen aufgenommene Fabrikation von schweißeisernen Lang- und Querschwellen durch das für diese Zwecke aufgenommene Flußeisen empfindliche Einbuße erlitt. In dem Geschäftsbericht von $1885 / 80$ heißt es dann mit Bezug auf die Rentabilität dieser Neuanlage: „Das Horster Werk ist in erster Linie auf die Fabrikation von Bauträgern angewiesen. Infolge der ungeheuren Unterbietungen der konkurrierenden Werke untereinander, die sich das Verkaufsgebiet streitig machten, ging der Gewinn stark zurück.“

$\mathrm{Da}$ nun in Horst der ganze Betrieb auf die Fabrikation von Schweißeisen eingerichtet war, so wurde, um wenigstens teilweise eine Ausnutzung der für die Fabrikation von Schweißeisen vorhandenen Einrichtungen zu ermöglichen, 1892/93 die Fabrikation von Nieten und Schrauben aufgenommen. Für diese Produkte lag auf den übrigen Werken der Union ein regelmäßiger und starker Bedarf vor. Diese Anlage entwickelte sich in der Folgezeit befriedigend.

Der Puddelbetrieb wurde weiterhin immer stärker eingeschränkt. An Stelle der aus demselben hervorgegangenen schweißeisernen Luppen mußten bei der Trägerfabrikation Flußeisenblöcke verarbeitet werden, wofür die Einrichtungen aber zum Teil nicht geeignet waren. Die Fabrikation von flußeisernen Trägern blieb jedoch Hauptzweig (Geschäftsbericht vom Jahre 1897/98). Daneben werden heute auch Schienen und Schwellen gewalzt.

Das Horster Werk, dessen Hochöfen während der letzten Krisis länger als $1 \frac{1}{2}$ Jahre außer Betrieb waren und dessen Walzwerk sogar während des ganzen Jahres 1902/03 noch still lag, hat heute weder Puddel-, noch Bessemer-, noch Thomasbetrieb. Das Thomasroheisen, das es erbläst, schickt es nach Dortmund. Dort wird es in Stahl verwandelt, um dann wieder nach Horst zurückzukommen. Die damit verknüpften umständlichen Arbeiten, vor allem der Transport und das wiederholte Einschmelzen, verteuern die Produktion bedeutend. So sehen wir hier dieselben Mängel in der Ökonomie des Betriebes wie auf dem Hattinger Werke. Beide Werke genügen nicht den Anforderungen, die man vom wirtschaftlichen Standpunkte an sie zu stellen berechtigt ist. 
Damit hätten wir unser Urteil, daß die Verschmelzung verschiedener Betriebe zum Zwecke der Produktion einer möglichst großen Anzahl von Handelsartikeln der Eisenindustrie ein Fehler war, in seinem ersten Teile erhärtet, denn wir sahen, $d$ a $B$ di e V e r schmelzung fürdas Gesamtunternehmenkein Segen war, und die Betriebe in Horst und Hattingen ver$k$ ü m m erten.

Es bleibi nun noch übrig zu beweisen, daß auch die prinzipielle Bedeutung der Herstellung von Spezialartikeln keineswegs so weit ging, da $\beta$ man die letztere als einen Talismann gegen die Störungen des Marktes und die Erschütterungen der Volkswirtschaft durch die Krisen betrachten könnte. Ursprünglich hatten die Gründer geglaubt, die Union durch die Vielseitigkeit und Besonderheit ihrer Produkte von den Wirkungen der Krisen emanzipieren zu können. Ein Unternehmen, das, wie die Union, alle Zweige der Eisenindustrie umfaßte, sollte dadurch gegen den üblen Einfluß wechselnder Konjunkturen in den einzelnen Branchen der Industrie gefeit werden! Dieser Plan und seine Durchführung aber wurde durch die Schicksale der Union kompromittiert. Bereits die Krisis der 70er Jahre zerstörte mit einem Schlage den Glauben, daB Mannigfaltigkeit der Produktion und Kultus der Spezialität ein Abwehrmittel gegen die Folgen von Krisen für den eigenen Betrieb sei. Aber die Geschichte ist dazu da, daß die Menschen nichts aus ihr lernen. Damals lagen bereits die Erfahrungen eines Unternehmens vor, das ganz auf demselben Prinzip aufgebaut war wie die Union, nämlich der Aktiengesellschaft für Bergbau und Hüttenbetrieb Phönix, die wir später betrachten werden. Aber die Praktiker sehen vielfach nicht über die Peripherie ihrer täglichen Erfahrungen hinaus. Dafür nur ein Beispiel, das zeigt, wie schnell die Erfahrungen der Vergangenheit vergessen werden. In dem Bericht der Direktion der Union vom Jahre 1882 steht als Illustration zu dem Gesagten folgendes: „Die Erfahrungen der letzten Jahre sind ganz danach angetan, uns in unseren Ansichten zu stärken und den Vorteil in das rechte Licht zu stellen, welchen ein Werk besitzt, das nicht auf die Produktion einer einzigen Spezialität in der Eisenindustrie beschränkt, sondern vielmehr auf breiter und die einzelnen Ungleichheiten des Marktes ausgleichender Basis errichtet ist. Diese breite Basis ist umsomehr anzustreben, als der Eisenbahnbau in den meisten Kulturländern der Erde, wenn auch nicht zum Stillstande, doch zu einem gewissen Beharrungszustande gekommen ist." Es bedurfte einer dreißigjährigen Geschichte, in der jede ein- 
zelne große Krisis dasselbe predigte, ehe die Verwaltung erkannte, da $B$ ihr Standpunkt in dieser Bezichung von Grund aus verkehrt sei. Sämtliche Krisen, die über die Union hereinbrachen, bewiesen, daß sie in der Produktion von Spezialitäten kein Gegenmittel besaß. $\mathrm{DaB}$ gerade dieses Prinzip den Betrieb starr machte, ist dann crst spät - vielleicht zu spät - erkannt worden. Erst in dem Bericht über das Krisenjahr 1900/01 heißt es: „Die Hüttenbetriebe der Union wurden besonders ungünstig beeinflußt, einesteils weil sie auf den Ankauf des überwiegend größten Teils der verbrauchten Rohstoffe angewiesen waren, und andererseits, weil es außerordentlich schwierig war, die weit verzweigten Betriebe den so plötzlich veränderten Verhältnissen anzupassen." Der Bericht vom 9. Juni 1902 bemerkt weiter folgendes: „Obwohl große Summen aufgewandt wurden, um die Einrichtung der Werke den veränderten Verhältnissen anzupassen, blieb doch der Übelstand bestehen, daß die Entwicklung der Werke durch die gegenseitig notwendige Rücksichtnahme auf das ihnen zugewiesene Fabrikationsprogramm gehemmt wurde." In demselben Bericht wird dann weiter zugestanden: „Die Vereinigung des Dortmunder Werkes mit den Werken Henrichshütte und Horst nebst den dazu gehörigen Bergwerken zu e in em Ganzen, so wohl erwogen sie seiner Zeit gewesen ist, hat sich unter den im Laufe der Zeit veränderten Verhältnissen nicht bewährt... Es ist daher in Aussicht genommen, die Henrichshütte nebst den bei der Gründung der Union von der früheren Aktiengesellschaft Henrichshütte eingebrachten Kohlenzechen und Eisensteinbergwerken zu veräußern und zu diesem Zwecke eine Aktiengesellschaft zu bilden, an die das Unternehmen zu übertragen sein würcie. "*)

Somit ergibt sich für unsere wissenschaftliche Betrachtung als Resultat dieses Abschnitts folgendes: Das ursprüngliche Programm der Union kränkelte an einem prinzipiellen Fehler. Dieser Fehler beunruhigte und störte die Rentabilität. Er lag in der Vereinigung räumlich getrennter Betriebe und dem Glauben, durch Mannigfaltigkeit der Produktion eine Pièce de résistance gegen die verheerenden Wirkungen wirtschaftlicher Krisen zu schaffen. Die Entwicklung

-) Während des Druckes dieser Zeilen durcheilt die Zeitungen die Nachricht, da $\mathrm{B}$ die Dortmunder Union die Henrichshütte an die Maschinenfabrik Henschel \& Sohn in Kassel einschließlich der Vorräte für 9,4 Millionen Mark verkauft habe. 
ergab nun als Resultat: Die Unmöglichkeit der weiteren Dezentralisation undein immerstärkeres $Z$ urückgehen der einzelnen Werksanlagen zugunsten des Dortmunder Etablissements. Je mehrsichdieses ausreckte und vervollkommete, desto mehr schrumpften jene zusammen. Deshalb werden bereits frühzeitig ganze Teile des Unternehmens abgestoBen, nämlich die Svabenswerke, die Hochofenanlage in Othfresen, die Bredelarer Hochofenanlage und GieBerei und schlieBlich das Aplerbecker Walzwerk. Diese Politikmachte Halt vorden Anlagen in Horst und Hattingen, weil sich das Ziel in den Köpfender beteiligten Kreise noch nichtzu vollständiger Klarheit verdichtet hatte. Deshalbuares a uch notwendig, diese Anlagen, die heutevon Dortmund a us ernährt werden müssen, näherkennenzulernen. Aus ihrerGeschichte ergibtsich die Notwendigkeit, da $B$ sie ihr Schicksal mit den bereits aufgehobenen Betrieben teilen müssen, um, nationalökonomisch gesprochen, einer weiteren Konzentration des Unternehmensaneinen Produktionsstandort nicht längerim Wegezustehen.

Wir haben bis jetzt die speziellen Ursachen der Unrentabilität der Union erörtert. Sie werden aber dadurch in ihrer Wirkung noch potenziert, daß sie sich mit allgemeinen kreuzen. Hierher gehört in erster Linie der große Umschwung in den Produktionsverhältnissen, der durch technische Revolutionen auf dem Gebiete der Eisenindustrie provoziert wurde, die wir früher bereits kennen lernten. Ich habe schon an anderem Orte erwähnt, daB die Erzeugung der Union hauptsächlich auf der Schienenfabrikation beruhte. Das entsprach den wirtschaftlichen Verhältnissen. Efeuartig hatte sich zu Beginn der 70er Jahre die Nachfrage nach Eisenbahnmaterial an dem Angebot emporgerankt, um teilweise über dasselbe hinauszuwachsen. Die Hüttenwerke konnten nicht genug Schienen, Räder, Achsen und sonstige Massenfabrikate liefern. Angestachelt zur Vermehrung ihrer Produktivkräfte bauten die meisten Werke neben den vorhandenen Puddelbetrieben große Bessemeranlagen, um konkurrenzfähig zu bleiben. Kaum war die Produktionskraft verdoppelt, da geriet der Eisenbahnbau ins Stocken. Die 
Nachfrage nach Schienen etc. wurde müde und schlief zeitweise ganz ein. Nun mußten sich die großen Werke nach anderen Artikelı unschen, sie mußten für den Ausfall an Beschäftigung auf dem Gebiete des Eisenbahnoberbaus anderswo Ersatz suchen, zu neuen Produktionszweigen übergehen. Hier kam nun vor allen Dingen in Betracht das große Produktionsgebiet des Handelseisens, das dem Absatz anfangs noch gewaltige Perspektiven eröffnete. Unter Handelseisen verstehen wir bekanntlich Eisen mit einfachem Querschnitt, also Quadrat-, Flach-, Rund-, Oval-, Sechs- und Achtkanteisen. Aber hicrin entwickelte sich in kurzer Zeit ein starker Wettbewerb. Dic Erzeugung dieser Artikel führte bald zu einer neuen Überproduktion. Nun begann man in der zweiten Hälfte der 80er und Anfang der 90er Jahre Handelseisen aus Stahl herzustellen, d. h. das im Bessemer-, Thomas- und Martinbetrieb gewonnene Flußeisen zu Handelseisen auszuwalzen.

Die Union hat auf diesem Gebiete nur die Aufgaben akzeptiert, die die technische und ökonomische Entwicklung der Eisenindustrie vorzeichneten. Als die Eisenbahnverwaltungen keine Schweißeisenschienen mehr abnahmen, mußte sie den Betrieb, d. h. die Walzwerke und Öfen umgestalten, um Stahlschienen produzieren zu können. Die Umwandlung in der Produktion der Union läßt sich dahin charakterisieren, daß mit dem Zurückgehen der Schienenfabrikation und mit der Verdrängung der Eisenschiene durch die Stahlschiene der Schwerpunkt der Produktion allmählich übcrgeht auf die Erzeugung von Eisenartikeln des täglichen Verbrauchs. Die durch diese Umwälzung hervorgerufene Krisis war eine der tiefgehendsten und traf namentlich die Werke in Horst und Henrichshütte, von denen, wie früler erwähnt, das crstere ausschließlich, das letztere wenigstens vorzugsweise auf die Fabrikation von Eisenschienen eingerichtet war.

Diesc Umgestaltung berührte indes nicht bloß die Walzwerke, sondern brachte auch in der Rohmaterialienfrage, insbesondere in der Roheisenfabrikation, eine tiefgreifende Änderung mit sich. Von den 15 Hochöfen der Union waren 6 ausschließlich auf die Produktion von phosphorhaltigem Roheisen, welches nach dem früheren Stande der Technik, d. h. vor 1879, zur Stahlfabrikation keine Verwendung finden konnte, basiert. Die geographische Lage der erwähnten 6 Hochöfen machte es, wie der Geschäftsbericht 1881/82 ausführt, unmöglich auf demselben so, wie dies von anderen Werken geschah, mit importierten Erzen Bessemerroheisen zu erblasen. 
Diese Umwälzung in den Produktionsverhältnissen hatte nun zur Folge, daß die Stahlerzeugung auf dem Dortmunder Werk konzentriert wird. Durch neue Thomas- und Martinanlagen wird dasselbe für eine schwunghafte Massenfabrikation eingerichtet, allerdings auf Kosten der übrigen Werke der Union. Daher weist der Bericht über das Jahr 1893/94 darauf hin, daß die fortschreitende Verdrängung des Schweißeisens durch das Flußeisen, die sich in raschem Tempo auf Träger, Bleche und Handelseisen ausdehnte, große Schwierigkeiten verursachte, sowohl bezüglich der technischen Einrichtungen als auch in bezug auf das einheitliche Zusammenarbeiten der räumlich getrennten Werke der Gesellschaft.

Wir haben in dem Vorhergehenden ein weiteres Moment erkannt, das für die ungünstige Lage der Union mit verantwortlich gemacht werden muB: Dadurch, daB das $S c h w e i B$ eisen immermehrund mehrdurch das FluBeisen, oder anders a usgedrückt, der Puddelbetriebimmer heftiger und rücksichtsloser durch den Bessemer-, Thomasund Martinbetrieb verdrängt wurde, ergab sich für die Union eine vollständige Verschiebung des Fabrikationsprogramms. Der Puddelbetrieb wurde zum Teil eingestellt, die Stahlerzeugung in Dortmund konzentriert. Mit dem Zurückgehen der Eisenproduktion und der Ersetzung des SchweiBeisens durch FluBeisen wird einerseits der Schwerpunkt der Produktion a uf die Erzeugungvon Handelseisen und Handelsstahl, andererseits auf die Erzeugung von Stahlschienen gelegt. Diesen UmwandlungsprozeB haben alle Hüttenwerke in Deutschland durchmachen müssen. Sie befanden sich in der gleichen Lage wie die Union nur mit dem Unterschiede, da $B$ es ihnen in den meisten Fällengelang, der Schwierigkeiten Herrzu werden. Für die Union aber wurde die veränderte Produktionsweise eine Quelleungeheurerfinanzieller Kraftanstrengungen und - schlechter Geschäfte.

$\mathrm{Zu}$ den allgemeinen Ursachen ist weiterhin der Einflu $\mathbf{B}$ der $\mathrm{Kr}$ ise $\mathrm{n}$ auf die Union zu rechnen. Wäre die Eisenkonjunktur stets eine gute gewesen, so hätten sich die Fehler, die man in bezug auf die Überwertung der Anlagen, die Organisation des Betriebes, die Rohstoffbeschaffung und die Mannigfaltigkeit der Waren- 
erzeugung gemacht hatte, nicht so herausarbeiten können, wie dies tatsächlich der Fall war.

Gleich das erste Geschäftsjahr war ein Jahr schroffsten Konjunkturwechsels. In allen eisenproduzierenden Ländern, vor allem aber in Deutschland, stiegen unter dem Einfluß ungeheurer Geldsummen die Preise kataraktartig in dic Höhe. Im ersten Halbjahre 1872 hoben sie sich pro Tonne

für Stabeisen . . . . . . . von 192 auf 360 M.
für gewöhnliche Eisenbahnschienen " 192 " 324 "
für Bleche. . . . . . . . . " 270 " 480 "

um sich bis zum Herbst auf dieser Höhe zu halten. Als dann im Frühling 1873 von Wien aus die Sterbeglocke des wirtschaftlichen Aufschwungs läutete, begann der ungeheure Entwertungsprozeß, der die Eisenindustrie in den folgenden Jahren so schwer in Mitleidenschaft zog.

Besonders intensiv wirkte der Preisrückgang auf die Union. Die Verwaltung hatte sich in Übereinstimmung mit den in der rheinisch-westfälischen Eisenindustrie herkömmlichen Gebräuchen wegen des Bezuges der Rohmaterialien in der Blütezeit ihres crsten Geschäftsjahres auf längere Zeit im voraus gedeckt, also erhebliche Quanten zu den hohen Preisen einer voraufgegangenen Pcriode noch nachträglich abzunehmen, als die Preise des Fabrikats bereits tief gefallen waren. Diese Engagements mußten um so nachteiliger für sie ausfallen, als die Fertigstellung der Bauten infolge verspäteter Lieferung von Maschinen, Mangel an Arbeitskräften etc. sich stark verzögerte und später außerdem erhebliche Umbauten nötig wurden. Infolgedessen konnte die Verarbeitung dieser Rohmaterialien durchaus nicht in dem bei dem Abschlusse vorausgesetzten Umfange erfolgen, und es häuften sich riesenhafte Bestände, und zwar Bestände zu exzeptionell hohen Preisen, in einem das Normalbedürfnis weit übersteigenden Maße an. Ihr Wert, zum Selbstkostenpreis berechnet, belief sich im Januar 1874 auf nahezu 20 Millionen Mark. In den 6 Jahren von $1872 / 73$ bis $1878 / 79$ betrug der Durchschnittsprels pro 1000 Kilogramm Walzfabrikate: 248,05; 221,46, 190,36; 152,$56 ; 139,06 ; 126,40$ Mark.

Unter diesen Verhältnissen ergriff die Union alle die Maßregeln, die aus der Geschichte der Krisen bekannt sind. Sie sucht vor allen Dingen den Betrieb einzuschränken und die Selbstkosten auf ein niedrigeres Niveau herunterzu$\mathrm{d} r$ ücken. In einem einzigen Jahre werden allein 3307 Ar- 
beiter entlassen, oder im Stile der Geschäftsberichte gesprochen: vom 30. Juni 1873 bis zum 30. Juni 1874 sinkt der Personalbestand des Werkes von 12436 auf 9129 Mann (incl. Beamte) und erreicht am 30. Juni 1877 seinen tiefsten Stand mit 5322 Mann. Die Krisis verminderte demnach den Arbeiterbestand der Union um 6114 Arbeiter. Außer diesem großen Opfer an Menschen iorderte sie nicht minder große Opfer an Lohn. Der Durchschnittsverdienst eines Arbeiters sank von 1378,35 Mark im Jahre 1873/74 auf 797,53 Mark im Jahre 1877/78. Die dadurch herbeigeführte Verminderung der Produktionskosten fällt ohne weiteres ins Auge. Die Arbeiterziffer voll 1873 hat die Union bis zur Gegenwart niemals wieder erreicht. Am nächsten kommt ihr noch die Zahl des Jahres 1900, wo das Werk 12412 Arbeiter beschäftigte. Auch der Lohn ist in ihrer Geschichte nicht mehr auf den Durchschnitt von 1378,35 Mark (1873/74) emporgeklommen; er betrug 1900 1291,02 Mark.

Ein weiteres Mittel, um über die Krisis hinwegzukommen, das auch in den späteren Jahren eine große Rolle spielt, denn die Union hat sich eigentlich immer in einer Krisis befunden, war der Verkauf von Rohstoffen an Dritte. Es werden Kohlen, Erze und Roheisen zur Weiterverarbeitung verkauft. Dieser Absatz erlangt eine ziemliche Ausdehnung. So wurden z. B. 1876/77 an Eisenstein gefördert 53772 Tonnen. Davon brauchten die verschiedenen Hochofenanlagen der Union im ganzen 23186 Tonnen; an Dritte wurde verkauft 29338 Tonnen, also über die Hälfte der ganzen Produktion, mit einem Erlös von 310766 Mark.

Ein weiteres Mittel, das die Union, wie die anderen großen kapitalistischen Betriebe anwandte, um die Wirkung der Krisis abzuschwächen, ist der Exportzu niedrigen Preisen nach dem Auslande. Der Unternehmer steht vor der Alternat::e, entweder den Betrieb be de u te $\mathrm{n}$ d zu reduzieren, eine größere Anzahl Öfen kalt zu legen, oder aber den Betrieb bis zu einem gewissen Grade aufrecht zu erhalten, um das erzielte Produkt zum oder unter dem Produktionskostenpreise auf den Weltmarkt zu werfen. Alle Krisen haben nun bisher e in Erfahrungsresultat ergeben, das sich ubereinstimmend bei fast allen großen Werken wiederholt: Der Export wird forciert! So auch bei der Union. Bei ihr erreichte die Produktionsziffer fertiger Fabrikate 1875/76 mit 87,4 Millionen $\mathrm{kg}$ ihren tiefsten Punkt und stieg dann 1877/78, obgleich eine Besserung der Konjunktur nicht eingetreten war, auf 121 Millionen $\mathrm{kg}$. Es würde fehlerhaft sein, diese vergrößerte Erzeugung auf der Basis des Exports als ein 
günstiges Zeichen anzusehen. Deshalb heißt es auch in dem Bericht des genannten Jahres: „Diese Steigerung der Produktion beweist zwar eine vermehrte Arbeitsleistung, bietet aber keineswegs einen Beweis für eine gewinnbringende Lage der Industrie ... Denn die Steigerung ist nur möglich geworden durch einen häufig mit direktem Verlust verbundenen Zwangsexport nach dem Auslande, lediglich zu dem Zwecke, um derjenigen Massenproduktion einen Abfluß zu verschaffen, welche ihrerseits wieder erforderlich ist, um so billig produzieren zu können, wie die Konkurrenz des Auslandes zur Aufrechterhaltung des Betriebes der eigenen Werke es erfordert. Würde man von einem solchen, in den einzelnen Abschlüssen häufig direkt verlustbringenden Export absehen, so würde man die Produktionsziffer so bedeutend ermäßigen müssen und dadurch die Selbstkosten dieser verminderten Produktion so bedeutend erhöhen, daß der hierdurch entstehende indirekte Verlust weit erheblicher wäre als der direkte Verlust bei einzelnen Abschlüssen nach dem Auslande; die Betriebsfähigkeit der mit so erhöhten Selbstkosten arbeitenden Werke würde ernstlich in Frage gestellt sein, wenn nicht unmöglich werden."

Die zweite Krisis, die die deutsche Eisenindustrie heimsuchte, dauerte von 1883-1887. Im Jahre 1883 begann der internationale Markt für die Hauptexportartikel Schienen und Draht zu verflauen. In dieser Zeit, sagt die Verwaltung der Union 1885/86, gelang es nur, „durch die Vervollkommnung des technischen Betriebes und äußerste Sparsamkeit auf allen Gebieten einen Teil des Ausfalles auszugleichen, den der fortwährend starke Rückgang der Verkaufspreise im Gefolge hatte." 1886 erfolgte dann die Auflösung der Internationalen Schienengemeinschaft. Dies hatte eine so erbitterte und unwirtschaftliche Konkurrenz und demgemä $B$ einen so niedrigen Preis für dieses Fabrikat auf dem Weltmarkt zur Folge, daB das Werk es vorzog, die Schienenfabrikation vorübergehend einzustellen. Aber auch das inländische Schienengeschäft wurde durch das Auftreten der ausländischen Konkurrenz bei den Submissionen der deutschen Bahnverwaltungen wesentlich beeinträchtigt.

Während so auf der einen Seite in der Krisis der 80er Jahre das Schienenkartell zusammenbrach, war diese Periode andererseits die Geburtsstunde einer Anzahl neuer Kartelle auf dem Gebiete der Eisenindustrie. Vor Ablauf des Jahres 1886 wurde die Roheisenkonvention gegründet. Diese Vereinbarung führte weiter zu der Konvention der Trägerwerke und schließlich im August 1887 zu der 
in Dortmund etablierten gemeinsamen Verkaufsstelle der Stabeisen produzierenden Werke in Rheinland-Westfalen, worüber an anderer Stelle bereits das Wesentliche gesagt wurde. Nunmehr war auch die Union in der Lage, den Ausfall in der Gesamtproduktion an Fertigfabrikaten, der durch die Einschränkung der Schienenfabrikation bewirkt worden war, reichlich auszugleichen durch die Mehrproduktion an Stab- und Façoneisen. Auch für Grob- und Feinbleche hatte sich ein Syndikat gebildet, dem die Union angehörte. Es kann gar keinem Zweifel unterliegen, daß ihre Ergebnisse durch die Kartellorganisation gehoben worden sind. „Wir haben“, heißt es in dem Bericht 1887/88, „uns fortgesetzt an die Förderung dieser für die ganze Eisen- und Stahlindustrie wichtigen Bestrebungen lebhaft beteiligt und das gegen das Vorjahr günstigere Gewinnresultat... ist wesentlich auch den auf diesem Gebiete erzielten Erfolgen zu danken.“

Allerdings ist die weitere Stellung der Union zu den Kartellen keine einheitliche gewesen. So z. B. zum Trägerkartell. Es bestand seit 1886 als reines Preiskartell, d. h. nicht die Produktion, sondern der Preis wurde geregelt. Über dieses Kartell heißt es im Bericht des Jahres 1892: „Durch die seitens einiger Werke neu aufgenommene Trägerfabrikation wurde, obwohl sie der Preisvereinigung beitraten, das den älteren Werken verbleibende Arbeitsquantum wiederholt so vermindert, daß der Wert der Vereinigung für dieselben fraglich wurde." 1891 wurde die Auflösung der Vereinigung beschlossen. Dasselbe Schicksal erlitt der auch auf bloßer Preisvereinbarung beruhende Grobblechverband, nachdem sich bereits im Herbst 1890 die Unmöglichkeit herausgestellt hatte, den Feinblechverband aufrecht zu erhalten. Der Auflösung dieser beiden Verbände folgte ein ungeheurer Preisrückgang der Bleche. 1891 standen die Blechpreise um 80-90 Mark pro Tonne niedriger als 1890.

Damit tritt die Union in die dritte Krisenperiode ein, die Zeit von 1890-1894. Nachdem die alten Verbände zerfallen, steht das Werk keineswegs mehr den Kartellen mit so ungeteilter Sympathie gegenüber wie in den $80 \mathrm{er}$ Jahren, wo man noch allgemein glaubte, in dem Zusammenschluß der Unternehmer zur Regulierung der Preise, resp. der Produktion ein Heilmittel gegen die Krisen gefunden zu haben. In die Berichte der Union schleichen sich Klagen über die Kartelle ein. So empfindet es die Leitung ungerechtfertigt, daB der Stabeisenverband, der bis zum 31. Dezember 1893 bestand, dem Werke nicht annähernd das für seinen Betrieb erforderliche 
Arbeitsquantum zuweisen konnte, so da $\beta$ eine intensive Ausdehnung seiner Einrichtungen und die hieraus entstehenden Vorteile ihm versagt blieben.

Ähnlich klingt es dann aus den Berichten über die letzte Krisis, die die Jahre 1900-1903 umfaßt, heraus, daß die Kartelle ein Hindernis für das Werk seien. In dem Bericht über die außerordentliche Generalversammlung vom 9. Juni 1902 wird ausgeführt, daß die freie Aktion der Werke, besonders auf kaufmännischem Gebiete, durch die in der Eisenindustrie immer mehr um sich greifende Entwicklung der Syndikate und Konventionen behindert werde. Die für das eine Werk nötige Zugehörigkeit zu solchen Vereinigungen hindert das andere Werk, diejenigen Vorteile auszunutzen, welche den mit ihm in Wettbewerb stehenden freien Werken ohne Mühe zufallen. Der sich hieraus ergebende Widerstreit der Interessen konnte bei der Union nur mit Opfern für das Gesamtunternehmen ausgeglichen werden. Der eingetretene Stimmungsumschlag in bezug auf die Stellung der Verwaltung gegenüber den Kartellen hat aber nicht verhindert, daß die Union dem Anfang 1904 zustande gekommenen Stahlwerkverband ebenfalls beitrat.

Die letzte Krisis, die in den Beginn des neu anbrechenden Jahrhunderts fällt, wirkte auf die Gesellschaft in derselben einschmeidenden Weise wie die früheren Konjunkturrückgänge. Besonders schwierig gestaltete sich die Lage infolge der Wechselbeziehung zwischen dem Dortmunder Werk und den beiden Werken in Horst und Henrichshütte. Darüber sagt der Geschäftsbericht 1900/01 folgendes: „In der zweiten Hälfte des Jahres 1899 und Anfang 1900 konnte die Nachfrage nach Halbzeug auch nicht annähernd befriedigt werden. Unter dem Einfluß dieses lang andauernden Mangels kauften sowohl die Händler wie die Halbzeug verarbeitenden Werke so große Mengen, da $B$ der Bedarf über ein Jahr hinaus gedeckt war. Die Union konnte sich jedoch an diesen langsichtigen und gewinnbringenden Verkäufen nicht beteiligen, weil das Dortmunder Werk alles nicht selbst verarbeitete Halbzeug an die Werke in Horst und Henrichshütte abgeben mußte, deren bisherige Lieferanten bei der stürmischen Nachfrage versagten. Als nun der Umschwung erfolgte, und die Beschäftigung der Werke in Horst und Henrichshütte zurückging, wurde der Betrieb des Dortmunder Stahlwerkes aufs empfindlichste benachteiligt, weil ein Absatz des von Horst und Henrichshütte weniger abgenommenen Halbzeuges auf dem äußeren Markte nicht mehr möglich war. Es mußte daher die Stahlerzeugung in 
Dortmund rasch ganz erheblich eingeschränkt werden, und sofort trat an Stelle des bisherigen Mangels ein Überschuß an Roheisen. Es ist nicht möglich gewesen, diesen Überschuß durch Verkäufe abzustoßen und dadurch die Ansammlung größerer Vorräte zu verhüten." Aus dieser Darstellung geht hervor, wie ungünstig die Abhängigkeit vom Dortmunder Werke die beiden anderen Etablissements beeinflußte. Bei diesen lagen daher die Verhältnisse am schlimmsten. In Horst wurde der Hochofen-, Puddel- und Walzwerkbetrieb ganz eingestellt, und nur die Achsenfabrik, sowie die Muttern- und Schraubenfabrik blieben, wenn auch eingeschränkt, in Betrieb. Auch die Henrichshütte hatte in den beiden ersten Jahren sehr zu leiden. Der Rückgang der Nachfrage nach Blechen trat früher ein und war größer als bei allen anderen Erzeugnissen der Eisenindustrie. Die Verluste dieses Werkes wurden größtenteils durch den Verkauf des aus den Vorjahren übernommenen großen Roheisenbestandes gedeckt.

Allerdings hat es den Anschein, als ob 1902/03 sich die Lage der Union wieder günstiger gestaltete, denn sie konnte in dem genannten Jahre auf die Vorzugsaktien lit. D 5\% und auf die Aktien lit. C 2\% Dividende verteilen. Allein aus der Bilanz ergibt sich, daß diese Dividenden aus den tatsächlichen Betriebsgewinnen des Geschäftsjahres nicht hätten gezahlt werden können, sondern daß ihre Auszahlungen nur durch Zuhilfenahme von Rückstellungen ermöglicht wurde. Der mit 1271768 Mark bezifferte Reingewinn kommt nämlich dadurch zustande, daß dem „Konto der vorbehaltenen Abschreibungen“ 1067550 Mark entnommen und in die Gewinn- und Verlustrechnung eingestellt sind. Es ergibt sich weiter, daß auch der Speziaireservefond, der Ende Juni 1902 mit 2,6 Millionen Mark dotiert war, jetzt nur noch 1721026 Mark beträgt. Es sind demnach im ganzen mehr als 1,8 Millionen Mark zur Aufbesserung des Erträgnisses pro 1902/03 aus den früheren Rückstellungen herangezogen worden.*)

Damit hätten wir auch die Ingerenz der Krisen a uf das Werkbehandelt. Dasselbelitt, trotz seiner spezialisierten Produktion, mit der ganzen deutschen Eisenindustrie unter vier groBen Niedergängender Konjunktur. Am schlimmsten wirkte auf das noch nichtgenügend fundierte Unternehmendie Baissevon 1873-1879. Eine ungeheure Entwertung

-) Siehe Handelsteil des Berliner Tageblattes vom 6. Oktober 1903. 
derzu Hochkonjunkturpreisengekauften Rohstoffe tratein. Als Reaktion gegendie schädigenden Wirkungendieser Krisis sehen wirdiePolitikderUnion, deren Aktien damals an der Berliner Börse auf $4 \%$ heruntersanken, a uf dreierleigerichtet: Erstens a uf eine Erniedrigung der Produktionskosten, zweitens a uf eine AbstoBung eines Teils seiner Rohstoffe durch Verkäufe an Dritte und drittens auf den Exporteines relativgroBen Teils seiner Fabrikate, um den Betriebin einem gewissen Umfange aufrechterhalter zu können.

Nach einer kurzen Erholung folgte dann die Stagnationvon $1883-1887$. Als Hauptabwehrmittel gegen die Schädigungen dieser Periode sucht das WerkAnschluß andie Kartellbestrebungenderdeutschen Eisenindustrie. Mit Hingabe beteiligt es sich an den bestehenden Verbänden, von denen ein Teil jedoch nach kurzer Zeit zusammenbricht, weil er a uf bloBer Fixierung der Preise beruhte.

Nach diesen Erfahrungen ändert dann das Werk seine Haltung. In der folgenden $\mathrm{Kr}$ is is von 1890 bis 1894 und in der letzten Baisse, die über die Eisenindustrie hereinbrach und die von 1900-1903 - dauerte, steht es nicht mehr ganz auf dem Standpunkteungeteilter Zustimmung zuden Kartellorganisationen. Jedenfalls hängt dieser Wechsel mit seinerdauernd schlechten finanziellen Situationzusammen, anderbekanntlich auch die Hochkonjunkturperiodevon 1895-1900 nichtviel zu ändern vermochte.

Die letzte Krisis schädigte, wie wir sahen, namentlich die Betriebe in Horst und Hattingen, aber a uch das Dortmunder Werk wurdeteilweise, infolge seiner Beziehungen zu denselben, derartig mitge. nommen, daB selbst das Jahr 1902/03, das für die Eisenindustrie im allgemeinen wieder bessere Ergebnisse brachte, bei der Union nur durch einen Kunstgriffinder Bilanzierung zueinem Reinertrage gezwungen werden konnte. 
Wir haben im Vorhergehenden eine Reihe von Ursachen kennen gelernt, aus deren Zusammenwirken die finanziellen Mißerfolge der Dortmunder Union resultieren. Man kann behaupten, daß es auf dem großen Gebiete der Eisenindustrie keine einzige Aktiengesellschaft gibt, die im Laufe der Zeit so große Kapitalien absorbiert hat, wie gerade dieses Unternehmen. Man hat es mit einem Sumpf verglichen, der Millionen über Millionen verschlang, und selbst heute hat es noch nicht den Anschein, als ob dieser Schlund gesättigt wäre. Es ist daher nicht uninteressant, den finanziellen $\mathrm{Aufbau}$ eines derartigen Unternehmens im Detail näher kennen zu lernen.

Das Aktienkapital der Union wurde, wie eingangs erwähnt, auf 33 Millionen Mark festgesetzt. Bei der Errichtung der Gesellschaft am 2. Februar 1872 wurden hiervon 15 Millionen Mark übernommen, wovon 12 Millionen zur öffentlichen Subskription gelangten. Den Rest von 18 Millionen Mark erhielten die Aktionäre der Gesellschaft Neuschottland und Henrichshütte. Bald darauf, am 5. Oktober 1872, erfolgte nach dem Erwerb der Eisensteingruben und Hochöfen von Bredelar und der Svabenswerke eine Erhöhung des Aktienkapitals um 6,6 Millionen auf 39,6 Millionen Mark. Der Nominalwert der Aktien betrug 600 Mark. Aber das genügte noch nicht. In der Generalversammlung vom 3. November 1873 wird gegen Verpfändung des Immobiliarvermögens die Aufnahme einer sechsprozentigen Anleihe im Betrage von 18 Millionen Mark beschlossen. Bald nach der Generalversammlung gelangte die Anleihe von einem Konsortium zur Emission. Aber bereits der zweite Geschäftsbericht konstatiert, daß die Bauten auf der Union einen erheblichen Mehraufwand erforderten und das Geld nicht ausreiche. Dazu kam die Unterbilanz des Jahres 1873/74. „Zur Beseitigung derselben“, heißt es im Geschäftsbericht des genannten Jahres, ,und zur Deckung des obigen Mehrbedarfes müssen der Gesellschaft neue Mittel in entsprechender Höhe zugeführt werden, was angemessen nur durch die Emission von Stammprioritäten bewerkstelligt werden kann." In der außerordentlichen Generalversammlung vom 15. Februar 1875 wurde daher beschlossen, das Aktierkapital auf 41,4 Millionen Mark festzusetzen und es in zwei Kategorien zu zerlegen, nämlich in privilegierte Aktien lit. A im Betrage von nom. 15 Millionen Mark und in Stammaktien lit. B im Betrage von 26,4 Millionen Mark. Die ersteren hatten das Recht einer Vorzugsdividende von $6 \%$. Sie wurden, da von den bisherigen Aktionären das statutarische Bezugsrecht unter den obwaltenden Verhältnissen nicht ausgeübt wurde, von 
den Hauptbeteiligten des Konsortiums, welches die Union ins Leben gerufen hatte, zum Parikurse übernommen und voll bezahlt. Außerdem wurde das bisherige Grundkapital der Gesellschaft reduziert und zwar im Verhältnis von 3:2. Es geschah das in der Weise, daB der Nominalbetrag jeder Aktie durch Abstempelung von 600 auf 400 Mark heruntergesetzt wurde. Es blieben dem ursprünglichen Aktionär also noch $66 \% \frac{1}{3} \%$ seines Nominalkapitals. Für die Gesellschaft ergab sich aus dieser Operation ein Buchgewinn von 13,2 Millionen Mark, der zur Deckung der Unterbilanz des vergangenen Jahres, zur Wiederherstellung des Reservefonds und zu Abschreibungen Verwendung fand. Damals wurden aber nicht sämtliche Aktien zur Abstempelung eingereicht, und an der Berliner Börse wurden lange Zeit beide Aktien gehandelt, nämlich gewöhnliche Stücke und abgestempelte Stücke. Ein Wertunterschied bestand nicht. Ja, es wurden sogar die nicht abgestempelten Stücke durchweg höher bezahlt als zu zwei Drittel des Kurses der abgestempelten Stücke. Das ist einer der vielen Widersprüche, die die Börse mitunter beliebt. Nach dem inneren Werte mußtc eigentlich der Kurs der nicht abgestempelten Aktien etwas niedriger als zwei Drittel des Kurses der abgestempelten sich belaufen, schon wegen der usancemäßig mit $4 \% \mathrm{zu}$ berechnenden Stückzinsen, dann aber auch deshalb, weil die nicht abgestempelten Stücke als solche gar keine statutenmäßige Giltigkeit mehr besaßen, also unter allen Umständen behufs Teilnahme an der Generalversammlung, behufs neuer Dividendenscheine etc. nachträglich doch noch abgestempelt werden mußten, wodurch immerhin Spesen, Porti etc. erwachsen.

Aber der ersten Rekonstruktion des Unternehmens, wie sie in der Generalversammlung vom 15. Februar 1875 beschlossen war, und nachher ausgeführt wurde, sollte bald eine zweite folgen. Für die Bilanz des Jahres 1874/75 wurden zwar die Entwertung und Verluste durch die Abschreibungen aus der Kapitalreduktion vollständig ausgeglichen. Durch die neu emittierten Aktien lit. A wurden die dem Unternehmen entzogenen liquiden Mittel wieder neu zugeführt. Trotzdem blieb der Passivstatus der Union noch stark belastet. In den folgenden Jahren steigt die Schulden- und Zinsenlast wieder bedeutend an. Noch 1874/75 hatte die Union allein über 2 Millionen Mark Zinsen zu zahlen. Als Grund wird außer der früheren Unterbilanz angeführt der alle Erwartungen übersteigende Mehrbedarf von 12 Millionen Mark für Bauten, die empfindliche Entwertung der früher angewachsenen Magazinbestände, bedeutende Ersatz- 
leistungen für die noch von der Gesellschaft Neuschottland ausgeführten österreichischen Schienenlieferungen, sowie die großen Verluste an außenstehenden Forderungen, insbesondere bei der falliten Gesellschaft F. PleBner \& Co. in Höhe von mehr als 700000 Mark.

Infolge dieser mißlichen Verhältnisse, die in den folgenden Jahren sich noch mehr verschlimmerten, wurde für den 14. März 1878 eine außerordentliche Generalversammlung einberufen. Auf derselben wurde erstens eine weitere Reduktion des Aktienkapitals beschlossen und demgemä $\beta$ der Nominalwert der Aktien beider Kategorien auf den handelsgesetzlich zulässigen Minimalbetrag von 300 Mark pro Aktie fixiert. Alle Aktien der Union hatten nunmehr den Nominalwert von 300 Mark. Durch diese Reduktion des Nominalwertes von 400 auf 300 Mark wurde eine Summe von 10350000 Mark disponibel. Dem ursprünglichen Aktionär blieben jetzt noch 50\% seines Nominalkapitals.

Zweitens wird das Aktienkapital vergröBert, und zwar durch Emission von nom. 10350000 Mark Aktien lit. A, so daB das gesamte unter diesem Buchstaben auftretende Kapital nunmehr 21600000 Mark beträgt. Sollte diese Vergrößerung nicht ausreichen, dann ist die Gesellschaft befugt, Aktien lit. A bis zum Betrage von 30 Mill. Mark auszugeben. Diese neuen Aktien lit. A. sollen laut Statut gerade soviel Dividende erhalten wie die alten Aktien lit. A, also mit ihnen vollständig gleich berechtigt sein.

Drittens wird, und darin liegt der Schwerpunkt der ganzen Rekonstruktion, beschlossen, den alten Aktionären, die wir als B-Aktionäre bezeichnen wollen, den Umtausch ihrer Aktien in solche lit. A anzubieten. Drei alte sollen als Vollzahlung auf eine Stammprioritätsaktie lit. A angesehen werden, d. h. der Besitz von drei alten Aktien lit. B. das Anrecht auf eine neue geben. Nehmen wir an, daß sämtliche Aktionäre davon Gebrauch machten (der gröBte Teil hat es tatsächlich getan), dann wurden die 19,8 Millionen Mark auf 6,6 Mill. Mark reduziert, und die Gesellschaft hatte davon einen Vorteil, der sich auf 13,2 Millionen Mark belief. Es blieben nunmehr dem Aktionär, der seine Aktien in dem angegebenen Verhältnis von 3:1 umtauschte, noch $1 / 6$ seines ursprünglich $\_n$ Kapitals, d. h. 16-17\%.

In der Generalversammlung vom 3. Juli 1879 wurde dann die Tilgung der sechsprozentigen Obligationen beschlossen. An Stelle dieser alten Anleihe übernimmt die Diskontogesellschaft eine neue fünfprozentige. Der Subskriptionspreis betrug 1011/4\% gegen Rück- 
zahlung zu $110 \%$. Das Konsortium üternahm die Hälfte zum Kurse von $99 \%$.

Im Jahre 1879/80 wird dann das Aktienkapital lit. A um weitere 6 Millionen Mark erhöht und den B-Aktionären mit ihrem Kapital von 5818000 Mark eine letzte Frist zum Umtausch gegen Aktien lit. A offen gelassen.

In den 80er Jahren verschlechterten sich die finanziellen Grundlagen der Gesellschaft nur wenig, erst in den 90er Jahren drohen wiederum gewaltige Katastrophen den ganzen Bau zu erschüttern. Von 1892-1895 wuchsen die Schulden von 20,3 auf 29,3 Millionen Mark, davon waren 1895 über 8 Millionen Mark Bankschulden. Gläubigerin war auch hier wieder die Diskontogesellschaft. Um diese schwebende Schuld zu tilgen und die Neubauten bezahlen zu können, waren weitere Mittel nötig. Dieselben wurden nach den Beschlüssen in der außerordentlichen Generalversammlung vom 25. Januar 1896 auf zweierlei Weise aufgebracht:

Erstens: das Aktienkapital lit. A wird auf 39 Millionen Mark erhöht; von einer weiteren Erhöhung und Emission auf 45 Millionen Mark mußte man absehen, da der Kursstand der Aktien cine Begebung derselben zu Pari nicht gestattete.

Zweitens: das Grundkapital der Gesellschaft wird durch Emission von 9000 Stück Vorzugsaktien lit. C à 1500 Mark um 13,5 Millionen Mark erhöht. Diese Aktien lit. C erhalten eine Vorzugsdividende von 5\%. Das Aktienkapital lit. A soll erst dann an einer Dividende teilnehmen, wenn die Vorzugsaktien lit. C mit 5\% befriedigt sind.

Diese neuen Aktien wurden zum Kurse von 1001/2\% von der Diskontogesellschaft übernommen, d. h. sie zahlte der Gesellschaft $13 \frac{1}{2}$ Million aus, verdiente $1 / 2 \%$ und bot nun die Aktien dem Publikum an. Diese fünfprozentigen Vorzugsaktien, wie man sie schlauer Weise nannte, erzielten, als sie zum ersten Male an der Berliner Börse gehandelt wurden, einen Kurs von 101,75\%. Volkswirtschaftlich betrachtet haben wir es bei der Entstehung der Aktien lit. C mit der Umwandlung einer fest verzinslichen Schuld in Aktien zu tun. Hierin liegt auch der Schlüssel, warum eine Bank, wie die Diskontogesellschaft an der Dortmunder Union sich nicht verblutet hat. Die Diskontogesellschaft lieh zu allen Stunden der Union ungeheure Vorschüsse in bar, aber sie ließ sich bald dafür Effekten geben, und begab diese weiter an das Publikum. Infolgedessen dürfte sie auch an der Union keine Verluste erlitten haben, ganz zu schweigen 
von den Gewinnen, die mit den erwähnten Transaktionen der Kreditgewährung verknüpft sind.

In der Versammlung am 25. Januar 1896 wurde von der Verwaltung der Union proponiert, die Aktien lit. A im Verhältnis von $5: 2$ zusammenzulegen. Darauf erhob sich in den Kreisen der Aktionäre ein Sturm der Entrüstung. Der Vorschlag wurde als ungerecht, unbegründet und verfrüht von der Majorität des Aktienkapitals zurückgewiesen, trotzdem die ganze Sanierungstransaktion ,mit pomphafter Aufwendung allen Raffinements moderner Finanzkunst" inszeniert worden war. (Zukunft 30. XI. 01). Es wurde daher am 26. November 1896 eine neue außerordentliche Generalversammlung einberufen, in der die Vorschläge der Verwaltung auch nicht durchgingen, wohl aber die der koalierten Aktionäre. Die Verwaltung wollte 23 Millionen Mark zu Abschreibungen verfügbar machen durch eine Heruntersetzung des Aktienkapitals von 52,5 auf 29,1 Million Mark, d. h. durch eine Zusammenlegung von 5:3. Demgegenüber setzten die Aktionäre, da eine Reduktion unvermeidlich war, und es sich nur um ihre quantitative Bemessung handelte, folgendes durch: Das Grundkapital der Gesellschaft wird in ein einheitliches, unterschiedsloses Kapital von nom. 33 Millionen Mark vermindert, und zwar in der Weise, daB für nom. 3000 Mark Aktien lit. A eine vollbezahlte Vorzugsaktie lit $C$ von nom. 1500 Mark gewährt wird. Die noch im Umlauf befindlichen Aktien lit. B werden so behandelt, als ob sie bereits in Aktien lit. A umgetauscht wären. Das kombinierte Grundkapital der Gesellschaft wird also von 52,5 auf 33 Millionen Mark heruntergesetzt, und zwar in der Weise, daB der Nominalbetrag der Aktien lit. A im Verhältnis von 2:1, also von 39 Millionen auf 19,5 Millionen Mark reduziert wird. Dieser reduzierte Betrag sollte in allen Teilen, also insbesondere auch in bezug auf die Gewinnbeteiligung den bestehenden Vorzugsaktien lit. C gleichgestellt sein. Infolge dieser Umwandlungen schafft sich die Gesellschaft einen Buchgewinn von 19,5 Millionen Mark. Dem ursprünglichen Aktionär aber blieben nur noch $1 / 12$ oder ca. $8 \%$ des Nominalwertes seiner Aktien.

Im Geschäftsjahr 1898/99 wird dann das Aktienkapital von 33 auf 42 Millionen Mark erhöht. Das Plus von 9 Millionen Mark wird gebraucht zum vollständigen Erwerb der Zeche Adolf von Hansemann, von der die Union bereits 501 Kuxe besaB, ferner zum Bau von Arbeiterwohnungen. „Hiermit ist schon früher begonnen worden und 137 Wohnungen sind bereits bezogen. Weitere 146 Wohnungen werden noch im laufenden Jahre (1899) vollendet werden. 
Aber auch über das laufende Jahr hinaus wird mit diesen Bauten fortgefahren werden müssen, um dadurch eine dauernde Belegschaft für dic Zeche zu gewinnen." (Geschäftsbericht 1898/99.)

In der außerordentlichen Generalversammlung vom 9. Juni 1902 wird dann zweierlei beschlossen:

1. Eine Herabsetzung des Grundkapitals von 42 auf 25,2 Millionen Mark durch Zusammenlegung der Aktien lit. A im Verhältnis von 5:3. Dadurch erzielt die Gesellschaft einen Buchgewinn von 16,8 Millionen Mark. Der ursprüngliche Aktionär erleidet einen weiteren Verlust. Er hat jetzt nur noch $1 / 20$ oder ca. $5 \%$ seines ursprünglichen Kapitals in Händen.

2. Erhöhung des Grundkapitals auf 36 Millionen Mark durch Ausgabe von 10,8 Millionen Mark für Vorzugsaktien lit. D. Diese letzteren werden ebenfalls wieder von der Diskontogesellschaft gezeichnet und zu 100\% übernommen. Sie erhalten eine Vorzugsdividende bis zu 5\%, nach ihnen die Aktien lit. C eine Dividende bis zu 4\%. Ein dann noch verbleibender ÜberschuB wird auf sämtliche Aktien jeder Gattung nach ihrem Nennwert verteilt. Ist auf die Aktien lit. C während vier aufeinanderfolgender Jahre eine Dividende von $5 \%$ verteilt worden, so entfallen sämtliche Unterschiede zwischen beiden Aktienkategorien, und es wird damit das Gesamtkapital ein einheitliches und unterschiedsloses.

Ich möchte zum Schluß noch auf einen Vorgang aufmerksam machen, der sich bei der Kotierung der Aktien lit. D an der Berliner Börse ereignete. Die Zulassungsstelle derselben wollte die Einführung dieser Aktien nicht genehmigen, bevor nicht die nächstjährige Bilanz vorläge. Die Diskontogesellschaft beschwerte sich über den Beschluß bei dem Ältestenkollegium, dem bekanntlich die Berliner Börse gehört, und setzte die Einführung der D-Aktien auf diesem Wege durch.

Soviel über die finanzielle Geschichte der Union, und über die ungeheuren Verluste, die mit dem Besitz von Unionaktien für den Inhaber verbunden waren. Die kärglichen Gewinne, die sie ausschüttete, kommen demgegenüber gar nicht in Betracht. Ein Bild davon mögen folgende Zahlen geben: Die Union verteilte 1872/73 $12 \%$ Dividende. In den folgenden Jahren gar nichts. Dann erhielten die Aktien lit. A von 1878/79-1895/96: 0, 2, 21/2, 4, 5, 1, 11/4, 1/3, $1 / 3,2,3,4,2,1,1,0,0,0 \%$, die Aktien lit. C 1895/96-1902/03: 5, $5,5,6,7,0,0,2 \%$, die Aktien lit. D 1902/03: 5\%.

Werfen wir zum SchluB noch einen kurzen Rück- 
blick auf die finanzielle Geschichte der Union, so sehen wir ein kompliziertes Durcheinander finanzieller MaBregeln, die alle veranlabt werden durch den HeiBhungerdes Unternehmensnach Kapital, und dieser wieder steht im Zusammenhange mit den Erfordernissen der Bilanz und des Betriebes. Verluste zudecken und Produktionsmittelneuanzuschaffen, das waren die beiden wichtigsten Motive. Um nun das Geld für diese beiden $Z$ wecke zu erhalten, ist die Union nach zwei Richtungen hin vorgegangen, und damit haben wir den leitenden Faden, der sich durch alle groben Perioden ihrer Sanierung hindurchzieht, gewonnen. Sie hat einmal, um den Passivsaldo zu beseitigen, durch Zusammenlegung der Aktien das Nominalkapital stark heruntergesetzt. Durch diese Reduktionen wurde ein Buchgewinnerzielt:

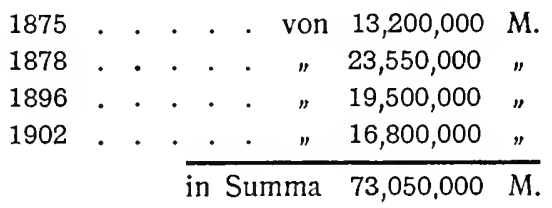

Nicht weniger als über 73 Millionen Mark sind im Laufevon $30 \mathrm{~J}$ ahrendurcheine Kettevon Zusammenlegungender Aktien, die wir näherkennen lernten, verschwunden. Wollte man aber an Stelle des Nominalwertes den Kurswert zugrunde legen, und würde man Obligationen und Bankschulden noch mit berücksichtigen, so würde diese Zahl noch bedeutend höher sein. Lindenberg spricht in seinem Buche ,50 Jahre Geschichte einer Spekulationsbank“*) sogar von 130 Millionen Mark, allerdings ohneden rechnerischen Nachweisdafürzuerbringen. Diese Verluste haben sich auf Kosten der Aktionäre vollzogen. Wir habengesehen, daB der ursprüngliche Aktionär im Laufe der Zeiterst $331 / 3$, dann 50 , dann $83-84$, dann 92 und schließlich $95 \%$ seines $\mathrm{Ka}$ pitals verloren hat, so daB er heute nur noch ca. $5 \%$

*) a. a. O., p. 120 . 
des früheren Nominalwertesseiner Unionaktien besitzt. Zu diesen Kapitalreduktionen gesellen sich dannKapitalerhöhungen, die aufder Basis des Prioritätensystems vorgenommen werden. Es folgen n a cheinander Aktienemmissicnen (Lit. A, B, C, D), von denendiefolgende immermehr Rechte gewährtals die vorhergehende. Bei allen diesen Transaktionen stand die Diskontogesellschaft der Union helfend zur Seite. Hättediesefinanzielle Unterstützung gefehlt, so wäredie Union längst in Konkurs geraten.

Soliegen heute, nacheinerdreiBigjährigen Vergangenheit die Dinge: Ein großes und stolzes Unternehmen von Weltruf, das sich dereinst rühmte, ,a n Größe des Zieles fast ohne Beispiel“" zu sein, geht, belastet durch die Vergangenheit, langsam an seinem geschichtlichen Verhängnis zu Grundewennesihm nichtgelingt, die Fehlerzubeseitigen, die wir in dieser Darstellung kennen lernten.

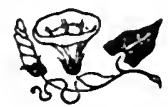




\section{Phönix.}

Es gibt meines Erachtens unter den deutschen Eisenwerken keines, das in seiner Verfassung, seinem Aufbau und seiner ganzen geschichtlichen Entwicklung soviel Ähnlichkeit mit der Dortmunder Union aufwiese, wie das Unternehmen, das in diesem Abschnitt Gegenstand eingehender Untersuchung sein soll. Diese ursprünglich und vor allem wieder in neuester Zeit stark hervortretenden verwandtschaftlichen Beziehungen zweier vollständig unabhängig voneinander dastehender Werke haben in der Tat etwas Überraschendes, aber sie treten, wenn man im Geiste die ältesten und die jüngsten Jahre beider an sich vorüberziehen läßt, so klar hervor, daB man sie unmöglich übersehen kann. Allerdings nimmt die Entwicklung des rheinischen Werks einen relativ günstigeren Verlauf als die des westfälischen. Das beruht im wesentlichen darauf, da $B$ es dem ersteren teilweise gelang, die Quellen seiner Mißerfolge zu verstopfen, was bei dem letzteren, wie wir sahen, bisher nicht der Fall war.

Wir beginnen mit der Gründung. Am 10. November 1852 wurde die Firma Th. Michiels \& $\mathrm{Co}$. in Eschweiler-Aue in eine Aktiengesellschaft umgewandelt unter dem Namen Phönix, anonyme Gesellschaft für Bergbau und Hüttenbetrieb. Ihr Besitz erstreckte sich auf ein Walzwerk und einige Eisensteingruben. Um nun das Erz selbst schmelzen zu können, erbaute die Gesellschaft 1853 zwei Hütten: die eine zu Kupferdreh, die andere zu Laar bei Ruhrort. 1855 wurden diese Betriebe mit einer Hütte der Société des Mines et Fonderies du Rhin Charles Detillieux et Co, zu Borbeck vereinigt. Damit Hand in Hand ging eine Erhöhung des ursprünglich 4,5 Mill. betragenden Aktienkapitals auf 18 Mill. Mark, die jedoch zu einem Teil nicht zur Emission gelangten.

Das eigenartige dieser Genesis liegt ganz ähnlich wie bei der Dortmunder Union darin, da $B$ mehrere Betriebe, die räumlich weit voneinander getrennt sind, zu einem einheitlichen Unternehmen ver- 
schmolzen werden. Die anonyme Gesellschaft Phönix repräsentiere also die Vereinigung früher getrennter Etablissements. Sie stellte sich die Aufgabe, die Fabrikation des Roh- und Fertigeisens nach englischer Methode in die Kohlendistrikte der Preußischen Rheinprovinz einzuführen. In dem Bericht vom 30. Oktober 1855 heißt es wörtlich: „Jene anfänglich durch vereinzelte Anstrengungen geschaffenen Etablissements haben durch ihre Vereinigung Kraft gewonnen und bilden jetzt ein vollkommen zusammenhängendes Ganze, welches den Vergleich mit den gröBten in Belgien und Frankreich geschaffenen Werken derselben Art aushält.“

An diese Kräftezusammenballung knüpften die Gründer große Hoffnungen. Als damals der GroBbetrieb, der ja schon den ganzen Bergbau des Mittelalters beherrschte, um die Mitte des 19. Jahrhunderts in Rheinland-Westfalen, also wesentlich später als in Oberschlesien, seinen Einzug in die Eisenhüttenindustrie hielt, da verbanden sich damit die weitgehendsten Erwartungen. Es darf daher nicht wunder nehmen, wenn in dem Geschäftsbericht von 1856 das Unternehmen über sich selbst folgendermaßen urteilt: „In der Tat ist die Gesellschaft Phönix dic bedeutendste aller bisher in Deutschland zum Zwecke der Eisenfabrikation gegründeten Gesellschaften und vereinigt in sich alle Elemente, welche erforderlich sind, um ihr eine glänzende Zukunft zu sichern."

Diese Erwartungen stützten sich auf drei Grundlagen:

1. Auf die metallurgischen Reichtümer der Gesellschaft an Eisenerzen. Die Gruben, welche die Eisenerze lieferten, lagen in drei großen Distrikten: Es befanden sich 43 Konzessionen gegen fixierte Abgaben im NieBnutz der Gesellschaft im Ruhrbassin; ferner 16 groBe Förderungsstellen an den Rhein- und Moselufern und schlieBlich 95 Konzessionen im Herzogtum Nassau. Die Gesamtproduktion an Erzen stellte sich 1855/56 auf über 125000 Tonnen. „Dieser unschätzbare Reichtum“, sagt der Bericht, „sichert uns unseren Bedarf an Erzen*) in der für die Darstellung des Roheisens wünschenswertesten Auswahl. Wir können ohne Übertreibung behaupten, daB in dieser Beziehung keine andere metallurgische Gesellschaft im Lande ähnliche Hilfsquellen besitzt." Natürlich konnte man damals noch nicht voraussehen, welche Revolution die Eisenindustrie in ihren Tiefen aufwühlen, und welchen Wert in Zukunft das Eisenerz an der Ruhr, am Rhein und an der Lahn haben

*) Gemeint ist die Deckung des Bedarfes. 
werde. Heute ist die Phönixhütte geradeso wie die Westfälischen Werke hauptsächlich auf den Kauf fremder Erze angewiesen. Damals aber lagen die Verhältnisse noch anders.

2. BesaB die Gesellschaft zwei Kohlenzechen in $\mathrm{Pacht}$. Eine dritte, Rhein-Elbe, die im Abbau begriffen war, wird 1856 an die Gelsenkirchener Gesellschaft für Kohlengrubenbetrieb zum Preise von 720000 Mark verkauft. Das Werk verdiente daran 282000 Mark. Es hatte die Zeche bei der Fusion mit der oben erwähnten französischen Gesellschaft für Rheinischen Bergbau und Hüttenbetrieb erworben.

Diese Politik, Kohlenzechen zu pachten, wurde später aufgegeben, weil die betreffenden Kohlenbergwerke große Kosten verursachten und Zubußen erforderten. Allerdings kehrte man in den 90er Jahren, wie wir noch sehen werden, wieder zur Selbstbedarfsdeckung zurück.

In den 50er Jahren waren die Produktionskosten der Rohstoffe noch verhältnismäBig hohe. Dazu trug hauptsächlich bei der kostspielige Transport derselben $z u$ den Hütten. Anfänglich waren es Bauern der Umgegend, die die Erze von den Gruben der Gesellschaft zu den Uferstellen fuhren. Aber bald schafft sie sich eigene Pferde an und nimmt den Transport des Urmaterials selbst in die Hand. Derselbe bildete einen wichtigen Tätigkeitszweig der Gesellschaft. Sie unterhielt 254 eigene Zugpferde, 47 eigene Schiffe, die den Eisenstein von den verschiedenen Lagerstellen an den Lahnufern bis nach Lahnstein und Ruhrort brachten. Natürlich wurde infolge der getrennten Lage der Betriebe die Fabrikation nicht unbedeutend verteuert. In welcher Weise die ungünstigen Schiffahrtsverhältnisse auf der Lahn mitwirkten, werden wir später sehen.

Der bei der Schmelzung der Erze erforderliche Kalkstein wurde anfangs von verschiedenen Lieferanten beschafft. Aber sehr bald wurde dieser Modus verlassen. Zur Vermeidung der aus unvollkommener Einhaltung der betreffenden Lieferungsverträge möglicherweise entstehenden Gefahren und namentlich auch um Preissteigerungen entgegenzutreten, kaufte die Gesellschaft zwei Kalksteinbrüche. Der Ankaufspreis derselben wurde durch die Ausbeute selbst amortisiert.

3. Das ganze Unternehmen basiert nun auf der Verarbeitung des Roheisens in ren Stahl-und Walzwerken. Es verbindet also die Erzeugung der Rohstoffe mit ihrer Veredlung. Es bleibt nicht bei der Förderung von Kohle und Eisenstein stehen, sondern es wandelt dieselben in Fabrikate für den 
Markt um. Für die Phönixhütte brachte dieses Programm gleich im Anfange große Vorteile mit sich. Gegen die gesteigerten Produktionskosten der Kohle in der ersten Zeit des Betriebes wird durch Verbesserung in der Fabrikationsweise angekämpft, und die Mehrausgaben für Rohstoffe werden durch die Mehreinnahmen für das Fabrikat überkompensiert.

Der Schwerpunkt der Fabrikation beruhte in der Herstellung von Eisenbahnschienen. Dieselben wurden aus dem in den Puddelöfen hergesteliten Schweißeisen erzeugt. „Unsere Gesellschaft“, schreibt der Geschäftsbericht über das Jahr 1856/57, „hat sich einen wohlverdienten Ruf durch die gute Qualität ihrer Schienen erworben und darf daher im Fortschritt nicht stehen bleiben. Die Schienenfabrikation, welche ihren Hauptabsatz fördert, wird immer ihren wichtigsten Industriezweig bilden." Damals schrieb die Eisenbahndirektion noch das Hämmern der Schienen vor, ein heute vollständig verlassenes Verfahren. Infolgedessen wird ein Teil der Luppenpressen durch Hämmer ersetzt. Die Eisenbahn zahlte für das Hämmerı von 1000 Pfund Schienen einen um 9 Mark höheren Preis, welcher ungefähr die Mehrkosten der Fabrikation ausmachte. Die Schienen wurden in den beiden Etablissements von Eschweiler-Aue und in Ruhrort hergestellt. Die Produktion belief sich im Jahre 1854/55 in Eschweiler-Aue und Ruhrort:

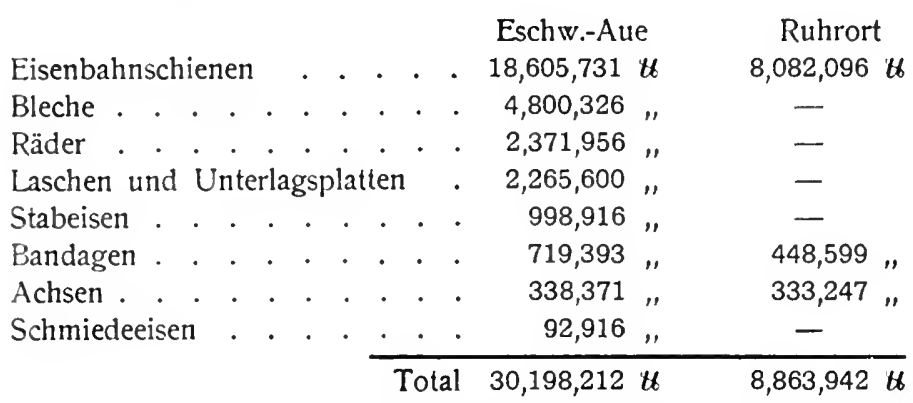

d. h., es wurden im ganzen hergestellt 18250 Tonnen fertiges Fabrikat.

Das waren die Verhältnisse, auf die sich die Erwartungen stützten. Der natürliche Reichtum an Eisenerz und Kohlen und die Fabrikation von Eisenbahnschienen und Eisenbahnoberbaumaterial bildeten die Grundlage des jungen Unternehmens. Wenn man nun den Geschäftsberichten allein vertraut, kann man nicht verstehen, wie dieses 
anscheinend auf so sicherer Grundlage fundierte Werk nach wenigen Jahren vor dem Bankerott stehen konnte. Sieht man näher zu, so erkennt man, daB bei der Gründung bedeutende Fehler gemacht wurden, und $\mathrm{da} B$ auch der ganze Gründungsvorgang keineswegs so korrekt verlaufen war wie das hätte sein müssen. Die Börse hat für solche Dinge ein feines Verständnis. Längst vor Ausbruch der großen Handelskrisis des Jahres 1857 erlitten die Aktien des Phönix beträchtliche Kursrückgänge. Damals schrieb die älteste und angesehenste Finanzzeitschrift Deutschlands, der Frankfurter „Aktionär“, unterm 14. Oktober 1855 (p. 331) über den Phönix folgendes: „Diese Gesellschaft gehört zu jenen pomphaften Unternehmungen Pariser Spekulation, die mit Millionen auftretend in einem kühnen Sprunge Erfolge erstreben, wozu seit jeher überall in der Welt nur arbeitsame Ausdauer, mühevolle Erfahrung und weise Ökonomie geführt haben. Auf dem Felde der Industrie reifen die Früchte nicht über Nacht."

Welches waren nun die Ursachen, die den Keim des Verfalls in kurzer Zeit zu nähren imstande waren? Aus der weiteren Entwicklung und den ergriffenen Maßnahmen ergibt sich folgendes: In erster Linie bestand die Schwierigkeit darin, daß räumlich weit voneinander getrennte Betriebe einheitlich arbeiten. Sie lag begründet in der Entstehungsgeschichte des Unternehmens.

Ferner bestand ein eklatantes Mißverhältnis zwischen stehendem und umlaufendem Kapital. Das hatte seine Ursachen in folgendem: Bevor das ganze Aktienkapital im Betrage von 18 Millionen Mark untergebracht war, schritt die Verwaltung zu größeren Anlagen unter der Voraussetzung, die nicht untergebrachten 4,8 Millionen Mark würden sich leicht realisieren lassen. Das war aber nicht der Fall. Die Ausdehnung und die technische Vervollkommnung der Anlagen überschritt daher bald das verfügbare Kapital. Schließlich ergab sich, $\mathrm{da} B$ die Anlagen mehr kosteten, als ursprünglich vorausgesetzt war. Die Erweiterung der Produktionsmittel galoppierte gleichsam über das zur Disposition stehende Kapital hinaus.

Um sich nun neue Betriebsmittel zu verschaffen, versuchte die Gesellschaft zwei Wege einzuschlagen, ohne daß es ihr jedoch gelungen wäre, zum Ziele zu gelangen. Einmal wollte sie an Stelle der noch im Portefeuille befindlichen Aktien Obligationen emittieren. Aber damals hingen derartige Maßnahmen noch von der Genehmigung der Landesregierung ab. Keine Gesellschaft konnte ihr Betriebskapital aus freien Stücken vergrößern. Es war dies noch eine lebendig gebliebene Reminiszenz an die landesväterliche Politik der Vergangen- 
heit. So versagte denn die Regierung ihre Zustimmung. Das einzige Mittel, das nun noch übrig blieb, um zur al pari Ausgabe der Aktien zu gelangen, war, sie in privilegierte Aktien umzuwandeln. Diese sollten $6 \%$ Zinsen vor jeder anderen Verteilung einer Dividende aus dem Reingewinn erhalten. In der außerordentlichen Generalversammlung vom 11. Mai 1858 wird der Antrag der Direktion angenommen, „daß zur Verbesserung der Finanzlage der Gesellschaft durch Vermehrung des Betriebsfonds und gleichzeitig zur Ermöglichung der Emission der 16000 Prioritätsaktien die durch die Direktion vorgeschlagene Zahlungsweise der Dividende durch Prioritätsaktien al pari bis zur vollständigen Emission dieser Prioritätsaktien als eine unumgängliche Notwendigkeit erscheine." In bezug auf die bisher nicht begebenen sollten 25 Aktien der früheren Emission ein Anrecht auf eine privilegierte Aktie haben. Solche Vorzugsaktien sollten auch in den folgenden Jahren ausgegeben werden bis zur Vervollständigung des statutenmäßigen Gesellschaftskapitals auf 18 Millionen Mark. Als nun aber 1857 die Krisis ausbrach, wurde es unmöglich, diese Aktien unterzubringen. Der Plan, dadurch genügende Geldmittel zu erhalten, war also auch gescheitert. Über diesen geldlosen Zustand klagt der Bericht vom 11. Mai 1858 in beweglichen Worten: „Die Gesellschaft Phönix bietet auf der einen. Seite große metallurgische Reichtümer, herrliche Hüttenanlagen, eine blühende Industrie (nur durch vorübergehende Verlegenheiten etwas leidend: gemeint ist die Krisis von 1857-1860), eine von den Konsumenten gerühmte Fabrikationsmethode, zahlreiche Aufträge, welche beinahe ihre ganzen Produktionskräfte bis zum Monat April 1859 in Anspruch nehmen, und einen regelmäßigen Gewinn, den wir mit Recht als gesichert betrachten dürfen. Auf der anderen Seite finden. wir einen offenbar unzulänglichen Betriebsfond, die Notwendigkeit, fremden Kredit in einem Maße in Anspruch zu nehmen, welches zu vergrößern verderblich wäre, der vielmehr eine Einschränkung dringend erheischt, und endlich die Unmöglichkeit, augenblicklich die einzigen Wertpapiere anzubringen, zu deren Ausgabe wir befugt sind. Solche Vorteile, meine Herren, darf man nicht beeinträchtigen, und solche Übel nicht vergrößern. Deshr"b schlagen wir Ihnen aus vollster Überzeugung vor, die zu verteilende Dividende auf $4 \%$ festzustellen." In diesen Worten ist bereits gesagt, wie die Gesellschaft, die sich das nötige Betriebskapital weder durch Ausgabe von Obligationen, noch durch Aktien verschaffen konnte, verfuhr: Sie nahm den Akzept- und Lombardkredit der Bankhäuser im weitgehend- 
sten Maße in Anspruch. Bekanntlich sind das aber sehr teure Kredite. 1857, als einem Werte von über 6 Millionen Mark an Vorräten, Rohstoffen und Fabrikaten ein wirklicher Betriebsfond von 426000 Mark gegenüberstand, kosteten die Bankkredite nicht weniger als 360000 Mark. Dazu traten nun während der Krisis noch Verluste. Das Jahr 1856/57 hatte noch einen Gewinn von 1471137 Mark gebracht Die folgenden beiden Jahre ergaben keinen Gewinn und die Bilanz von 1859/60 schloß sogar mit einem Verlust von 395091 Mark. In dem letztgenannten Jahre betrugen die Generalunkosten die Summe von 596286 Mark. Davon entfielen allein 505500 Mark auf die Beschaffung der Betriebsmittel, d. h. auf Zinsen und Diskontgebühren an die verschiedenen Bankiers. Es war noch ein Glück, für das Unternehmen zu nennen, $\mathrm{da} \beta$ es ihm gelang, kurz vor Ausbruch des italienischen Krieges einen Vertrag mit den Bankhäusern, mit denen es in Geschäftsverbindung stand, abzuschließen, in dem sie der Gesellschaft einen Kredit von 3660000 Mark für 6 Jahre garantierten. Aber auch diese Summe reichte nicht aus. „Um die im Laufe des verflossenen Jahres", heißt es in dem Geschäftsbericht von 1859/60, ,fällig werdenden Verpflichtungen erfüllen zu können, waren wir indessen nicht nur genötigt, den von den Bankiers uns eröffneten Kredit zu erschöpfen, sondern mußten mehrmals durch Eskomptierung von Fakturen uns die nötigen Mittel für bestimmte Verfallzeiten sicher stellen." Dann heißt es weiter: „Der Kredit bei den Bankiers ist erschöpft. Über die aus den vorhandenen Aufträgen zu erzielenden Geldmittel mußte meistens schon vor Beendigung der Lieferung verfügt werden." Damals versuchte die Direktion auf alle mögliche Art und Weise aus der Klemme herauszukommen, sei es durch Verpfändung oder Verkauf von Waren, sei es durch den Versuch, neue Anleihen aufzunehmen. SchlieBlich wandte sie sich durch Zirkulare an ihre Aktionäre, um dieselben unter Darlegung der mißlichen Verhältnisse des Unternehmens aufzufordern, durch Subskription neu zu emittierender Obligationen der Gesellschaft die Mittel zu bieten, ihren Verpflichtungen nachkommen zu können, und sich das nötige Betriebskapital zu verschaffen. Aber alle diese Versuche führten nicht zu dem gewünschten Erfolg. Infolgedessen stand im Jahre 1860 die Gesellschaft vor dem finanziellen Zusammenbruch: Wenn sie kein Geld mehr bekam, mußte sie ihre Zahlungen einstellen, konnte sie ihren Betrieb nicht weiter führen, und das ganze Aktienkapital wäre verloren gewesen.

Inwieweit durch eine fehlerhafte Organisation der Verwaltung 
und durch ungeeignete Persönlichkeiten in derselben die Schwierigkeiten der Gesellschaft bedingt, resp. vergrößert wurden, läßt sich heute wegen Mangel an Material leider nicht mehr mit genügender Sicherheit feststellen. Jedenfalls hatte man hier verschiedene Fehler genacht, und auch darin zeigt sich eine Übereinstimmung mit den späteren Verhältnissen der Dortmunder Union. So war der Sitz und die Zentralverwaltung der Gesellschaft weit ab von den Etablissements nach Köln gelegt worden. Eine elfköpfige Direktion leitete die Geschäfte. Aber sie war teuer und erfüllte ihre Zwecke nicht. Generaldirektor war Charles Detillieux, ein Franzose. Auch hier scheint eine zu starke Zentralisation sich nicht bewährt zu haben, wenigstens geht das aus der späteren Reorganisation hervor, wo man dieses Prinzip fallen lieB.

Schließlich müssen wir noch ein Moment erwähnen, das den Betrieb der Hütte stark schädigte und die ungünstigen Ergebnisse sicherlich mit bestimmt hat: nämlich die Schwierigkeit des Erztransportes. Vor Eröffnung der Lahnbahn, d. h. vor 1862/63, war der Transport der Eisenerze zu den Hochöfen wegen des niedrigen Wasserstandes der Lahn vielfach derartig eingeschränkt, daß sich an den Lagerplätzen große Erzmassen anhäuften, für die Hochöfen aber kein genügendes Material an Ort und Stelle war. Daher heißt es im Geschäftsbericht von 1858: „Denn obgleich wir auf den Gruben und Uferplätzen 60000 Tonnen Eisenstein vorrätig haben, konnten wir uns, ohne ein Steigen der Gewässer, derselben nicht bedienen und waren daher genötigt und sind es noch immer, von weit her einen Teil des zum Betriebe unserer Hochöfen nötigen Eisensteins zu bezichen. Außerdem waren wir gezwungen, die Hälfte unserer Hochöfen auszublasen und den dadurch entstandenen Ausfall an Roheisen zum Betriebe der Fabrikation durch Ankauf in Belgien zu ersetzen ..." Einen ähnlichen Zusammenhang zwischen dem Hochofenbetrieb und der FluBschiffahrt, resp. dem Wasserstande, lernten wir bereits bei dem Hattinger Werk der Dortmunder Union kennen. Gewiß waren diese Verhältnisse sehr exzeptionell, und sie wurden durch die Eröffnung der Lahnbahn gehoben, aber es war notwendig, ihrer an dieser Stelle zu gedenken.

So haben wir denn, von den letzteren auf Naturereignissen beruhenden Verhältnissen abgesehen, drei Punkte kennen gelernt, bei denen eine Reorganisation einsetzen muBte: nämlich die räumliche Trennung der Be- 
triebe, ferner die Beschaffung von Betriebsmitteln und schlieBlich die Organisation der Verwaltung.

Es war ganz zweifellos, daß der Konstruktion des Unternehmens prinzipielle Fehler zu Grunde lagen, die in den ersten Jahren der Tätigkeit der Gesellschaft erst unberrerkt und verschleiert hervortraten, aber durch die Krisis in der Eisenindustrie von 1857-1860 gleichsam erst herausgearbeitet wurden. In dieser geschäftsflauen Zeit gingen die Aufträge und Bestellungen stark zurück. Die Preise der Eisenfabrikate sanken. Die Selbstkosten stiegen in nicht unbeträchtlichem Maße. Der größte Teil der Öfen feierte. Auch die Gruben lagen still, denn der geförderte Eisenvorrat reichte aus, die Hütte zu beschäftigen. Ein großer Teil der übernommenen Schienenlieferungen, die immer noch die Hauptmasse der Produktion ausmachten, bestand nur in Umwalzung von altem Eisen, wobei nur wenig eigenes Roheisen Verwendung fand. Die Produktion im ganzen sank beinahe auf die Hälfte. Der einzige Artikel, in dem im Geschäftsjahr 1859/60 eine nennenswerte Steigerung gegen das Vorjahr zu verzeichnen war, war Handelseisen. Aus alledem ergab sich die Notwendigkeit, den Wertbestand $z u$ reduzieren, mit anderen Worten: es trat eine allgemeine Entwertung ein.

Unter diesen Umständen war eine finanzielle und administrative Reorganisation unbedingt erforderlich. Die Bankiers der Gesellschaft arbeiteten nun einen Plan aus, der mit seinen Vorschlägen anknüpft an die Ursachen, die das Unternehmen bis vor die Katastrophe gebracht hatten. Wir hatten gesehen, daß in der räumlichen Trennung verschiedener Betriebe, resp. in ihrer Fusion zu einem einheitlichen Unternehmen eine dauernde Quelle von Schwierigkeiten lag. Hier war daher der Hebel einzusetzen. Im Gegensatz zur Dortmunder Union wurde dieser Punkt frühzeitig richtig erkannt, wenngleich die theoretische Erkenntnis nicht durch praktische Maßnahmen unterstützt, ja, die Dezentralisation der Betriebe in allerneuester Zeit sogar durch Angliederung eines weit verzweigten fremden Unternehmens noch erhöht worden ist.

Es wurde daher von der zur Untersuchung eingesetzten Kommission gefordert: Verkauf derjenigen Etablissements, welche die Gesellschaft entbehren kann. Auf diese Forderung ist man später nicht mehr zurückgekommen, aber die heutigen Verhältnisse des Phönix zeigen, wie sehr man damit gesündigt hat. Die heute bestehende Unterbilanz von Eschweiler-Aue hängt damit zusammen.

Der zweite Punkt war die finanzielle Reorganisation. Die Bankiers 
hatten hauptsächlich von dieser ihre weitere Kreditgewährung abhängig gemacht, namentlich David Hansemann, der in der Direktion der Gesellschaft saß. Das bisherige Grundkapital von 18 Millionen Mark wird durch Reduktion des Nominalwertes und Vernichtung der noch nicht begebenen Aktien in ein solches von 1,8 Millionen Mark umgewandelt. Die abgestempelten Aktien erhalten den Buchstaben B. Durch diese Herabminderung der Passiven erzielte die Gesellschaft einen Bilanzgewinn von 16,2 Millionen Mark. Außerdem werden 7,5 Millionen Mark neue Aktien lit. A und nach Bedürfnis 1,5 Millionen Mark (die aber erst 1873 in der Bilanz erscheinen), ausgegeben. Das Gesamtkapital der Gesellschaft beträgt nunmehr 9,3 Millionen Mark. Nachdem diese riesenhafte Division des Aktienkapitals vorgenommen war, konnte die Gesellschaft mit Recht von sich sagen: „Wir dürfen wohl die Behauptung aufstellen, daß nicht manche Gesellschaft im Zolivereine besteht, deren Werke zu so billigem Preise in den Büchern figurieren und die auf so solider Basis beruht." (Geschäftsbericht von 1862/63.)

Der dritte Punkt betrifft die Reorganisation der Verwaltung. Zunächst wird das Domizil der Gesellschaft und ihrer Zentralverwaltung von Köln nach Laar verlegt. An Stelle der elfgliedrigen Direktion tritt eine dreigliedrige. Sie untersteht der Kontrolle des Administrationsrates. Dieser wurde erst in der außerordentlichen Generalversammlung im Jahre 1859 zum Schutze der Aktionäre eingesetzt. Ein neuer Generaldirektor tritt an die Spitze des Betriebes. Die Rechte der Aktionäre werden erweitert. Nach dem alten Statut bestanden die Rechte derselben eigentlich nur darin, daB sie alljährlich Bilanzrevisoren ernannten und die Bilanz guthießen. Nach dem neuen Statut sind die Aktionäre befugt, in der Generalversammlung vermittelst der Wahl der Mitglieder des Administrationsrates permanente Kontrolleure zu ernennen (Artikel 19), ja, eine integrale Neuwahl vorzunehmen, wenn etwa sich herausstellte, daß durch die Majorität der gewählten Mitglieder das Vertrauen der Aktionäre nicht gerechtfertigt würde. Das war der erste Schritt der Annäherung an das moderne Aufsichtsratwesen.

Die neuen Statuten erlangten am 18. November 1860 die landesherrliche Genehmigung. Damit schlieBt der erste Akt in der Geschichte des Phönix.

Resumieren wir noch einmal die wesentlichen Punkte, so ergibt sich folgendes: Die Aktiengesellschaft Phönix ist das Produkt der Verschmelzung verschiedener Eta- 
blissements, die räumlich getrennt, von einem Punkte, nämlich ursprünglich von Köln aus, verwaltet wurden. Das Unternehmen beruhte auf dem Reichtumeigener Eisen-und Kohlengruben und a uf der Verarbeitung des in eigenen Hochöfen gewonnenen Roheisens $z u$ handelsfertiger Ware. Der Schwerpunkt der Fabrikation lag in der Herstellung von Schienen. Gestützt auf diese Unterlagen nahm das junge Unternehmen in den ersten Jahren seines Bestehenseinenstürmischen Anlauf, dereine GröBe der Leistung und des Erfolges erwarten lieB, die ihm die erste Stelle unterden Eisenwerken des Zollvereins hätte zuerteilen können. Allein noch vor Ausbruch der Krisis des Jahres 1857 zeigte sich, da $B$ die Weiterentwicklung an Schwierigkeiten anstie $B$, die dem Unternehmen lebensgefährlich werden sollten. Zunächst war es die weite Entfernung dereinzelnen Betriebe voneinander, welchedie Leitung und die Produktion erschwerte. Weiter kam ein finanzielles Moment von gröBter Tragweite in Betracht. Die Gesellschaft hatte ihre Aktien nur teilweise untergebracht. Als sie nun ihre Produktionsmittel vergröBerte - die ersten Jahre waren hauptsächlich Baujahre - da entstand ein MiBverhältnis $z w$ ischen umlaufendem und stehendem Betriebskapital. Um dies zubeseitigen, versuchtedie Verwaltung neue Aktien und Obligationen a uszugeben. Aber das gelang nicht aus Gründen, die wir kennen lernten. Darauf versuchte sie, die noch in ihrem Portefeuille befindlichen 4,8 Millionen Mark durch Umwandlung in Prioritätsaktien verlockender zu machen. Jedoch die ausbrechende Krisis legte diesen Modus der Kapitalbeschaffung brach. Da alle diese Mittel versagten, blieb nur noch die Möglichkeit, teure Bankkredite in Anspruch zu nehmen. Diese verschlangen riesige Summen. Der Phönix wurde ein zinsenfressendes Unternehmen. Jahrelang wurde nur für die Bankiers gearbeitet. SchlieBlich zogen auch diese ihrem Kredit eine Grenze und knüpften weitere Kapitalvor- 
schüsse an eine fundamentale Reorganisation der Gesellschaft. Die Sanierung war daher ein Gebot der Notwendigkeit, denn schlieBlich kann auch das gröBte Unternehmen seine Kontoreschlie $B$ en, wenn es keinen Kredit mehrerhält. In diesem Augenblick ruhte die Existenz des Phönix auf des Messers Schneide. Sie trieb im Schnelltempo einer Katastrophezu. Ein rascher Eingriff war unvermeidlich. Was nun folgte, war so radikal gedacht, daB wohl kaum eine Gesellschaft in Deutschland existieren dürfte, deren Aktien miteinem Schlage im Nominalwertso heruntergesetzt wurden, wie die des Phönix. Das bisherige Grundkapital von 18 Millionen Mark wurde in ein solches von 1,8 Millionen verwandelt, d. h. die Aktien wurden zusammengelegt im Verhält$n$ is von 10:1, 16,2 Millionen Mark verschwanden in den Büchern der Gesellschaft. AuBerdem wurden, wie wir sahen, 7,5 Millionen neuer Aktien lit. A ausgegeben. An diese finanzielle Reorganisation, die durchaus im Mittelpunkt steht, schloB sich eine Änderung in der Organisation der Verwaltung. Sie wird dezentralisiert. Ihr Sitz ist nicht mehr Köln, sondern Laar. Die Rechteder Aktionärewerden erweitert.

Das sind die Grundzüge der im Vorhergehenden dargestellten ersten Entwicklung des Phönix.

Nach der Reorganisation im Jahre 1860 trat das Unternehmen in eine Periode ein, die, da die allgemeinen Verhältnisse der Eisenindustrie nicht ungünstig waren, auf der Grundlage sehr niedriger Buchziffern finanziell günstige Resultate zeitigen mußte. Weil die einzelnen Konten stark heruntergeschrieben waren, wird aus den Gewinnen nichts dem Reservefond zugeführt, und dieses Prinzip beibehalten, solange derselbe nicht unter 744693 Mark herabsank. Die finanziellen Resultate waren folgende:

\begin{tabular}{|c|c|c|c|}
\hline \multirow{2}{*}{ Jahr } & \multirow{2}{*}{ Reingewinne } & \multicolumn{2}{|c|}{ Dividenden } \\
\hline & & lit. A & lit. $B$ \\
\hline $1860 / 61$ & $254,016 \mathrm{M}$ & $6 \underset{p o}{g}$ & - \\
\hline $1861 / 2$ & 596,001 & $7 \%$ & $2,78 \%$ \\
\hline $1862 / 3$ & 674,772 & $71 / 2 \stackrel{0}{N}$ & $41 \% \%$ \\
\hline $1863 / 4$ & 814,062 & $81 / 2 \%$ & $6,94 \%$ \\
\hline
\end{tabular}




\begin{tabular}{|c|c|c|c|}
\hline \multirow{2}{*}{ Jahr } & \multirow{2}{*}{ Reingewinne } & \multicolumn{2}{|c|}{ Dividenden } \\
\hline & & lit. A & lit. B \\
\hline $1864 / 5$ & $1,021,347 \mathrm{M}$ & $10 \%$ & $11^{1 / 9} \%$ \\
\hline $1865 / 6$ & $1,098,354$ & $10^{1} / 2 \%$ & $121 / 2 \%$ \\
\hline $1866 / 7$ & $1,169,481$ & $11 \%$ & $13^{4} / 5 \%$ \\
\hline $1867 / 8$ & $1,641,255$ & $15 \%$ & $25 \%$ \\
\hline $1868 / 9$ & $1,910,952, "$ & $17 \%$ & $305 / 9 \%$ \\
\hline $1869 / 70$ & $1,770,663$ & $16 \%$ & $27 \%$ \\
\hline $1870 / 1$ & $1,257,552$ & $12 \%$ & $16^{2} / 3 \%$ \\
\hline $1871 / 2$ & $1,653,657$, & $15 \stackrel{o}{\%}$ & $25 \%$ \\
\hline $1872 / 3$ & $1,969,574$ & $15 \%$ & $30 \%$ \\
\hline $1873 / 4$ & $1,086,528$, & $8 \stackrel{\alpha}{o}$ & $62 / 3 \%$ \\
\hline
\end{tabular}

Aus dieser Tabelle ergibt sich, daB der Gesellschaft steigende Reingewinne erwuchsen, und da $B$ im Jahre 1868/69 die Dividende ihren Kulminationspunkt mit 305\% für die Aktien lit. B und $17 \%$ für die Aktien lit. A erreichte, ein Resultat, dem nur das Gründerjahr 1872/73 nahe kam.

Um einen Überblick zu erhalten, betrachten wir nun das Charakteristische dieser von guten Geschäftsgewinnen erfüllten Periode auf drei Gebieten:

1. auf dem Gebiete der Rohstoffversorgung,

2. auf dem Gebiete der Produktion,

3. auf dem Gebiete der gemeinnützigen Tätigkeit.

In den 60er Jahren vollzieht sich eine Änderung in der ökonomischen Lage der Kohlenzechen. Die Gesellschaft beginnt an denselben zu laborieren. Die Zeche Graf Beust erforderte wiederholt Zubuße. SchlieBlich verkauft die Gesellschaft im Jahre 1864 die Nutzungs- und Administrationsrechte, welche ihr noch bis zum Jahre 1884 zustanden, für die Summe von 780000 Mark an Friedrich Grillo, resp. an die Firma Krupp.

In bezug auf den Transport der Erze treffen wir jetzt günstigere Verhältnisse als früher. Im Geschäftsjahr 1862/63 wurde der Betrieb der Lahnbahn eröffnet. Dieselbe gestattete eine verhältnismäßig billige und regelmäßige Anfuhr an den Rhein. Jedoch werden die Lahnschiffe beibehalten, damit der Transport nicht allein von der Eisenbahn abhängig sei. An Erzen wurden von den in der Gegend der Lahn belegenen Gruben befördert:

$\begin{array}{lcc} & 1862 / 3 & 1863 / 4 \\ \text { auf der Lahnbahn } & 34,420,000 \text { \& } & 71,989,000 \text { \& } \\ \text { per Schiff } & 76,750,000 ~ " & 27,402,200 ~\end{array}$

"Velche Bedeutung diese Bahn für das Hüttenwerk hatte, erkennt 
man aus den Zahlen des Jahres 1863/64, wo die Lahn nur fünf Monate fahrbar war.

Was die Produktion anbelangt, so liegt zwar in den 60er Jahren der Schwerpunkt noch in der Schienenfabrikation, aber sie nimmt bereits leise $a b$. Hingegen nimmt die Herstellung von Handelseisen gewaltig zu. Der Sitz dieser Fabrikation wird Eschweiler-Aue. Von 18,S Millionen Pfund fertigen Fabrikates entfallen bereits 1861/62 10,1 Million auf Handels- und profiliertes Eisen. In Ruhrort wird 1862/63 die Fabrikation von Feinkorn-Puddelstahl und zementierten Schienen neu aufgenommen und die Fabrikation von Stabeisen durch Errichtung einer Waizenstraße für Feineisen bedeutend erhöht. In Eschweiler-Aue hingegen wird die Herstellung von Scheibenrädern mit angeschweißten Unterringen und von ganz schmiedecisernen Rädern in verschiedener Form eingeführt. Außerdem wird in Eschweiler-Aue eine Fabrik feuerfester Steine errichtet. Die Lage dieses Werkes hat sich in dieser Periode von Grund auf geändert. $1870 / 71$ hatte man in Laar mit dem Bau eines großen Stahlwerkes begonnen. Durch die Einführung des Bessemerverfahrens wird ein ProzeB der Konzentration der Hauptbetriebszweige in Ruhrort eingeleitet. Während anfangs die Hütte in Eschweiler-Aue hauptsächlich Eisenluppen und Schweißeisenfertigfabrikate, also Handelseisen, Eisenbleche, Räder, Achsen, Radreifen und vor allem Eisenbahnschienen hergestellt hatte, wird durch den BessemerprozeB die Aufgabe der Hütte verschoben, indem ihre Hauptbetriebszweige Schienen, Achsen und Radreifenfabrikation nach Ruhrort verlegt werden. So blieb für die Hütte in Eschweiler-Aue lediglich die Erzeugung von Schweißeisen, dessen historisches Schicksal heute ja besiegelt ist. Wir sehen also in dieser Periode bereits die ersten Folgen einer gewaltigen Verschiebung: Der Schwerpunkt des Phönix rückt von Eschweiler-Aue nach Ruhrort. Damit werden gleichsam die Voraussetzungen geboren, um diesem Betriebe eine sekundäre, nebensächliche, ja notleidende Stellung innerhalb des Gesamtunternehmens zu schaffen. Er unterliegt demselben historischen Schicksal, wie die Nebenwerke der Dortmunder Union.

Die Produktion in den 60er und zu Beginn der 70er Jahre wird stimuliert durch eine Reihe von Neubauten. Es werden z. B. neue Koksöfen errichtet, drei große Dampfhämmer aufgestellt, die Puddelöfen ausgebaut etc. Das Geld zu diesen Neubauten wird größtenteils aus den Überschüssen des Betriebes genommen. Überhaupt zeigt sich eine vorsichtige Finanzpolitik: Niedrige Bewertung der Aktiven, 
hohe Abschreibungen. Natürlich war es bei einem so billig zu Buche stehenden Unternehmen nicht schwer, ohne neu aufzunehmendes Kapital den Betrieb zu erweitern. Diese Expansion erreicht aber ihren Höhepunkt erst in der Gründerperiode. Wie die Verhältnisse damals lagen, war die rechtzeitige Fertigstellung, namentlich des Stahlwerkes, zu dessen Bau 11/2 Millionen Mark neuer Aktien lit. A emittiert werden mußten, nicht möglich gewesen. So wurde das Unternehmen durch die gewaltige Ausdehnung seiner Anlagen auf ein Produktionsmaß zugeschnitten, das seine Berechtigung nur bei Fortdauer der Hochkonjunktur haben konnte. Die Vermehrung der Produktionsmittel war daher für die kommende Krisis ein die bisherige Prosperität unterminierendes Element. Von einigen Aktionären wurde das richtig erkannt. In der Generalversammlung von 1873 stellten sie eine Reihe von Anträgen. Darunter befand sich einer, welcher fordert, daß die Bilanz in ihren Hauptpositionen nach einzelnen Geschäftszweigen dargestellt und außerdem der Nachweis der Substanzvermehrung seit der Rekonstruktion erbracht werde. Allein dieser Vorsto $B$ wurde durch die Hauptaktionäre und die Verwaltung kontrekariert mit Artikel 33 der Statuten, in welchem es heißt: „Die Generalversammlung hat zuvörderst darüber zu beschließen, ob die Anträge in Erwägung gezogen werden sollen." Die Generalversammlung beschloß demgemä $\beta$, daß sie nicht in Erwägung gezogen werden sollten, und so blieb alles beim alten.

Aus dieser Periode von 1860-1873 haben wir aber noch der Schöpfung von Einrichtungen zu gedenken, bei denen der Sozialpolitiker gern verweilt, zumal ihm dazu bei den großen Aktiengesellschaften nicht viel Gelegenheit geboten wird: den Wohlfahrtseinrichtungen. $\mathrm{Da}$ ich mich bei der Ilseder Hütte über dieses Gebiet ausführlich verbreitet habe, wird es genügen, hier nur auf einiges hinzuweisen, zumal der Geist auch bei dieser Gesellschaft derselbe ist, wie bei denjenigen, die wir schon kennen gelernt haben. In dem genannten Zeitraum beginnt die Phönix-Gesellschaft Geld auszugeben für gemeinnützige Zwecke, für Hospitäler, Kirchen und Schulen, Beamte und Arbeiter. Es handelt sich hauptsächlich um Beisteuern zu dem Bau eines Krankenhauses, veranlaßt durch das Auftreten der Cholera um die Mitte der 60er Jahre, „die auf unseren Werken und besonders in Laar viele und gute Arbeiter hinwegraffte"; ferner um die Zuschüsse zu dem Bau eines evangelischen Schulhauses in Hinsbeck bei Kupferdreh; um eine Invalidenstiftung, um Unterstützung der durch den Krieg und die Cholera hart be- 
troffenen Familien und um Gratifikationen für Beamte. Auch diese Geldopfer dürften teilweise zur Förderung der Erwerbszwecke des Unternelımens beigetragen haben. Wenigstens spricht sich ein späterer Geschäftsbericht in etwas unvorsichtiger Weise folgendermaßen aus: „Ferner haben wir der Direktion 1000 Taler für gemeinnützige, im Interesse des Geschäftes liegende Zwecke zur Verfügung gestellt.“ (Geschäftsbericht von 1873/74).

Resumé: Nach der Reorganisation arbeitet die Gesellschaft mit gutem Erfolge. Die allgemein günstige Situation der Eisenindustrie und die gute Finanzlage des Unternehmens nach der Sanierung ermöglicheneinenerheblichen Unternehmerprofit. Inzwischen vollziehen sich bedeutende Änderungen: Die Kohlenzechen des Phönix werden notleidend. Der Schwerpunkt der Schienenproduktion wird nach Laarverlegt. Letzteres hängtzusammen mit der Einführung des Bessemerverfahrens. Das Werk in EschWeiler-Aue, das anfangs hauptsächlich Eisenluppen und SchweiBeisenfertigfabrikate herstellte, verliert zugunsten des Ruhrorter Werkes nicht nur seine ursprüngliche Produktion, sondern es rückt, was seine Bedeutung fürdie Fabrikation anbelangt, in den Hintergrund. Diese Periode, die mit der groBen Krisis der 70 er Jahre ihren AbschluB findet, war fernerdurchzogen voneinigen sozialpolitischen Gedanken und $M a ß n a h m e n$, die wirkurzberührten.

Die Krisis von 1873-79, die auf diese dreizehn Jahre befriedigender Arbeit folgte, wurde bei dem Phönix durch folgende Momente vorbereitet:

1870/71 war in Laar der Bau eines großen Stahlwerkes in Angriff genommen worden. Um die nötigen Mittel hierfür zu haben, wurden, wie schon angedeutet, 1872 1,5 Millionen Mark Aktien lit. A neu emittiert. Aber die Lieferanten blieben mit der Lieferung des Materials im Rückstand. Der Bau verzögerte sich. Die Bessemeranlage kam erst im Juli 1873, der erste Martinofen erst im November dieses Jahres, das Walzwerk erst im Mai 1874 in Betrieb. Mit dieser stark erweiterten Produktion trat der Phönix in die Krisis cin.

Ich habe schon angedeutet, daß die Gründerperiode nicht jenen 
extremen Einfluß auf die Produktions- und Gewinnziffern des Werkes äußerte, wie dies bei anderen Unternehmungen damals der Fall war. Die Gewinne erreichten in den beiden Jahren nach dem deutschfranzösischen Kriege nicht einmal mehr die Zahlen von 1868-1870. Das hatte seinen Grund teilweise darin, daß die Hausse nicht sogleich Einfluß auf die Steigerung der Betriebsergebnisse gewann. Die Gesellschaft konnte aus der Hochkonjunktur und der kolossalen Preissteigerung nicht den entsprechenden Vorteil ziehen, da sie erst ziemlich bedeutende, zu billigerem Preise abgeschlossene Geschäfte abwickeln mußte. Die langen Geschäftsabschlüsse hinderten sie an der Konjunkturausnutzung. So hatte das Werk im ersten Semester des Jahres 1871/72 namentlich in Schienen nur Aufträge auszuführen, welche noch größtenteils während des Krieges zu niedrigen Preisen übernommen worden waren. Der ausgedehnte Betrieb eines so großen Werkes wie des Phönix bedingt die Notwendigkeit, Lieferungsgeschäfte für längere Zeit im voraus abzuschließen. Die Einwirkung einer Preissteigerung macht sich aus diesem Grunde erst allmählich, in der Hauptsache erst nach Ablauf von 6 Monaten geltend. Wir können daher auch bei fast allen Aktiengesellschaften der Eisenindustrie beobachten, da $B$ der Großbetrieb die Tendenz hat, die Preisverhältnisse auf eine längere Durchschnittsperiode zu übertragen. Infolgedessen ragen die höheren Preise der Hausse in die Perioden der Baisse, und die niedrigeren Preise der letzteren noch wie große Schlagschatten in die Perioden der Hochkonjunktur hinein. So birgt der GroBbetrieb in sich ein den schroffen Wechsel der Konjunktur zügelndes Element. Diese Darlegungen erklären es auch, warum bereits nach Ausbruch der Krisis der Phönix für das Geschäftsjahr 1873/74 einen nicht unbedeutenden Reingewinn erzielte, der eine Dividende von 8 und $6 \frac{2}{3} \%$ zu verteilen ermöglichte.

Das bedenklichste Moment aber lag darin, daß sich vor Ausbruch der Krisis die Magazinbestände zu einer ungeheuren Höhe ansammelten. Sie beliefen sich im Jahre $1871 / 72$ auf 3,6 Millionen, 1872/73 auf 8 Millionen Mark. Diese riesige Zunahme hatte ihren Grund hauptsächlich in den für das Stahlwerk angekauften Erzen, die aus Afrika und anderen überseeischen Ländern bezogen waren. Diese Massen konnten, weil sich die Inbetriebsetzung des Stahlwerkes, wie wir gesehen, so lange hinausschob, nicht verarbeitet werden. Sie repräsentierten ein zinsenfressendes Kapital. Ebenso waren auch die Eisensteinvorräte zu Kupferdreh und auf den Gruben stark angewachsen, weil die Fertigstellung der bezüglichen Hochöfen eine 
unverhältnismäBig lange Zeit in Aispruch nahm. 1873/74 hatten die Magazinbestände eine Höhe von nahezu 9 Millionen erreicht.

Infolgedessen wachsen, ganz wic einst vor Ausbruch der Krisis des Jahres 1S57, die Bankschulden ungeheuer an. Si betragen nicht weniger als $7 \frac{1}{2}$ Million Mark. Ihre Zunahme wird von der Direktion auf folgende Momente zurückgeführt: Zunächst auf die Preissteigerung aller Betriebsmaterialien, dann auf die Erhöhung der Arbeitslöhne und schließlich auf die Errichtung neuer, und die Vergrößerung bestehender Werke. Der Bau des Stahlwerkes absorbierte allein die bei der letzten Aktienemission liquid gewordene Summe von 1,5 Millionen Mark und erforderte außerdem noch ein Kapital von 1,8 Millionen Mark. In dem Berichte des Administrationsrates in der außerordentlichen Generalversammlung vom 30. Oktober 1873 heißt es : „Eine Schuldenlast von $2 \frac{1}{2}$ Millionen Taler ..., die Anfang Januar künftigen Jahres (1874) infolge Auszahlung von Dividenden mehr als $3 \frac{1}{2}$ Million Taler betragen wird, kann als angemessen nicht gelten." Deshalb wird in der erwähnten Versammlung die Erhöhung des Aktienkapitals beschlossen und zwar um 4,5 Mill. Mark Aktien lit. A und 900000 Mark Aktien lit. B. In der Bilanz vom 30. Juni 1873 figuriert noch das alte Kapital mit 10,8 Millionen Mark, in der cies Jahres 1874 bereits das neue mit 16,2 Millionen Mark. Mit einem derartig, nämlich um 5,4 Millionen Mark gestiegenen Kapital, das nach Verzinsung geradezu lechzt, tritt das Unternehmen in die Krisis ein.

Aus diesen Tatsachen können wir auf rein deduktivem Wege bereits jetzt den Schluß ziehen, daß die Krisis die Gesellschaft außerordentlich in Mitleidenschaft ziehen mußte, weil ihre Grundlagen nicht mehr genügend feste waren.

Wir sahen, um es noch einmal kurz zu wiederholen, wie sich a m Vorabend der Krisis, gleich wie in den 50 er Jahren, eine Reihe von Schwierigkeiten aufeinandertürmen. Als solche lernten wir kennen:

1. Starkerweiterte Produktionsmittel, die zu Hochkonjunkturpreisen hergestellt, erst beim Ausbruch der Krisis betriebsfertig werden.

2. Ungenügende Ausnutzung der alten Produktionsmittel infolge langer Geschäftsabschlüsse $z u$ niedrigen Preisen.

3. Häufungder Magazinbeständein Zusam menhang 
mit derverspäteten Inbetriebsetzung des neu erbauten Stahlwerkes und der neuen Hochöfen.

4. Hohe Belastung der Gesellschaft mit Schulden. Infolgedessen Vermehrungdes Betriebskapitals um 5,4 Millionendurch BeschluB vom 30. Oktober 1873.

Die rückgängige Konjunktur kam aus Gründen, die wir bereits. kennen lernten, im Jahre $1873 / 74$ bei dem Phönix noch nicht mit voller Durchschlagskraft zur Geltung. Erst die folgenden Jahre zermürbten die Gesellschaft in hohem Maße. Wir würden die Dinge nun aber nicht richtig beurteilen, wollten wir der Krisis allein Schuld geben. Sie wird vielmehr verschärft durch eine Reihe von Momenten, die ursprünglich in keinem oder nur entferntem Zusammenhange mit ihr stehen. Diese Momente waren folgende:

Mit dem 1. August 1874 traten Tariferhöhungen auf den Eisenbahnen ein. Die Eisenbahngesellschaften hatten die Befugnis erhalten, die Tarife um 20\% zu erhöhen. Davon machten Gebrauch die für den Phönix wichtige Bergisch-Märkische und Köln-Mindener Eisenbahn. Da nun die Schlesischen Bahnen ihre Tarife nur wenig oder gar nicht erhöhten, klagen die Geschäftsberichte des Phönix, daß es den schlesischen Hütten möglich sei, den rheinisch-westfälischen in Gebieten Konkurrenz zu machen, die von diesen bisher allein beherrscht wurden. Für das Ausland und den Transitverkehr blieben indes die früheren Frachtsätze bestehen.

Wurde nun die Gesellschaft durch diese neue Tarifpolitik der Eisenbahnen nur benachteiligt, so erlitt sie direkte Verluste auf andere Weise, nämlich durch den Zusammenbruch einer Baugesellschaft und durch den Eisenbahnspekulanten Strousberg. Die Gesellschaft hatte ihm große Posten von Rädern und Schienen geliefert, die er aber nur zum Teil bezahlte. Der Rest ging verloren.

Schließlich wurden die wirtschaftlichen Verhältnisse noch durch Naturereignisse ungünstig beeinflußt. Im Frühjahr 1876 fanden große Rheinüberschwemmungen statt. Infolgedessen mußte die Hütte zu Laar 3 Wochen außer Betrieb gesetzt werden. Außerdem entstand auf der Zeche Carolus Magnus ein Brand des Schachtturmes. Den Schaden trug zwar die Versicherungsgesellschaft. Allein der Betrieb war 8 Wochen lang unterbrochen.

Das waren die den zukünftigen Zustand des Unternehmens ver- 
schärfenden Ereignisse. Die Wirkungen der Krisis selbst kommen nun in folgenden Details zum Ausdruck.

Fünf Jahre lang, von $1874 / 75$ bis $1878 / 79$ wird eine Dividende nicht gezahlt. 1875 beträgt der Verlust 872791 Mark. Er wird aus dem Reservefond gedeckt. 1876/77 beläuft sich die Unterbilanz auf 116891 Mark. Zur Deckung derselben wird der Reservefond von 27208 Mark verwandt und der Rest des Verlustes von 89682 Mark auf neue Rechnung vorgetragen.

Während der Krisis liegt das Schienengeschäft vollständig darnieder. An Stelle der Schienen tritt immer mehr die Fabrikation von Handelseisen. Dazu kommt die immer weitere Ausdehnung der Bessemerfabrikate, die die schweißeisernen Schienen fast ganz verdrängen. Zur Illustration dieser Tatsache seien folgende Zahlen angefülırt. Die Produktion des Phönix betrug:

$\begin{array}{crrr} & 1874 / 5 & 1875,6 \\ \text { An eisernen Schienen und Schienenbefestigungen } & 14,767,560 \mathrm{~kg} & 8,751,181 \mathrm{~kg} \\ \text { " Stahlschienen und Stahlbefestigungsteilen } & 9,771,058 \text { " } 11,414,212 \text { " } \\ \text { " Handels- und profiliertem Eisen } & 14,534,263 \text { " } 16,034,012 \text { " }\end{array}$

Infolge dieser starken Produktion an Handelseisen, die auch für die anderen Eisenwerke Rheinlands und Westfalens typisch ist, entstand eine natürliche Überproduktion in diesen Artikeln, die den Preis stark drückte.

Daher sucht die Phönixhütte durch Aufnahme eines neuen Produktionszweiges der allgemeinen Konkurrenz in Handelseisen, wenn auch nicht zu entrinnen, so doch ihre Wirkungen zu mildern. 1876 beginnt das Werk in Laar die Herstellung von eisernen Lang- und Querschwellen. Die Nachfrage nach diesem Fabrikat war aber anfangs noch nicht so gro $\beta$, daß es möglich gewesen wäre, besonders gegenüber der lothringischen Konkurrenz einen lohnenden Betrieb einzuführen. Immerhin betrug $1877 / 78$ die Produktion bereits $3 \frac{1}{2}$ Millionen Kilogramm.

Der Export wird im Gegensatz zu anderen Werken nur ganz nebenbei betrieben. In dem Bericht über das Jahr 1878/79 heißt es: „Wir konnten uns nicht entschließen, in großem Umfange Geschäfte auf dem auswärtigen Markt zu suchen, die nur zu Verlustpreisen abzuschließen waren." Nähere Gründe für diese sonst in Krisenzeiten nicht übliche Zurückhaltung in bezug auf den Export werden außer dem genannten nicht angegeben.

Das wesentliche Mittel, um sich während der Krisis über Wasser 
zu halten, war also nicht das massenhafte Abstoßen der Überproduktion des Werkes auf den Weltmarkt. Es suchte vielmehr im eigenen Betriebe die Produktionskosten möglichst weit herunterzusetzen, um dadurch die niedrigen Verkaufspreise einigermaßen auszugleichen. Man kann in den Geschäftsberichten lesen, daß das Werk niemals geglaubt hätte, so billig produzieren zu können. Auch hier ist die Not die Lehrmeisterin der Menschen.

Soviel über die Krisis. Sie wird verschärft durch die Tariferhöhungen der Eisenbahnen, auf die der Phö$n$ ix beiseinen Bezügen angewiesen war, durch Lieferungsverluste und durch Betriebsstörungen, veranlaßt durch Überschwemmung und Feuersbrunst. Die Krisis legt vor allen Dingen das Schienengeschäft in Fesseln. Die Produktion an Handelseisen nimm tdagegenzu. Durch A ufnahmeeinesneuen Froduktionszweiges -- eiserne Lang- und Querschwellen - sucht der Phönix der Konkurrenz die Spitze zu bieten. Der Export wird nur mäBig betrieben, dabei aber die Produktionskosten auf ein möglichst niedriges $M$ a $B$ heruntergesetzt.

Die 80er Jahre haben, entsprechend der allgemein ungünstigen Lage der deutschen Eisenindustrie, auch den Phönix mitberührt, allein das Unternehmen nicht sehr stark in Mitleidenschaft gezogen. Mit dem Jahre 1888 beginnt dasselbe wieder zu prosperieren und bis zum Ablauf des Jahrhunderts verhältnismäBig hohe Reingewinne und gute Dividenden abzuwerfen, um dann allerdings mit dem Beginn des neuen Jahrhunderts in eine entgegengesetzte Entwicklung. einzutreten. Näheres ergibt sich aus folgender Tabelle.

\begin{tabular}{|c|c|c|c|c|}
\hline \multirow{2}{*}{ Jahr } & \multirow[b]{2}{*}{ Reingewinn } & \multicolumn{3}{|c|}{ D i vidende } \\
\hline & & Lit $A$ & Lit B & \\
\hline $1880 / 1$ & $457,092 \mathrm{M}$ & $3 \%$ & - & \\
\hline $81 / 2$ & 935,610, & 6, & - & \\
\hline $82 / 3$ & $1,177,417$ & 6, & - & \\
\hline $83 / 4$ & 535,355 & $31 / 2 \%$ & - & \\
\hline $84 / 5$ & $393,161, "$ & $21 / 2 n$ & - & \\
\hline $85 / 6$ & 396,033, & $21 / 2 n$ & - & \\
\hline $86 / 7$ & $401,784, \prime$ & $2^{1 /} / 2 \prime$ & - & \\
\hline $87 / 8$ & 948,180, & $6 \%$ & - & \\
\hline & & $\begin{array}{l}\text { abgest. } \\
\text { Aktien }\end{array}$ & $\begin{array}{l}\text { nicht abgest. } \\
\text { Lit. A. }\end{array}$ & $\begin{array}{l}\text { älteste } \\
\text { notl. }\end{array}$ \\
\hline $88 / 9$ & $1,111,001, "$ & $7 \%$ & $6 \%$ & $1 \%$ \\
\hline $1889 / 90$ & $1,947,603$ & 10, & 6. & 4, \\
\hline
\end{tabular}




\begin{tabular}{|c|c|c|c|c|}
\hline Jahr & Reingewinn & $\begin{array}{l}\text { abgest. } \\
\text { Aktien }\end{array}$ & $\begin{array}{l}\mathrm{i} \text { v i d e n d } \\
\text { nicht abgest. } \\
\text { Lit A }\end{array}$ & $\begin{array}{c}\text { älteste } \\
\text { notl. }\end{array}$ \\
\hline $90 / 91$ & $2,163,737 \mathrm{M}$. & $10 \stackrel{\alpha}{\%}$ & $6 \%$ & $4 \%$ \\
\hline $91 / 2$ & $1,922,800$ & 10, & 6, & 4, \\
\hline $92 / 3$ & $1,417,843$ & 8, & 6, & 2, \\
\hline $93 / 4$ & $2,041,887$ & 10, & 6, & 4, \\
\hline $94 / 5$ & $1,772,816$ & 10, & 6, & 4, \\
\hline $95 / 6$ & $1,755,316$ & 10, & 6, & 4, \\
\hline $96 / 7$ & $2,833,059$ & 13, & $81 / 2 \%$ & $41 / 2 \%$ \\
\hline & & \multicolumn{3}{|c|}{ Einheitliches Aktienkapital } \\
\hline $97 / 8$ & $3,370,304$, & \multicolumn{3}{|c|}{$11 \stackrel{d}{0}_{0}^{\prime}$} \\
\hline $98 / 9$ & $3,549,034$ & \multicolumn{3}{|c|}{11,} \\
\hline $1899 / 1900$ & $5,079,361$ & \multicolumn{3}{|c|}{15,} \\
\hline $1900 / 01$ & $1,319,135$ & \multicolumn{3}{|c|}{4,} \\
\hline $01 / 02$ & 604,056 & \multicolumn{3}{|c|}{-} \\
\hline $02 / 03$ & $3,540,561$ & \multicolumn{3}{|c|}{8} \\
\hline
\end{tabular}

In der folgenden Geschichte, deren Abglanz die in diesen Zahlenreihen zum Ausdruck kommenden Rentabilitätsverhältnisse sind, liegt der Akzent der Entwicklung des Unternehmens auf drei Gebieten:

1. auf dem Gebiete der Rohstoffversorgung,

2. auf dem Gebiete der Produktion und der technischen Ausgestaltung des Betriebes,

3. a uf dem Gebiete des durch die Fusion mit der Westfälischen Union in andere Bahnen gelenkten Absatzes.

Was die Rohstoffversorgung anbelangt, so hat sich die Gesellschaft sowohl in bezug auf Kohlen als auch in bezug auf Eisenerz von dem Gedanken leiten lassen, den Bedarf ihrer Werke an diesen wichtigen Rohstoffen aus eigenen Gruben zu decken. Die Verwirklichung dieses Gedankens hat bei der Kohle längere Zeit geruht. Bei den Eisenerzen ist er nur in sehr geringem Maße durchführbar gewesen.

Wir behandeln zunächst die Geschichte der Deckung des Kohlenbedarfes, die sich in scharfen und klaren Umrissen aus den Geschäftsberichten erkennen läßt. Die Gesellschaft hatte, wie früher erwähnt, ursprünglich drei Kohlenzechen, von denen die eine, Rhein-Elbe, 1856 verkauft wurde. Eine zweite, die Zeche Graf Beust, erforderte wiederholt Zubuße und wurde 1864 ebenfalls veräußert. Die dritte Zeche, Carolus Magnus, hatte einen sehr ungünstig in einer Ecke der Konzession gelegenen Schacht und ergab ebenfalls schlechte Resultate, so daß auch hier lange Zeit Zubußen nötig waren. 1867/68 
ergab sie zum ersten Male wieder einen Gewinn. Der dreißigjährige Pachtvertrag lief mit dem Jahre $1883 \mathrm{ab}$. Damit tritt die Gesellschaft aus der Verwaltung dieser Zeche und dem Genusse der gepachteten Kuxe aus. Nunmehr besaB sie keine eigenen Kohlengruben mehr und mußte sich alles für den Betrieb erforderliche Kohlenmaterial kaufen. Damit beginnt eine neue Periode. In diese Zeit der ausschlieBlichen Abhängigkeit vom Kohlenmarkt fallen viele Klagen von seiten des Unternehmens. Als namentlich am Ende der 80er Jahre die Kohlenpreise infolge des Streiks der westfälischen Kohlenarbeiter stark in die Höhe gingen, nahmen die Klagen über die hohen Preise gar kein Ende. Dies dürfte auch der Hauptgrund gewesen sein, warum der Phönix wieder zur Selbstbedarfsdeckung zurückkehrt. 1896 erwirbt er die Aktien der Meidericher Steinkohlenbergwerke. Der Ankaufspreis betrug nahezu 6 Millionen Mark. Zu diesem Zwecke wird das Aktienkapital des Phönix um 4050000 Mark erhöht. Die jungen Aktien wurden von einem Konsortium zum Preise von 151\% übernommen. Von den Meidericher Werken ist am wichtigsten für die Befriedigung des Kohlenbedarfes die Zeche Westende mit 12 Millionen qm Gerechtsame in nächster Nähe des Laarer Hüttenwerkes. Sie fördert aus zwei, mit allen maschinellen Einrichtungen versehenen Schächten arbeitstäglich ca. 1500 Tonnen Kohlen. Angestrebt, und nach Errichtung der geplanten horizontalen Förderanlagen jedenfalls auch erreicht, wird eine Förderung von 2000 Tonnen. „Wir dürfen“, sagt die Verwaltung, „mit gutem Grunde erwarten, daß die Leistung pro Mann und Schicht sich in Zukunft durchschnittlich auf 1 Tonne belaufen wird." 1902/03 betrug die Förderung 480004 Tonnen Kohle. In dem Geschäftsbericht dieses Jahres heißt es über die Vorteile, die der Gesellschaft aus dem Besitz der Zeche erwachsen: „Ferner ist die Verwendung möglichst großer Mengen Kohlen unserer eigenen Zeche Westende bei Meiderich von der größten Wichtigkeit für uns, um einerseits Fracht zu sparen, andererseits die weit teureren Flammkohlen entbehren zu können und endlich auch die Verkaufsprovision des Kohlensyndikats zu vermeiden. Wir brauchen jetzt $64-65 \%$ der eigenen Förderung gegen 35-40\% im vorigen Jahre." $\mathrm{Zu}$ dieser Zeche gehört eine Koksofenbatterie von 60 Öfen, die arbeitstäglich 200 Tonnen Koks produziert. Im letzten Jahre betrug die Leistung nur 55797 Tonnen Koks. Das genügt selbstverständlich für die Versorgung der $4 \mathrm{im}$ Betriebe befindlichen Hochöfen nicht und deshalb müssen nicht unbedeutende Mengen Koks zugekauft werden. 
Es ist leider nicht möglich, über die Maßnahmen des Werkes in bezug auf die Eisenerzversorgung ein gleich klares, wirtschaftliches Bild zu entwerfen wie über die Beschaffung der Kohlen, da die Geschäftsberichte nicht den nötigen Anhalt geben.

Wir sahen bereits, daß die Gesellschaft ursprünglich 3 große Grubenkomplexe besaB, im Ruhrbezirk, an den Rhein- und Moselufern und im Herzogtum Nassau.

Über das Schicksal der Gruben im Ruhrbezirk wissen wir nichts. Wir können annehmen, daß sie größtenteils abgebaut sind. Ebensowenig sind wir orientiert über die in der Rheinprovinz gelegenen Gruben.

Diese Erzquellen vergrößern sich in der Gründerperiode. Damals, in den Jahren 1871/72, begann die Gesellschaft in Gemeinschaft mit der Gutehoffnungshütte in Oberhausen 18 große Felder Minette durch Bohrung und Schürfarbeiten aufzuschließen und durch Mutung als Eigentum zu erwerben. Der Ertrag dieser Gruben wurde jedoch größtenteils verkauft, da der Transport nach den Hochöfen am Rhein zu teuer war und sich infolgedessen in mäßigen Grenzen hielt. Auch der Eisenbahntarif vom 1. Mai 1893 brachte in bezug auf Eisenerz aus Lothringen dem Werke keine Vorteile, da derselbe keine Gültigkeit hatte für Sendungen, die teils die Bahn, teils die $W^{\prime}$ asserstraBe benutzten. Die Eisenbahnfrachten waren also zu hoch. Andererseits kommt auch der Wasserweg für den Transport der Eisenerze der in Lothringen gelegenen Gerechtsame nicht durchgehend in Betracht, da die längst ersehnte Kanalisierung der Mosel noch fehlt. Wenn nicht alles täuscht, so liegt hier die Zukunft der Erzversorgung des Phönix. Die wichtigste Grube, die die Gesellschaft in Lothringen besitzt, ist die Grube Karl Lueg bei Fentsch. Sie war die einzige, die dort während der letzten Krisis in Betrieb war. Ihre Förderung belief sich 1902/03 auf 284670 Tonnen. Jedoch betrug der eigene Verbrauch des Werkes an Minette nur 93332 Tonnen.

Die Eisensteingruben in Nassau haben in letzter Zeit stark in der Ergiebigkeit nachgelassen. Die Förderung betrug:

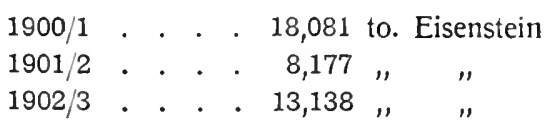

„Bei der geringen Ergiebigkeit und Rentabilität des dortigen Bergbaues", heißt es in dem Geschäftsbericht des zuletztgenannten Jahres, ,beabsichtigen wir, nach Abbau der vorgerichteten Menge, 
die sämtlichen Zechen bis auf Rotenberg, wo ein größeres Vorkommen edlen Steins nachgewiesen ist, einzustellen."

Überblicken wir näher das Detail, so ergibt sich, daß der Phönix heute folgende Eisensteinwerke besitzt: 236 Gruben in der Rheinprovinz mit einer Feldergröße von 600 Mill. qm. Dann 19 Gruben in Elsaß-Lothringen, gemeinschaftlich mit der Gutehoffnungshütte, mit einer Feldergröße von ca. 37 Millionen qm. Ferner 82 Gruben in Hessen-Nassau mit einer Feldergröße von über 30 Millionen qm. Und eine Grube in Westfalen von über 4 Millionen qm. AuBerdem hat das Unternehmen 2 Manganerzbergwerke, eins in Hessen-Nassau und eins in der Rheinprovinz. Von diesen zahlreichen Gruben sind, nach den Angaben, die der Phönix anläßlich der Düsseldorfer Ausstellung machte, nur 7 in Betrieb mit einer Belegschaft von 472 Köpfen und einer Förderung, die bereits in den obigen Zahlen näher angegeben ist. Aber diesc Produktion an Eisenerz genügt keineswegs zur vollständigen Bedarfsdeckung, und infolgedessen muß ein beträchtlicher Teil dieses Rohmaterials zugekauft werden.

Auch in bezug auf einen so wichtigen Rohstoff wie den $\mathrm{Kalk}$ suchte die Gesellschaft vom Markte unabhängig zu werden. Sie hatte bereits früher das Kalkbergwerk Dornap besessen, es aber wieder verkauft aus unbekannten Gründen. 1894/95 wird nun das Gut „zum Kolk" erworben, um den Bedarf des Werkes an Kalk für die Zukunit sicher zu stellen.

Die vorhergehende Analyse ergibt folgende Resultate: Die Kohlenversorgungspolitik des Phönixgeht von dem Erwerb eigener Kohlenzechen aus. Aber das im Bergbau so wechselnde Glück entwertetediese anfangs reichen Lager. Infolgedessen wird für eine Zeit von ca. 10 Jahren die Idee der auch vorher in der Praxis nurteilweise durchgeführten Selbstversorgung aufgegeben, um in der Mitteder 90 er Jahre durch den Ankauf der Meidericher Steinkohlenbergwerke wieder aufgenommen zu werden.

In bezug auf die Eisensteingruben ergab sich, da $B$ hierinder Hauptsachedrei Komplexe zu unterscheiden sind: die Rhein- und Ruhrgruben, über deren Schicksal wir nicht näher orientiert sind, die Gerechtsame in ElsaB-Lothringen, die den wichtigsten Besitz des Phönix an Eisensteingruben darstellt, und in denen die Zukunft seiner Eisenerz- 
versorgung verankert liegt, obgleich der gröBte Teil noch des Aufschlusses harrt, und die Gruben in Nassau, die am Rande der Erschöpfung stehen. Das Werk dürfte heute zum größten Teil auf den Bezug fremder in- und ausländischer Erze angewiesen sein, da diese infolge ihres hohen Erzgehaltes für die Roheisenerzeugung immer noch billigersind, als seine Minetterze in Lothringen.

Was die Produktion anbelangt, so ist zunächst ihre Erweiterung in die Augen fallend. Dieselbe steht in Verbindung mit der ganzen technischen Ausgestaltung des Betriebes, und es ist von Wert, damit gleichzeitig einen Überblick über das ganze Unterne hmen zu verbinden.*)

Als sich das Werk von den Folgen der Krisis der 70er Jahre erholt hatte, ging es, gestärkt durch das Aufflackern der Erwerbstätigkeit und infolge der Besserung der Eisenkonjunktur 1882/83 an den Bau eines Stahlwerkes zur Durchführung des Thomasprozesses. 1879 hatte der Phönix, wie viele andere Werke, die Gerechtsame auf das Thomasverfahren zum Preise von 300000 Mark erworben und in Raten bis zum Jahre 1887 abgezahlt. 1884 wurde das neue Thomasstahlwerk in Laar dem Betriebe übergeben. Die Kosten dafür wurden nicht, wie dereinst für das Bessemerstahlwerk, durch Neuemission junger Aktien aufgebracht, sondern aus eigenen Mitteln, ohne Aufnahme einer Anleihe, bestritten. Allerdings scheint der Bau, wenigstens teilweise, nicht sehr solide gewesen zu sein, denn am 20. Juni 1894 stürzte plötzlich das Dach über dem Thomaswerk mitten im Betriebe zusammen. 3 Arbeiter wurden erschlagen, 4 andere verletzt. Der Betrieb konnte erst am 18. Juli, und zwar unter freiem Himmel, wieder aufgenommen werden. Das Thomaswerk enthält heute 3 Converter, von denen stets nur einer in Betrieb ist, während die beiden anderen in Reserve stehen. Für den ganzen Betrieb wird das Prinzip verfolgt, für jede Maschine eine Reserve zu haben, so daB eine Betriebsstockung nicht stattfinden kann. Das feuerfeste basische Futter für die Converter wird in einer besonderen Abteilung fabriziert. Aus Dolomit und Teer werden mit Preßmaschi-

*) Für die folgende Darstellung benutze ich hauptsächlich die Beschreibung der Betriebsanlagen, die von seiten der Verwaltung für die Düsseldorfer Industrie- und Gewerbeausstellung von 1902 herausgegeben wurde. 
nen unter hohem Druck die Ziegel gepreßt. Das Einsatzgewicht in den Converter beträgt 12,5 Tonnen flüssiges Roheisen, die Blasedauer 9-15 Minuten. Dieses Roheisen kommt entweder direkt flüssig von den Hochöfen in Laar, oder in festem Zustande von den der Gesellschaft gehörigen Hochöfen in Borbeck und Kupferdreh, sowie von fremden Hütten. In letzterem Falle muß es erst in Cupolöfen eingeschmolzen werden, ganz wie es in Peine mit dem Ilseder Roheisen geschieht. Das flüssige Eisen von Hoch- und Cupolöfen wird dann in einem Roheisenmischer von 150 Tonnen lnhalt eingegossen. Hier mischen sich die verschiedenen Qualitäten und es tritt ein Ausgleich der Qualitätsdifferenzen der einzelnen Roheisensorten ein. Der für die Fabrikation nicht erwünschte Schwefel verbrennt. Von da aus kommt das Eisen dann zu den Convertern. Dieselben werden vollständig auf maschinellem Wege beschickt und bedient. Ein mit Wasserdruck betriebener Drehkran trägt auf der einen Seite die Pfanne mit flüssigem Roheisen, während er auf der anderen Seite eine Pfanne für die Aufnahme des fertigen Stahls mit sich führt. Vor dem Eingießen des Roheisens in den Converter wird letzterer mit Kalk im Gewicht von 15-18\% des Roheisens beschickt, damit von dem Kalk die Phosphorsäure aufgenommen werden kann. Während des Abgießens der Schlacke werden dann in den Converter $80-100 \mathrm{~kg}$ auf Rotglut erwärmtes Ferromangan, das aus eigenen Manganerzbergwerken stammt, geworfen, um das Metallbad zu desoxydieren. Das so erhaltene Flußeisen hat stets einen Kohlenstoffgehalt von $0,05 \%$, ist also Eisen weichster Qualität. Wird ein härteres Material, also ein solches mit höherem Kohlenstoffgehalt, verlangt, so wird das der Hütte Phönix patentierte Kohlungsverfahren angewandt. Dasselbe besteht darin, da $B$ das reine abfließende Flußeisen in der Pfanne mit einer, je nach gewünschtem Kohlenstoffgehalt bestimmten Menge Kokspulver vermischt wird. Der Kohlenstoff der Koks wird dabei von dem flüssigen Eisen unter heftiger Reaktion begierig aufgenommen. Auf diese Weise kann man Stahl mit 0,2 bis 1\% und mehr Kohlenstoff herstellen. Dieses Kohlungsverfahren hat gegenüber den älteren Methoden den Vorteil, daß man damit einen reinen Kohlenstoffstahl erzeugen kann in Verbindung mit größerer Sicherheit im Treffen der gewünschten Beschaffenheit. Der Converterkran übergibt dann die gefüllte Stahlpfanne einem zweiten Kran, dem sogenannten Gießkran. Dieser gieBt sie in gußeiserne Formen (Coquillen) aus zu einzelnen Blöcken von je ca, $2600 \mathrm{~kg}$ Gewicht. Diese Blöcke kommen in die Wärme- 
gruben und wandern von da in das Blockwalzwerk. Die Erzeugung von Rohstahl aus den Thomasbirnen belief sich im Geschäftsjahr 1902/03 auf 224509 Tonnen.

Außer der Thomasanlage ist ein Martinwerk vorhanden. Dasselbe umfaßt heute 6 Siemens-Martinschmelzöfen. In diesen werden, wie der Leser bereits weiß, die bei der Verarbeitung des Eisens entstehenden Abfälle sowie angekauftes Altmaterial unter Zusatz von 25\% Roheisen mittels Stcinkohlengas geschmolzen. Zum Ein- und Fertigschmelzen des Metallbades sind 4-5 Stunden erforderlich. Es können also täglich 4-6 Chargen gemacht werden. Die Erzeugung belief sich 1902/03 auf 78538 Tonnen.

In Verbindung mit den eben erwähnten Anlagen stehen dann die Walzwerke. Das Blockwalzwerk, das zur Zeit noch im Betrieb ist, ist veraltet. Es hat $z$. B. keine selbsttätigen Kippvorrichtungen. Die Walzen haben einen Durchmesser von nur $950 \mathrm{~mm}$. Sie werden durch Dampf angetrieben. In diesem Walzwerk werden die Blöcke auf je nach dem Verwendungszweck verlangten Abmessungen vorgewalzt und mittels einer Scheere zerschnitten. Von diesen vorgewalzten Blöcken wird ein Teil von anderen Walzwerksabteilungen in derselben Hitze noch weiter verwalzt, und der Rest in mehr oder weniger abgekühltem Zustande den verschiedenen Verbrauchsstätten des Werks zugeführt, oder auch als Halbfabrikat an auswärtige Kundschaft abgegeben. Da, wie erwähnt, dieses Blockwalzwerk nicht mehr den Anforderungen einer fortgeschrittenen Technik entspricht, so ist z. Zt. ein neues im Bau. Es erhält automatisch wirkende Kippvorrichtungen, Walzen mit einem Durchmesser von $1150 \mathrm{~mm}$ und elektrischen Antrieb. Der letztere wird durch die Verwendung der Hochofengase erzielt, stellt sich also wesentlich billiger, als der Dampfantrieb des alten Blockwalzwerkes.

In Verbindung mit dem Blockwalzwerk steht ein heute ebenfalls veraltetes Knüppelwalzwerk und ein Schienenwalzwerk. In dem ersteren befindet sich eine Walzenstraße mit Walzen von $750 \mathrm{~mm}$ Durchmesser für Knüppel und Platinen. Die Knüppel werden auf fremden Walzenstraßen zu Draht weiter verwalzt, die Platinen hingegen an fremde Blechwalzwerke und Fabriken von Kleineisenzeug abgesetzt. Die Erzeugung dieser Straße an Halbfabrikaten beläuft sich in 12stündiger Schicht auf ca. 450 Tonnen.

Das Schienenwalzwerk empfängt die vorgewalzten Blöcke mittels eines $97 \mathrm{~m}$ langen Hochrollganges. Ehe sie in einer Hitze ausgewalzt werden, werden sie in 2-3 Rollöfen nachgewärmt. Die 
Leistung des Schienenwalzwerkes in 12 Stunden beträgt 200-210 Tonnen Schienen oder Schwellen. Seit 1880 hat der Phönix auf dem Gebiete der Schienenfabrikation eine Spezialität entwickelt. Es sind die unter dem Namen „Phönix-Rillen-Schienen“ bekannten Straßenbahnschienen.

Von dem genannten Jahre an bis zur Gegenwart sind auf der Schienenstraße über $10000 \mathrm{~km}$ Geleise ausgewalzt worden, die nach allen Ländern der Erde geliefert wurden. Die Schienen weisen über 90 verschiedene Profile auf. Mit der Lieferung der Rillenschienen hängt die Fabrikation von Weichen und Kreuzungen zusammen, für welche seit Anfang der 90er Jahre eine besondere, täglich 6-7 fertige, nach patentierten Spezialkonstruktionen ausgeführte Straßenbahnweichen liefernde Abteilung errichtet ist.

An Walzwerken sind außer dem Knüppel- und Schienenwalzwerk vorhanden: eine Drahtstraße, auf welcher in 12 Stunden (mit einem Ofen) 25-35 Tonnen Draht in der Dicke von 4,8 bis $8 \mathrm{~mm}$, oder Stabeisen im Gewicht von ca. 25-35 Tonnen pro Schicht erzeugt werden können.

Ferner weist das Werk auf: Eine Schienenstraße für Grubenschienen und Schwellen mit einer Erzeugung von 45 Tonnen in 12 Stunden. Weiter eine Universal- und Grobstraße für Flacheisen bis $450 \mathrm{~mm}$ Breite, Rund- und Vierkanteisen bis $200 \mathrm{~mm}$, Unterlagsplatten und Laschen. Leistungsfähigkeit: $35-50$ Tonnen in 12 Stunden; außerdem eine Mittelstraße für Stabeisen mit einer Leistungsfähigkeit von 17 Tonnen Eisen und 36 Tonnen Flußeisen in je 12 Stunden. Schließlich eine Feinstraße, ebenfalls für Stabeisen mit einer Leistungsfähigkeit von 36-40 Tonnen in 12 Stunden.

Außerdem besteht im AnschluB an die Puddelöfen eine Luppenstraße mit 2 Hämmern. Im ganzen hatte die Gesellschaft 1902/03 im Durchschnitt 36,25 Puddelöfen in Betrieb. Die Produktion an Luppen betrug 40678 Tonnen. Die Luppen werden gewalzt zu Flacheisen, dann mit der Scheere zerschnitten und in Pakete gepackt, im Ofen erhitzt und verwalzt. Seit der umfangreichen Einführung der Flußstahlbereitung ist dieser Betrieb wesentlich eingeschränkt.

Ferner schließt sich an das Walzwerk eine neuerbaute Walzendreherei, in der sämtliche Walzen, fertig zum Einlegen, bearbeitet werden. Die Drehbänke sind mit elektrischem Antriebe versehen, so daß jede für sich unabhängig in und außer Betrieb genommen werden kann.

In einem Hammerwerk mit 18 Hämmern werden geschmiedet: 
Eisenbahnachsen, Kugeln für Kugelmühlen, z. B. für Thomasmühlen, Ringe für Radreifen und Schmiedestücke aller Art. Die Leistung aus einem Rollofen beträgt etwa 45 Tonnen in 12 Stunden.

Das Radreifenwalzwerk walzt aus einem Rollofen in 12 Stunden etwa 135-200 Eisenbahnradreifen im Gewichte von 40 Tonnen.

Von besonderem Interesse ist das Preßwerk der Laarer Hütte. Die Anregung zu dieser Anlage wurde durch eine Anfrage nach Geschossen mit physikalischen Eigenschaften gegeben, die nach der gewöhnlichen Arbeitsmethode kaum oder schwer herzustellen waren. Infolgedessen wurde zu Beginn des Jahres 1892 die Fabrikation von nahtlosen Hohlkörpern der verschiedensten Formen aufgenommen. Die Haupterzeugnisse bestehen in Kriegsmaterial, und zwar Geschossen aller Art mit verschiedenen physikalischen Eigenschaften, sodann aber in nahtlosen Flaschen für hochgespannte Gase, wie Wasserstoff und Sauerstoff, sowie Flüssigkeiten, wie flüssige Kohlensäure, Ammoniak etc., ferner nahtlosen Stahlröhren etc. Das Werk, das, infolge der großen Nachfrage und der Ausdehnung der Fabrikation auf immer mehr Erzeugnisse, von Jahr zu Jahr erweitert werden mußte, besteht aus zwei Abteilungen: Dem Preßraum mit einer Anzahl Loch- und Ziehpressen und einer Dreherei mit ca. 100 Drehbänken. In Zusammenhang damit steht ein gröBerer Probierund Abnahmeraum. Die Produktion für 1901 betrug an

Geschossen und Hüllen bis zu $240 \mathrm{~mm}$ Durchmesser

ca. 210000 Stück

Nahtlosen Stahlflaschen und Hüllen bis zu $300 \mathrm{~mm}$ Durchmesser

ca. 29000 Stück

Weiteren Geschoßteilen und Hohlkörpern verschiedener Art

ca. 70000 Stück

An PreB- und Façonstücken

ca. $\quad 400$ Tons.

Einen verhältnismäßig großen Umfang hat die mechanische $\mathrm{Ab}$ teilung. In ihr werden die Neuanlagen der Hütte entworfen und eigene Konstruktionen zum Teil ausgeführt, sowie alle Reparaturen, die in den einzelnen Betrieben nötig sind, vorgenommen. Sie leitet ferner den ganzen maschinellen und Dampfkesselbetrieb. Im Jahre 1900/01 wurde sie vollständig umgebaut. Heute kann man sie in folgende Unterabteilungen zerlegen:

a) Eine Maschinenfabrik, bestehend aus Schlosserei, Dreherei, Hobelei, Schmiede, Klempnerei und Sattlerei.

b) Eine Kesselschmiede. 
c) Eine Gießerei mit einer Jahreserzeugung von 11000 bis 12000 Tonnen.

d) Eine mechanische Modellschreinerei.

e) Eine mechanische Zimmer- und Schreinerwerkstätte.

Der Gesellschaft gehört ferner eine Thomasphosphatfabrik, die aber an dic chemischen Werke in Biebrich verpachtet ist. Sie besteht aus 18 Kugelmühlen, die die Thomasschlacke pulverisieren. Elevatoren befördern das Mehl direkt auf die automatische Wage. Die 18 Mühlen liefern täglich 54 Doppelwaggons (à Waggon 10 Tons). Von je 5 Waggons wird eine Durchschnittsprobe genommen und im Laboratorium der Phosphorsäuregehalt festgestellt. Danach wird das Mehl bezahlt. Es kostet das Kilogramm Gesamtphosphorsäure $21^{1 / 4}$ Pfg. und citratlösliche Phosphorsäure 241/4 Pfg.

SchlieBlich hat das Werk eine Fabrik feuerfester Steine. Diese Steine werden hergestellt aus verschiedenem Material: aus Ton, der vom Westerwald und aus der Pfalz stammt, aus verschiedenen Quarzarten und aus alten Ofensteinen, die in Kugelmühlen gemahlen werden. Diese feuerfesten Steine werden gebraucht zum Ausfüttern der Martin- und Thomasstahlpfannen, ferner zur Bekleidung von Schweiß- und Cupolöfen etc. Die Gesamterzeugung, außer der basischen Masse, für we!che eine bereits früher erwähnte Dolomitfabrik vorhanden ist, belief sich im Jahre 1901 auf 6200 Tonnen.

Diese Einzelwerke werden mit dem nötigen Roheisen versorgt durch die Hochofenanlagen. Der Phönix hat ihrer drei:

Die erste liegt in Laar. Sie umfaßt 6 Hochöfen. Davon sind 3 neu und 3 alt. Jene produzieren 200-250 Tonnen, diese 100 bis 120 Tonnen. Von den 6 Öfen ist gegenwärtig Ofen III außer Betrieb und Ofen Vl noch nicht in Betrieb. Im Geschäftsbericht 1902/03 heißt es: „Die Hochöfen in Laar arbeiten noch immer nicht befriedigend, wenn auch besser wie im vorigen Jahre. Wir haben noch gar zu häufig mit Hängen der Gichten zu kämpfen. Während des ganzen Jahres waren 4 Hochöfen in Betrieb. Darunter zwei neue große und zwei alte kleine." Die Produktion dieser 4 im Betriebe befindlichen Hochöfen belief sich im genannten Geschäftsjahre auf 204119 Tonnen. An die Hochofen- schlieBt sich eine Koksofenanlage. Dieselbe hat 2 Solvaybatterien von je 24 Öfen mit Gewinnung von Teer, Ammoniak, Benzol und Sulphat, 2 Ottobatterien von je 32 und eine von 60 Öfen. Die Erzeugung der Koksöfen betrug im Jahre 1901131400 Tonnen.

Die zweite Hochofenanlage befindet sich in Berge-Borbeck. Sie 
hat drei Hochöfen, von denen jedoch nic mehr als zwei im Feuer sind. „Während vor 30 Jahren", heißt es in der Ausstellungsschrift, „die Erzeugung in zwei Hochöfen nur 19000 Tonnen betragen hat, sind im vorigen Kalenderjahre 190151527 Tonnen Roheisen in einem Ofen erblasen worden, obgleich die Dimensionen der Hochöfen nicht wesentlich verändert, beziehungsweise vergrößert worden sind. Der Rauminhalt der Hochöfen in Berge-Borbeck hat lange nur je etwa $100 \mathrm{cbm}$ betragen, und erst in neuester Zeit sind die Hochöfen erhöht und bis zu $380 \mathrm{cbm}$ Rauminhalt vergröBert worden. Es wird hauptsächlich Thomaseisen erzeugt, welches an das Stahlwerk der Hütte Phönix bei Ruhrort geliefert wird, und außerdem Qualitätspuddeleisen für die Werke der jetzt zur Gesellschaft gehörigen, ehemaligen Westfälischen Union in Hamm." Es sei noch erwähnt, daß im Geschäftsbericht 1902/03 die Roheisenproduktion des einen im Betriebe befindlichen Hochofens in Berge-Borbeck mit 71064 Tonnen angegeben wird. Die Koksöfen produzieren nach den Angaben der Festschrift 39993 Tonnen Koks.

Die dritte Hochofenanlage liegt in Kupferdreh, an der Ruhr. Sie umfaßt 2 Hochöfen von ca. $300 \mathrm{cbm}$ Inhalt. Aber auch hier befindet sich nur einer in Betrieb. Die Produktion betrug 1902/03 33205 Tonnen. Sie war also um die Hälfte geringer als in BergeBorbeck.

Während zu Anfang des Betriebes der Hütte, in den 50er Jahren, hauptsächlich Brauneisenstein und Blackband aus nächster Nähe zum Teil per Achse, zum Teil per Schiff auf der Ruhr herbeigeschafft und verhüttet wurden, und auch der Versand des Roheisens teilweise auf der Ruhr stattfand, wird heute der ganze Bezug der zum Teil aus weiter Ferne kommenden Erze und der ganze Versand des Roheisens durch die Eisenbahn bewirkt.

In den zur Hütte gehörigen 36 Koksöfen wurden 190131718 Tonnen Kohlen verkokt und daraus 20455 Tonnen Koks erzeugt. Nebenbetriebe zur Gewinnung von Teer, Ammoniak, Benzol und Sulphat scheinen auch hier zu fehlen.

SchlieBlich haben wir noch das Werk in Eschweiler-Aue zu erwähnen, in dem einst der Schwerpunkt der Produktion ruhte. In dieser Hütte lag ursprünglich die Bedeutung des Phönix. Aber gerade dieses Stammwerk der Gesellschaft büßte mit den großen Umwandlungen in der Eisenindustrie, wie sie durch die Einführung des Bessemerprozesses herbeigeführt wurden, vollständig an Bedeutung ein. Ich habe an anderer Stelle bereits diese Wandlungen ge- 
schildert. In den 80er Jahren wird dann namentlich über schlechte Geschäftsergebnisse geklagt. So heißt es in dem Bericht über das Jahr 1884/85: „Sehr ungünstig lagen die Verhältnisse in EschweilerAue. Da das Werk von alters her nur auf Eisenfabrikation eingerichtet war, mußte es bei dem immer mehr zunehmenden Absatz in Stahlartikeln in eine vollständige Abhängigkeit zur Laarer Hütte oder anderen Stahlwerken geraten und verlor damit die Möglichkeit zu gewinnbringender Arbeit..."Um nun das Werk nicht eingehen zu lassen, wurde im Jahre 1888 ein Martinwerk mit 4 Öfen errichtet mit einer Leistungsfähigkeit von etwa 45-50000 Tonnen Flußstahl im Jahre. Ein Ofen vollendet in 24 Stunden 5-6 Einsätze mit je 12 Tonnen Ausbringen an Stahl. Infolge dieser geringen Produktion sind an Stelle der alten zwei neue Öfen errichtet, von denen einer bereits fertig gestellt und ein zweiter im Bau begriffen ist. Vergossen wird der Stahl hauptsächlich zu Blöcken für die eigenen Formeisen- und Blechwalzwerke, welche zumeist auf Konstruktionsund Schiffbaumaterial arbeiten, sowie zu Schmiedeblöcken für das eigene Hammerwerk; seit längerer Zeit wird auch ein großer Teil zu Stahlformguß - Lokomotivrädern, Maschinenteilen, Spindeln etc. verwandt. Rohblöcke werden verkauft.

Das ganze Werk in Eschweiler-Aue ist nur klein. Es besteht aus folgenden Abteilungen:

1. Aus dem schon erwähnten Martinwerke.

2. Aus einer Räderfabrik. In dieser werden alle Arten Lokomotiv-, Tender-, Normal- und Straßenbahnwagenräder hergestellt. Seit 1901 auch Lokomotivradsätze mit Rädern aus StahlformguB. Die Leistungsfähigkeit der Räderfabrik beträgt 7-8000 Satz pro Jahr. Die Werkstätte besitzt 88 Spezialwerkzeugmaschinen. An Stelle der Räderschmiede trat Ende des Jahres 1897 ein Räderpreßwerk, in welchem innerhalb 12 Stunden 105-120 Stück Radsterne, je nach Größe, fertiggestellt werden können.

3. Aus einem Blechwalzwerk. Seit 1897 ist eine Triostraße, ein Feinblech- und ein Universalwalzwerk im Betriebe mit einer Leistungsfähigkeit von 2500 bis 3000 Tonnen Blechen. Es werden alle Sorten Bleche, glatte sowohl wie geriffelte bis zu jeder Stärke hergestellt.

4. Aus einem Formwalzwerk. Das gewalzte Formeisen dient zum Kriegs- und Handelsschiffbau, ferner als Konstruktionsmaterial für den Eisenbahn- und Brückenbau.

5. Aus einer Steinfabrik. In derselben werden sowohl saure als 
auch basische feuerfeste Steine für den eigenen Bedarf hergestellt.

Diese Details mögen genügen, um einen Überblick über die wichtigsten Gesamtanlagen des Phönix vor seiner Fusion mit der Westfälischen Union zu geben. Aus der Beschreibung läßt sich erkennen, daB viele Einrichtungen veraltet sind. Mit dem Um- resp. Neubau ist bereits begonnen. So wird gegenwärtig der großartigste Fortschritt auf dem Gebiete des Eisenhüttenwesens, die Verwendung der Hochofengase als Antriebskraft, in die Praxis umgesetzt, um die Produktionskosten zu vermindern. Zwei Gasexplosionsmaschinen à 800 H.P. sind bereits im Betrieb, drei große zu je 1000 Pferden im Bau. Es wurde ferner darauf hingewiesen, daß das Blockwalzwerk veraltet ist, daB automatische, Menschen sparende Vorrichtungen vielfach fehlen, daß bei den Koksöfen nur teilweise die Nebenprodukte gewonnen werden usw. „Bei den enormen Fortschritten“, heißt es inı Geschäftsbericht 1902/03, ,welche die Eisen- und Stahlindustrie in den letzten Jalıren gemacht hat, denen unsere gesamte Konkurrenz gefolgt ist, ist Stillstand gleich Rückschritt. Es bleibt uns nichts anderes übrig, als auch unsere Einrichtungen den neuen Anforderungen entsprechend umzugestalten. Mit unseren verschiedenen Hochofenanlagen haben wir schon vor mehreren Jahren begonnen und sind damit sozusagen fertig. Die Leistungsfähigkeit hat sich mehr als verdoppelt. Zur noch besseren Ausnutzung und zur Verwertung eines Teils der Hochofengase müssen noch je eine Gasgebläsemaschine für Laar und Borbeck beschafft werden. Die Gasreinigung ist weiter durchzuführen. Der ÜberschuB an Gasen wird direkt zu Betriebszwecken oder indirekt durch Umsetzung in Elektrizität und dann zu weiteren Verwendungen verwertet. In Laar dient diese zum Betriebe des Stahlwerkes, des Walzwerkes und fast sämtlicher Nebenwerkstätten. In Borbeck sind die Gase an die Kontinentale Hochofengasgesellschaft gegen eine jährliche Abgabe pro Hochofen und Beteiligung am Reingewinn des Unternehmens verpachtet... Endlich muB mit der weiteren Verwendung der Elektrizität eine Verbesserung der Betriebs- und Transporteinrichtungen verbunden werden, um Dampf und Löhne zu sparen. In allen diesen Richtungen haben wir schon manches erreicht und sind mit weiteren Verbesserungen beschäftigt. Damit wird auch eine bessere Ausnutzung unseres Stahlwerkes und eine wesentliche Hebung der Produktionsfähigkeit desselben verbunden sein."

Natürlich erfordert die Vervollkommnung der Produktionsmittel 
viel Geld. $4 \frac{1}{2}$ Million Mark stehen dem Werke zu Bauzwecken bereits zur Verfügung. Aber auch diese Summe reicht noch nicht aus. In der außerordentlichen Generalversammlung vom 30. Oktober 1903 wird beschlossen, das Aktienkapital der Gesellschaft von 30 auf 35 Millionen Mark zu erhöhen. Begründet wird diese weitere starke Erhöhung des Betriebskapitals damit, daß der Phönix, dessen Einrichtungen in mancher Beziehung mit dem gewaltigen Fortschritt der Technik nicht Schritt gehalten haben, nicht nur gröBere Umbauten, sondern auch Neubauten ausführen muß. „Wir müssen“, resumiert die Verwaltung in dem letzterwähnten Bericht, „unsere Zeche Westende weiter ausbauen und die Hochofengase unserer verschiedenen Hütten nutzbar machen. Dazu gehören Gasmaschinen und elektrische Einrichtungen. Wir müssen auch unsere Stahlwerke, Walzwerke und unsere Transporteinrichtungen den neusten, gewaltigen Fortschritten der Hüttentechnik entsprechend ausgestalten."

Die großen finanziellen Anstrengungen resultieren, wie wir sehen, in letzter Instanz aus dem freien Wettbewerb. Gespornt durch die Konkurrenz muß der Phönix seine Einrichtungen modernisieren, um nicht unter den großen Werken in zweite Linie zu geraten. Fast alles aber kommt dem Hauptwerke in Laar zu gute. In ihm ruht heute der Schwerpunkt der Produktion.

Resumé: Diese Übersicht zeigt, daB der Phönix ein reich gegliedertes Unternehmenist, dessen Produktion die mannigfachsten Gebiete erfaBt und im Laufe der Zeit erweitert hat. Es wird genügen, hier in Summa nocheinmaldievorhandenen Abteilungen übersichtlichzusammenzustellen. Die Hütte in Laar bei Ruhrort umfaBt: Ein Stahlwerk, ein Martinwerk, ein Blockwalzwerk, ein Knüppel-und Schienenwalzwerk, eine Walzendreherei, ein Hammerwerk, ein Radreifenwalzwerk, ein PreBwerk, eine mechanische Abteilung, eine Thomasphosphatfabrik, eine Fabrik feuerfester Steine und eine Hochofenanlage. Diese Anlagen bilden heute das Haupt-aber nicht das Stammwerkder Gesellschaft. Die ganze Bedeutung des Phönix konzentriert sich allmählich in den genannten Betrieben. AuBerdieser Hütte besitzt die Gesellschaft noch zwei Hochofenanlagen, die eine in Kupferdreh und die andere in Berge-Borbeck. 
Das ursprüngliche Unternehmen lag in Eschweiler-Aue. Es istständigvonseinerfrüheren Höhe heruntergesunken. Es wäre noch schlimmer gekommen, hätte man nicht 1888 seiner Produktion in Stahlartikeln eine Grundlage gegebendurch Errichtung eines Martinwerkes. Heute besteht diese Abteilung noch aus einer StahlformgieBerei (Räderfabrik), einem Blechwalzwerk, einem Formwalzwerk und einer Steinfabrik. Das Werkbesitztkeine Hochöfen, muB alsodas Roheisen beziehen.

Das bedeutendste Ereignis aus der neueren Geschichte des Phönix bildet seine Verschmelzung mit der Westfälischen Union im Jahre 1898. Dieses Unternehmen entstand als Aktiengesellschaft in der Weise, daß mit einem Kapital von 10,5 Millionen Mark eine Anzahl von Drahtwerken unter einer Firma vereinigt wurden. Dic Ausstellungsschrift enthält hierüber folgende Angaben: „Im Jahre 1873 wurden die Firmen Cosack \& Comp. in Hamm i. W., A. \& Th Linnhoff in Lippstadt und Belecke, Ed. Schmidt in Nachrodt und Friedrich Thomée in Werdohl in eine Aktiengesellschaft umgewandelt, welche sich unter dem Namen „Westfälische Union", Aktiengesellschaft für Bergbau, Eisen- und Drahtindustrie konstituierte, mit ihrem Sitz in Hamm i. W. Zu den oben aufgeführten Werken wurde das Puddel- und Walzwerk in Einsal bei Altena, Herrn von Holzbrink gehörig, gepachtet und in St. Petersburg ein Werk, bestehend aus Drahtzieherei und Stiftenfabrik, erworben. Sämtliche Werke wurden in vollem Betriebe übernommen."

Das Charakteristische besteht auch bei dieser Schöpfung darin, daß örtlich auseinanderliegende Betriebe zu einem Produktionsorganismus unter einheitlicher Leitung miteinander verbunden wurden. Aber bald zeigten sich bei der Westfälischen Union ganz ähnliche Folgen wie bei der Dortmunder Union. Der Organismus war zu stark belastet. Er bestand aus 7 Gliedern, nämlich den Werken zu Hamm, Nachrodt, Lippstadt, Belecke, Einsal, Werdohl und St. Petersburg. Von diesen 7 Werken wurden im Laufe der Zeit nicht weniger als 3 abgestoBen.

Zunächst das Puddel- und Drahtwalzwerk in Einsal. Die Westfälische Union war nicht Eigentümerin desselben, sondern Besitzerin. Das Werk war nicht imstande, auch nur die kontraktliche Pachtsumme aufzubringen. Da eine ErmäBigung vom Eigentümer nicht 
zu erreichen war, so wurde der am 1. Juli 1878 ablaufende Vertrag nicht wieder erneuert, und das Etablissement schied aus der Westfälischen Union aus.

Dasselbe Schicksal teilte am 1. Januar 1879 das Werk in Werdohl. Es produzierte ebenfalls Luppen, Walzdraht, Stabeisen, gezogenen Draht und Drahtstifte. Der Verkauf dieses Werkes steht zweifelsohne mit dem schlechten Geschäftsgange der 70er Jahre in $\mathrm{Zu}$ sammenhang.

Wie schon erwähnt, beruhte die Westfälische Union auf der Herstellung von Walzdraht. Damals aber gingen zahlreiche Werke, die bisher Schienen produziert hatten, zur Walzdrahtproduktion über, um ihre kalt liegenden Puddelöfen zu beschäftigen. Die Folge der auf diese Weise gesteigerten Drahtproduktion war ein abnormes Werfen der Preise, besonders auch auf dem Exportmarkt. Als Beleg für diese Tatsache seien einige Zahlen aus den Geschäftsberichten der Westfälischen Union während der Krisis der 70er Jahre angeführt. Von ihren sämtlichen Werken wurden versandt:

\begin{tabular}{|c|c|c|c|c|c|c|c|c|c|c|c|c|c|}
\hline & & Mill & $t$ & $\mathrm{im}$ & ret & $V$ & 11,3 & Mill. & & & & & \\
\hline 5 & 36,0 & " & $"$ & & $n$ & $n$ & 9,1 & $"$ & " & ", & 254,76 & , & " \\
\hline & 37,3 & $n$ & $"$ & " & " & " & 7,9 & " & & & 213,43 & " & \\
\hline & 42,7 & " & $"$ & $"$ & $"$ & $"$ & 8,2 & $"$ & $n$ & $"$ & 191,79 & $"$ & $"$ \\
\hline 78 & 45,9 & ", & ", & " & " & , & 8,3 & $"$ & & & 181,34 & ", & \\
\hline $78 / 9$ & 42,8 & & $"$ & $"$ & ", & " & 7,5 & & " & , & 174,93 & , & ," \\
\hline
\end{tabular}

Hieraus ergibt sich, daß zwar die Produktion des Werkes während der Krisis stieg, ihr Wert aber sank, und zwar auf die Tonne berechnet um nicht weniger als ca. 45\%. Mit dieser Wertverminderung steht die bereits erwähnte Absplitterung des Einsaler und Werdohler Etablissements in Zusammenhang.

Das dritte Werk, das ebenfalls aus der Zusammengehörigkeit mit der Westfälischen Union ausschied, war die St. Petersburger Draht- und Nagelfabrik. Die Gründe hierfür dürften in folgenden Spezialursachen zu suchen sein. Zunächst ebenfalls in der Krisis der 70er Jahre. Dann brach der russisch-türkische Krieg aus. Infolge dessen konnte das Werk in den 70er Jahren zu keiner rechten Entwicklung kommen. Endlich frohlockt der Geschäftsbericht 1879/80: „Zum ersten Male sind wir in der Lage, Ihnen über diese Abteilung einen günstigen Bericht zu geben. Die erzielten Resultate lassen uns hoffen, da $B$ das Lehrgeld dort jetzt gezahlt ist, da $B$ wir endlich dort auch ernten werden." Aber die Verwaltung täuschte sich. 
Der Beginn des neuen Dezenniums sollte nicht den Anfang einer besseren Zeit bedeuten. Im Juni 1881 brannte ein großer Teil des Petersburger Werkes nieder. Da aber bereits in den früheren Jahren sehr große Abschreibungen vorgenommen worden waren, so fiel der Brandschaden für den Anteil der Westfälischen Union an dem Petersburger Werke - es existierten noch 2 Tcilhaber, die zusammen 50000 Mark eingelegt hatten - nicht so sehr ins Gewicht. Viel größeren Schaden verursachten zwei andere Momente, nämlich das Sinken der russischen Valuta und die Erhöhung der russischen Drahtzölle im Jahre 1882. Schon in den 70er Jahren klagt die Union, „daß das fortwährende Fallen des Rubelkurses die Rohmaterialien verteure, ohne daß durch entsprechende Erhöhung der Verkaufspreise ein Ausgleich zu erreichen gewesen wäre." (Gescluätsbericht 1876/77). In dem Bericht über das Jahr 1881/82 heißt es dann: „Der Ausfall an Produktion infolge des Brandes, die ungünstigen Verhältnisse in Rußland, insbesondere der schlechte Stand der russischen Valuta becinflußten das Resultat ungünstig." Dazu kamen noch die Zollverhältnisse. Der Bericht von 1876/77 gibt an, daß die Erhebung des Zolles in Gold eine Verteuerung desselben um ca. 30\% bedeute. Nun wurde aber im Herbst 1882 der russische Eingangszoll auf Rundeisen von $1 / 4$ Zoll und darunter voll 75 Mark pro Tonne auf 214,50 Mark erhöht, und damit der Import in diesen Artikeln so gut wie abgeschnitten. „Wie schon bemerkt", heißt es in dem Geschäftsbericht 1882/83, „können wir des hohen Zolls wegen Walzdraht nicht mehr nach Rußland senden. Damit verliert die dortige Zweigniederlassung für uns wesentlich an Bedeutung, zumal es bei den unsicheren Zollverhältnissen nicht opportun erschien, dieselbe noch durch Anlage einer Drahtwalze nebst Zubehör zu vergrößern, um so von hier zu sendende Drahtknüppel auswalzen zu können. Wir richteten daher unsere Bemühungen darauf, das Petersburger Werk anderweitig möglichst günstig zu verwerten... Um in dieser Beziehung nicht behindert zu sein, mußten wir suchen, uns die volle freie Disposition über unser Eigentum zu verschaffen. Wir tilgten daher die Hypothek der Staatkreditgesellschaft und lösten die Verträge mit den Kapitalbeteiligten unter Ausgleichung sämtlicher schwebender Differenzen und Prozesse auf." 1883 wurde das Werk an die Gesellschaft der St. Petersburger Eisen- und Drahtwerke verkauft. Die Westfälische Union erhielt den Kaufpreis zum Teil in Aktien und Obligationen, und zwar 50000 Rubel Aktien und 427500 Rubel Obligationen. In die Bilanz 
der Westfälischen Union werden diese nicht börsengängigen Effekten mit 96773 Mark für die Aktien und 870963 Mark für die Obligationen eingestellt. Die Transaktion bestand also darin, daß das Petersburger Werk in eine selbständige Aktiengesellschaft verwandelt und die Westfälische Union Mitteilhaber und Gläubiger wurde.

Außer der Überlastung des Gesamtunternehmens mit zu vielen örtlich auseinanderliegenden Etablissements wurde die Westfälische Union lange Zeit in ihrer Entwicklung außerordentlich gehindert durch die in ihr Statut aufgenommenen Gründerrechte. Dieselben bestanden darin, daß bei jeder Neuemission von Aktien diese den im Besitze der genannten Rechte befindlichen Gründern, zur anderen Hälfte den jeweiligen Aktionären, al pari angeboten werden mußten. Von den Gründern verzichteten drei auf ihre Ansprüche. Die Rechte der Draht- und Eisenindustrie zu Hamm, der Rechtsvorgängerin in der Union, gingen auf diese über. So blieb nur noch die Berechtigung eines Gründers, eines Bankiers Seelig in Berlin. Derselbe hatte Anspruch auf $311 / 2 \%$ jeder neuen Aktienemission. Dieses Bezugsvorrecht der Gründer sowohl wie der Aktionäre aber wurde bald zu einer drückenden Last, zu einem Hemmschuh für die Weiterentwicklung des Unternehmens. Jede Vergrößerung der Produktionsmittel, jede Erweiterung der Anlagen durch Neubau oder Erwerbung, jede Beteiligung an Gruben, Fabriken etc., soweit sie auf Ausgabe junger Aktien basiert waren, wurde dadurçh unmöglich. Die Gründerrechte bildeten die Barriere, über die die Gesellschaft nicht hinweg konnte, um sich von den Schwankungen des Rohstoffmarktes zu emanzipieren. Kurz, die Gründerrechte widersprachen der kapitalistischen Tendenz des Unternehmens. Eine Vergrößerung des Werkes wäre infolge des Agios der Aktien zu teuer geworden. Daher mußten sie fallen. Sie wurden 1890 offiziell aufgehoben unter Opferung einer Ablösungssumme von 80000 Mark.

Die Geschichte der Westfälischen Union, die im wesentlichen eine Geschichte der Drahtindustrie in den letzten 30 Jahren sein würde, näher zu verfolgen, geht hier nicht an. Für die Zwecke unserer Darstellung ist es jedoch an dieser Stelle noch wichtig, die nach der Verschmelzung mit der Phönixgesellschaft bestehende Dezenttralisation der Westfälischen Union kurz zu skizzieren und dabei gleichzeitig ihr Fabrikationsprogramm anzudeuten.

Das Unternehmen zerfällt heute, nach AbstoBung der geschilderten 3 Werke, in 4 Abteilungen:

1. Die Werke in Hamm. Dieselben umfassen ein Puddelwerk, 
ein Stabeisenwalzwerk, bestehend aus Grob-, Mittel- und Feinstrecke, ein Drahtwalzwerk, eine Nietenfabrik, eine Drahtzieherei, eine Verzinkerei, eine Stacheldrahtfabrik mit 9 Stacheldrahtmaschinen, eine Stiftenfabrik mit 146 Stiftmaschinen, eine Lackiererci, eine Eisenvitriolfabrik, eine FaBfabrik, die die für den Versand von Draht und Drahtstiften notwendigen Fässer herstellt, eine Geflechtfabrik mit 21 Maschinen, die sechseckiges, und 8 Maschinen, die viereckiges Geflecht liefern, eine Achsenfabrik (Schmiede und Dreherei), eine Stangenzieherei, eine Wellenfabrik, mechanische Werkstätten, bestehend aus Dreherei, Reparaturschlosserei und Schmiede, Modellund Bauschreinerei, Sattlerei, schlieBlich eine GieBerei, in welcher der für den eigenen Bedarf erforderliche Eisen- und Metallguß hergestellt wird. Dazu kommt noch eine eigene Gasanstalt, die das Gas für die Beleuchtung der Räume liefert.

2. Das Werk in Nachrodt. Diese Abteilung umfaBt folgende Anlagen: ein Puddelwerk, ein Stab- und Bandeisenwalzwerk, ein Drahtwalzwerk, ein Blechwalzwerk, eine Blechverzinnerei mit zugehöriger Beizerei, ein Rondenstanzwerk, bestehend aus 5 Maschinen zum Stanzen von Ronden, mechanische Werkstätten wie in Hamm und eine Gießerei.

3. Das Werk in Lippstadt. Diese Abteilung zerfällt in ein Puddelwerk, ein Stabeisenwalzwerk, nur aus einer Mittelstraße bestehend, eine DrahtstraBe, eine Drahtzieherei, eine Stiftenfabrik, eine Federnfabrik, eine Blumendrahtfabrik, eine Eisenvitriolfabrik, eine FaBfabrik und mechanische Werkstätten.

4. Das Werk in Belecke. Hier sind vorhanden: eine Drahtzieherei, eine Stiftenfabrik, eine Eisenvitriolfabrik, eine FaBfabrik und mechanische Werkstätten.

Aus dieser Zusammenstellung ergibt sich, daB alle 4 Abteilungen einen ziemlich übereinstimmenden Betrieb und im wesentlichen dasselbe Fabrikationsprogramm haben. Sie verarbeiten in erster Linie Schweißeisen und fabrizieren Stäbe, um daraus als Ganzfabrikat hauptsächlich Draht herzustellen. Innerhalb dieser Produktion zeigt sich eine weitere Spezialisation insofern, als aus dem Draht auch Nägel, Stifte, Federn, Nieten, Ronden hergestellt werden. Besondere Maschinen liefern zusammenhängende Drahtgeflechte. $\mathrm{DaB}$ noch Nebenprodukte gewonnen werden, wie der zu Eisenvitriol verarbeitete Grünspan, verdient ebenfalls hervorgehoben zu werden. Der Schwerpunkt der Produktion liegt in Hamm, wo auch die Spezialisation in bezug auf die Erzeugung am gröBten ist. 
So viel über die Westfälische Union.

Ob die Fusion beider Werke in den Bedürfnissen der Produktion begründet lag, oder vielmehr eine mit den Finanzinteressen der beteiligten Gruppen verquickte Operation war, entzieht sich für den Außenstehenden der genaueren Beurteilung.

Was das erstere Moment anbelangt, so läßt sich ohne weiteres erkennen, daß der Absatz an Fertigerzeugnissen mehr in den Vordergrund tritt, denn jetzt kann der Phönix sein Halbzeug in Hamm etc. zu Draht weiter verarbeiten. Trotzdem scheint, nach historischen und analogen Erfahrungen bei der Dortmunder Union zu urteilen, die Vereinigung kaum von Nutzen. Wir sahen bereits an anderer Stelle, daß die Erweiterung der örtlichen Dezentralisation und der Spezialisation in der Produktion Nachteile im Gefolge hatte. Allerdings steht die Verwaltung des Phönix auf einem anderen Standpunkt. Gegen Ende der 90er Jahre, als auch die Konjunktur für Draht eine sehr günstige war, arbeitete die Westfälische Union mit großen Gewinnen und unter dem Eindruck dieser Tatsache bemerkt der Geschäftsbericht des Phönix von 1899/1900: „Die Ergebnisse der letzten Jahre beweisen, daß die Vereinigung des Phönix mit der Westfälischen Union ein richtiger Schritt war, dessen günstige Einwirkung sich in schlechten Zeiten vielleicht noch mehr zeigen wird." Diese Erwartung hat sich nicht erfüllt. Die Spezialisation erwies sich nicht imstande, das Risiko während der letzten Krisis herabzumindern. Die Dividende des Phönix betrug 1899/1900 noch 15\%, 1900/01 sank sie auf 4\%, 1901/02 sogar auf 0\%, um dann 1902/03 auf $8 \%$ zu steigen. Eine Abtönung der Wirkungen der Krisis auf das Unternehmen wird man aus diesen Ziffern schwerlich herauslesen können, im Gegenteil, es scheint schwieriger, ein so hohes Kapital, wie es der Phönix nach Absorption der Westfälischen Union aufweist, zu verzinsen. Es wäre kurzsichtig, diesen Zusammenhang übersehen zu wollen. Das Betriebskapital des Phönix hat sich von 1896-1903 mehr als verdoppelt, während es in der langen Zeit von 1873-1896 stabil auf 16,2 Millionen Mark verharrte. Der Vollständigkeit halber sei hier noch erwähnt, daß vom 1. Mai 1890 ab von den Aktien lit. B je 9 zu 300 Mark in abgestempelte Aktien lit. A zu 1200 Mark zusammengelegt wurden. Daraus ergab sich ein Buchgewinn von 1,5 Millionen Mark. Diese Reduktion wurde jedoch dahin ausgeglichen, daß weitere 1,5 Millionen Mark abgestempelter Aktien lit. A zur Emission gelangten. Von dieser Transaktion abgesehen, erfolgt dann 1896 nach längerer Pause die erste Vermehrung des Aktienkapitals 
um 4050000 Mark, und 1898 schließt sich daran eine zweite. Es werden behufs Angliederung der Westfälischen Union und zur Vermehrung des Betriebskapitals 9750000 Mark Aktien ausgegeben. Aber diese Riesensumme genügte noch nicht. In der außerordentlichen Generalversammlung vom 30. Oktober 1903 wurde, wie bereits früher erwähnt, das Betriebskapital noch um weitere 5 Millionen vermehrt, so daß es z. Zt. 35 Millionen beträgt, d. h. beinahe an das der Dortmunder Union mit 36 Millionen Mark heranreicht. Allerdings ist dabei nicht zu vergessen, daß die Produktion des Phönix heute größer ist als die der Dortmunder Union. Es betrug die Gesamtproduktion an fertigem Eisen und Stahl:

$\begin{array}{lrc} & 1898 / 9 & 1901 / 2 \\ \text { beim Phönix . . . . } & 303,382 \mathrm{t} & 321,421 \mathrm{t} \\ \text { bei der Dortmunder Union } & 290,554, & 258,001\end{array}$

Fassen wir zum Schluß das Wesentliche noch einmal kurz zusammen: Das hervorragendste Ereignis a us der neueren Geschichte des Phönix ist ohne $Z$ weifel seine Vereinigung mit der Westfälischen Union. Das angegliederte Unternehmen beruht in der Hauptsache auf der Herstellung von Draht. Aus seiner Geschichte ist besonders wichtig die Entlastung des Produktionsorganismus durch AbstoBung dreier Werke. Ferner die Tatsache, daB die statutarisch festgelegten Gründerrechte lange Zeit die Expansiondes Unternehmens durch Aufnahme von neuem Aktienkapital hinderten, bis auch sie unter dem Druck derkapitalistischen Entwicklung zusammenbrachen. Die Verschmelzung mit der Westfälischen Union hatte fürden Phönix zur Folge: eine Vermehrung und weitere Spezialisierung seiner Produktion durch die Aufnahme der Drahtfabrikation in großem Umfange und die damit gegebene Möglichkeit, seine eigenen Rohmaterialien und Halbfabrikate in höherem $M$ a Be als dies früher der Fall war in eigenen Betriebenzuverarbeiten und zuveredeln. Eine weitere Folge war eine VergröBerung der lokalen Dezentralisation und auf finanziellem Gebiet eine nicht unbedeutende Kapitalsvermehrung, so da $B$ der Phönix in bezug auf die Höhe des Aktien- 
kapitals unter den groBen Eisenwerken Deutschlands nach Krupp mit 160 Millionen Mark und der Dortmunder Union mit 36 Millionen Mark in dritter Reihe rangiert.

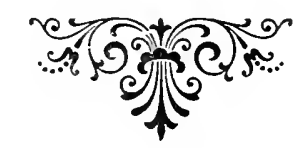




\section{Die vereinigte Königs- und Laura-Hütte.}

Das größte und heute auch unstreitig hervorragendste Werk der oberschlesischen Eisenindustrie ist die Königshütte. Es hat alle drei Formen der gewerblichen Unternehmung durchlaufen, die uns bekannt sind: von 1802-1869 war es Staatsbetrieb, ging dann für ganz kurze Zeit in Privathände über, d. h. in die Form der Einzelunternehmung, um bald darauf von 1871 bis zur Gegenwart in der Form des gesellschaftlichen Unternehmens eine bedeutende Rolle zu spielen. Danach läßt sich die Geschichte der Königshütte in zwei große Perioden einteilen. In der ersten tritt sie als Staatsbetrieb auf, in der zweiten als Aktiengesellschaft; von der dazwischenliegenden kurzen Zeit, wo sie in Privatbesitz war, können wir bei der Einteilung mit Fug abstrahieren.

Ich beabsichtige im folgenden die erste Periode nur ganz kurz zu bchandeln, um so ausführlicher aber der zweite, und zwar aus dem Grunde, weil über den fiskalischen Betrieb der Königshütte das Wesentliche bereits in einer datenreichen Denkschrift, die anläßlich des hundertjährigen Bestehens der Unternehmung von der Verwaltung herausgegeben wurde, zusammengestellt ist, und weil die zweite Periode, in der das unpersönliche Kapital von der Hütte Besitz ergreift, und an Stelle des Staates die Leitung übernimmt, nur ganz kurz behandelt ist. Die Zeit vor 1871 wird in der Festschrift auf 66 Seiten zur Darstellung gebracht, hingegen widmet sie der ganzen Zeit von 1871-1902 nur 11 Seiten. Das ist um so merkwürdiger, als ein Vergleich der ersten mit der zweiten Periode durchaus zu Gunsten der letzteren ausfällt. Das Unternehmen hat als Aktiengesellschaft viel mehr geleistet und höhere Erträge erzielt wie als Staatsbetrieb.

Mit der Schilderung der Königshütte betreten wir einen neuen, für den Nationalökonomen, der die Gradabstufung der kapitalistischen Entwicklung in der Eisenindustrie studieren will, außerordentlich interessanten Boden: Oberschlesien. Hier waren schon vor anderthalb 
Jahrhunderten große Unternehmungen von seiten des preußischen Staates ins Leben gerufen worden. Ihr intellektueller Urheber war Friedrich der Große. Für die damalige absolute Monarchie entsprang der Gedanke in Oberschlesien die Eisenindustrie ,in Flor zu bringen", in erster Linie militärischen Interessen. Der Staat wollte die für den Krieg notwendigen Eiseninstrumente selbst fabrizieren. In dem Reskript Friedrich Il. vom 15. Oktober 1781 an die Provinzialbehörden wird hervorgehoben, $\mathrm{da} \beta$ es in erster Linie für den Staat darauf ankommt, „daß man alle Bergprodukte, welche die Natur einem Lande gegeben, ohne anderen Branchen der Staatswirtschaft $\mathrm{zu}$ schaden, mit den geringsten Kosten und der besten Qualität mit beständigem Nachhalt zu gewinnen suche, zuerst aber auf die unentbehrlichsten und besonders zu Kriegszwecken notwendigen sein Augenmerk richte." Aber Friedrich der Große wollte nicht nur eine bedeutende, dem militärischen Staatsinteresse nutzende Eisenindustrie schaffen, er wollte sie auch fördern. In dieser Hinsicht treten die merkantilistischen Anschauungen des großen Königs deutlich zu Tage, d. h. die Regeln jener großen praktischen Staatspolitik, die die westeuropäischen Länder vom 16.-18. Jahrhundert beherrschte. Um den Absatz an Eisen zu erhöhen, führte er die sogenannte Distribution ein, d. h. die inländischen Eisenkonsumenten wurden zur Abrahme bestimmter Eisenmengen gezwungen. Auf anderen Industriegebieten verfuhr er ähnlich: so schrieb er vor, wieviel jede Familie Porzellan kaufen solle etc. Man kann sich heute kaum eine Vorstellung davon machen, wie gehässig vielfach diese von dem absoluten Polizeistaat vorgenommenen Eingriffe in die Privatwirtschaft wirkten. Infolgedessen wurde bereits 1780 der Abnahmezwang für Eisen wieder aufgehoben. Um angemessene Preise für die Eisenfabrikate zu ermöglichen, gehörte der „Schutz der nationalen Arbeit", wie wir heute sagen würden, in das System der politischen Maßregeln, das den Inbegriff des Merkantilismus ausmachte. Es wurde das Importverbot fremden Eisens nach Oberschlesien und anderen Provinzen eingeführt. Die merkantilistische Politik sah in dem Prohibitivzoll ein Mittel, die Industrie des eigenen Landes zu fördern.

Unter der Herrschaft dieser politischen Anschauungen wurden nun eine Reihe von Staatsbetrieben in Oberschlesien ins Leben gerufen. So bereits 1754 das Eisenwerk in Malapane für MunitionsguB; ferner wurde in Gleiwitz eine Eisengießerei angelegt, die später für die Königshütte von großer Wichtigkeit werden sollte. Trotz- 
dem scheint Friedrich der Große kein absoluter Anhänger des Staatsbetriebes gewesen zu sein; in einer Kabinettsorder sagte er gelegentlich einmal: „Mein lieber Etatsminister Freiherr von Heinitz, glaube er mir, es gibt viele Dinge, welche die Privaten besser verstehen als wir."“)

Der bedeutendste Staatsbetricb aber, der in der Folgezeit in Oberschlesien entstand, war die Königshütte. Die unmittelbare Veranlassung zu ihrer Entstehung bildete die Entdeckung großer Steinkohlenflötze. Erst nachdem man in Oberschlesien die unermeBlichen Kohlenschätze näher kennen gelernt hatte, schritt man zum Bau der Königshütte, d. h. zweier Hochöfen mit Nebengebäuden in nächster Nähe der Königsgrube, ,so daB die Kohlen aus dem Schacht unmittelbar in die Kohlenwagen gestürzt und nach der Koksbank gebracht werden konnten." Diese beiden Öfen repräsentierten die erste Kokshochofenanlage auf dem Kontinent. Das dazu nötige Kapital belief sich auf 40000 Taler. Nach den Angaben der Festschrift, auf die sich die foigende Darstellung im einzelnen stützt, erhielten die zuerst erbauten Hochöfen eine Höhe von $40 \mathrm{FuB}$ und eine Kohlensackweite von 11 FuB 4 Zoll; beide waren durch eine gemeinschaftliche Gießhütte miteinander verbunden. $\mathrm{Zu}$ diesen beiden Hochöfen kam dann 1805-1807 ein dritter. Der vierte wurde erst 1818 erbaut. Das in Königshütte produzierte Roh- und Gießereieisen kam fast ausschließlich nach der Königlichen Eisengießerei in Gleiwitz, die ökonomisch in einem ganz engen Konnex mit der Königshütte stand. So wurden z. B. alle Maschinen, die letztere brauchte, in Gleiwitz gebaut. Allerdings verursachte der Transport des Roheisens nach Gleiwitz große Schwierigkeiten. Er vollzog sich durch Landfuhrwerk auf erbärmlichen Wegen. Erst 1829 wurde eine Chaussee von Königshütte nach Gleiwitz gebaut. Eisenbahnen existierten ebenfalls noch nicht, und der Wasserweg kam für den Transport kaum in Betracht, denn der Klodnitzkanal war in unzureichenden Dimensionen ausgeführt worden. „Nachdem im November 1806 der Kanal von Laband aus schiffbar gemacht war, sind erst im Jahre 1823 die Schleusen desselben in der Weise erweitert worden, da $B$ Oderkähne hinaufkommen konnten, so daB von diesem Zeitpunkt ab Kohlen und Eisen direkt nach Breslau, Berlin und Magdeburg verladen werden konnten. Die schwankenden Schiffahrtsver-

*) A. Paniow'ski: „Die Montanindustrie Oherschlesiens vor 100 Jahren (1799)." Kattowitz 1899, p. 15. 
hältnisse auf der Oder machten jedoch diese Verladung unsicher." (Festschrift p. 19.) Was die Erzanfuhr anbelangt, so wurde dieselbe von einer großen Anzahl von Gewinnungspunkten aus in Angriff genommen. Die Abfuhr besorgten Bauern der Umgegend. Dieser Nebenerwerb legte in das ursprünglich rein agrarische Milieu die erste Bresche. Ja, die Bauern von Chorzow gingen so weit, sich das Recht auf Vekturanz beim Verkauf von Land an die Hütte hypothekarisch zusichern zu lassen. Die Bauern waren froh, neben der Landwirtschaft, namentlich im Winter, in der Industrie eine finanzielle Beihilfe zu finden. Ihre Bezahlung war daher und wegen ihrer niedrigen Lebenshaltung und ihrer Bedürfnislosigkeit eine sehr geringe. Demgemäß waren auch die Arbeitskosten auf der Hütte außerordentlich mäßig. Die Zahl der auf dem Bergwerke und der Hütte selbst beschäftigten Personen betrug 173 Mann. Der durchschnittliche Arbeitslohn belief sich auf 10 Silbergroschen, das heißt 1 Mark.

Welchen Effekt zeitigte nun das Zusammenwirken dieser drei große1 Produktionsfaktoren Natur, Kapital und Arbeit?

Dic Betriebsresultate waren in den ersten Jahren des Bestehens der Königshütte keine günstigen. Der junge Betrieb hatte unter einer Summe von Schwierigkeiten zu leiden. Die Hochöfen brannten nicht ordentlich. Die erste Hüttenreise des Redenofens z. B. dauerte nur 11 Wochen. Dann traten Versetzungen ein. Die oberschlesischen Koks erwiesen sich zum Eisenschmelzen weniger geeignet als die festen Koks aus englischen Fettkohlen. Dazu kam die Armut der oberschlesischen Erze an Eisen, von der später die Rede sein soll, und die ungleichartigen Beimischungen von Sand, Lehm, Kalk und namentlich Zink, diesem gefährlichen Feinde des Hochofenprozesses. Die schwefelsäurehaltigen Wasser der Grube, die zum Maschinenbetrieb verwandt wurden, zerfraßen das Metall und verstopften infolge ihrer Ockerabsätze häufig die Maschinenteile. „Aber alle diese Schwierigkeiten", sagt die Festschrift, „wurden mehr als aufgewogen durch die Leichtigkeit der Gewinnung von Kohle, Erz und Kalkstein, welche sich in unmittelbarer Nachbarschaft zusammenfanden und durch die außerordentlich mäBigen Preise, zu denen sie bei niedrigen Lohn- und Frachtsätzen zum Hüttenplatz geschafft werden konnten. Diese Umstände allein haben den Eisenhüttenbetrieb in Oberschlesien ermöglicht. Die Erzeugungskosten des Roheisens entsprachen schon sehr bald annähernd den Erwartungen, und bereits im Jahre 1804 konnte das Werk trotz vieler Unkosten bei einer Procuktion von 20000 Zentner Roheisen den ersten baren Über. 
schuß von 5226 Taler an die Staatskasse abführen. Das große, mit vielen jahrelangen Mühen geförderte Unternehmen war gelungen."

In der Folgezeit entwickelte sich die Königshütte verhältnismäßig langsam. Allerdings verdoppelte der Bau des vierten Hochofens im Jahre 1818 die Eisenproduktion. Sie betrug 18181472 Tonnen und stieg 1819 auf 3053 Tonnen. In dem folgenden Jahrzehnt ragt sie aber nicht viel über die letzte Ziffer hinaus. Auch eine Weiterentwicklung der Betriebsanlagen fand nicht statt. Die Hütte blieb bei der Herstellung von Roheisen stehen. Ein eigenes Puddelwerk besaß sie nicht, ebensowenig ein Walzwerk. Den weiteren Schritt zur Herstellung schmiedbaren Eisens zu machen, blieb einer späteren Zeit vorbehalten.

Die Gründe für diesen mangelhaften Aufschwung der Königshütte sind in folgenden Verhältnissen zu suchen. Zunächst in dem Fehlen einer großen, massenhaft Eisen verbrauchenden Industrie, wie sie später die Maschinenfabriken und der Eisenbahnbau darstellten. Es fehlten noch die eigentlichen kapitalistischen Grundlagen der Massenerzeugung, oder, wie Sombart sich ausdrückt, die Emanzipation des Menschen vom Organischen. Ferner war es die englische Konkurrenz, die auch der Königshütte sehr viel zu schaffen machte, als sie bis nach Oberschlesien eindrang und Gießereieisen zu einem außerordentlich billigen Preise auf den Markt warf. Allerdings muß man die Zeit der Kontinentalsperre hiervon ausnehmen, in der das Werk florierte. Der englische Eisenexport war unterbrochen, und die damals bestehenden deutschen Werke hatten Zeit genug, den Konsum an das teurere, eigene Fabrikat zu gewöhnen. Das größte Hindernis aber war die technische Rückständigkeit der deutschen Betriebe gegenüber den englischen. Die Kokshochöfen der Königshütte bilden zwar eine Ausnahme, aber auch sie produzierten nicht so billig wie die englischen. Fast allgemein wurde das Eisen noch im Frischfeuer mit Holzkohlen geschmolzen, während in Großbritannien bereits um das Jahr 1800 dieser Betrieb auf dem Aussterbeetat stand. 1842 gab es in ganz Deutschland nur noch einen einzigen Holzkohlenhochofen, während nach Sering*) von der Hochofenproduktion des Zollvereins erst 10,8\% mit Koks oder gemischtem Brennmaterial hergestelit wurden. Das lag einerseits an der technischen Rückständigkeit der Bureaukratie, andererseits aber an den Interessen des schle-

*) "Geschichte der preußisch-deutschen Eisenzölle von 1818 bis zur Gegenwart ${ }^{*}$ in Schmollers staats- und sozialwissenschaftlichen Forschungen III, 4. Heft, 1882, p. 58. 
sischen Agraradels in bezug auf die vorteilhafte Verwertung seiner Holzbestände. Die Bureaukratie war - von einzelnen Männern abgesehen - auch damals nicht elastisch genug, um den in England längst vollzogenen Fortschritt zu acceptieren. So warnt der Oberhüttenverwalter Reil vor einer Ausdehnung des Steinkohlenbetriebes der Königshütte. 1828 berichtet er nach Berlin, daß die Waldbesitzer Oberschlesiens große Aufforstungen vorgenommen hätten, so daß der Holzkohlenhochofen- und der Frischfeuerbetrieb in Oberschlesien noch auf lange Zeit gesichert sei. (Festschrift p. 30.) Die schlesischen Agrarmagnaten hatten ein großes Interesse daran, den technischen Fortschritt in der Industrie hintenan zu halten, weil sie, so lange der Holzkohlenbetrieb herrschte, ihre Waldbestände gut verwerten konnten. Deshalb blieb die Eisenerzeugung in den Holzkohlenhochöfen Oberschlesiens bedeutend teurer als die Eisenproduktion in den Steinkohlenöfen Englanćs. Darin liegt der wesentliche Grund für die Überlegenheit Englands auf dem Gebiete des Eisenexports. Dieser erreichte nun eine enorme Höhe in den 30er und namentlich Anfang der 40er Jahre, als schottisches Gießereiroheisen in großen Massen nach Schlesien eindrang. Auf der Königlichen Hütte in Gleiwitz, dem Hauptkonsumenten des Roheisens der Königshütte, wurde 1842 ein Quantum von 9000 Zentner schottischen Gießereiroheisens verarbeitet. Das englische Roheisen kostete 3 Mark loco Oberschlesien, während die Erzeugungskosten in Königshütte sich auf 3,3 Mark stellten. Die Herstellungskosten des Holzkohlenroheisens waren natürlich noch bedeutend höher. In der Festschrift werden die Wirkungen dieser Verhältnisse auf die Königshütte folgendermaßen geschildert (p. 32): „Wegen schlechten Geschäftsganges in der Gießerei klagt das Hüttenamt im Jahre 1834 zum ersten Male seit seinem Bestehen über Mangel an Absatz. Die Vermehrung der Roheisenbestände in Gleiwitz und Königshütte beginne bedenklich zu werden. Man sieht sich veranlaßt, auf stärkere Verwendung von Koksroheisen zur Stabeisenfabrikation in den Frischfeuern Bedacht zu nehmen, und es wird zu dem Ende, um das siliciumreiche Roheisen hierzu geeigneter zu machen, ein englisches Feinfeuer gebaut. Daneben blieben allerdings auch die Verhandlungen wegen Anlage eines Puddel- und Walzwerks in Königshütte im Gange ... Unter den erwähnten, außerordentlich schwierigen Verhältnissen übernahm der Hüttenmeister Eck die Betriebsleitung der Hochöfen von Königshütte, und es gelang ihm in wenigen Jahren, derselben Herr zu werden. Er änderte den Betrieb so viel als möglich 
dahin $a b$, da $\beta$ die Hochöfen nicht mehr wie früher vorwiegend Gießereiroheisen, sondern zur Verarbeitung in Frischfeuern geeignetes Produkt erzeugten. Zum Raffinieren der siliciumreicheren Erzeugnisse aber wandte er statt der mit Koks betriebenen englischen Raffinierfeuer Gasflammöfen mit Steinkohlenfeuerung an, welche von ihm erfunden und konstruiert wurden. Das flüssige Roheisen wurde direkt aus dem Hochofen in dieselben abgestochen und mit hochgespanntem Gebläsewind aus scharf stechenden Düsen bchandelt, hierdurch wurde das graue Koksroheisen in weißes, gefeintes Eisen umgewandelt. Eck hatte hierbei einen durchschlagenden Erfolg. „Es verdient namentlich besondere Anerkennung", schrieb der Minister im Erlaß vom 30. April 1843, „daß ohnerachtet der sehr nachteiligen Konkurrenz des englischen Eisens die landesherrlichen Eisenhütten im allgemeinen nicht ungünstig abgeschlossen haben."

Der weitere Ausbau der Königshütte und ihr eigentlicher Aufschwung steht im Zusammenhange mit den großen Revolutionen im Verkehrswesen, die durch den Bau und die Inbetriebsetzung von Eisenbahnen hervorgerufen wurden. Die Herstellung der Eisenbahnen erforderte große Quantitäten von Eisen und provozierte geradezu eine auf Massenherstellung berechnete Großindustrie. Ein weiteres Moment war die Zunahme des Maschinenbaus. In Preußen wurden an für die Industrie tätigen Dampfmaschinen nach Zahl und Stärke aufgezeichnet:

$\begin{array}{ccc} & \text { Maschinen } & \text { Pferdekräfte } \\ 1837 & 419 & 7355 \\ 1840 & 615 & 11,712 \\ 1843 & 863 & 16,498 \\ 1846 & 1139 & 21,715 \\ 1849 & 1445 & 29,483 \\ 1852 & 2124 & 43,051\end{array}$

Unter diesen nahmen nach Anzahl und Kraft bei weitem den ersten Rang die für den Berg-, Hütten- und Salinenbetrieb bestimmten Maschinen ein; dann folgten die Spinnerei, Weberei und Walkerei, an dritter Stelle aber die metallischen und an vierter die Maschinenfabriken.*)

Die Anforderungen des Eisenbahnbaues und später des Maschinenbaues führten zu einer Vergrößerung der Königshütte. Bisher war der Erzeugungsprozeß eingliedrig, denn die Hütte basierte auf der Herstellung von Roheisen; nunmehr wird er dreigliedrig

*) Sering, a. a. O., p. 53. 
gemacht, und zwar durch den Neubau eines Puddel- und eines Walzwerkes. Das Projekt, 8 Puddelöfen, 7 Schweiß- und Wärmeöfen und je 1 Stab- und Schienenwalzwerk zu errichten, kam von 1838 bis 1844 zur Ausführung. Das neue Werk, dessen Kosten auf 150000 Taler veranschlagt worden waren, erhielt zu Ehren des damaligen Finanzministers den Namen Alvenslebenhütte. Die Produktion des ersten Betriebsjahres 1845 überflügelte noch die von der Verwaltung gehegten Erwartungen. Sie betrug 19052 Zentner Kolbeneisen, 5200 Zentner Stabeisen, 19249 Zentner Eisenbahnschienen und 85000 Zentner Rohschienen.

Die Zeit, in der die Königshütte und ihr Supplement, die Alvenslebenhütte, einen großen Aufschwung nahm, war handelspolitisch gekennzeichnet durch die Einführung von Schutzzöllen auf Roheisen und Schmiedeeisen. Damit sollte ein Ausgleich geschaffen werden zwischen der billigeren Produktion des Auslandes und der teureren des Inlandes. Die mit dem 1. September 1844 in Kraft getretenen Schutzzölle auf Roheisen und Stabeisen wandten sich in erster Linie gegen die stürmische Konkurrenz Englands, deren Einfluß auf die deutschen Eisenwerke wir bereits kennen lernten. Die Wirkung dieser Zölle war allerdings nicht die Beseitigung der fremden Konkurrenz, wohl aber ihre Einschränkung.

Unter diesem Schutzzollsystem, das im wesentlichen bis zu der Ära der westeuropäischen Handelsverträge, d. h. bis Anfang der 60er Jahre in Geltung blieb, entstanden eine große Anzahl von Konkurrenzwerken in Oberschlesien. Dieser Periode verdanken ihre Entstehung die Falvahütte, die Friedenshütte, die Eintrachthütte, die Maria- und Sophienhütte, die Baildonhütte, die Herminenhütte, das Piela-Zawadzkiwerk, die Hugohütte und die Donnersmarckhütte. Das gefährlichste Unternehmen für die Königshütte wurde aber ein Privatwerk des Grafen Hugo Henkel von Donnersmarck. Derselbe erbaute 1835-1838 mit Hilfe englischer Ingenieure und nach englischem Muster ein großes Hochofen-, Puddel- und Walzwerk in verhältnismäßig geringer Entfernung von der Königshütte. Dieses große Privatunternehmen erhielt den Namen Laurahütte. Es begann damit, der Staatshütte die besten Beamten und Arbeiter wegzunehmen, z. B. den Hüttenmeister Naglo.

Obgleich der Verbrauch an Eisen stark gestiegen war, machten doch all diese Werke der Königshütte eine nicht unbedeutende Konkurrenz. Diese Konkurrenz hätte nun der Sporn zum Fortschritt sein sollen. Allein der Staatsbetrieb war nicht wagemutig genug, 
um die Vergrößerung und Vervollkommnung der bestehenden Einrichtungen rechtzeitig durchzuführen. Die Festschrift gibt eine detaillierte Darstellung der in den betreffenden Ministerien gepflogenen Erwägungen, die allzulange auf dem Papier standen, ehe sie in die Praxis umgesetzt wurden. Die Sünden, die man damals beging, ließen sich in bezug auf ihre Wirkungen nicht wieder gut machen und führten, wie wir später sehen werden, zum schließlichen Verkauf der Hütte. Es ist daher interessant, die Pläne kurz zu verzeichnen, die in einer Zeit fieberhafter Produktion in der Eisenindustrie nicht zur Ausführung gediehen und infolge dieses negativen Resultates zu einer starken Schädigung der Königshütte führten.

Bereits 1846 hatte die Hüttenverwaltung ein Projekt ausgearbeitet, nach dem die Produktionsmittel wesentlich verstärkt werden sollten. Es sollte ein neuer großer Ofen in Gleiwitz und 2 in Königshütte gebaut werden; ferner sollten die alten Öfen in neue von großen Dimensionen umgewandelt werden. Die Kosten berechnete man auf 248000 Taler. Dieser Plan wurde dem Könige vorgelegt. „Aber Friedrich Wilhelm IV.“, heißt es in der Denkschrift p. 44/45, ,scheint nicht gewillt gewesen zu sein, die Vorteile der Eisenkonjunktur, welche er zum Teil durch den gewährten Zollschutz veranlaßt hatte, in Konkurrenz mit den Privatwerken zur Erweiterung der fiskalischen Hütten auszunutzen. Mit Kabinettsorder vom 4. September 1846 genehmigte er zuvörderst nur den Neubau von zwei Hochöfen für beide Werke zusammen, und zwar lediglich unter Verwendung der extraordinären Überschüsse aus dem Betriebe von $1847 \mathrm{ab}$ gerechnet und bemerkte dann: „Was die auf der Königshütte und in Gleiwitz vorhandenen baufälligen Öfen betrifft, so gebe ich Ihrer näheren Erwägung anheim, ob dieselben nicht mit Rücksicht auf die gegenwärtig für die Eisenfabrikation günstigen Konjunkturen noch eine Zeitlang im Betriebe zu erhalten sein werden und ob es nicht angemessen sein möchte, den Umbau dieser Öfen, sobald sie nicht länger benutzt werden können, auf drei zu beschränken und so eine Vermehrung der Gesamtzahl fiskalischer Hochöfen in Oberschlesien zu vermeiden, weil es sehr zweifelhaft ist, wie lange die gegenwärtige günstige Konjunktur für den Eisenhüttenbetrieb dauern wird, sobald aber eine Stockung eintritt, neue Klagen über eine Vermehrung der fiskalischen Konkurrenz nicht fehlen werden." Diese schwerwiegende Entscheidung hatte zur Folge, daB der ganze vorbereitete Plan einstweilen fallen gelassen werden muBte, weil die 
fiskalischen Hüttenkassen noch eine namhafte Schuldenlast aus Vorjahren abzutragen hatten, ehe sie extraordinäre Überschüsse aus ihren Erträgen nachweisen konnten."

Das große Hungerjahr 1848 gab dann der Bergverwaltung ein neues Motiv, um den Bau der beiden neuen Hochöfen auf der Königshütte zu verlangen. Sie gingen davon aus, daB ,die bekannte Not in Oberschlesien nicht unwesentlich vermindert werden würde, wenn bald durch allerhöchste Genehmigung bei diesen Bauten recht viele Bauarbeiter angestellt und dadurch Leben und Verdienst dem armen Volke gegeben werden könnte." Dieses sozialpolitische Argument veranlaßte den König, auf den die revolutionäre Bewegung der Märztage einen starken Eindruck gemacht hatte, auf eine Vorlage des Finanzministers, durch Kabinettsorder vom 17. April 1848 zu bestimmen, daß das zum Bau erforderliche Geld aus der schlesischen Oberbergamtshauptkasse zu Brieg vorschußweise entnommen werden solle. Allein das Finanzministerium konnte sich zur Hergabe der Summe nicht entschließen, und auch die Oberrechnungskammer erhob Bedenken. 1850 kam dann in der Person des Hütteninspektors Eck ein Mann in die Verwaltung der Königshütte, der mit großem Eifer die alten Pläne wieder aufnahm. Aber dieser, durch seine Reisen in die schottischen Eisenbezirke besonders orientierte Beamte starb 1852 an der Cholera. Ein MinisterialerlaB aus demselben Jahre zog überdies die Ausführung des Bauetats wegen dringender anderweitiger Ausgaben einstweilen wieder zurück. Da nun von der Vergrößerung des Werkes seine Konkurrenzfähigkeit abhing, ist es begreiflich, daß die maßgebenden Kreise schlieBlich den Monarchen selbst für den Neubau zu gewinnen suchten. Anlaß dazu gab die zum 50jährigen Jubiläum des Werkes veranstaltete Feier, zu der der König persönlich erschien. „Die Feier“, schreibt die Festschrift (p. 48), „,welche allerdings wegen der zu iener Zeit herrschenden Cholera bis auf den 29. August 1853 verschoben werden mußte, nahm einen glänzenden Verlauf, und der König schenkte besonders der Walzung des Konstruktionsmaterials für die Ostbahnbrücke in Dirschau, welche ihm in der Alvenslebenhütte vorgeführt wurde, seine besondere Aufmerksamkeit und Teilnahme. Wie man erwartet hatte, nahmen von jetzt ab auch die Erweiterungsbauten für die Alvenslebenhütte einen flotten Fortgang." Nunmehr wurde in demselben Jahre das ursprüngliche Projekt dahin erweitert, „daB neben dem Umbau der alten Öfen in vergrößerten Dimensionen noch vier weitere neue Hochöfen moderner Konstruktion, zwei neue 
Gebläsemaschinen von je 100 Pferdekräften und zwei dergleichen von 120-150 Pferdekräften, ferner 108 (Wittenberger) geschlossene Verkokungsöfen mit darüber liegenden Dampfkesseln, sowie eine Feinofenhütte und zwei Gasflammöfen errichtet werden sollten und daß außer dem früher geplanten und zum Teil bereits ausgeführten Erweiterungsbau der alten Alvenslebenhütte, welcher neben einer Grobstrecke von 120 Pferdekräften ein Kesselblechwalzwerk von 100 Pferdekräften nebst Schweißöfen mit darüber liegenden Kesseln enthielt, ein großartiges neues Schienen- und Stabeisenwalzund Hammerwerk (Alvenslebenhütte II) errichtet wurde, welches gegenüber der alten Walzhütte Platz fand. Diese letztere, die alte Alvenslebenhütte, wurde in allen ihren Teilen ausschließlich zu einem Puddel- und Rohschienenwalzwerk umgewandelt, in welcher 22 Puddelöfen Platz fanden, während in der neuen Alvenslebenhütte 11 ein Schienenwalzwerk, ein großes Stabeisenwalzwerk nebst einem angehängten kleineren Stabeisenwalzwerk, beide von einer 120- bis 150-pferdekräftigen Maschine betrieben, sowie endlich ein kleines Feineisenwalzwerk mit 30-pferdekräftiger Maschine, sämtlich mit den erforderlichen Hilfsmaschinen und mit zusammen 16 Schweißöfen mit 7 dahinter liegenden Dampfkesseln und 4 Reservekesseln aufrgestellt werden sollten. Dieser Bau kam einem vollständigen Neubau der gesamten Königshütte gleich und wurde mit einigen Abänderungen bis zum Jahre 1860 mit einem Kostenaufwande von nahe an $11 / 2$ Millionen Talern zur Durchführung gebracht, und das Werk erhielt hiermit im wesentlichen die Gestalt, welche es im Jahre 1869 beim Übergang in Privatbesitz hatte. Man rechnete bei dieser großartigen Erweiterung auf eine Erzeugung von ca. 500000 Zentner Roheisen und 300000 Zentner Walzwerksfabrikate." (Festschrift p. 51).

Man kann wohl sagen, selten hat ein Werk die goldenen Tage des Aufschwungs durch unzureichende Einrichtungen und ängstliche Erwägungen so wenig genutzt, wie die Königshütte. Als dann gegen Ende der 50er Jahre die neuen Anlagen nach und nach in Betrieb kamen, war bereits ein schwerer Rückschlag in der Eisenkonjunktur eingetreten. Die großen Schienenaufträge hatten bedeutend nachgelassen, englisches Eisen war wieder in großen Massen auf dem deutschen Markte erschienen - 1858 allein über 5 Millionen Zentner. Die neuen Produktionsmittel der neu entstandenen Werke aber vermehrten in den fünfziger Jahren und in der Folgezeit die Erzeugung gegen früher bedeutend und führten sie in ein Tempo über, an 
das man früher nie gedacht hatte. Es betrug auf der Königshütte. die Herstellung an

\begin{tabular}{|c|c|c|c|c|c|c|c|c|c|c|}
\hline \multirow[b]{2}{*}{1856} & \multicolumn{2}{|c|}{ Roheisen } & \multicolumn{2}{|c|}{$\begin{array}{l}\text { raff. } \\
\text { Roheisen }\end{array}$} & \multicolumn{2}{|c|}{$\begin{array}{c}\text { Guß- } \\
\text { waren }\end{array}$} & \multicolumn{2}{|c|}{$\begin{array}{c}\text { Halb- } \\
\text { fabrikate }\end{array}$} & \multicolumn{2}{|c|}{$\begin{array}{l}\text { Fertig- } \\
\text { fabrikate }\end{array}$} \\
\hline & 5,650 & $t$ & 1,496 & $\mathrm{t}$ & 1,088 & $\mathrm{t}$ & 7,683 & $\mathrm{t}$ & 5,915 & $\mathrm{t}$ \\
\hline 1857 & 10,002 & , & 2,508 & $n$ & 1,226 & , & 11,212 & , & 8,249 & , \\
\hline 1858 & 11,178 & $"$ & 2,459 & $"$ & 1,389 & " & 12,335 & , & 9,595 & " \\
\hline 1859 & 12,153 & $"$ & 1,583 & $"$ & 1,007 & $"$ & 10,622 & " & 7,559 & $"$ \\
\hline 1860 & 13,651 & $"$ & 2,252 & $"$ & 886 & " & 11,296 & $"$ & 8,315 & " \\
\hline 1861 & 15,208 & $"$ & 3,135 & $"$ & 1,185 & ", & 12,956 & $"$ & 10,338 & " \\
\hline 1862 & 16,662 & $"$ & 3,839 & $"$ & 1,323 & " & 14,438 & $"$ & 11,561 & $"$ \\
\hline 1863 & 19,112 & $"$ & 3,850 & $"$ & 1,370 & " & 15,435 & $"$ & 11,739 & " \\
\hline 1864 & 21,335 & $"$ & 4,180 & $"$ & 1,632 & " & 19,581 & " & 15,229 & $"$ \\
\hline 1865 & 24,315 & $"$ & 3,999 & $"$ & 2,022 & , & 21,297 & " & 17,024 & " \\
\hline
\end{tabular}

Dazu kamen nun noch andere Momente, die die Hoffnungen reduzierten, die man auf die durch die Vermehrung der Produktionsmittel erwarteten günstigen Ergebnisse gesetzt hatte. Zunächst führte die Steigerung der Produktion zu einer Verarbeitung auch weniger guter Eisenerze. Mit der Erhöhung der Produktion ging daher eine Verschlechterung des Produktes Hand in Hand, Klagen hierüber waren an der Tagesordnung. Ferner begannen die Produktionskosten bedeutend zu steigen. Die Bau- und Betriebskosten wurden teurer. Die Löhne gingen in die Höhe. Aus der Staatskasse wurden bereits 1853 Gelder zur Anlage von Arbeiterkolonien gegeben. Schließlich war es der unaufhörliche Wechsel der Betriebsbeamten, vor allem der Baumeister und Direktoren, der den Gang des Werkes schädigte. Die meisten gingen - auch während des Baues - in die Konkurrenzwerke über, die von Privaten oder Aktiengesellschaften errichtet waren. Infolgedessen war die technische Ausführung der Neuanlagen nicht vollständig befriedigend, und später wurden viele kostspielige Veränderungen nötig.

Aus diesen Schwierigkeiten suchte nun der seit 1860 als Chef der Bergverwaltung fungierende Ministerialdirektor und Oberberghauptmann Krug von Nidda die Königshütte zu retten, und zwar durch Einführung einer Reihe technischer Verbesserungen. Allerdings ist auch er nicht imstande gewesen, die ursprüngliche Bestimmung des Unternehmens zu verwirklichen, Musteranstalt des. Staates gegenüber den Privatwerken zu sein. Aber der intellektuelle Einfluß dieses Mannes ist auf die Leistungen der Königshütte immerhin nicht unbedeutend gewesen. In bezug auf die eingeführten Verbesserungen, die namentlich den Hochofenbetrieb und die maschi- 
nellen Leistungen betrafen, bemerkt die Festschrift (p. 59): „Durch Verstärkung der Gebläsekraft, Erweiterung der Ofengestelle, bessere Windverteilung und Erwärmung wurde die Wochenproduktion einzelner Öfen in den Jahren 1867-1869 auf 4-5000 Zentner gebracht, und die Selbstkosten des Roheisens wurden wiederum auf 28 Sgr. pro Zentner herabgedrückt. Im Walzwerk wurden durch Vermehrung der Zahl der Puddelöfen bis auf 62 Stück angemessene Produktionsverhältnisse hergestellt, wodurch unter Leitung des Hüttenmeisters Jüttner die Produktionsziffern erhöht und die Selbstkosten ermäBigt wurden. In den Jahren 1860 bis 1869 stieg die Produktion der Hochofenanlage von 13651 auf 38475 Tonnen, die des Walzwerks von 8315 Tonnen auf 31110 Tonnen und die Betriebsergebnisse des Werkes hoben sich beträchtlich. Eine besonders glänzende Entwicklung fand damals die Erzeugung von Eisenbahnschienen mit aufgeschweißtem Feinkornkopf, durch welche Fabrikation die deutsche Eisenindustrie die englische in bezug auf vorzügliche Qualität der Eisenbahnschienen völlig aus dem Felde schlug und sich die Alleinherrschaft auf dem deutschen Schienenmarkt sicherte." Vor allem aber akzeptierte die Königshüttc im Jahre 1865 den größten Fortschritt, der in den 50er Jahren in der Herstellung schmiedbaren Eisens gemacht worden war. Sie führte den Bessemerprozeß ein. Von Krug hatte die Annahme des neuen Verfahrens in Oberschlesien als eine „Ehrenpflicht der Staatshüttenwerke" bezeichnet. Es wurde die bereits 1864 fertig gestellte Bessemeranlage des Hoerder Bergwerks- und Hüttenvereins besucht, über die Brauchbarkeit der oberschlesischen Erze für den Prozeß wurden eingehende chemische Untersuchungen veranstaltet, weiter wurden Gutachten eingeholt und schlieBlich eine Summe von 28000 Taler für den Bau von 2 Convertern disponibel gemacht. In diesen kleinen, nur 5 Tonnen Inhalt fassenden Birnen wurden Ende Januar 1865 die ersten Bessemerchargen geblasen, zur Vorsicht erst mit englischem Hämatiteisen, dann aber mit oberschlesischem Roheisen. Die Erfolge waren gute, ,,so daB bereits in einer Submission vom 8. März desselben Jahres eine Lieferung von 2500 Stück Bessemerstahlschienen für die Oberschlesische Eisenbahn übernommen wurde, für welche die Blöcke unter einem Dampfhammer von 200 Zentner Fallgewicht abgeschmiedet und mit dem vorhandenen Schienenwalzwerk abgewalzt werden konnten." (Festschr. p. 62.)

Aber dieser Fortschritt, der sich im Vergleich zu früheren Maßnahmen relativ schnell vollzog, sollte der letzte sein, der der In:- 
tiative des Staates und seiner Fürsorge für die Königshütte seine Entstehung verdankte. In den 60er Jahren stand die liberale Weltanschauung auf der Mittagshöhe ihres Erfolges. Für sie war der Staatsbetrieb wie die ganze Einmischung des Staates in das Erwerbsleben im Vergleich zu früheren Zeiten nichts wünschenswertes mehr. Dazu kam die freihändlerische Politik der Regierung, die die fremden Märkte der deutschen GroBindustrie eröffnete. Am Ende der 60er Jahre bestürmte die oberschlesische Konkurrenz den Finanzminister, das Werk zu verkaufen. Auf dem Wege der Submission fiel es 1869 in die Hände des meistbietenden Käufers, des damaligen Grafen Hugo Henckel von Donnersmarck, des Besitzers der Laurahütte. Über die Bedingungen, die zum Verkauf des Werkes führten, macht die Festschrift (p. 62-65) folgende Mitteilungen: „Die geschäftliche Lage der Königshütte hatte sich zwar ... in der zweiten Hälfte der 60er Jahre zum besseren gewendet, trotzdem wurde die Absicht, den Verkauf des Werkes baldigst durchzuführen, von der Bergverwaltung niemals aufgegeben. Man hielt den ursprünglichen Zweck desselben, als Musteranstalt für die Privatindustrie zu dienen, bei dem großen Aufschwunge der letzteren für erledigt. Die Aufnahme eines Wettbewerbs mit den Privathütten erschien nicht im staatswirtschaftlichen Interesse und versprach bei der geschilderten Sachlage auch keinen Erfolg, um so weniger, als die Verwaltung der königlichen Werke, an die gesetzlich festgelegten Ökonomiepläne gebunden, dem Betriebsdirigenten niemals diejenige Freiheit in der Bewegung gestatten durfte, welche den Direktoren der Privathütten beim Wechsel der Konjunkturen zu statten kam. Dadurch, daB die Königshütte bereits seit fast zwei Jahrzehnten gewissermaßen unter dem Hammer stand, und durch den hierdurch mitverschuldeten häufigen Wechsel der Beamten hatten sich die Verhältnisse und die Aussichten des Werkes ungemein verschlechtert und so erschwert, daß von der Weiterführung dieses komplizierten industriellen Unternehmens für die Staatsverwaltung erhebliche Inkonvenienzen befürchtet wurden. Hierzu kam endlich, daB die allgemeine Handelspolitik in Preußen eine für den Eisenhüttenbetrieb ungünstige Wendung genommen hatte. Die in den 40er Jahren aufgekommene Neigung der Regierung, die Industrie durch Schutzzölle zu unterstützen, hatte, zunächst aus Gründen der Zollvereinspolitik Preußens gegen Österreich, längst wieder einer freihändlerischen Richtung Platz gemacht... Der Eisenabsatz nach Österreich war lebhafter geworden, und so stand gerade für Oberschlesien augenblicklich eine günstigere Konjunktur 
in Aussicht. Dies hatte zur Folge, daB im Jahre 1868 wiederum einige hervorragende Industrielle Oberschlesiens mit neuen Kaufanträgen wegen der Königshütte an die Bergverwaltung herantraten. Nun glaubte dieselbe nicht länger mit der Abstoßung des Hüttenwerks zögern zu dürfen, und die Verkaufsverhandlungen wurden energisch in Angriff genommen ... Nunmehr wurde auch der Verkauf der Hütte - nach einem gänzlich miBglückten Versuche einer mündlichen Versteigerung, welche mit Rücksicht auf die Kommunalverhältnisse ein allzu niedriges, unannehmbares Gebot geliefert hatte, - im Wege der schriftlichen Submission durchgesetzt, und am 1. Januar 1870 ging das Werk mit allem Zubehör, namentlich auch mit allem Besitz an Erz und Kalksteinfeldern in das Eigentum des Grafen Hugo Henckel von Donnersmarck auf Naclo über, zu cinem Kaufpreis ron 1003000 Taler, wobei ein Feldesteil der fiskalischen Steinkohlengrube König in Größe von 695000 Quadratlachter, welcher der Hütte am zugänglichsten gelegen war, als Zubehör mit überwiesen wurde ... Der Ratgeber, welcher den Grafen Hugo Henckel zu diesem Geschäft veranlaßt hatte, war der Direktor Richter von der dem Grafen selbst gehörigen Laurahütte. Derselbe war früher als Hilfsarbeiter des Hüttendirektors Paul in Königshütte als fiskalischer Beamter beschäftigt gewesen und war in die Verhältnisse des Werkes genau eingeweiht. Er hatte mit der ihm eigenen genialen Kombinationsgabe die großen Vorteile durchschaut, welche der Erwerb dieses, wenn auch in der öffentlichen Meinung stark kompromittierten Staatswerks bei seiner Vereinigung mit der Laurahütte in einer Hand bieten könne. Die üble Meinung von dem Werk der Königshütte war aber so stark, daß der Generaldirektor der preuBischen Besitzungen des Grafen Hugo Henckel, der Bergrat Ficinus, es ablehnte, das Werk in seinen Verwaltungskreis mit zu übernehmen. Dasselbe wurde hicrauf als eine besondere Abteilung unter demı Namen „Das Berg- und Hüttenwerk Königshütte“ dem Geschäftskreis der österreichischen Besitzungen angegliedert und dem Generaldirektor Ritter in Wien unterstellt. Richter trat als Werksdirektor an die Spitze desselben, indem er aus dem Direktorium der Laurahütte ausschied und die Betriebsleitung, bezw. Inbetriebssetzung des bisher der Königsgrube, nunmehr der Königshütte zugehörigen Feldesteils - Gräfin Lauragrube genannt - dem Bergassessor Junghann übertrug."

So viel über die Geschichte und das Schicksal der Königshütte als Staatsbetrieb. Fassen wir noch einmal die wichtigsten Ergebnisse 
dieser ersten Abschnitte zusammen: Das Unternehmen wurde 1802 gegründet zum Zweckeder Erzeugung von Roheisen. Die Produktionsbedingungen lagen verankerteinmalindemunermeBlichen ReichtumgroBer Steinkohlenflötze, fernerinbilligen Arbeitskräften. Das wichtigste Kapital, d. h. die Produktionsmittel, bestanden aus 2 , später 4 Hochöfen, die zum Unterschiedevon anderen mit Koks betrieben wurden. Der Hauptkonsument des darin fabrizierten Roheisens war die königliche EisengieBerei in Gleiwitz. Bis zur Einführung der Eisenzölle im Jahre 1844 war die Entwicklung der Königshütte, von den ersten Zeiten ihres Bestehens abgesehen, stark inhibiert durch die Konkurrenzdes Auslandes, namentlichdes englischen und schottischen Eisens, nachdieserZeit durch die Konkurrenz des Inlandes, d. h. der groBen in Oberschlesien entstandenen Privatwerke und A ktiengesellschaftender Eisenindustrie, insbesondere der Laurahütte. Die tieferen Ursachen für die Superiorität des englischen Wettbewerbes lagen einerseits in der technischen Rückständigkeit der preuBischen Büreaukratie, die Neuerungen schwer zugänglich war, und andererseits in den materiellen Interessenderschlesischen GroBgrundbesitzer, soweit sie das Holz für die Holzkohlen der Hochöfen lieferten. Der wichtigste Fortschritt der Königshütte bestand nun in ihrer ökonomischen Emanzipation von der Gleiwitzer Hütte, oder noch deutlicher ausgedrückt, in dem Übergang von der Roheisenerzeugung zur Herstellung von Fertig- und Ganzfabrikaten. Durch den 1844 beendeten Bauder Alvenslebenhüttemit einem Puddel-und zwei Walzwerken für Stab- und Schienenfabrikation trat an Stelledes frühereneinfacheneindreigliedriger ProduktionsprozeB. Durch dieses Werk wurde die Königshüttebefähigt, indie AusnutzungdergroBen, durch den Eisenbahnbau in Deutschland geschaffenen Konjunktur einzugreifen. Aber diese Glanzperiode begann bereits in der zweiten Hälfte der 50 er Jahre für das Unternehmen zu verblassen. Es 
geriet mit der GröBe und Qualität seiner Produktionsmittel wie seiner Produkte ins Hintertreffen. Die Privatkonkurrenz wartechnisch a $\mathrm{f}$ eine höhere Stufe der Erzeugungsfähigkeit geklommen, die Königshütte abervermochte alseinziemlichkonservativer, im höchsten Grade schwer beweglicher Organismus nicht $z$ u folgen. Allerdings sah das Jahr 1860 nach langen VorberatungenundVerzögerungen vergröBerte Hochofenanlagen und einen Umbau der gesamten Königshütte, dereinem Neubaugleichkam. A uch in den folgenden Jahren wurden unter neuer Leitung Verbesserungen vorgenommen, ja, 1865 sogar ein Stahlwerk erbaut, und damitein neuer Fortschritt eingeführt. Allein die finanziellen Ergebnisse, die Konkurrenz deranderen Eisen-und Stahlwerke, sowie die Wandlung in den politischen Anschaungen waren dem Staatsbetriebe nicht mehr günstig. Infolgedessen wurde 1869 die Königshütte mit der Alvenslebenhütte als Ganzes für den Preis von über 3 Millionen Mark verkauft. So diskreditiert in der öffentlichen Meinung war das Unternehmen, daB der Generaldirektor des neuen Besitzers, des Grafen Hugo Henckel von Donnersmarck, es als unhonorig ablehnte, die Königshütte in den Verwaltungskreis der preuBischen Besitzungen des Grafen aufzunehmen. Damit endigt die Geschichte der Königshütte als Staatsbetrieb. Das Fazit, das wir a us ihrer Entwicklungziehen können, is t keingünstiges; esentsprachnichtder Lösungder Aufgabe, die die Königshütte als Musteranstalt des States erfüllen sollte.

II.

Die Königshütte blieb nur ganz kurze Zeit im Besitz des Grafen von Donnersmarck. Als das Unternehmen unter dem Stern einer glänzenden Konjunktur im Jahre 1870 mit einem Ertrage von 1,2 Millionen Mark abschloB, war die Stunde gekommen, um es in eine Aktiengesellschaft zu verwandeln, und es mit seinem bisher gefährlichsten Konkurrenten, der Laurahütte, zu kombinieren. Zu diesem Zwecke bildete sich ein Konsortium, das gegen einen Kaufpreis von 
18 Millionen Mark beide Werke erwarb. Die Aktien wurden von der österreichischen Kreditanstalt zum Parikurse auf den Markt gebracht. Die Übergabe erfolgte am 1. Juli 1871. Damit beginnt die Vereinigte Königs- und Laurahütte, Aktiengesellschaft für Bergbauund Hüttenbetrieb, mit dem Sitz in Berlin, ihre Tätigkeit.

Im folgenden soll dieselbe in drei Abschnitten zum Gegenstand der Darstellung gemacht werden. Wir behandeln:

1. die Rohstoffversorgung des Unternehmens,

2. das Fabrikationsprogramm und seine Aus gestaltung,

3. die Absatzverhältnisse.

Die beiden wichtigsten Rohstoffe für jedes Hüttenwerk sind Eisenerz und Kohle. Für die Vereinigte Königs- und Laurahütte liegen die Verhältnisse für beide nicht gleichartig. Oberschlesien hat bekanntlich eine besondere Art von Eisenerz, die man Brauneisenstein nennt. Dazu kommen noch Spateisenerze. Diese Erze sind nicht reich, sondern arm an Eisen, sie enthalten vielfach nur $25-28 \%$ wirkliches Metall. Der schwache Eisengehalt aber verteuert ihre Verarbeitung und drückt ihnen infolgedessen den Stempel der Minderwertigkeit auf. Sie sind außerdem mulmig. Ein für den Hochofenprozeß geeignetes Erz aber muß stückig sein. Hat es, wie in Oberschlesien, eine erdige Beschaffenheit, so können nur $11-13 \%$ in den Hochofen gebracht werden, und den übrigen Einsatz müssen edle, stückige Erze bilden. Wollte man mehr solche erdigen Erze einsetzen, dann würde es nicht möglich sein, Wind durch den Hochofen zu blasen. Ferner enthalten diese Erze viel Wasser. Wird das haldenfeuchte Erz getrocknet, dann ist allerdings der Erzgehalt ein etwas höherer. Schließlich aber sind die Erze auch nicht rein, sie führen vielfach Verunreinigungen mit sich wie Zink und den nie fehlenden silberhaltigen Bleiglanz. Diese drei Eigenschaften der oberschlesischen Brauneisenerze: ihre Metallarmut, ihr Wasserreichtum und ihre Verunreinigungen haben nun in bezug auf die Ökonomie des Betriebes zur Folge, daß der Brennstoffaufwand ein verhältnismäßig hoher sein muß. Ein metallarmes Erz zu zerschmelzen erfordert wegen der großen Masse der beigemengten Erzarten mehr Koks. Zur Verschlackung der Kieselsäure sind außerdem große Zuschläge von Kalk nötig. Kommen die Erze mit nicht unbeträchtlichem Wassergehalt in den Hochofen, so wird zur Verdampfung des Wassers ebenfalls mehr Wärme gebraucht, und schließlich muß das in den 
Erzen enthaltene Zink, das durch Ansetzen im Ofen den Betrieb stören und auf die Qualität des Eisens ungünstig einwirken würde, verdampft werden, was wiederum mehr Brennmaterial erfordert.") Die Beschaffenheit der Erze erfordert also einen größeren Aufwand an Koks, welcher die Produktionskosten des Betriebes ungünstig beeinfluBt. Wir werden später sehen, daß der auch heute noch auf der Königshütte in ziemlich ausgedehntem Maße bestehende Puddelbetrieb mitbedingt ist durch die Qualität der oberschlesischen Erze, vor allen Dingen durch den ungünstigen Phosphorgehalt derselben.

Außerdem kommt in Betracht ciie Quantität der Eisenerze, die der Königshütte zur Verfügung stehen. Hier handelt es sich um folgende Fragen: Welche Eisenerzmassen schöpft sie aus eigenen Bergwerken? Welche historische Wandlungen haben sich hier vollzogen? Reicht der Vorrat heute zu einer kompletten Alimentierung der Hochöfen aus? Diese Fragen haben wir jetzt zu beantworten.

In dem bei der Gründung der Gesellschaft veröffentlichten Prospekt heißt es: Die eigenen Erzbergwerke umfassen ca. 500 Morgen und sind $1 / 4-1 / 2$ Meile von der Hütte entfernt, verbunden durch Lokomotiv- und Pferdeeisenbahnen. Sic liefern z. Zt. ca. 2 Millionen Zentner Erze pro Jahr, d. h. also 100000 Tonnen. Diese Eisenerze gelangten nun Anfang der 70er Jahre zumeist per Roßbahn auf die Hütte. Diese Art der Beförderung aber war, da es sich um Massentransporte handelte, ziemlich kostspielig. Erst 1880 wird die Umwandlung des bisher auf dem Schienenwege der Hütte üblichen Betriebes mit Pferden in Maschinenbetrieb, der Umbau der Schienengleise und die Anschaffung eigener Lokomotiven beschlossen. In dem Geschäftsbericht von 1884/85 heißt es dann, daß die Einrichtung des Lokomotivbetriebes auf den Werken die Summe von 221000 Mark erfordert habe. Mit dieser Ersetzung der tierischen Kraft durch die Lokomotive trat ohne Zweifel eine Verbilligung des Erztransportes ein.

Aus der von der Verwaltung in den 70er Jahren und der Folgezeit eingeschlagenen Rohstoffpolitik läßt sich erkennen, daß die vorhin erwähnten Eisenerzfelder in Oberschlesien für den Bedarf der Hochöfen von Anfang an nicht genügten. Bereits der Geschäftsbericht von 1873/74 meldet den Erwerb einer Spateisensteingrube in Ungarn.

*) Über die Beschaffenheit der Erze siehe von Renauld: „Der Bergbau und die Hüttenindustrie von Oberschlesien 1884-97." Stuttgart 1900, p. 190 ff. 
Von besonderem Interesse aber sind die Eisenerzacquisitionen der Gesellschaft in Schweden. In der Gegend von Wäldö, etwa 12 Meilen nördlich von Stockholm, dicht an der Meeresküste gelegen, erwirbt das Werk einen Bergbau auf Magneteisenstein gegen Zahlung eines Förderzinses von $10 \mathrm{Pfg}$. pro $50 \mathrm{~kg}$. Die Erze kamen per Schiff nach Stettin und gelangten von dort aus per Eisenbahn nach Königshütte, wo sie als Zusatz zu den wenig qualifizierten oberschlesischen Erzen dank ihrer Phosphorarmut bei der Erzeugung von Bessemerflußeisen Verwendung fanden. Der Geschäftsbericht sagt liierüber: „Die bisherige Gattierung schwedischer Erze mit schlesischen hat ein ganz vorzügliches Material zur Bessemerstahlerzeugung ergeben und soll bis auf weiteres beibehalten werden." Allein die eigene Förderung aus den schwedischen Gruben wurde bereits 1875 wieder eingestellt, und zwar mit Rücksicht darauf, „daß z. Zt. Bessemererze zu billigem Preise anderwärts zu haben sind." Wir sehen hier ein ähnliches Resultat wie bei der Dortmunder Union, die sich ebenfalls in dem Bezuge schwedischer Erze aus den von ihr erworbenen Svabenswerken getäuscht hatte, weil sie die damaligen Schwierigkeiten und Kosten des Transportes, ähnlich wie die Königshütte, unterschätzte.

Neben diesen Mißerfolgen im Auslande schreitet dann die Gesellschaft zu neuen Erwerbungen von Eisenfeldern im Inlande. In nächster Nähe der Königshütte werden 465 Quadratmeter Eisenfelder angekauft, ferner wird auf die Dauer von 20 Jahren die reiche Magneteisensteingrube Bergfreiheit bei Schmiedeberg gepachtet. Diese Grube sollte der Hütte phosphorfreie Eisenerze für den BessemerprozeB liefern. Allein 1885 wird bereits die Erzgewinnung dieser Grube bedeutend eingeschränkt, weil sich die Fracht bis nach Königshütte als zu hoch herausstellte. Vielleicht hängt diese Einschränkung auch mit dem schlechten Geschäftsgange der damaligen Zeit zusammen. Von allen Gruben der Königshütte liefert heute die Bergfreiheitgrube das meiste Erz.

Unterdessen hatte das Werk das Thomasverfahren bei sich eingeführt, nachdem es die dem Erfinder erteilten Patente erworben hatte, und zwar einmal die Lizenz für die eigenen Werke, zum andern aber in Gemeinschaft mit der Oberschlesischen Eisenbahnbedarfsaktiengesellschaft zur Hälfte das ausschlieBliche Recht der Anwendung für die Provinz Schlesien. Mit der Einführung des Thomasprozesses war auf der Königshütte ein ziemlich starker Bedarf nach phosphorhaltigen Eisenerzen erwacht. Zur Sicherung dieses Bedarfes wurden 
um die Mitte der 80er Jahre weitere Erwerbungen phosphorhaltiger Erzlager in Galizien gemacht, und daselbst durch Mutung das Recht der Erzgewinnung auf 1199 Hektar erworben. Dazu kamen mit den später noch zu behandelnden russischen Erwerbungen noch Eisenerzfelder in Rußland.

Mehr läßt sich aus den Geschäftsberichten leider nicht erkennen. Nach den Angaben der Festschrift hat die Königshütte heute circa 240 Hektar eigener Eisenerzfelder in Oberschlesien, und außerdem steht ihr das Recht der Eisenerzförderung auf einer Anzahl von Flächen zu, die insgesamt ca. 740 Hektar umfassen. Diese Felder jedoch stehen heute größtenteils am Rande der Erschöpfung. Die sich darin aussprechende Abnahme der Eisenerze in Oberschlesien bildet ein Analogon zu dem Verschwinden der Raseneisensteinvorrätc im nördlichen Deutschland, nur mit dem Unterschiede, daB in Oberschlesien die Erschöpfung etwas später beginnt. Für das Jahr 1891 verzeichnete die Statistik der oberschlesischen Berg- und Hüttenwerke noch 56 Eisenerzförderungen mit einer Produktion von 641173 Tonnen Brauneisenerze und 5276 Tonnen Toneisenstein; für das Jahr 1900 wurden aber nur 44 Eisenerzförderungen mit einer Produktion von 382090 Tonnen Brauneisenerze, sowie 599 Tonnen Toneisenstein aufgeführt; 1902 förderten nur noch 35 Eisenerzgruben mit einer Produktion von 390642 Tonnen Brauneisenerz und 857 Tonnen Toneisenstein. Unter diesem von der Statistik festgestellten Abnahmeprozeß hat auch die Königshütte zu leiden. Im Betriebe sind zur Zeit nur ihre Tarnowitzer und Bobrowniker Eisenerzförderungen in Oberschlesien. Dieselben haben eine Belegschaft von 120 Mann und liefern täglich etwa 60 Tonnen Brauneisenerz. Gegenwärtig steht in bezug auf die Förderung obenan die Bergfreiheitgrube bei Schmiedeberg, dann folgen die oberschlesischen Gruben, und schlieBlich die Erzförderungen in Rußland und den übrigen Ländern. Im Jahre 1902/03 förderten

Die Bergfreiheitgrube . • . . 30,865 t
Die oberschlesischen Gruben . . . 21,545 ",
Die Gruben in Rußland . . . . 14,563 ",
Die sonstigen Gruben im Auslande 3,990 ",
\[ \text { im ganzen 70,964 t } \]

Aus diesen Zahlen ergibt sich, daß die Erwerbungen von Eisenerzfeldern im Auslande nicht von Erfolg gekrönt waren.

Reicht nun diese Menge der selbstgeförderten Erze zur Be- 
sorgung der Hochöfen aus? Die Geschäftsberichte geben auf diese Frage keine Antwort, aber wir können auch hier die Berichte, selbst wo sie schweigen, zum Reden zwingen. Der letzte Geschäftsausweis stellt fest, daß die 10 Hochöfen des Unternehmens 212387 Tonnen Roheisen produzierten. Nehmen wir an, daß die 70964 Tonnen Erz 31000 Tonnen Roheisen ergeben haben, ${ }^{*}$ ) so trug die eigene Förderung im Jahre 1902/03 nur mit $141 / 2 \%$ an der Gesamtroheisenerzeugung bei. Danach ist es klar, daB die eigenen Erze bei weitem nicht ausreichen, sondern daß der größte Teil des zur Roheisenerzeugung nötigen Erzes verkauft werden muB. Neben Rußland kommen als Lieferanten hauptsächlich in Betracht Schweden und Spanien. Aus Spanien werden speziell die Rio-Tintokiese bezogen. Nach Renauld**) gehen diese Kiese im Seeschiff bis Stettin bezw. Hamburg, gelangen von da möglichst auf dem Wasserwege nach Breslau, werden dann zur Entschwefelung per Eisenbahn nach Saarau, und von da ebenfalls mit der Bahn als sogenanntes Purple ore nach Oberschlesien zur Verhüttung übersandt. Dies an sich äußerst reiche Eisenerz enthält auch noch Kupfer, Gold und Silber als schätzbare Nebenbestandteile. Davon werden wir des weiteren bei der Gewinnung der Nebenprodukte handeln. Dieser starke Bezug fremder Erze, der in Zukunft wahrscheinlich noch größer werden wird, bedingt eine nicht unwesentliche Verteuerung dieses wichtigen Rohstoffes durch den Transport. Nach Sympher ${ }^{* * *}$ ) betrug 1894 der Preis für $60 \%$ iges Grängesberger Eisenerz mit 1\% Phosphorgehalt 13 Mark pro Tonne frei Waggon Stettin. Dieser Preis erhöht sich um die Eisenbahnfracht nach Oberschlesien, die nach dem bisherigen Satz von Mark 1,34+6.-, mit 7,53 Mark pro Tonne einschließlich Anrückegebühr, oder rund 7,60 Mark pro Tonne beträgt, so daß der Gesamtpreis sich frei Hütte auf etwa 20,60 Mark pro Tonne stellt gegen 14,85 Mark pro Tonne in Duisburg und etwa 17 Mark pro Tonne in Dortmund. $\mathrm{DaB}$ infolge der größeren Entfernung, trotz der niedrigen Erztarife, die fremden Erze für die Königshütte bedeutend teurer bezahlt werden müssen als von den rheinisch-westfälischen Werken, liegt auf der Hand. Dadurch aber wird die Pro-

*) Dies ist der Fall, wenn wir den Erzgehait der Bergfreiheitgrube mit 48\%, den Gehalt der oberschlesischen Erze mit $27 \%$, den der russischen mit $60 \%$ und den der ausländischen Gruben mit $42 \%$ in die Rechnung einstellen, was eher zu hoch als zu niedrig ist.

*) Renauld, a. a. O., p. 193.

****, Sympher, a. a. O., p. 145. 
duktion des Roheisens stärker belastet. Eine Erhöhung der Selbstkosten tritt also auf jeden Fall ein: sowohl bei der Verwendung eigener, oberschlesischen Gruben entstammender, armer, als auch bei der Verwendung fremder, reicher, aber mit größeren Frachtkosten belasteter Erze.

Aus dem bisher Gesagten geht hervor, $d a B$ die $E$ isener zversorgung der Vereinigten Königs-und Laurahütte als günstignichtbezeichnetwerdenkann. Die Eisenerze, diesie aus eigenen Gruben schöpft, tragengegenwärtig nurmit $14 \frac{1}{2} \%$ zur Gesamtroheisenerzeugung bei, so daB $85 \%$ derselben auf das Konto fremder Erzbezügezu setzen ist. Daherhat sich die Hütte frühzeitig bestrebt, eigene Erzförderungen im Auslande zu erwerben, in Ungarn, in Galizien, in Schweden und in RuBland. Von den inländischen Erwerbungen kommen a $B$ er den am Rande der Erschöpfung stehenden in Oberschlesien nur in Betracht die Bergfreiheitgrube bei Schmiedeberg, deren Förderung im letzten Jahre allein $43 \%$ der Gesamtförderung der Gruben der Gesellschaft be trug. Bei weitem dergröBte Teil wird heute aus dem A uslandebezogen, a us Schweden, Spanien, Rußland, Österreich, um die armen eigenen Erze damit anzureichern. Mit der Verwendung fremder Erze aber steigen wiederum die Produktionskosten, weil die Entfernungen zu den Hauptexportgebieten gröBer sind als nach dem rheinisch-westfälischen Konkurrenzgebiete. In bezug auf die Eisenerzversorgung steht nach alle dem der Betrieb ökonomisch ungünstig da.

Ganz anders gestaltet sich die Versorgung des Werkes mit Kohlen. Die Kohlengruben der Königshütte sind in jeder Beziehung geradezu das Gegenstück zu ihren Erzgruben. Dem Mangel an eigenem Erz steht ein Überfluß an eigener Kohle gegenüber. Oberschlesien ist bekanntlich nach dem Ruhrortbezirk das größte Kohlengebiet Deutschlands. Nach Nasse*) entfallen von den ca. 109 Milliar-

*) Nasse: „Die Steinkohlenvorräte der europäischen Staaten, insbesondere Deutschlands und deren Erschöpfung." Berlin 1893. 
den Tonnen gewinnbarer Steinkohlen Deutschlands 50 Milliarden Tonnen auf den Ruhrbezirk, 45 Milliarden Tonnen auf Oberschlesien. Dieser Reichtum an Kohlen kommt zunächst zum Ausdruck in der Mächtigkeit der Flötze. So ist z. B. bei der Gräfin Lauragrube, die dicht vor der Königshütte liegt, von unten nach oben auf gezählt, das Sattelflötz durchschnittlich $8 \mathrm{~m}$ mächtig, das Heinzmannflötz durchschnittlich 2,25, und das Gerhardflötz durchschnittlich $6 \mathrm{~m}$. Solche Mächtigkeiten von $4-6 \mathrm{~m}$, wie sie die Flötze in Oberschlesien in der Regel aufweisen, sind in dem niederrheinisch-westfälischen Kohlenbecken nicht zu finden.

Die Steinkohlenflötze sind aber nicht nur mächtig, sondern auch rein und günstig gelagert, nämlich nahe der Erdoberfläche. Infolgedessen ist die Gewinnung mit niedrigen Selbstkosten verbunden. Mit Bezug hierauf sagt Renauld*): „Indes läßt sich doch das eine mit Sicherheit behaupten, daß die durchschnittlichen Förderungskosten der oberschlesischen Kohlenwerke erheblich geringer sind als die aller anderen Kohlenbezirke, England nicht ausgenommen. In keinem Kohlenbecken geht der Bergbau in so geringer Tiefe vor sich, und sind daher die Schachtanlagen verhältnismäßig so billig wie in Oberschlesien. Nirgends ist die Förderlänge, welche die Kohle vom Gewinnungspunkt bis zur Hängebank des Schachtes zu durchlaufen hat, die Förderung demnach, so wenig kostspielig wie dort. Nirgends dürfte schließlich das Hauptmaterial des Bergbaus, das Holz, so wohlfeil sein."

Die Produktionskosten werden ferner durch eine sehr mäßig entlohnte Arbeiterschaft auf einem niedrigen Niveau gehalten. Gerade im Kohlenbergbau ist ja der Anteil der menschlichen Arbeitskraft am Wert des Produktes ein außerordentlich hoher, weil hier die Handarbeit noch immer dominiert, und in diese alte Grundlage des Betriebes, in Deutschland wenigstens, durch die Schrämmaschine noch keine Bresche geschlagen ist. Die oberschlesischen Kohlenarbeiter sind Slaven; trotz ihrer niedrigen Entlohnung ist ihre Leistungsfähigkeit eine große. Die Jahresleistung eines Arbeiters im oberschlesischen Kohlenbergbau ist, verglichen mit Niederschlesien, dem Ruhrbezirk und Saarbrücken am höchsten.**) Das hängt zusammen mit der Leichtigkeit der Gewinnung der Kohlen.

Schließlich darf nicht übersehen werden, daß auch das Anlage-

*) Renauld, a. a. O, p. 51.

${ }^{* *}$ ) Siehe von Renauld, a. a. O, p. 51. 
kapital klein ist, denn die Kohlengruben befinden sich zum überwiegenden Teil noch in erster Hand.

Durch das Zusammenwirken dieser Momente sind die Selbstkosten der Kohlengewinnung auch bei der Königs- und Laurahütte außerordentlich gering. Die Grubenpreise ihrer, wie der anderen oberschlesischen Kohlen sind daher die niedrigsten, die es gibt. Daher hat die Königshütte versucht, ihren Kohlenbesitz nach Möglichkeit zu vermehren. Bereits bei ihrer Gründung umspannte sie sehr ergiebige Steinkohlenbergwerke, vor allem die Gräfin Lauragrube und eine Anzahl mit ihr verbundener Gruben. „Aus unseren Kohlenfeldern“, heißt es im Prospekt, ,sind nach Abzug der Abbauverluste aus einer Tiefe von 20-100 Lachter unter Tage, und ohne Rücksicht auf die tieferliegenden Flötze, 1550 Millionen Zentner Steinkohlen zu gewinnen." Seitdem hat sich der verfügbare Vorrat aber noch bedeutend vergrößert. Dies geschah durch umfangreiche Neuerwerbungen zu Beginn der 80er Jahre. Damals kaufte das Werk die Siemianowitzer Steinkohlengruben bei Laurahütte zum Preise von 1127400 Mark und darauf das Landgut Antonienhof, zwischen Königshütte und Beuthen gelegen, zum Preise von 406500 Mark. Dieses Rittergut, das 2251/2 Hektar umfaßt, bedeckte in seiner ganzen Ausdehnung die Steinkohlengrube Gottgebeglück. Durch diesen Ankauf steigt die Ausdehnung der Kohlenfelder von 8,5 auf 23 Millionen Quadratmeter. Die Politik, weiter Kohlenfelder zu erwerben, wird auch in der Folgezeit beibehalten. In dem Geschäftsbericht 1902/03 heißt es: „Zur Stärkung des Fundaments unseres Unternehmens für die Zukunft, haben wir eine sich bietende Gelegenheit wahrgenommen, um einige neue Kohlengruben anzukaufen, welche zum Teil in unmittelbarem AnschluB an unsere älteren Felder bei Dubensko, zum Teil in ihrer Nähe gelegen, und daher für uns wertvoll sind; dieselben - Marianne, Metasglück und Hermann August - haben einen Flächeninhalt von rund 5,4 Millionen Quadratmeter."

Heute besitzt die Königshütte 3 große Grubenkomplexe: 1. die Gräfin Lauragrube, 2. die Laurahüttengrube, und 3. die Dubenskogruben.

Die Produktion von Steinkohlen hat sich im Laufe von 30 Jahren vervierfacht. Sie betrug im Geschäftsjahr 1871/72 580668 Tonnen und stieg dann, wenn auch mitunter durch rückgängige Konjunkturkurven beeinflußt, im allgemeinen fortlaufend bis zum Jahre 1900/01, wo sie mit 2462882 Tonnen ihren höchsten Punkt erreichte. In 
den beiden folgenden Jahren blieb die Produktion mit 2,4 Millionen Tonnen nahezu auf derselben Höhe.

Kein anderes Hüttenwerk in Deutschland hat $\mathrm{m}$. W. derartige Kohlenmengen aufzuweisen; zum Vergleich verweise ich auf die Kohlenerzeugung der bereits früher behandelten Werke. Dieselbe betrug 1902/03:

bei der Dortmunder Union . . . . . . 602,812 t
bei dem Hoerder Bergwerks- und Hüttenverein 452,432 "
beim Phönix . . . . . . . . . . . 480,004 ",

Aber selbst die Hütten mit noch ausgedehnterem Grubenbesitz reichen an den Kohlenreichtum der Königs- und Laurahütte nicht heran. Die Kohlenerzeugung belief sich im genannten Jahre

bei der Gutehoffnungshütte . . . . . . . . . . auf 1,613,269 t beim Bochumer Verein für Bergbau- und Gußstahlfabrikation " 1,209,676 ", bei den Rheinischen Stahlwerken . . . . . . . . . "845,736 "

Die günstige Einwirkung eigener Kohlengruben auf die Rentabilität des Hüttenbetriebes läßt sich, neben der Königshütte, auch bei anderen Gesellschaften konstatieren, z. B. bei der Kattowitzer Aktiengesellschaft für Eisenhüttenbetrieb. Daneben gibt es Werke, die keine eigenen Kohlen haben. Wollen diese Werke mit den über den Selbstverbrauch hinaus Kohlen produzierenden und dadurch eine mehr oder weniger große Einnahme auslösenden Werken konkurrenzfähig bleiben, dann suchen sie die Mängel ihrer Rohstoffversorgung im weiteren Fabrikationsproze $B$ in der Weise auszugleichen, daß sie ihrer Fabrikation eine bestimmte Richtung geben, ihre Fabrikate spezialisieren und verfeinern. So ist z. B. das Huldschinskysche Werk in Gleiwitz, das weder Kohlen- noch Eisengruben besitzt, aus der Röhrenfabrikation hervorgegangen. Noch heute bildet diese Spezialität die Basis des ganzen Betriebes. Die Caro-Hegenscheidtsche Gesellschaft sucht ihre Force in der Draht- und Nagelfabrikation, die Bismarckhütte in ihre Tiegelgußstahlbereitung etc. Es würde eine vergleichende Untersuchung dazu gehören - worauf ich aufmerksam mache - um im einzelnen festzustellen, ob das Fehlen eigener Kohlengruben, die entweder den eigenen Bedarf decken oder aber über denselben hinaus produzieren, die Rentabilität in dem Maße herabmindert, daB die Verminderung nicht durch die Spezialitätenfabrikation und Verfeinerung der Produkte ausgeglichen werden kann.

Wir haben also gesehen, welchen großen EinfluB die Existenz eigener Kohlenlager auf den Betrieb hat. Ja, bei der Königs- und 
Laurahütte bildet sie sogar die wichtigste Grundlage. Bereits in dem Bericht über das Jahr 1896/97 wird der Steinkohlengrubenbesitz als das wichtigste Fundament des Unternehmens bezeichnet. Hier ruht heute in der Tat der Schwerpunkt. Der Steinkohlengrubenbetrieb bildet den rentabelsten der vorhandenen Betriebszweige. Die weitaus größten Einnahmen fließen aus dieser Quelle.

Aber auch dieses glänzende Bild zeigt eine dunkle Stelle. In den Geschäftsberichten findet sich regelmäßig die Angabe, daß noch so und so viel Tonnen Kohlen jährlich hinzugekauft werden müssen. Wie ist das, fragt man sich, nach dem vorher Gesagten möglich? Der Schlüssel für diese Erscheinung liegt in der Tatsache, daß die eigenen Kohlen der Königs- und Laurahütte wenig oder gar nicht zur Verkokung geeignet sind, und zwar wegen ihrer geringen Backfähigkeit. Der Koks, mit dem die Hochöfen beschickt werden, entsteht bekanntlich in Koksöfen aus Kohlenkörnchen, die in der Hitze zusammenbacken, und je besser dies geschieht, desto fester ist der Koks. Diese wichtige Eigenschaft wird bedingt durch den Gehalt an flüchtigen Bestandteilen (Bitumen). Entwickelt die Kohle zu wenig oder zu viel Gas, so können die Stückchen nicht fest zusammenbacken. Das ist nun aber bei den Kohlen der Königs- und Laurahütte der Fall, und infolgedessen fehlen ihr die Kohlen, aus denen sie Koks herstellt. Das Werk ist daher darauf angewiesen, Backkohle zu kaufen. 1902/03 betrug diese Menge 168493 Tonnen, hingegen wurden von den selbstgeförderten Kohlen im eigenen Betriebe verbraucht 670159 Tonnen, d. h. nur 27\% der eigenen Förderung, und an Fremde verkauft 1739678 Tonnen oder 73\% der eigenen Produktion. Es handelt sich bei diesem Verbrauch eigener Kohlen aber nicht um die Koksbereitung, sondern hauptsächlich um die Heizung der Dampfkessel, der Pucidelöfen etc. Ob sich die erstgenannte Zahl in der Folgezeit verringern wird, muß abgewartet werden. In der Generalversammlung am 31. Oktober 1903 sagte der jetzige Generaldirektor der Vereinigten Königs- und Laurahütte, Geheimer Bergrat Junghann: Sehr wertvoll ist der Umstand, daß die auf der Dubenskogrube in den letzten Wochen gemachten Aufschlüsse den gehegten Erwartungen vollkommen entsprochen haben, und man ein Flötz von $2 \frac{1}{2} \mathrm{~m}$ Mächtigkeit gefunden habe, das $1,8 \mathrm{~m}$ reine Kohle liefere. Es werde damit ein großes Grubenfeld von 10 Maximalfeldern erschlossen werden. Von besonderer Wichtigkeit sei aber der Umstand, daB die Verkokung der Kohle ein außerordentlich günstiges Resultat geliefert habe. Hierdurch werde es in 3-4 Jahren möglich sein, den 
Hochofenbetrieb so zu gestalten, daß er ein viel besseres Resultat zeitigen werde, als bisher.

Die meisten Kokskohlen in Oberschlesien besitzt heute der Fiskus. $\mathrm{Da} \beta$ die Königshütte hier nicht auf die Privatunternehmung angewiesen ist, hat für sie manche Vorteile. Die Kohlenpreise werden halbjährlich festgesetzt, und die Produktion dann auf die einzelnen in Betracht kommenden Abnehmer verteilt. Aber auch die Kohle, die der Staat liefert, ist kein Ideal für die Koksbereitung. Sie ist im allgemeinen zu weich und mürbe. Damit, und mit der bereits früher erwähnten mulmigen Beschaffenheit der oberschlesischen Erze hängt nun eine große ökonomische Tatsache zusammen, die für die kapitalistische Entwicklung der Königs- und Laurahütte ein wohl kaum zu überwindendes Hindernis bildet. Infolge der geringen Festigkeit der Koks können die Hochöfen nicht über eine bestimmte Höhe hinaus gebaut werden. Damit ist der Massenproduktion an Roheisen in einem Ofen nach oben hin ein Hemmschuh angelegt. Wir sahen, wie in Rheinland-Westfalen bei den führenden Werken die Hochöfen immer größer und größer wurden und damit die Leistung eines Hochofentages beständig wuchs. Auf der Königshütte aber, wie auch auf den übrigen oberschlesischen Werken, wird dieses Wachstum von einem bestimmten Punkte an gehindert durch die Beschaffenheit des Brennmaterials. Die Königshütte hat gegenwärtig die größten Hochöfen Oberschlesiens, aber sie produzieren täglich nur 90-100 Tonnen - die kleineren entsprechend weniger - , während bei den westfälischen Werken die doppelte Leistung die Regel ist, ja, wie früher erwähnt, die großen Hochöfen der Vereinigten Staaten täglich Durchschnittsleistungen von 400-600 Tonnen aufweisen. In der Festschrift werden die Größenverhältnisse der Hochöfen folgendermaßell angegeben. (Festschr. p. 81). Es betrug bei

$\begin{array}{rcc}\text { Ofen } & \text { der Fassungsraum } & \text { die Höhe } \\ \text { II. } & 264 \mathrm{cbm} & 16 \mathrm{~m} \\ \text { III. } & 363, " & 19 \mathrm{~m} \\ \text { IV. } & 268, " & 17 \mathrm{~m} \\ \text { V. } & 235, " & 14,5 \mathrm{~m} \\ \text { VI. } & 369, " & 20 \mathrm{~m} \\ \text { VII. } & 363, " & 19,5 \mathrm{~m} \\ \text { VIII. } & 369, " & 20 \mathrm{~m}\end{array}$

Die beiden höchsten Öfen erreichen, wie sich hieraus ergibt, die Höhe von $20 \mathrm{~m}$, während in Rheinland-Westfalen Öfen von $30 \mathrm{~m}$ Höhe keine Seltenheit sind. Würde man in Oberschlesien 
höher bauen, so würde der Koks zerdrückt werden. Die Beschaffenheit des Koks unterbindet also eine größere Massenproduktion. Daher ist auch die Roheisenproduktion der Königs- und Laurahütte im Vergleich zu anderen Hochofenwerken, trotz der groBen Zahl ihrer Öfen, nämlich 10, klein. Sie betrug

$1902 / 3$ nur

212,387 bei 5 im Betriebe befindl. Öfen*)

hingegen bei der Dortmunder

Union

in Hoerde.

beim Phönix

und bei der Ilsederhüitte .

\begin{tabular}{|c|c|c|}
\hline 386,410 & " & " \\
\hline 335,396 & & " \\
\hline 308,388 & & " \\
\hline 229,172 & & " \\
\hline
\end{tabular}

Fassen wir die Resultate dieses Abschnittes kurz zusammen: Während die Eisenerze mit sehr hohen Kosten gewonnen werden, gleichgültig ob sie nun im eigenen Betrieb gefördert oder aber gekauft werden, liegen die Dinge beiden Kohlen gerade umgekehrt. Reiche, große, reine, günstig gelagerte Kohlenflötze liefernzugeringen Selbstkosten einen, den Bedarf des eigenen Werkes weit überflügelnden ÜberschuB, der a uf den Markt kommt. Die Politik der über die Selbstbedarfsdeckungswirtschaft stark hinaus ragenden Kohlenproduktion wurdedurch Neuerwerbungen Anfang der 80 er Jahre und zu Beginn des neuen Jahrhunderts noch mehr gekräftigt. Im Laufe von 30 Jahren erfolgte eine Vervierfachung der Erzeugung. Heute beträgt die Menge der geförderten Steinkohlen 2,4 Millionen Tonnen. Mit dieser Rekordziffer gewinnt die Königshütte einen Konkurrenzvorsprung vorden übrigen Werken, die, so weit sie keine Kohlenzechen besitzen, die MiBstände ihrer Abhängigkeit vom Kohlenmarkt und die dadurch bedingte teurere Produktion auszugleichen versuchen durch Herstellung von Spezialitäten. Allerdings muB auch die Königshütte jährlich noch ein bestimmtes Quantum Kohle kaufen, weil ihre eigene Kohlewegen ihrergeringen Backfähigkeit sich nichtzurVerkokungeignet, aberauchdievom Fiskus gelieferte Kokskohle gibt keinen genügend festen

*) AuBerdem waren 2 Ö́en noch 52 Wochen im Betrieb.

Stillich, Nationalökonomische Forschungen, Band I. 
Koks, so da $B$ durch diesen Umstand, sowie durch die früher erwähnte erdige Beschaffenheit der zurVerhüttung gelangenden oberschlesischen Eisenerze, einer erhöhten Produktion der Hochöfen Zügel angelegt werden. Infolgedessen kann hier die kapitalistische Ausgestaltung des Betriebes im Sinne einer noch mehrgesteigerten Massenerzeugung von Roheisen nicht über ein bestimmtes Niveau hinauseilen, dadurch aber wird der Konkurrenzkampf mit der rheinisch-westfälischen Massenindustrie wieder um eine Linie zuungunsten des oberschlesischen Werkes verschoben.

Wir haben gesehen, daß es zwei Momente waren, die störend und erschwerend in die Produktion des Roheisens eingriffen: 1. die Beschaffenheit der Eisenerze und 2. die Beschaffenheit der eigenen Kohle, die sich nicht zur Verkokung eignet. Diese Momente verteuern den Hochofenprozeß, d. h. die Herstellung des Roheisens nicht unerheblich. Infolgedessen waren die Erträgnisse des Hochofenbetriebes unbefriedigend, ja, sie verwandelten sich beim Wechsel der Konjunktur häufig in ihr Gegenteil, d. h. der Hochofenbetrieb erforderte Zubußen. Um nun ein Korrektiv gegen diese Verhältnisse zu schaffen, führte eine weitblickende Verwaltung auf dem Hüttenbetrieb noch solche Produktionszweige ein, die geeignet waren, die Unrentabilität des Hochofenprozesses zu mildern, resp. zu beseitigen, und die Erträgnisse zu vergrößern. Durch diese Nebenanlagen sollte ein Gegengewicht gegen die hohen Selbstkosten der Herstellung des Roheisens geschaffen werden.

So entsteht Anfang der 80er Jahre eine Teer- und Anfang der 90er Jahre eine Ammoniakfabrik. Teer und Ammoniak sind Stoffe, die in den aus den Koksöfen abströmenden Gasen enthalten sind, und die früher ungenutzt blieben. Heute werden diese Gase durch Exhaustoren abgesaugt und auf der Königshütte in zwei Kondensationsanstalten mit zusammen 32 Kühlern und 20 Wäschen abgekühlt und gewaschen.*) An der Spitze steht die Teerproduktion. Sie betrug im ersten Jahre der Tätigkeit der Anlage 1882/83 nur 109 Tonnen und hielt sich bis zum Jahre 1892 in engen Grenzen. In diesen 10 Jahren

*) Die Angabe der technischen Einrichtungen und Leistungen der Nebenanlagen entnehme ich der Festschrift. 
erreichte sie mit 574 Tonnen im Jahre 1887/88 ihre höchste Ziffer. Anfang der 90er Jahre werden dann die Anlagen bedeutend leistungsfähiger gestaltet. „Um unsere Werke“, sagt der Geschäftsbericht 1891,92, ,den schlechten Einnahmen und den holien Ausgaben gegenüber existenzfähig zu erhalten, haben wir auch im vergangenen Jahre auf die Rekonstruktion und Einfügung solcher Betriebsapparate, welche die Erzeugungskosten vermindern, große Summen verwendet. Eine Vergrößerung der Produktion (es handelt sich um Eisenfabrikate) streben wir nicht an, weil wir in einer solchen die einzige Veranlassung zu einem kontinuierlichen Niedergang der Preise erblicken.“ Die in dem ersten Satze angedeuteten Neueinrichtungen vermehrten nun die Teererzeugung bedeutend. Sie betrug 1891/92 noch 344 Tonnen, 1892/93 aber bereits 1604 Tonnen und steigt dann 1901/02 auf 7448 Tonnen. Dieser Teer wird an große Teerproduktenfabriken verkauft, die ihn präparieren und weiter verarbeiten (Anilinfarbenfabrikation). Damit wird der Kontakt des Unternehmens mit der chemischen Industrie hergestellt.

Mit dem Jalire 1891/92 war auch das erste Ammoniak aus den Koksofengasen gewonnen. Durch Behandlung mit Schwefelsäure, die bekanntlich ziemlich billig ist, wird daraus ein künstliches Düngemittel hergestellt, das für die Landwirtschaft von Wert ist. Die Darstellung des schwefelsauren Ammoniaks erfolgt in 6 Abtreibeapparaten und 7 Sättigungskästen; nachdem es durch Lagerung auf Abtropf- und Lagerbühnen und schließlich durch Zentrifugieren von der mitgerissenen Lauge vollständig befreit ist, wird es nach erfolgter Trocknung gemahlen. Die Schwefelsäure muß das Werk kaufen. 1889/90 wurde zwar der Plan ventiliert, cine Schwefelsäurefabrik zu bauen, aber nicht zur Ausführung gebracht. Die Produktion an schwefelsaurem Ammoniak betrug 1891/92 erst 90 Tonnen, 10 Jahre später aber stellte sie sich bereits auf 2487 Tonnen. Das Produkt wird in Säcke verpackt und an Düngerfabriken verkauft.

Ein weiterer Nebenbetrieb, der zur finanziellen Kräftigung des für sich allein nicht rentierenden Hochofenbetriebes dient, ist die Kupferextraktionsanstalt. Diese Anlage kam Ende 1883 in Betrieb. Der Geschäftsbericht des Jahres 1883/84 weist darauf hin, daß diese Anstalt die Aufgabe habe, aus den Rückständen der Schwefelsäurefabriken Kupfer zu extrahieren, die so gereinigte Masse zur Roheisendarstellung gut verwendbar zu machen und somit dem sehr fühlbaren Mangel an reichen, gutartigen und wohlfeilen Eisenerzen abzuhelfen. Wie bereits früher erwähnt, bezieht die Königshütte 
auch spanische Rio-Tintokiese. Diese Schwefelkiese müssen erst von ihrem Schwefel befrcit werden, oder in der Sprache der Chemie ausgedrückt, in die Oxydform übergeführt werden, ehe sie für den HochofenprozeB tauglich sind. Für die Schwefelsäurefabriken, die bei dieser Arbeit in erster Linie beteiligt sind, lohnt es sich nicht, allen Schwefel herauszuziehen, für den Hüttenbetrieb aber nur dann, wenn die Erze Kupfer enthalten. Die auf der Königshütte verarbeiteten Abbrände aus spanischen und portugiesischen Schwefelkiesen werden einem Röst- und LaugeprozeB, letztere nur einem LaugeprozeB, unterworfen. Diese Lauge enthält außer dem Kupfer noch Silber und Gold. Das Kupfer wird durch Eisen zur Ausfällung gebracht. Die auf diese Weise entkupferten Schwefelkiese haben eine purpurrote Farbe, man nennt sie daher Purple ore. Leider hat das gewonnene Eisenerz einen für den Hochofenproze $\beta$ sehr unerwünschten Zustand: es ist pulverförmig. Die erhaltenen kleinen Körner zu brikettieren ist eine der bisher nicht gelösten Fragen der Technik. Die Extraktionsanstalt der Königshütte hat an Betriebsmitteln 8 Rostöfen mit 5 Kondensationstürmen, 36 Laugekästen und 32 Zementierkästen mit dazu gehörigen Hilfsapparaten. Sie lieferte 1900/01 35322 Tonnen Purple ore, 1117 Tonnen 100\%iges Zementkupfer, $755 \mathrm{~kg}$ Silber und 2,6 kg Gold.

Hier sei noch einer eingegangenen Produktion gedacht, die von 1809-1899 bestand, der Zinkgewinnung. Die Erträge sind in den einzelnen Jahren sehr wechselnd gewesen, doch betrugen sie seit 1878/79 stets über 1000 Tonnen, mit Ausnahme des Sterbejahres dieser Produktion. Bereits in dem ersten Geschäftsbericht der Aktiengesellschaft wird erwähnt, daß die Zinkfabrikation nur nebensächlich und zumeist zur Verarbeitung der beim Hochofenbetrieb gewonnenen zinkhaltigen Materialien fortgesetzt werde. Aus 100265 Zentnern Zinkerz wurden 1871/72 $139291 / 2$ Zentner Rohzink gewonnen. Die Zinkhütte wurde dann Anfang 1899 gänzlich kalt gelegt, und zwar aus Mangel an eigenem Galmei.

Schließlich ist noch eine kleine Zementfabrik zur Verwertung der Hochofenschlacke zu erwähnen. Die Hochofenschlacke ist bekanntlich ein Abfallprodukt, mit dem man ursprünglich nichts anzufangen wußte. Sie wurde - und das geschieht heute noch vielfach - auf Halden gestürzt und so entstanden die großen Schlackenberge auf den Terrains der Eisenhütten. Diese nutzlose Aufstapelung konnte sich jedoch nur so lange allgemein halten, als die Bodenpreise niedrig waren. Mit der Verteuerung des Grund und Bodens in der 
Nähe der Hütten wurde die Lösung des Problems einer Verwertung der Schlacke immer dringender. In den letzten 30 Jahren hat man versucht, die Schlacke auf verschiedene Weise zu benutzen. Man basaltierte sie in manchen Fällen, um sic auf die Chausseen und Wege zu schütten. Aber die Pferde, die diese Chausseen betraten, wurden hufkrank, indem häufig kleine Glassplitter in den Huf drangen. Eine andere Verwendungsart, die uns hier speziell interessiert, ist die Fabrikation von Eisen-Portlandzement. Ein Wasserstrahl reißt die aus dem Hochofen kontinuierlich hervorstürzende glühende Schlacke in einer Rinne mit sich fort. Dadurch wird sie körnig. Sie granuliert. Mit Kalkhydrat gemischt, wird sie dann in Ziegelform gebracht und in cinen Zementofen gesetzt, wo das ganze absintert. Das so erhaltene Material ist ein vorzüglicher Zement, der bald mit den eigentlichen Portlandzementfabriken in scharfen Wettbewerb trat und viel zu der schlechten Lage dieser Industrie beigetragen hat, zumal da der Eisenportlandzement sehr billig auf den Markt gebracht werden konnte.

Zur Herstcllung des letzteren wurde nun in Laurahütte eine Fabrik errichtet, die im Geschäftsjahr 1872/73 in Betrieb kam, und die so befriedigende Resultate gab, „daß sie voraussichtlich zur Anlage einer großen Fabrik, und somit eines neuen lukrativen Betriebszweiges in nicht zu ferner Zeit Veranlassung geben werde." Dieser Betrieb wird dann vergrößert. In dem Geschäftsbericht 1879/80 heißt es über die Resultate: „Die Darstellung von Zement auf der Laurahütte unter Mitverwendung der Hochofenschlacke hat sich gut entwickelt... Das Fabrikat ist in Oberschlesien gut eingeführt und konkurriert mit anderen seit langem gut renommierten Sorten." Allein die Herstellung von Zement auf der Laurahütte hat das zu Ende gehende Jahrhundert nicht überlebt. Im Jahre 1899 wird die Fabrikation eingestellt. Als Grund des Absterbens dieses Betriebszweiges gibt der Geschäftsbericht 1898/99 an, daB die Einrichtungen für die Herstellung veraltet waren und zum zeitgemäßen Umbau beträchtliche Kapitalaufwendungen nötig gewesen wären.

In der vorhergehenden Analyse der wirtschaftlichen Bedingungen, unter denen der Hochofenbetrieb der Königs- und Laurahütte arbeitet, erkannten wir, daB derselbe an und für sich, infolge der Beschaffenheit der Erze und der Koks mit auBerordentlich hohen Selbstkosten belastet ist, also ein sehr teures Roheisen liefert. Um ihn nun finanziell 
zu stützen, wurden folgende Nebenanlagen geschaffen, die entweder direkt oder indirekt mit der Roheisenerzeugung in Verbindung stehen: Von der schon langebestehenden Zinkhütte abgesehen, wurden ins Lebengerufen 1882 eineTeerfabrik, 1891 eine Ammoniakfabrik, 1897 eine Benzolfabrik zur Aus beutung der wertvollen Bestandteile der bei der Koksdestillation abströmenden Gichtgase. Ferner 1883 eine Kupferextraktionsanstalt, und in demselben Jahreeine Portlandzementfabrik, die jedoch 1899 geschlossen wurde.

Wir kommen nun zum zweiten Punkt, nämlich der Darstellung des Fabrikationsprogramms der Königshütte, durch das die Schilderung der folgenden Einrichtungen erst in das richtige Licht gerückt wird. Die folgende Untersuchung wird, um gleich die Hauptsache vorweg zu nehmen, zeigen, daß sich das Fabrikationsprogramm des Werkes auf zwei Grundgedanken aufbaut: einmal auf einer möglichst weitgehenden Anwendung menschlicher Arbeitskraft, und zweitens auf der Herstellung von Fertigfabrikaten.

Von allen auf Aktien errichteten Eisenhüttenwerken, außer Krupp, ist heute die Vereinigte Königs- und Laurahütte dasjenige, das die größte Arbeiterzahl beschäftigt. Der durchschnittliche Arbeiterbestand betrug 1902/03

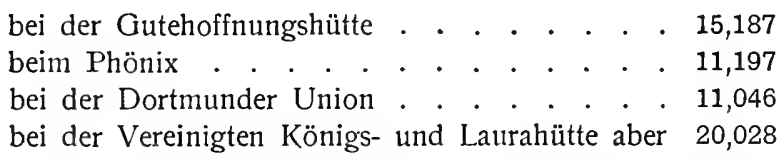

In dieser Zahl sind enthalten auch die Beamten, die Unterbeamten und Meister. Auf die einzelnen Werke der Gesellschaft verteilen sie sich folgendermaßen. Es waren beschäftigt:

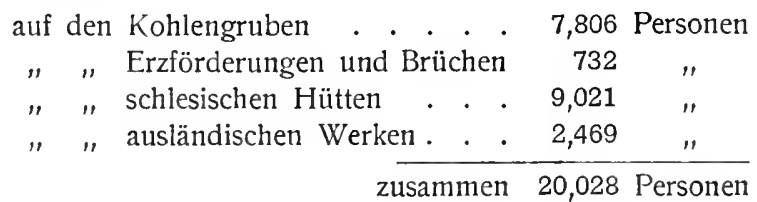

Hieraus ergibt sich, daß die große Arbeiterzahl einmal bedingt ist durch den auf menschlicher Handarbeit beruhenden ausgedehnten Kohlenbergbau des Unternehmens. Einen zweiten Grund werden wir später kennen lernen. 
Unter den 20028 Arbeitern in weiteren Sinne befinden sich 1368 weibliche und 1344 jugendliche und Invaliden. Hier finden wir im Eisenhüttenbetrieb zum erstenmal Frauen, die auf den Hüttenwerken Rheinland-Westfalens nicht vorkommen. Die Schwere der Industric hat der Schwäche des Geschlechts kein Hindernis in den Weg gelegt. Der Grund ist leicht ersichtlich. Die Frau arbeitet billiger als der Mann. DaB die Frau gerade im Eisenhïttenbetrieb Verwendung sucht und findet, hängt mit dem Mangel an anderen Fabrikbetricben und mit dem geringen Umfange der Landwirtschaft im oberschlesischen Industriebezirk zusammen. Die Zahl der Frauen ist auf der Königshütte ziemlich konstant geblieben. Heute werden sie hauptsächlich zu Transportarbeiten benutzt. Ihr Lohn beträgt etwa 1 Mark bei 11stündiger Arbeitszeit. Männer und Frauen sind Polen. Durch die ausschlieBliche Rekrutierung der Belegschaft aus dem kulturell rückständigen Gebiete Polens wird der Arbeitslohn natürlich um den für eine sehr tiefe Lebenshaltung notwendigen Standard herumpendeln, d. h. nur soviel betragen, als zur notwendigen Ernährung, Bekleidung und Behausung des Arbeiters notwendig ist, verbunden mit den Kosten für die Erziehung des Nachwuchses. An Arbeitslohn wurden 1902/03 gezahlt 16573461 Mark. Der durchschnittliche Jahresverdienst auf den deutschen Werken der Königsund Laurahütte betrug:

bei den männlichen Arbeitern . . . . . 972,07 M.

" " weiblichen " . . . . . 342,84 ",

" " jugendlichen Arbeitern und Invaliden 422,13 ,"

Diese niedrigen Löhne machen es verständlich, warum heute auf der Königshütte die Handarbeit noch einen so großen Spielraum einnimmt, mit anderen Worten, warum der moderne großkapitalistische Betrieb, wie wir ihn bei den rheinisch-westfälischen Werken kennen lernten, hier nicht in demselben Maße durchgeführt ist.

Das zeigt sich nun aber besonders deutlich in der Ausdehnung des Puddelbetriebes auf der Königshütte. Die Königshütte bildet jedoch keine Ausnahme, sondern reflektiert in dieser Beziehung nur die in Oberschlesien herrschenden Verhältnisse. Für Oberschlesien stellt sich nach Renauld*) das Prozentverhältnis der Produktion der einzelnen Roheisensorten wie folgt:

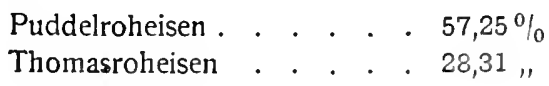

*) Renauld: a. a. O., p. 201. 


Gießereiroheisen . . . . . $7,47 \%$
Bessemerroheisen . . . 6,97 "

Die Königshütte hat heute noch 37 Puddelöfen, von denen 24 im Betriebe sind. Nach meinen Berechnungen macht die Schweißeisenproduktion der Königshütte noch 26\% ihrer Gesamtproduktion an schmiedbarem Eisen aus. Im Jahre 1900/01 erzeugte das Puddelwerk 2141 Tonnen Feinkornrohschienen, 33150 sehnige Rohschienen und außerdem 3023 Tonnen Riegel-, Gezähe- und Nabeneisen, im ganzen also 38320 Tonnen Puddelfabrikate.

Allerdings hat das Werk auch Bessemerbirnen und Martinöfen, aber beide sind wenig leistungsfähig und lassen technisch die $\mathrm{Er}$ füllung der an eine Massenfabrikation zu stellenden Anforderungen vermissen. In dem Stahlwerk kommt sowohl der saure als der basische ProzeB zur Anwendung in der Weise, daß in einem Converter von Montag bis Mittwoch saures, und von Donnerstag bis Sonnabend in zwei Convertern basisches Eisen geblasen wird. Jedoch schwankt das Verhältnis der Produktion an saurem und basischem Material je nach der Beschäftigung der Walzwerke. Die ganze Bessemerbetriebsanlage auf der Königshütte ist ferner veraltet, die drei Birnen, die jetzt (1904) noch um eine neue vermehrt werden sollen, liegen dicht nebeneinander. Als günstig kann dies nicht bezeichnet werden, weil schon die Nähe des basischen Futters und des sich bildenden Kalkstaubes den sauren Converter beeinflußt. Aber auch die Leistungsfähigkeit ist wenig befriedigend. Jede der drei Birnen hat einen Fassungsraum von 8 Tonnen. Das ist außerordentlich wenig. Die Gesamterzeugung an Bessemer- und Thomasmaterial betrug daher 1900/01 nur ca. 68000 Tonnen.

Der Bessemer- und Thomasbetrieb hat also auf der Königshütte eine größere Ausdehnung nicht erlangt. Es hängt das zweifelsohne auch zusammen mit der für den Flußeisenbetrieb wenig geeigneten Beschaffenheit der oberschlesischen Erze. Diese kommen, wie wir sahen, allerdings nur in geringem Maße in Betracht, aber so weit dies der Fall ist, stören sie durch die Ungunst ihres Phosphorgehaltes die Stahlerzeugung. Für den sauren BessemerprozeB kann man in der Regel nur ein Roheisen mit einem Phosphorgehalt unter $0,1 \%$, für den Thomasproze $B$ aber, wo der Phosphor als Brennstoff dient, nur ein Roheisen von über 1,5\% Phosphor verwenden. Oberschlesische Erze haben nun aber einen Phosphorgehalt, der zwischen 0,1 und $1,5 \%$ liegt und eignen sich daher weder für den sauren, noch für den basischen Prozeß besonders; für den ersteren haben 
sie zu viel, für den letzteren zu wenig Phosphor. Ein Verfahren aber, um solches Material mit einem Phosphorgehalt von 0,1 bis $1,5 \%$ mit Erfolg zu verarbeiten, ist noch nicht gefunden. In dem Phosphorgehalt aber liegt auch ein Grund dafür, warum der Bessemer- und Thomasbetrieb, der auf den rheinisch-westfälischen Werken heute durchgehends dominiert, auf der Königshütte nicht dieselbe Ausdehnung erlangt hat, und warum an seiner Stelle der alte, impotente Puddelbetrieb eine noch so große Bedeutung besitzt.

Neuerdings geht man nun mehr und mehr dazu über, den Martinbetrieb zu erweitern. Das Martinwerk umfaßte bisher 5 basisch zugestclite Siemens-Martinöfen, die ebenfalls nur klein sind. Das Ausbringen beträgt 10-12 Tonnen pro Charge. Sie werden mit der Hand beschickt. Automatische Beschickungsvorrichtungen fehlen. Die Erzeugung, die sich ausschlieBlich auf Qualitätsmaterial für Bleche, Schmiedestücke, Radreifen und Achsen beschränkt, betrug 1900/01 38323 Tonnen Blöcke. Gegenwärtig (1904) wird nun diese alte Anlage durch drei neue Martinöfen erweitert. Damit ist angedeutet, daB die Tendenz des Unternehmens auf eine Vergrößerung der Martinstahlerzeugung hinausläuft.

An die Martinofenanlage schließt sich eine Stahlfaçongießerei an. Der StahlfaçonguB wird teils roh gegossen, teils bearbeitet für Eisenbahnbedarf, Schiffbau, Lokomotiv- und Maschinenfabriken, Walz- und Hammerwerke etc. geliefert. 1900/01 wurden 1247 Tonnen Stahlgußwaren erzeugt. Von Bedeutung für die Ökonomie des Betriebes ist, daß man den gesamten Stahlwerkschutt über einen elektromagnetischen Schcideapparat führt, um das im Schutte enthaltene Klaubeisen wieder $\mathrm{zu}$ gewinnen.

Aus diesen Ausführungen ergibt sich folgendes: Auf der Königshütte ist die Produktion an schmiedbarem Eisen relativ gering. Der FluBeisenbetrieb steht nicht so im Vordergrunde wie auf den rheinischwestfälischen Werken, auch wenn in Zukunft eine Ausdehnung bevorsteht. Das kann bei dem dargelegten Umfang des Puddelbetriebes auch gar nicht anders sein. Es erzeugte, wie wir sahen:

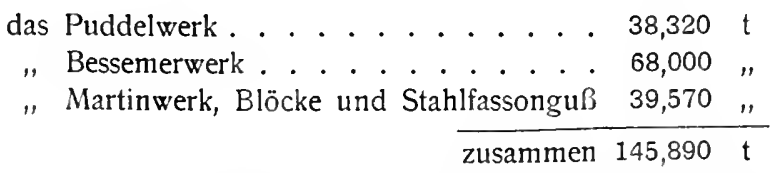

DerGrund, warum mandie Massenerzeugung bis - 
her nicht weiter ausgebildet hat, liegt einmal in den billigen Arbeitskräften. So werden diese zu einem Hinderungsmittel des Fortschritts und der Akzeptierung moderner, konkurrenzfähiger Betriebsmethoden. Auf der anderen Seite aber auch in der Beschaffenheit derzur Verwendung kommenden oberschlesischen Erzemiteinem Phosphorgehaltvon $1 / 10$ bis $1 \frac{1}{2} \%$, der der Convertierung in den Birnen $\mathrm{Sch}$ wierigkeiten entgegensetzt.

Der zweite Grundgedanke des Fabrikationsprogramms der Königshütte beruht in der Herstellung möglichst vieler Fertigfabrikate. Diese Richtung wird diktiert durch die hohen Selbstkosten des Roheisens wie des schmiedbaren Eisens auf der einen, und durch die Billigkeit der menschlichen Arbeit auf der anderen Seite. Infolge der letzteren wird die Produktionsverteuerung des noch im ersten Stadium der Entwicklung befindlichen Produktes in dem Maße zurückgedrängt, je weiter es durch die wertschaffende Kraft der Arbeit in das Stadium des Fertigfabrikates übergeführt wird. Dabei wirken die niedrigen Löhne, die in dem Verkaufspreis des Fertigfabrikates enthalten sind, gleichsam ausgleichend auf die Höhe der anderen Selbstkostenelemente, mit denen der ProduktionsprozeB im ersten Stadium zu rechnen hat.

Welches sind nun die wichtigsten Anlagen für Fertigerzeugnisse, und in welchen Massen werden diese hergestellt?

Eine Anzahl wichtiger Fertigfabrikate wird zunächst erzeugt auf dem großen Triostahlwalzwerk (mit 3 Gerüsten). Die Produktion betrug 1900/01 38459 Tonnen Walzfabrikate, und zwar Eisenbahnschienen, Schwellen, Laschen und Unterlagsplatteneisen, H-Eisen von 200-400 mm, und U-Eisen von 200-300 mm Höhe. Dann kommen Walzenstraßen für Handels- und Konstruktionseisen aller Art. Die Gesamtproduktion der 7 Strecken betrug 62790 Tonnen. Daran schließt sich ein Grobblechwalzwerk, aus dem rechtwinklige Bleche in Schweiß- und Flußeisenqualität hervorgehen. Im Jahre 1900/01 wurden 15145 Tonnen Fertigbleche erzeugt und an Halbzeug 1373 Tonnen Schweißkolben und 1240 Tonnen Platinen. SchlieBlich eine Feinblechstrecke mit 3 Gerüsten und einer Produktion von 2446 Tonnen Sturz- und Feinblechen. Die Gesamtproduktion an Walzfabrikaten auf den 10 erwähnten Walzenstrecken betrug demnach 121453 Tonnen. Der Geschäftsbericht für 1900/01 allerdings gibt eine etwas höhere Zahl an als die Festschrift, nämlich 
141571 Tonnen, oder mit Hinzurechnung geringerer oder Ausschußware 142055 Tonnen. 1902/03 wurden nach dem Geschäftsbericht an Walzwaren aller Art in Eisen und Stahl inkl. Ausschußwaren verkauft 147636 Tonnen.

AuBerdem kommt für die Herstellung von Fertigfabrikaten in Betracht eine Räder- und Weichenfabrik. Der Bau wurde bereits 1872/73 in Angriff genommen. In Betrieb kam die Anlage erst 1876/77. Der Wert der in dieser Werksabteilung hergestellten Fabrikate betrug 1900/01 2,7 Millionen Mark. Es wurden u. a. produziert 3351 Radsätze und 1227 Stück Zungenvorrichtungen.

Später als die Herstellung von Rädern und Weichen beginnt man mit der Herstellung von Maschinen. Ende 1889 erwarb das Werk die Aktien der Eintrachtshütte zum Kurse von 110\%. Die Aktiengesellschaft wurde aufgelöst und die Einrichtungen gingen vollständig in das Eigentum der Vereinigten Königs- und Laurahütte über. Drei Gründe waren für die Erwerbung dieses Etablissements maßgebend. Die Hütte wollte in erster Linie die Maschinen, mit denen sie arbeitet, selbst erzeugen, z. B. Fördermaschinen, und die vorhandenen Betriebsapparate retablieren. Sie wollte ferner ihre überschüssigen Vorräte an Kohlen noch weiter selbst verwerten, und das erzeugte Roheisen sowie ihre Halbfabrikate in einem eigenen Unternehmen weiter verarbeiten, und schlieBlich Maschinen für den Absatz produzieren. Durch Erwerbung dieser wohlfeilen und rentablen Fabrik wurde die Maschinenindustrie Oberschlesiens, welches bislang seine Maschinen vorzugsweise aus Sachsen, der Rheinprovinz, Westfalen und Berlin bezog, nicht unbedeutend gehoben.

Ferner errichtete das Werk eine Waggonfabrik. Sie besteht erst seit $1894 / 95$. Sie wurde ebenfalls zu dem Zwecke eingerichtet, um den Walzwerksprodukten eine höhere Verwertungsmöglichkeit zu eröffnen. In derselben werden Eisenbahngüterwagen jeder Art hergestellt. Die Räder und Radsätze und die meisten Beschlagteile bezieht die Waggonfabrik von der Räder- und Weichenfabrik, nur kleinere Beschlagteile werden in der eigenen Werkstatt ausgeführt. $1 \mathrm{~m}$ Jahre 1900/01 wurden 1260 Wagen hergestellt. Die Leistungsfähigkeit ist jedoch bei voller Beschäftigung eine größere. Wir sehen also, dieselbe ist bedeutend höher als die der Union, die 1902/03 nur 250 Waggons lieferte, bei voller Beschäftigung aber nur 700-800 Waggons im Jahre fertig stellen kann. Natürlich besteht auch auf diesem Gebiet eine scharfe Konkurrenz der Spezialindustrie. Die größte deutsche Waggonfabrik, van der Zypen in Köln, produziert, 
wenn man den Durchschnitt zu Grunde legt, an einem einzigen Tage 25 Güterwagen. Das ist Massenproduktion großen Stils.

Es verlohnt sich, auf die Gliederung der Waggonfabrik der Königshütte etwas näher einzugehen, und dabei einen Blick auf die Qualifikation der darin beschäftigten Arbeiter zu werfen. Die Waggonfabrik weist folgende Abteilungen auf:

1. Eine Schmiede, in der gelernte Arbeiter beschäftigt sind. Sie zerfallen in die Werkzeugschmiede, die Werkzeuge wie Bohrer, Meißel etc. herstellen, ferner in die Grob- und Hammerschmiede, die die Teile vorschmieden, und in die Fein- oder Feuerschmiede, die das Eisen dann weiter bearbeiten. Diese Schmiede sind nichts anderes als Handwerker, die der Fabrikbetrieb in sich aufgenommen hat. Die Einrichtung weist 13 Schmiedefeuer, 36 Nietfeuer, 19 Feldschmieden und 16 Ambosse auf. Durch 4 Ventilatoren werden die Schmiedefeuer mit Luft versorgt.

2. Eine mechanische Werkstatt. An Betriebsvorrichtungen sind hier vorhanden: 5 Elektromotoren von zusammen 511/2 PS., 26 Bohrmaschinen, 3 kombinierte Scheeren mit Lochstanzen, 4 einfache Lochstanzen, 3 Fräsmaschinen, 3 Kaltsägen, 3 Schleifmaschinen, eine Shapingmaschine etc.

3. Eine Montagehalle, in der die Teile zusammengestellt werden und der Aufbau des Kastengerippes erfolgt.

4. Eine Holzbearbeitungswerkstatt, in der Stellmacher und Tischler die Wagen mit Holz auskleiden. Dies sind Handwerker, aber sie haben im Unterschied von ihren Kollegen im Kleinbetrieb die ganze moderne Technik zu ihrer Verfügung; die Fabrik stattet sie mit ganz anderen Maschinen aus, als sich die selbständigen Handwerksmeister leisten können. Hier in dem kapitalistischen Betriebe, wo der Handwerker Lohnarbeiter geworden ist, gebietet er über ganz andere Energiequelien, und die Leistung ist daher eine höhere. In der Tischlerei der Waggonfabrik der Königshütte befinden sich 3 Elektromotore von zusammen 75 Pferdekräften, und diese setzen nicht weniger als 18 Holzbearbeitungsmaschinen in Bewegung: Kreissägen, Bandsägen, Hobelmaschinen, Abrichtmaschinen (die die Bretter an einer Seite hobeln), Zapf-, Fräs- und Kehlmaschinen etc. Eine Exhaustoranlage mit Separator dient zur Absaugung der Holzspähne. Dazu kommen dann noch die Hilfsmaschinen, die z. B. das Feilen der Sägen oder das Schleifen der Hobelmesser automatisch besorgen.

Die Tischler und Stellmacher, die hier das Holz bearbeiten, sind nun im Gegensatz zu einer Reihe von Arbeitern in der mecha- 
nischen Werkstatt, wo nicht Holz, sondern Eisen, mit analogen Maschinen gestanzt, geschnitten usw. wird, gelernte Arbeiter. Woher kommt das? Der Grund dafür scheint mir darin zu liegen, daß dem Eisenarbeiter an den Bohr- und Hobelmaschinen etc. der mechanischen Werkstatt dic schwierigere Arbeit durch die Vorzcichner abgenommen wird, und sie auf rein mechanische Tätigkeiten beschränkt bleiben. Das ist aber bei den Tischlern und Stellmachern in der Holzbearbeitungswerkstatt nicht der Fall. Diese sind Techniker und Zeichner in einer Person. Sie haben die schwierigere Zeichenarbeit und die rein mechanisch vor sich gehende Bedienung der Maschinen nicht geteilt, sondern zusammen auszuführen. Hierin liegt ein wesentlicher Unterschied, der uns auch erklärt, warum sie höher bezahlt werden als die Arbeiter der mechanischen Werkstatt.

Schließlich gehört hierher auch noch die Lackiererei, wo die Güterwagen ihren letzten Schliff erhalten. Sie werden mit roter Farbe angestrichen.

Eine weitere Fertigfabrikate erzeugende Werksanlage der Königshütte ist ilıre Brückenbauanstalt und Konstruktionswerkstätte. Sic ist auch erst seit 1894 in Betrieb und steht, was Größe und Produktion betrifft, den bei Beschreibung der Dortmunder Union erwähnten großen Brückenanstalten ebenbürtig zur Seite. Der Gesamtumsatz beträgt jährlich ca. 8000 Tonnen. Die Einnahme stellte sich 1900/01 nicht ganz auf 2 Millionen Mark. Aus dieser Abteilung gehen hervor Brücken und andere eiserne Überbauten, Gebäude und Dächer aus Eisenkonstruktion, Schachtringe, Separationsgebäude, Kohlenwäschen, Fördertürme und andere Eisenkonstruktionen verschiedener Art. Die wichtigsten von der Königshütte gebauten Brücken sind folgende: Warthebrücke bei Landsberg, Gewicht ca. 640 Tonnen, Oderbrücke bei Steinau, Gewicht ca. 1200 Tonnen, Oderbrücke bei Niederwutzen, Gewicht ca. 700 Tonnen, Oberhafenbrücke bei Hamburg, Gewicht ca. 1000 Tonnen, Oderflutbrücke bei Glogau, Gewicht ca. 800 Tonnen u. a. Die Brückenbauanstalt ist auch beteiligt an Lieferungen von eisernen Überbauten für die Schantung-Eisenbahngesellschaft, an welche bisher ca. 1400 Tonnen für verschiedene Bauwerke geliefert wurden. Die Werkstatt besitzt 55 Arbeitsmaschinen, welche sämtlich elektrisch angetrieben werden, hierzu ist eine Betriebskraft von 105 PS. erforderlich. (Festschr. p. 91.)

Schließlich haben wir noch das Preßwerk zu erwähnen, das erst seit 1899/1900 in Betrieb ist. Es fertigt Radgestelle mit Doppelspeichen aus Schweißeisen für Voll- und Kleinbahnwagen, Quer- 
träger für Plattformwagen, Buckelbleche etc., überhaupt alle vorkommenden Teile aus gepreßtem Stahlblech. An Betriebsvorrichtungen sind vorhanden: eine Kümpelpresse und eine Räderpresse mit Dampftreibeapparat, eine Keilschweißpresse, eine Speichenbiegepresse und Speichenschere. Außerdem 5 Bearbeitungsmaschinen. Der Gesamtumsatz des Jahres 1900/01 betrug 442195 Mark.

An diese großen Fabrikationsabteilungen schließen sich dann noch Reparaturwerkstätten, die in erster Linie Hilfsbetriebe sind und nur in geringem MaBe mit Arbeiten für Fremde beschäftigt werden. Hierher gehört: die sogenannte Hochofenschmiede, die Walzwerkschmiede, die Drehwerkstatt mit Drehbänken, Hobelmaschinen, Bohrmaschinen, Fräs-, Schleifmaschinen etc. Ferner eine Lokomotivwerkstatt und eine Zimmerwerkstatt.

Überblicken wir am Schlusse dieses Abschnittes noch einmal die Resultate: Wir lernten nach Erörterung der wirtschaftlichen Verhältnisse, unter denen der Hochofenbetrieb arbeitet, in zweiter Linie die Bedingungen kennen, die fürden SchweiB-und FluBeisenbetrieb der Königshütte charakteristisch sind. Wir erkannten, daß der Puddelbetrieb auf der Königs hütte-wenn wir hiervondem früher schon erwähnten Reichtum des Unternehmens an billigen Kohlen absehen - im wesentlichen auf zwei Pfeilern beruht: einmal auf der Beschaffenheit der oberschlesischen Erze, die einen Phosphorgehalt a ufweisen, dersie weder fürden sauren, noch fürden basischen Proze $B$ besonders geeignet erscheinen 1 ä $B t$, und andererseits auf dem groBen Angebot billiger polnischer Arbeitskräfte, die einen arbeitsintensiven Betriebgeradezuherausfordern. Ausdiesem Grunde ist dermit einem gröBeren fixen Kapital arbeitende FluBeisenbetrieb nicht in dem MaBe entwickelt wie in Rheinland-Westfalen. Die Birnen sind außerdem weniger leistungsfähig. In nächster Zeit wirdallerdings der Martinbetrieb wesentlich an Bedeutung gewinnen. Sowohldie Hoclöfenals a uch die Puddelund FluBeisenanlagenergebeneineverhältnismä Big teure Produktion. Während man nun die Hochofenanlage durch Schaffung besonderer Betriebefinanziell kräftigte, suchte man das verhältnismäBig 
teuererstandene Schwei $\beta-$ und FluBeisen durch Herstellung von Fertigfabrikaten mit Hilfe billiger Arbeitskräftekonkurrenzfähigzumachen. Deshalbbetrachteten wir in dritter Linie das Bestrebcn des Werkes, einen Ausgleichmitden hohen Produktionskosten des Roh-, Schweiß-und FluBeisenszuschaffen. Wir lernten auBerden in den Walzwerken hergestellten Fertigfabrikaten eine Räder- und Weichenfabrik (1872), eine Maschinenfabrik (1890), eine Waggonfabrik (1894), eine Brückenbauanstalt und Konstruktionswerkstatt (1894) und ein PreBwerk (1899) nebst Reparaturwerkstätten kennen. Durch alle diese Betriebe wird der Verbrauch des Werkes an eigenem Rohmaterial und Halbzeug bedeutend erhöht und die Herstellung von Fertigfabrikaten der vornehmste Zweck der Produktion.

Zum Schluß haben wir noch die Absatzverhältnisse der Königshütte zu betrachten. Im Vordergrunde steht der Absatz der Kohlen und der Fabrikate auf dem Inlandsmarkt. Die Bedeutung des letzteren ist mit dem Rückgang des Exports noch mehr gewachsen. Das natürliche Absatzgebiet ist Schlesien nebst den angrenzenden Provinzen. Nach den Untersuchungen Renaulds ist in Oberschlesien der Wasserversand gegenüber dem Eisenbahnversand bedeutend geringer als im Ruhrbezirk. Die Oder ist in ihrem Oberlauf nicht genügend reguliert. Dieser Strom hat für den Absatz der oberschlesischen Werke bei weitem nicht die Bedeutung wie der Rhein für die rheinischwestfälischen. Damit und mit der größeren Entfernung von den mittel- und norddeutschen Märkten hängt die höhere Fracht zusammen, die die oberschlesischen Werke zu tragen haben, obgleich die Regierung wiederholt die oberschlesischen Tarife heruntergesetzt hat. In einem Artikel der Vossischen Zeitung vom 5. November 1903 wird hierüber von sachverständiger Seite folgendes ausgeführt: „Die oberschlesische Eisenindustrie entbehrt infolge der Vernachlässigung der Oderregulierung der Wohltat eines Großschifffahrtsweges. Dazu steht der ausgiebigen Benutzung der Oder die Höhe der Vorfrachten nach den oberschlesischen Umschlagsplätzen entgegen. So kommen denn die dortigen Eisenwerke tatsächlich billiger aus, wenn sie sich ausschlieBlich auf den Eisenbahntransport verlassen. Hierin liegt nun ein ungeheurer Nachteil gegenüber der 
westdeutschen Industrie, steht dieser doch für den Export über See ein Netz vorzüglicher Wasserstraßen zur Verfügung, während ihr andererseits ihre relativ geringe Entfernung von den großen deutschen Seehäfen der Nordsee eine billige Eisenbahnfracht nach diesen hin sichert; ebenso kommt ihnen ihre geographische Lage im inländischen Geschäft aufs beste zu statten, indem ihre Erzeugnisse bei weitem geringere Bahnstrecken als diejenigen der oberschlesischen Werke zu durchlaufen haben, um an die Absatzzentren Mitteldeutschlands zu gelangen. Hieraus resultiert, daß Oberschlesien im Inlandgeschäft mit einer Frachtbelastung bis zu $2^{\mathbf{1}} / 4$ Mark pro $100 \mathrm{~kg}$, d. h. bis zu $25 \%$ des Wertes seiner Ware an Orten zu rechnen hat, wohin der Westen mit etwa 11/4 Mark Frachtspesen gelangen kann. Als charakteristischer Spezialfall sei angeführt, daß die westdeutschen Werke ab Oberhausen oder Duisburg mit 90 Pfennig bis 1 Mark Fracht pro 100 Kilogramm gewalzten Eisens nach Königsberg und Danzig kommen können, während Oberschlesien in diesem Falle etwa 1,70 Mark Frachtunkosten zu tragen hat. Die Dinge liegen nach alledem so, daß die oberschlesischen Walzwerke ohne besondere Opfer nur Schlesien und einen Teil der Provinz Posen als Absatzgebiet behaupten können, während nach allen anderen inländischen Plätzen hin nur unter der Parität der westdeutschen Preise Geschäfte gemacht werden können. Die Forderungen der oberschlesischen Eisenindustrie, man möge den oberen Lauf der Oder einer gründlichen Regulierung unterziehen, die Eisenbahnfrachtsätze nach den Umschlagsplätzen der oberen Oder analog der Tarifgestaltung für Exportware nach den Seehäfen ermäßigen und den Gebührentarif für die Schiffahrt auf der oberen Oder herabsetzen, sind nach alledem durchaus verständlich und nur zu billigen."

Durch den Bau eines Mittellandkanals, dem die oberschlesischen Montanindustriellen keineswegs günstig gegenüberstehen, würde die westdeutsche Konkurrenz noch schärfer werden. Daher werden Kompensationen von der Staatsregierung verlangt. Dieselben bestehen einmal in der Verbesserung der Wasserverhältnisse der Oder und weiter in der Gewährung von Frachtparität zwischen dem oberschlesischen und rheinisch-westfälischen Revier auf den Schnittpunkt Berlin.

Aus den Geschäftsberichten der Königshütte ist leider über den Absatz der Produkte der Königshütte nicht viel zu ersehen. In dem ersten Geschäftsbericht der Gesellschaft werden als die hauptsächlichsten Handelsartikel die Produkte der Walzwerke angegeben. „Sie 
werden nur auf Bestellung gefertigt und gelangen direkt aus den Hütten vermittelst der dahin führenden Eisenbahn an ihren Bestimmungsort. Der Verkauf sämtlicher Waren erfolgt durch die Direktion, welche in Berlin ihren Sitz hat, dem Werke die übernommenen Aufträge zuteilt, die Fakturen ausschreibt, die Geldbeträge einzieht, und die Werke mit Betriebsgeldern versorgt." Als die wichtigsten Absatzartikel werden im Geschäîtsbericht 1872/73 bezeichnet: Eisenbahnschienen, grobes und feines Handelseisen, sowie Façoneisen und Bleche. Mit dem Absatz von GuBwaren hatte das Werk anfangs wenig Glück. 1873/74 erzeugte die Gießerei 94178 Zentner Gußwaren. Dieselben dienten hauptsächlich zur Unterhaltung der Werksanlagen und zur Verwendung bei den Neubauten. Nach Ferigstellung der Bauten sollten die Gußwaren auf den Markt kommen. Ebenso versuchte die Gesellschaft Roheisen zu GieBereizwecken zu verkaufen. Hierüber heißt es in dem Geschäftsbericht 1876/77: „Zudem waren wir bemüht, Roheisen zu Gießereizwecken Eingang zu verschaffen und hatten in dieser Richtung einige, wenn auch nicht erhebliche Erfolge. Die Abneigung der Gießer gegen das deutsche Eisen entsprungen aus der alten Gewohnheit, englisches und schottisches zu verwenden - ist so gro $B$ und die Preise der letzteren Werke, welche begünstigt durch Zollfreiheit und enorm wohlfeile Frachten ganz Deutschland überfluten, sind so niedrig, da $B$ es uns große Anstrengungen und Opfer kostet, wenn wir neben ihnen einen nur mäßigen Absatz erziclen wollen." Ähnlich klingt der Tenor des Berichtes aus dem Jahre 1884/85. Dort heißt es: „Es ist uns nicht möglich, ein GieBereieisen zu erzeugen, welches mit dem billigen und für die meisten Zwecke ausreichenden englischen Material konkurrieren könnte, und der Bedarf an prima Ware, wie wir sie mit Vorteil erblasen und auf den Markt bringen können, ist nicht erheblich und wird obendrein von solchen Konsumenten, welche sich von ihrer alten Gewohnheit nicht losreißen können, meist in schottischen Marken - selbst zu höheren Preisen als die unsrigen sind - gedeckt." Mit allen Finessen suchte damals die Verwaltung nach neuen Absatzquellen, nach weiteren Verwertungsmöglichkeiten des geschaffenen Produkts. So wandte sie sich an eine Reihe von Kommunen, um dieselben zur Auspflasterung der Straßen mit Eisen resp. Stahl zu veranlassen. Der Ġeschäftsbericht $1878 / 79$ sagt über die negativen Erfolge dieses Vorgehens folgendes: „Die Bemühungen unserer Geschäftsleitung, StraBenpflasterungen in Eisen resp. Stahl auszuführen, haben bislang zu einem Resultate nicht geführt; die 
Stadtkommunen entschließen sich nur sehr schwer und langsam zur Aufnahme von Versuchen, welche unserer Ansicht und Erfahrung nach einen guten Erfolg, sowie den Städten ein vorzügliches, dauerhaftes Pflaster und unserer Industrie einen neuen Absatz versprechen."

Leider bicten die Geschäftsberichte über den inländischen Absatz kein weiteres Material. Ebenso dürftig ist dasselbe für den Absatz nach dem Auslande.

Die beiden Länder, zwischen denen die oberschlesische Eisenindustrie gleichsam eingekeilt liegt, sind Rußland und Österreich. Die geographische Lage für den Export ist also günstig. Allein beide Länder haben im Laufe der Zeit ihr Schutzzollsystem in der Weise ausgebildet, da $B$ dasselbe die Ausfuhr oberschlesischer Eisenfabrikate vor dem Abschluß der bekannten Handelsverträge geradezu unterband. Infolgedessen wurde der Absatz immer mehr auf den Inlandmarkt gedrängt. Bereits in dem Geschäftsbericht von 1876/77 klagt die Verwaltung: „Es fehlt den Werken nichts als ihr natürliches Absatzgebiet, d. h. ein Gebiet nicht größer als eine Kreisfläche mit einem Radius von 50-60 Meilen. Aber dieser Kreis fällt zum großen Teil nach Österreich und Rußland, und da das Deutsche Reich nicht imstande ist, die Zollschranken dieser Länder zu beseitigen, so hat es unserer Meinung nach die Pflicht, den Absatz unserer Produkte im Inland $\mathrm{zu}$ begünstigen, und die Werke, welche der Staat in seinem eigenen wohlverstandenen Interesse großgezogen, zu stützen und zu erhalten."

Welches waren nun die Folgen der hier nicht näher zu behandelnden zollpolitischen Maßregeln, die den Export der Königshütte so stark beeinträchtigten? Sie bestanden in der Verlegung der für den Export bestimmten Produktion hinter die Zollgrenze. 1882 wird in russisch Polen ein Walzwerk, die Katharinahütte, gebaut. Der Plan dazu war schon früher gefaßt, allein der russisch-türkische Krieg hinderte seine Ausführung. In dem Geschäftsbericht 1881/82 wird das Projekt näher beschrieben. Die Gesellschaft kauft jenseits der russischen Grenze, nicht fern dem Grenzorte Sosnowice, in russisch Polen, an der Warschau-Wiener Eisenbahn gelegen, ein der Herrschaft Sielce gehöriges Grundstück. Auf diesem wird nunmehr ein Eisenwerk errichtet mit folgenden Abteilungen: ein Walzwerk für starke und feinerc Blechsorten, und eines für leichtere Stabeisensorten, eine Puddelanlage zur Herstellung des erforderlichen Halbproduktes und eine Gießerei und Reparaturwerkstatt, sowie Wohngebäude für Beamte und Arbeiter. Es entsteht also ein zweigliedriges Werk, 
dessen Roheisenbedarf von den schlesischen Hochöfen der Königsund Laurahütte befriedigt wird, während es die nötigen Steinkohlen von den nahe gelegenen Sielcer Gruben entnimmt. 1882 ist das Werk teilweise fertig. Erst im zweiten Semester 1883 kommt es in vollen Betrieb. Die Verwaltung bezeichnet die Katharinahütte „als eine technisch gut disponierte und solid ausgeführte Anlage." Trotzdem rentierte sie anfangs nicht. Als Grund dafür wird im Geschäftsbericht 1883/84 angegeben cinmal die geringe Leistung eines ungeschulten Arbeiterpersonals und dann der Mangel an ausreichenden Aufträgen. „Die russische Kundschaft kauft nur ungern und zögernd das Fabrikat einer neuen Hütte und verlangt von solcher zunächst billigere Preise und tadellose Qualität. Hat sie sich von letzterer überzeugt, so pflegt sie dem inländischen Werke (d. h. dem deutschen) den Vorzug zu geben." Weiter wirkten die Zollerhöhungen auf Roheisen und Kohle für die Katharinahütte ungünstig. Die russische Regierung erhöhte 1884 den Roheisenzoll von 6 auf 9, und 1885 auf 12 Kopeken Gold per Pud, d. h. auf 24 Mark pro Tonne, so daß er mehr als die Hälfte des Wertes des Roheisens betrug. Gleichzeitig setzte sie den Zoll für Steinkohlen, welche über die polnische Grenze eingingen, von 1 auf $1 \frac{1}{2}$ Kopeken per Pud hinauf. Diese Steigerung des Zolles auf Rohmaterial mußte die bestehenden Fabriken, welche zu ihrem Betriebe Roheisen und Kohle verwandten und diese aus dem Auslande bezoger, unzweifelhaft schädigen, und die Entstehung neuer derartiger Etablissements in RuBland erschweren. Infolge dieser hohen Zölle wurde die Katharinahütte 1884/85 mit einer Mehrausgabe von ca. 90000 Rubel belastet. Dieser Summe aber stand ein Ausgleich durch eine entsprechende Stcigerung der Fabrikatzölle nicht gegenüber. Um diesen Betrag wurde der Bruttogewinn des genannten Jahres reduziert. Nachdem nun diese ersten Lehrjahre überwunden waren, begann die Katharinahütte zu prosperieren und für die Gesellschaft ein wertvolles Supplement ihrer schlesischen Produktion zu iverden. Während in Deutschland um die Mitte der 80er Jahre eine allgemeine Verflauung im Eisengeschäft eintrat, war die Katharinahütte im vollen Betrieb und reichlich beschäftigt, so daß sie vielfach von ihrem Überfluß an die schlesischen Werke abgeben konnte. „Die letzteren ergänzen“, heißt es in dem Bericht 1884/85, ,somit das auf der Katharinahütte überhaupt, oder zur rechten Zeit nicht Darstellbare, bleiben in gut vermittelter Fühlung mit dem russischen Markte und liefern der Katharinahütte Roheisen und Steinkohlen." Ebenso florierte das russische Werk auch im 
Anfang der 90er Jahre, als in Deutschland das Geschäft stark darniederlag. Rußland hatte damals große Eisenbahnunternehmungen auszuführen, und dieses bedingte für die russische Eisen- und Stahlindustrie eine günstige Konjunktur, an der auch die Königs- und Laurahütte durch ihr russisches Werk partizipierte. Infolge der höheren Erträge des letzteren wurden die niedrigeren Erträge der schlesischen Anlage überkompensiert. Wir sehen hier, wie solche Filialen im Auslande die Funktion einer internationalen Gewinnausgleichung für eine Gesellschaft übernehmen können. Es hängt das damit zusammen, daB die volkswirtschaftlichen Krisen in den verschiedenen Ländern oft sich nicht zu gleicher Zeit herausbilden. E in Beispiel wurde schon angeführt, ein zweites betrifft die letzte Krisis. Als 1899 Deutschland noch auf der Höhe einer eminent günstigen Konjunktur stand, war in Rußland bereits der Niedergang eingetreten. In diesem Jahre stǘzten die schlesischen Werke das russische Unternehmen, das unter der Ungunst der Verhältnisse zu leiden hatte. Andererseits ist zweifellos der Niedergang der deutschen Industrie von 1900-1902 durch die gleichzeitige Hochkonjunktur in den Vereinigten Staaten stark abgeschliffen worden.

Nach Errichtung der Katharinahütte hatte die Gesellschaft zwar weiter ein Interesse an der Erniedrigung der Rohmaterialzölle, zumal mit dem Mai 1887 eine Verdoppelung des Zolles auf Roheisen eingetreten war, andererseits aber ein Interesse an einer weiteren Steigerung der Fabrikatzölle, weil durch die letzteren alle die deutschen Exportwerke geschädigt wurden, die nicht selbst hinter der russischen Grenze Eisenindustrie trieben. Seit dieser Zeit geht nun eine merkwürdige Wandlung in der Seele dieser Gesellschaft vor sich. Vor der Errichtung der Katharinahütte hatte sie es für ganz selbstverständlich gehalten, daß die inländischen Hütten ihre Produkte billiger auf den Auslandsmarkt warfen als auf den Inlandsmarkt, um konkurrieren zu können. Diese Auffassung aber ändert sich mit einem Schlage, wo die Gesellschaft hinter der Zollgrenze ein eigenes Werk etabliert. Was früher verteidigt, wird jetzt angegriffen. Sie bedauert, daß der schlanke Absatz der Produkte der Katharinahütte zu Preisen vor sich geht, welche unter der Konkurrenz der außerrussischen Werke zu leiden hatten." (Geschäftsbericht 1884/85.)

Aus der Darstellung der Verhältnisse des russischen Werkes geht hervor, daß die sich darin dokumentierende internationale Expansion des Kapitalismus für die betreffenden Erwerbsgesellschaften gewisse Vorteile mit sich bringt: Si e erweitern ihren Markt, 
sparen den Zoll und erzielen in Krisenzeiten einen Ausgleich ihrer Einnahmen.

Wegen der damit verbundenen Vorteile ist nun die Königshütte nicht bei der Etablierung des einen Werkes in Rußland stehen geblieben, sondern sie hat 1896/97 noch ein zweites errichtet, dabei aber den Fehler beseitigt, der in der Abhängigkeit der Katharinahïtte vom Rohstoffmarkt und den Eingangszöllen auf Kohlen und Eisen lag. In dem genannten Jahre pachtet sie das Kaiserlich russische Hüttenwerk Blachownia bei Czenstochau in russisch Polen. Es besitzt eine Hochofenanlage, ferner eine GieBerei und cine mechanische Werkstatt, sowic ausgedehnte Toneisensteingruben bei Wrenczyca. Mit dem Besitz dieser Erzgruben war nun auch für die Katharinahütte ein günstigerer Status geschaffen. Der Geschäftsbericht 1896/97 sagt hierüber folgendes: „Die Ausbeutung der Toneisensteingruben wird zuvörderst, che die Hochofenanlage in Betrieb kommt, zur Deckung des Eisenbedarfs der in der Nähe gelegenen Katharinahütte verwandt, während die übrigen Betriebseinrichłungen von Blachownia zur weiteren vorteilhaften Verwertung der Katharinahütter Roheisens und zur Erzeugung von Werkstattprodukten dienen sollen, die in der industriereichen Umgebung guten Absatz finden."

Infolge des Bestehens dieser beiden Filialen ist das Exportinteresse der Königs- und Laurahütte natürlich ein verhältnismäßig geringes. Daß trotz der hohen Zölle, die ja durch die Handelsverträge mit Österreich und Rußland ermäßigt wurden, immerhin unter Umständen große Massen der Erzen:ynissc der Königshütte ins Ausland gelangen, geht aus einem Bericht des Unternchmens vom Jahre 1894/95, über das diesbezügliche Angaben gemacht werden, hervor. In diesem Jahre hatten die hohen Eisenbahnfrachten Oberschlesiens das Absatzgebiet der Vereinigten Königs- und Laurahütte im Norden Deutschlands eingeengt. Dies veranlaßte das Werk, Ersatz in einem verstärkten Export nach dem Auslande, besonders nach Rußland, zu suchen. An Handelswaren wurden im Auslande abgesetzt $45 \%$ des Gesamtabsatzes gegen 41,7\% im vorhergehenden Jahre. Der Grund für diesen kolossalen Export der Königshütte lag darin, daB 1893 der Handelsvertrag mit Rußland abgeschlossen worden war, der eine Zollherabsetzung mit sich brachte. Die auf der Königshütte aufgestauten Vorräte flossen nunmehr in großen Massen über die Grenze ab. Immerhin sind die beiden genannten Jahre in bezug auf die Ausfuhr der Königshütte als Ausnahmejahre usehen. Nach dem schon erwähnten Artikel in der Vossischen 
Zeitung kann man annehmen, daß die oberschlesischen Werke alles in allem nicht melir als zusammen 5\% ihrer Produktion ins Ausland versenden; diese $5 \%$ stellen natürlich nur die Durchschnittsziffer dar. Bei einigen Artikeln ist die Exportziffer bedeutend höher, so bei Stabeisen auf etwa $15 \%$, bei anderen Produkten entsprechend niedriger zu veranschlagen.

Soviel über den Absatz der Königs- und Laurahütte im In- und Auslande. Im ganzen wurden im Jahre 1902/03 daraus vereinnahmt $50 \frac{1}{2}$ Million Mark. An dieser Bareinnahme sind die russischen Werke beteiligt mit 3747196 Rubel. Die eben genannte Einnahme setzt sich zusammen aus folgenden, leider in ihren Verkaufswerten nicht näher spezialisierten Posten. Es wurden im genannten Jahre verkauft:

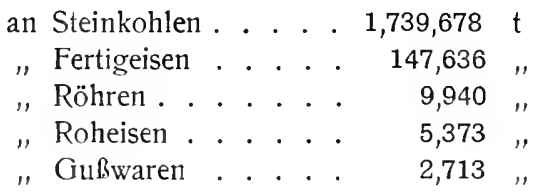

Produktion und Absatz der Königshütte sind im Laufe der letzten 30 Jahre außerordentlich gestiegen. Es betrug:

\begin{tabular}{|c|c|c|c|c|c|c|c|}
\hline die Produktion & $1871 / 2$ & & $1880 / 1$ & & $1890 / 1$ & & $1900 / 1$ \\
\hline an Steinkohlen & 580,668 & $t$ & 939,199 & $\mathrm{t}$ & $1,548,552$ & $t$ & $2,462,882$ \\
\hline $\begin{array}{l}\text { Walzeisen } \\
\text { Absatz }\end{array}$ & 66,320 & $"$ & 82,385 & $"$ & 128,237 & $"$ & 177,476 \\
\hline an Steinkohlen & - & & 269,724 & $"$ & 898,727 & $" \prime$ & $1,815,600$ \\
\hline „Walzeisen & 65,028 & $"$ & 78,785 & " & 122,668 & , & 142,055 \\
\hline
\end{tabular}

Hingegen ist in dieser ganzen Periode das Aktienkapital stabil geblieben. Ursprünglich betrug es 18 Millionen Mark. Dann wurde es durch Generalversammlungsbeschluß vom 24. April 1873 um 9 Millionen, also auf 27 Millionen Mark erhöht, und zwar im wesentlichen behufs Aufnahme der Stahlerzeugung, sowie Vermehrung der Steinkohlenförderung und Roheisenproduktion. Auf diesem Niveau ist es bis heute stehen geblieben. Die notwendigen Summen für den Bau der russischen Filiale, für den Ankauf neuer Steinkohlengruben, für die Erweiterung der Stahlerzeugung und den Bau von Anlagen zur Gewinnung verschiedener Nebenprodukte, sowie der Anlagen zur Verfeinerung und Weiterverarbeitung der Eisenerzeugnisse wurde durch zwei große Anleihen aufgebracht. Die erste aus dem Jahre 1885 betrug $7 \frac{1}{2}$ Million Mark. Sie erf $t^{*} \cdot r$ 
1895 eine Erhöhung auf 10 Millionen unter Reduktion des Zinsfubes von $4^{1 / 2}$ auf $3 \frac{1}{2} \%$. Auf dieser Höhe steht sie noch heute. Im übrigen wurden die Neuankäufe aus den Gewinnen des Betriebes bestritten, namentlich in günstigen Konjunkturjahren. So wurden z. B. die Kosten der Neuanschaffungen des Jahres 1897/98 durch Absclireibungen von etwa 3 Millionen Mark aus den Gewinnen gedeckt. Die zurzeit noch bestehenden Gründerrechte (cf. S. 176) dürften zum Teil die Scheu der Verwaltung vor der Vermehrung des Aktienkapitals durch die Ausgabe junger Aktien erklären.

Allerdings haben die schlechten Geschäftszeiten das Unternehmen vielfach in seiner Entwicklung gestört, aber sie haben doch nicht solchen Einfluß auf dasselbe gewonnen wie bei den Werken, die wir früher bereits kennen lernten. Das hängt zusammen mit der geringeren kapitalistischen Entwicklung der oberschlesischen Hüttenindustric überhaupt. Eine Massenproduktion konnte und kann sich infolgedessen bei der letzteren nicht in dem Maße entwickeln und den Markt überfluten wie bei der rheinisch-westfälischen Massenindustrie. Zunächst sehen wir, daB die große Krisis von 1873-79 in Oberschlesien später einsetzt. In der ersten Hälfte des Jahres 1873 ließ der Andrang der Käufer vorzugsweise in gewöhnlichem Handelseisen nach, während der Bedarf an Eisenbahnmaterial und Blechen nach wie vor ein großer blieb. Aber selbst das folgende Jahr bringt noch keine Schwierigkeiten. Noch im Geschäftsbericht 1873/74 frohlockt die Verwaltung: „Wir können mit besonderer Genugtuung an dieser Stelle die Bemerkung vorausschicken, daß dic Werke der Vereinigten Königs- und Laurahütte voll beschäftigt waren, da $B$ die Produktion in einzelnen Artikeln der vorjährigen nahezu gleich, in anderen, besonders in Steinkohlen, erheblich höher gewesen ist, daß die Produkte zu guten Preisen abgesetzt wurden, daß wir ein den schwierigen Verhältnissen gegenüber vorzügliches finanzielles Resultat erzielten und die Gesamtwerke durch fortlaufende Meliorationen und Neubauten nach allen Richtungen hin gestärkt und konkurrenzfähiger in das neue Geschäftsjahr hinübergeführt haben." In dem folgenden Jahre werclen die Schwierigkeiten allerdings größer, wenn auch das oberschlesische Absatzgebiet nicht so offen dem aggressive Eindringen fremder Eisenprodukte ausgesetzt war wie Rheinland-Westfalen. Vor allem diente dem Werk sein Steinkohlenabsatz als Mittel, um der heranzichenden Krisis entgegenzutreten. Mit Bezug hierauf heißt es 1875/76: „Dagegen ist das Geschäft in Steinkohle noch lohnend, obwohl die Eisen- 
hütten, sonst sehr starke Konsumenten, sowie in anderen Fabriken kaum die Hälfte ihres früheren Bedarfes entnehmen. Die in dem letzten Jahre dem Betriebe übergebenen Eisenbahnen haben neue Absatz- und Verbrauchsgebiete erschlossen, welche sich mehr und mehr der Steinkohle bedienen ..." Nun aber gingen die Preise weiter zurück. Die Preise in Roheisen und Walzwerkswaren mußten mit jedem neuen Abschluß nachgeben, jedoch vergrößer`e sich durch die erhebliche Reduktion die Walzeisenpreise das Absatzgebiet nicht unerheblich, „so daß z. Zt. Aufträge reichlich fließen." (Geschäftsbericht 1875/76.) Diese sinkenden Preise erweiterten gleichsam automatisch den Absatz. Während der Krisis spielt der Export der Königshütte keine bedeutende Rolle. Allerdings hatte sie einige Jahre hindurch eine nicht unbedeutende Ausfuhr von Schienen nach RuBland und Österreiclı und von Stahlprodukten nach Amerika. Aber mit der Schutzzollgesetzgebung des Auslandes sinkt dieser Anteil der auf fremde Märkte geworfenen Waren wieder. In dieser Zeit tritt ein anderes Moment als die Entlastung des Werkes durch den Export in den Vordergrund: die Verminderung der Erzeugungskosten. Dazu kommen Betriebseinschränkungen. „Anfangs,“ sagt die Verwaltung, ,wurde der Betrieb voll aufrecht erhalten. Später fanclen wir es jedoch profitabel, Eisen- und Stahlartikel nur insoweit zu fabrizieren, als wir mit Nutzen verkaufen konnten und dagegen die Produkte der Steinkohlengruben in größerem Maße direkt auf den Markt zu bringen." Aber mit dẹr Verflauung des Kohlenmarktes führte auch dieser Modus nicht mehr zu günstigen Ergebnissen. Daher folgert die Verwaltung: „Für die generelle Disposition in unserem Geschäftsbetrieb ist die Frage des Kohlenabsatzes von groBer Bedeutung. Wenn der letztere, wie im verflossenen Jahre, schwierig ist und der direkte Verkauf der Kohlen in großen Massen den Preis weiter zu werfen droht, so empfiehlt es sich, den Hüttenwerken größere Massen Kohlen zu überweisen, oder mit anderen Worten, die Hütten stärker zu betreiben, vorausgesetzt, daß die Kohlen im Kaufgelde der Hüttenprodukte eine angemessene Verwertung finden." (Geschäftsbericht 1877/78.) Die Resultate des Jahres 1878/79 waren die schlechtesten seit dem Bestehen der Gesellschait. Die Dividende betrug nur $1 \frac{1}{2} \%$.

In jener schweren Zeit erwartete die Eisenindustrie, die vorher durchaus freihändlerisch gewesen war, Hilfe von den Schutzzöllen. Die Bewegung ging aus von dem Vorsitzenden des Aufsichtsrates der Vereinigten Königs- und Laurahütte, dem Reichstagsabgeord- 
neten von Kardorff, der in seiner Broschüre "Gegen den Strom" auf die Notwendigkeit der Schutzzölle auch für die Eisenindustric hinwies. Durch das Gesetz von 1873 war das Roheisen zollfrei geworden, und die Schmiedeeisenzölle waren bedeutend ermäBigt. 1877 sollte auch der Schmiedeeisenzoll beseitigt werden. Diesem Gesetz galt der Kampf und die Agitation. 1874 konstituierte sich der „Verein deutscher Eisen- und Stahlinc'ustrieller", dessen Vorsitzender der damalige Generaldirektor der Königs- und Laurahütte Richter wurde. Im Dezember 1875 traten auf Veranlassung von Kardorifs 50 Großindustrielle zur Gründung des „Zentralverbandes deutscher Industrieller" zusammen, welcher sich als Vertretung der schutzzöllnerischen Interessen der deutschen Industrie konstituierte.*) Diese Agitation führte zu einem Umschwunge in der deutschen Wirtschaftspolitik, der zu bekannt ist, als daß ich hier weiter darauf einzugehen brauchte.

Aber bereits im Herbst 1879 kam ẹin Anstoß zur Besserung von einer Seite, von welcher man ihn am wenigsten erwarten konnte: Amerika. Noch vor wenigen Jahren ein starker Abnehmer für europäisches Eisen, hatte es sich zur Verstärkung sciner Produktion so weit unabhängig gemacht, daB es seinen gewöhnlichen Konsum zu decken vermochte; seine Betriebsmittel reichten aber nicht aus, um dem stark und plötzlich auftretenden Bedarf an Eisenmaterial, wie er sich im Jahre 1879 infolge sehr günstiger Ernten dort entwickelte, zu genügen. Die natürliche Folge davon war die Rückkehr auf den europäischen, und zunächst den englischen Markt; es wurden groBe Quantitäten von Roheisen und Alteisen, Halbprodukten in Stahl (steelbloms) und fertigen Schienen für amerikanische Rechnung aufgekauft, und dic Bewegung übertrug sich bald auf die Montanbezirke des Kontinents, zuerst auf Belgien, Westfalen und die Rheinprovinz und sodanin auf Schlesien. Wir sehen also, wie die Besserung der Geschäftslage bei der Königs- und Laurahütte erst spät eintritt.

Die 80er Jahre haben dann für das Unternehmen ebenfalls manche Schwierigkeiten gebracht, so $\mathrm{daB}$ die Dividende in den schlimmsten Zeiten 1885/86 $1 / 3$ und 1886/87 nur $1 / 2 \%$ betrug. Nunmehr waren es nicht mehr allein, wie in den 70er Jahren, die Schutzzölle, die man als Panacee proklamierte, denn dieselben standen ja in voller Blüte, sondern jetzt feierte der Kartellgedanke in der westfälischen wie auch in der oberschlesischen Industrie seinen Einzug. Unter

*) Siehe Festschrift p. $71 \mathrm{ff}$. 
Führung Richters bildete sich 1886 ein „Verband oberschlesischer Walzwerke", welcher nach den Angaben der Festschrift 1. die jeweilige Feststellung der Produktion und des Absatzes, 2. die Verteilung desselben unter die Verband'swerke nach bestimmten Grundsätzen und 3. die Etablierung einer gemeinschaftlichen Verkaufsstelle für alle Beteiligten in Berlin zur Durchführung brachte. Die günstigen Erfolge dieses Verbandes führten zu ähnlichen Vereinigungen der rheinisch-ivestfälischen, der mitteldeutschen und zuletzt der süddeutschen Werke. Alle 4 Gruppen traten dann $1887 \mathrm{zu}$ dem „Deutschen Walzwerksverbande" in Berlin zusammen. Über die Tätigkeit des Verbandes äußert sich die Festschrift (p. 74) wie folgt: „Richter führte den Vorsitz des Verbandes und leitete seine Geschäfte in einem so versöhnlichen Geiste, daß die neue Schöpfung allseitig eine wohlwollende Beurteilung fand. Die Verkaufspreise wurden in mäßigen Grenzen gehalten, die eine Einengung des Eisenverbrauchs nicht befürchten ließen, die Käufer faßten Vertrauen zu der neuen Einrichtung, und das Eisengeschäft belebte sich in erfreulicher Weise. Leider wurde jene Mäßigung, trotz der Bemühungen Richters, vom Verbande aufgegeben, als im Herbst 1889 in Amerika eine Eisenhausse eintrat, welche sich auch auf Deutschland übertrug. Die Eisenpreise wurden sprungweise bis auf 200 Mark und darüber aufgehöht, der Eisenverbrauch stockte, und da nunmehr die Preise schleunigst ermäßigt werden mußten, so schwand das Vertrauen der Konsumenten und Händler auf den Schutz vor Konjunkturverlusten, welchen sie vom Verbande erwartet hatten. Obwohl der Verband sein Ansehen bei der Kundschaft durch diesen Fehlgriff in etwas eingebüßt hatte, so wurde er doch im Jahre 1890 auf weitere drei Jahre verlängert, weil seine Vorteile für die Eisenwerke rückhaltlos anerkannt wurden. Jetzt indessen trat die Erscheinung ein, daß nach und nach eine immer größere Anzahl neuer, modern eingerichteter Eisenwerke erbaut wurden, welche sich nach ihrer Fertigstellung mit leichter Mühe die Aufnahme in den Verband zu günstigen Bedingungen erkämpften, so daß dieser allmählich auf 58 Werke mit nahezu 800 C00 Tonnen Jahresproduktion angewachsen war. Eine so gesteigerte Produktionsmenge vermochte der Verband nicht mehr unterzubringen, und man schritt am 20. November 1893, bald nach Richters Tode, zu seiner Auflösung." In der Generalversammlung vom 28. Oktober 1894 machte der nunmehrige Generaldirektor Junghann folgende Mitteilung:*) „Der 
Schlesisch-Mitteldeutsche Walzwerksveıband ist definitiv gekündigt. Es war nicht möglich, denselben fortzusetzen, weil das Peiner Walzwerk seinen Austritt angezeigt hatte. Ohne dies Werk sei der Verband undenkbar. Das Peiner Walzwerk war der Meinung, daß der Verband für die westfälische Konkurrenz wertvoller gewesen sei als für die Verbandswerke, und daß die Konkurrenz im Osten durch die einzelnen Werke weit intensiver bekämpft werden könnte, als durch den Verband. Das Borsigwerk sei außerhalb des Verbandes geblieben und mache große Konkurrenz, habe es auch verstanden, viele Kunden heranzuzichen, da seine jetzige Leitung eine zielbewußte und gute sei. Die Preise würden durch die westfälische Konkurrenz diktiert und könnten die oberschlesischen Werke dieselben nicht höher halten als diese... Borsig wolle Oberschlesien beherrschen." Schließlich heißt es im Geschäftsbericht des Jahres 1894/95: „Da der Schlesisch-Mitteldeutsche Verband in seinem isolierten Bestande sich für unsere Interessen mehr und mehr unfruchtbar erwiesen hatte, so hatten wir demselben gekündigt." In Oberschlesien traten nun nach Austritt der Königs- und Laurahütte die übrigen Werke zu einer neuen „Vereinigung der Oberschlesischen Walzwerke" zusammen, mit welcher die Königshütte ein Kartell bezüglich der Handhabung der Geschäfte einging.

In der Krisis von 1891-95 erfolgte dann, nach Abschluß des russischen Handelsvertrages, eine große Abstoßung von Eisenvorräten der Königshütte nach Rußland, um den Markt zu entlasten. Ich habe die diesbezüglichen Mengen schon an anderem Orte näher angegeben. Der oberschlesische Walzwerksverband glaubte dadurch eine bedeutende Aufbesserung der Preise für Eisenfabrikate herbeiführen zu können. Allein der Versuch mißlang, ,weil die westdeutschen Werke ihren Wettbewerb zu niedrigen Preisen bis nach Schlesien hin auszudehnen bestrebt waren." Hier sehen wir bereits klar und deutlich das Eingreifen der westlichen, auf der Massenproduktion beruhenden Werke für die bei weitem weniger produzierende Eisenindustrie Oberschlesiens verhängnisvoll werden. Die letzte Krisis von 1900 ff. hat diesen Zusammenhang noch schärfer hervortreten lassen. Diese Krisis ist für die oberschlesische Eisenindustrie im allgemeinen und für die Königshütte im besonderen im wesentlichen mit bedingt worden durch die Überproduktion der rheinisch-westfälischen Werke. Das Zurückgehen der Aufträge, die Verflauung des Marktes in Oberschlesien war nur eine Reflexerscheinung der wuchtigen Massenerzeugung der westlichen Kon- 
kurrenz. Auch die Kartelle der oberschlesischen Eisenindustrie konnten allein nichts ausrichten. Hierüber schreibt Kuh, Redakteur des Zentralblattes der Walzwerke folgendes:*) ,Durch seinen rücksichtslosen und bisweilen selbstmörderischen Wettbewerb hat der westliche Teil der deutschen Eisenerzeugung die östliche Konkurrenz oft mitgerissen, und die Schwankungen in der oberschlesischen Eisenindustrie sind zum groBen Teil nicht aus ihr selbst entstanden, sondern sie sind Reflexe der vom Westen her ausgehenden Unruhe. Als im Jahre 1900 der Umschwung eintrat, wäre es den schlesischen Werken möglich gewesen, das Krisenartige der Erscheinung zu mildern. Das Kartell der oberschlesischen Walzwerke und die Königsund Laurahütte operierten nach gemeinsamer Verabredung in der Weise, daß dem Handel, der in überstürzter Spekulation starke Verpflichtungen übernommen hatte, Preisermäßigungen von 210 auf 185 Mark pro Tonne gewährt wurden gegen die Verpflichtung sofortiger Spezifikation ... mit den westlichen Werken aber war keine Verständigung möglich." Kuh ist nun allerdings der Meinung, daß die oberschlesischen Werke immer das Gute gewollt, die bösen westfälischen Werke es aber nicht getan haben. Er ist ein Lobredner der oberschlesischen Hüttenindustrie, er meint sogar, ,von einer wirklichen Krisis kann in der oberschlesischen Montanindustrie nicht die Rede sein." Allein der tiefere Grund ist ihm entgangen, er beruht darin, daß in Oberschlesien wegen der geringen kapitalistischen Entwicklung tatsächlich eine eigentliche Überproduktion in der letzten Krise nicht bestand.

Was die speziellen Verhältnisse der Königs- und Laurahütte anbelangt, so betrug:

$\begin{array}{lccc} & 1900 / 01 & 1901 / 02 & 1902 / 03 \\ \text { die Zahl der Arbeiter } & 20,277 & 20,343 & 20,028 \\ \text { der gezahlte Arbeitslohn } & 17,477,528 & 17,002,416 & 16,573,461 \\ \text { die Bruttobareinnahme } & 59,0 \text { Mill. M. } & 51,4 \text { Mill. M. } & 50,5 \text { Mill. M. } \\ \text { die Dividende } & 14 \% & 10 \% & 11 \% \\ \text { Verkauftes Fertigeisen } & 142,055 \text { t } & 146,847 \text { t } & 147,636 \text { t }\end{array}$

Hieraus ergibt sich folgendes: Die Arbeiterzahl ist während der letzten Krisis ziemlich dieselbe geblieben, auch der Lohn hat sich gehalten, wenn auch im letzten Jahre eine Abschwächung eintrat. Die Bruttobareinnahmen sind zurückgegangen, die Masse der verkauften

*) Schriften des Vereins für Sozialpolitik, Band 106: „Die Störungen im deutschen Wirtschaftsleben während der Jahre $1900 \mathrm{ff.}$. Montan- und Eisenindustrie, Leipzig 1903, p. 192. 
Fabrikate aber ist gestiegen. Aus dem Geschäftsbericht ist ferner ersichtlich, daß nicht alle Zweige der Produktion von der Krisis berührt wurden. So heißt es in dem Bericht über das Jahr 1900/01: „Unsere Konstruktions- und Verfeinerungswerkstätten waren das ganze Jahr hindurch lebhaft beschäftigt und erhöhten ihren Umsatz gegen das Vorjahr um $9 \%$.“

Fassen wir zum SchluB noch einmal das Wesentliche dieses dritten Abschnittes zusammen: Das natürliche Absatzgebiet der Vereinigten Königs- und Laurahütte ist Schlesien. Ihr Exportinteresse ist verhältnismäBig gering. Die Gründe hierfür liegen einmal in dem Unternehmen selbst, nämlich in seiner geringeren Erzeugungskraft, zweitens aber in der Schutzzollpolitik der angrenzenden Länder. Die geringerekapitalistische Entwicklung bedingtnicht in dem Maße die Produktion für den Weltmarkt, wie dies bei den auf den Export angewiesenen rheinisch-westfälischen Werken der Fall ist. Der Plan, jenseits der russischen Grenze ein Eisenwerk zu erbauen, wurde durch die Befürchtung aus der Taufe gehoben, daB infolge der Steigerung der russischen Eingangszölle auf fabriziertes Eisen die Produkte der Königshütte allmählich vom russischen Markt ausgeschlossen werden würden. Durch die Erbauung der Katharinahütte erweiterte das Werk seinen Absatzmarkt, sparte den Zoll und war in der Lage, bei verschiedener Konjunktur im In-und Auslande seine Einnahmen auszugleichen. Um die Mitte der 90 er Jahre wird dann ein zweites Werk in RuBland gepachtet. Die Bedeutung dieses Besitzes liegt hauptsächlich in hochprozentigen Erzgruben, so da $B$ das Roheisen für die Fabrikation im Auslande nicht aus Schlesien bezogen $z u$ werde $n$ braucht, sondernz. T. von eigenen Hochöfen in RuBland geliefert wird. Mit diesen Erwerbungen steht die Aufnahmeder erwähnten Anleihen in Kausalzusammenhang, während das Aktienkapital von 1873 bis zur Gegenwart auf der Höhe von 27 Millionen Mark verharrt. Wir sahen schlieBlich, daB die Störungen im Wirtschaftsleben den Gang der Geschäfte der Königshütte nicht in 
dem MaBe beeinfluBten, wie bei den rheinisch-westfälischen Werken, so daB sie auch in Zeiten, wo der Zeiger des Wirtschaftslebens ungünstig stand, stets imstande war, eine Dividende zu verteilen. Auch dieses Moment hängt mit dem Grundcharakter des Unternehmens, der geringeren kapitalistischen Entwicklung, zusammen.

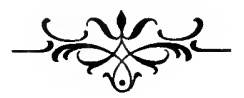




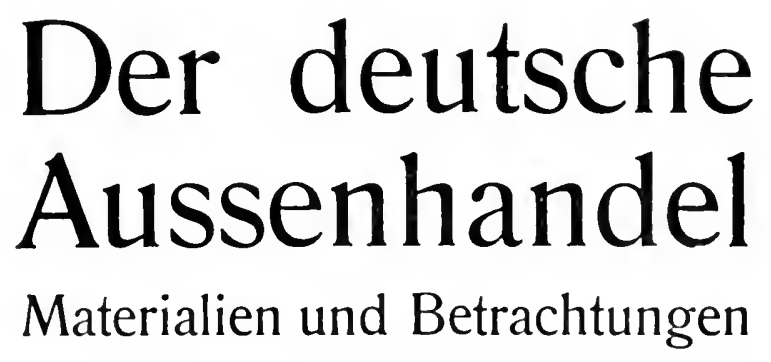

von

\section{GEORG GOTHEIN}

Mitglied des Reichstages.

1901. XXVII u. 827 Seiten kl. 40. Geb. 23 Mark.

Im Hinblick auf die Neuordnung der deutschen Handelspolitik geschrieben, bietet des Gothein'sche Werk eine erschöpfende, grundlegende Untersuchung über die Bedeutung des Außenhandels für das deutsche Volk, die Gründe seiner Entwickelung und seiner Notwendigkeit. Alles geschöpft aus den besten Quellen des praktischen Lebens und unter Benutzung vieler $\mathrm{Hunderte}$ von Gutachten von Industriellen und Kaufleuten.

In seinem speziellen Teile behandelt das Werk auf 712 Seiten den Außenhandel in den einzelnen Waren, die Ein- und Ausfuhr, die Zölle aller Kulturstaaten; es bespricht in jedem Fall die Frage der Inlandsbesteuerung, der Zollsätze des In- und Auslandes in ihren Wirkungen auf die heimische Industrie und den Verkehr mit den einzelnen Ländern.

Der ungeheuere Stoff ist von dem Verfasser, dem geschätzten Nationalökonomen und Parlamentarier, mit enormem Fleiß bearbeitet und übersichtlich gegliedert dargestellt worden. Ein ähnliches Werk kann keine der Kulturnationen aufweisen. 


\section{Die Bewegung der Warenpreise in Deutschland von 1851 bis 1901.}

Nebst zwei Ergänzungen:

Bankdiskont, Goldproduktion und Warenpreisstand.
Der Weizenpreis von 400 vor Chr. bis 1900 . OTTO SCHMITZ.

Mit 43 Tafeln und 2 Karten in farbigem Steindruck. 1903. 443 Seiten Lex. $8^{0}$. Geh. 12 Mk., geb. $14 M k$ :

KöInische Zeitung: „Die genaue Verfolgung der Warenpreisschwankungen ist für die Beurteilung der gesamten Tätigkeit eines jeden Wirtschaftskörpers von der größten Wichtigkeit. Haben doch die Preisbewegungen der wichtigsten Waren ebensowohl symptomatische Bedeutung für die Feststellung wichtıger wirtschaftlicher Vorgänge, wie sie anderseits die Ursache entscheidender Wendungen im Wirtschaftsleben sind. Die Bewegung der Arbeitslöhne wie des Unternehmergewinnes und des Kapitalzinses liängt in erster Linie von ihnen ab, und es ist deshalb für den Volkswirt wie für den Praktiker von der größten Wichtigkeit, vor allem einen Überblick über die Warenpreisbewegungen innerhalb größerer Zeitabschnitte zu gewinnen. Das ist bei der großen Fülle des Materials und wegen seiner weitgehenden Zersplitterung nicht leicht, und es ist deshalb jeder Versuch, auf diesem Gebiete größere Klarheit zu schaffen, mit Anerkennung zu begrüßen, sofern er mit tauglichen Mitteln und auf zuverlässiger Grundlage unternommen wird. Das darf der Arbeit nachgesagt werden, die Otto Sch m it z über di se wichtige Frage soeben veröffentlicht. Schmitz gibt nicht nur eine übersichtliche Darstellung der Warenpreisbewegungen an sich, sondern berechnet auch das Verhältnis des Preises jeder einzelnen Ware zu dem Gesamtwarenpreisstand jedes Zeitabschnittes. Was seine Arbeit besonders wertvoll macht, ist die systematische und leicht übersichtliche Form, deren Wert durch zanlreiche graphische Darstellungen noch wesentlich erhöht wird; soweit sich durch die von uns angestellten Stichproben und Nachprüfungen ermitteln lieB, sind die Angaben der einzelneu Übersichten durchaus zuverlässig. Besonders interessant ist die Gegenüberstellung der Vıränderungen der Warenpreise mit den Diskontschwankungen und mit der Entwicklung der Goldgewinnung. Die Schmitz'sche Arbest wird für jedermann, der einen Einblick in die tat:ächliche Bewegung der Warenpreise, in ihre innern und ursächlıchen Zusammentänge wie auch in ihre Wirkungen gewinnı’n will, unentbehrlıch sein. $\mathrm{Zu}$ wünschen wäre, daB sie auch für die tolge in derseiben systımatischen Weise weiter fortgeführt würde."

Schmoller's Jahrbücher: Wir müssen dem ungeheueren FleiB, mit dem die Riesenarbeit bewältigt worden ist, die volle Anerkentnung zollen. Die Aufopferung, mit der sich ein Privatmann einer solch zeitraubenden, langw iligen und kostspieligen Arbet, die eigenulic non den öftentli, hen Instituten zu besorgen wäre, unterzogen hat, ist über jedes Lob erhaben. 
W

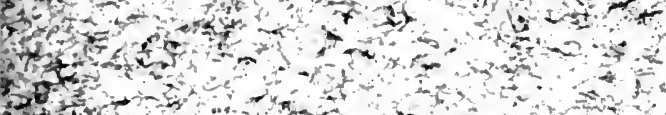

(1)

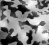

$4,+2+1$

W

teis

s.

4

(1) 
10

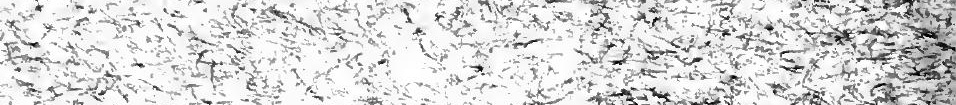

sitions

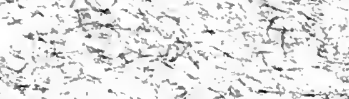

$$
\text { (1) }
$$

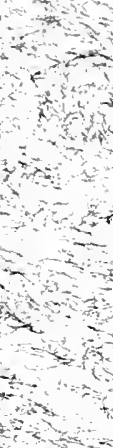





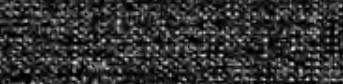

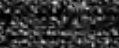
H.t.

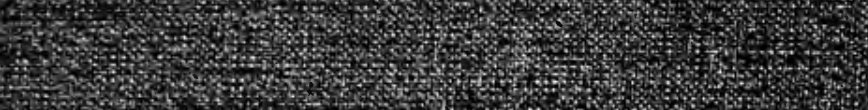

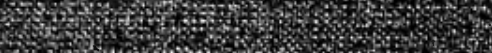

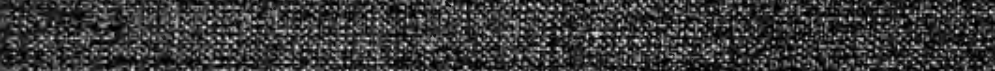

(1)

W.

F

W

T. H.

S.

H.t.

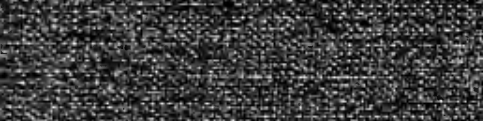

A

W

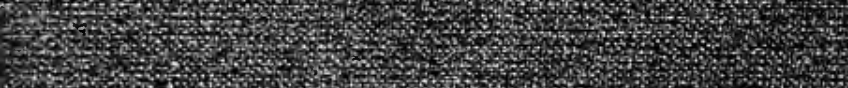

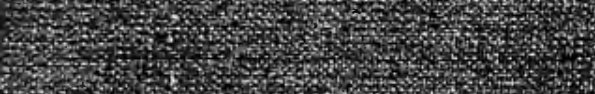

W.

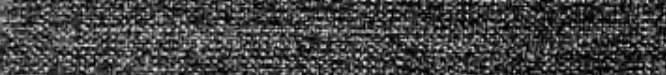

She

(5)

W.

W.

(x)

W.

(3)

F,

4.

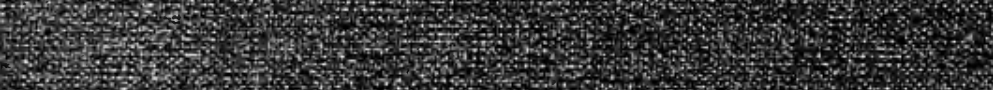

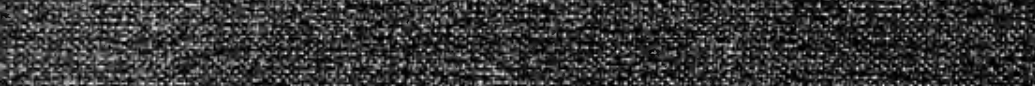

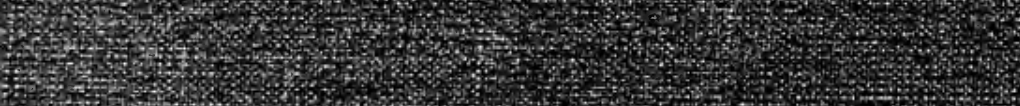

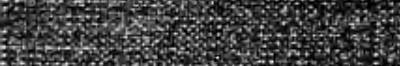

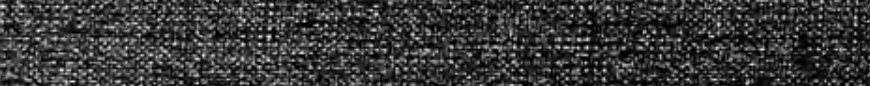

W.

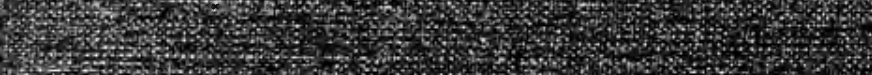

W

H.t.

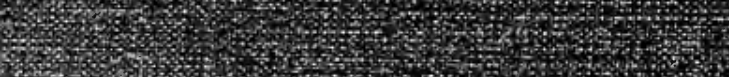

1, 